\title{
Lead-Bismuth Target Design for the Subcritical Multiplier (SCM) of the Accelerator Driven Test Facility (ADTF)
}

\section{By}

\section{Yousry Gohar, Phillip J. Finck, and Lubomir Krajtl}

Technology Development Division, Argonne National Laboratory, 9700 South Cass Avenue, Argonne, IL 60439

Joe Herceg, W. David Pointer, James Saiveau, and Tanju Sofu Reactor Analysis and Engineering Division, Argonne National Laboratory, 9700 South Cass Avenue, Argonne, IL 60439

\author{
Albert L. Hanson and Michael Todosow \\ Energy Sciences And Technology Department, Brookhaven National Laboratory \\ 12 South Upton Road, Upton, NY 11973 \\ Maria Koploy and Panto Mijatovic \\ General Atomics \\ 3550 General Atomics Court, San Diego, CA 92121
}

Work supported by the

Office of Nuclear Energy

U.S. Department of Energy

Under Contract W-31-109-Eng-38 


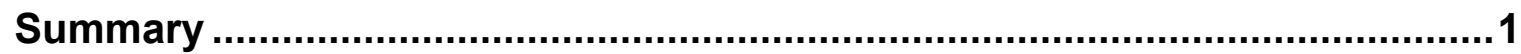

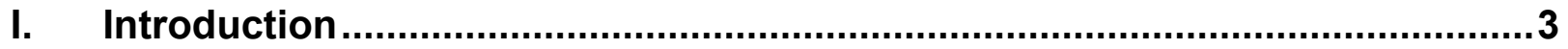

II. Design objectives and constraints ............................................................

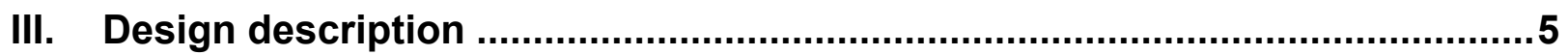

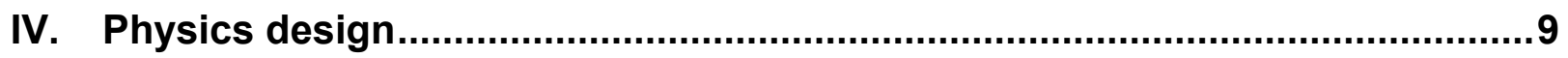

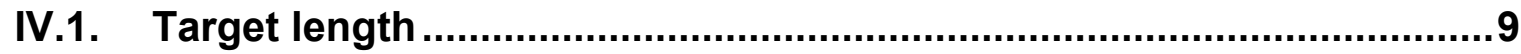

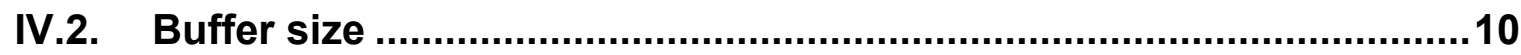

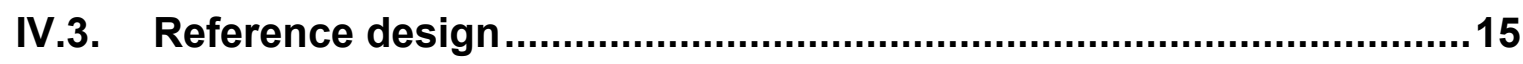

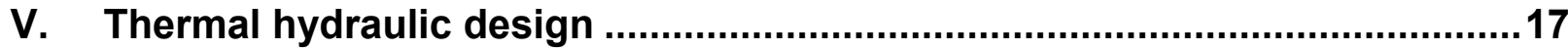

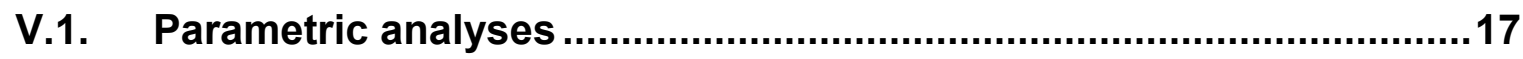

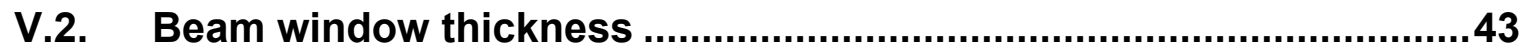

V.3. Coaxial geometry effect on the LBE temperature .............................44

V.4. Geometrical modifications for flow stability ....................................45

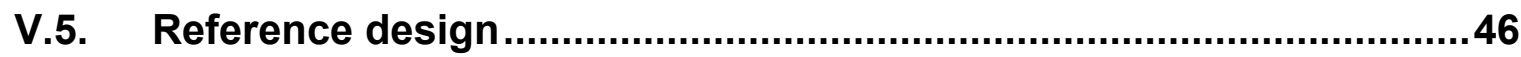

V.6. Beam profile effect on the peak window temperature ........................51

V.7. Target diameter effect on the peak window temperature...................51

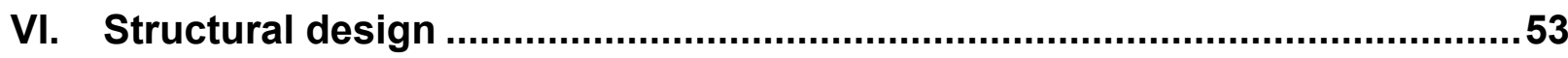

VI.1. Finite element models for stress analysis......................................53

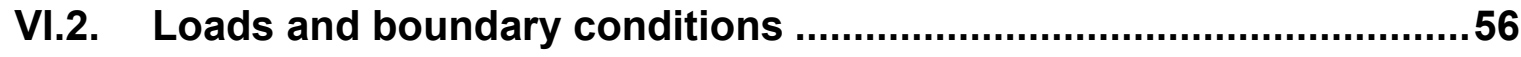

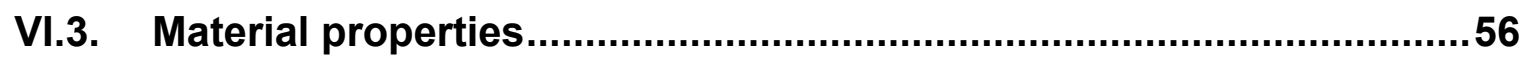

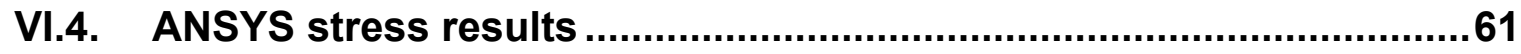

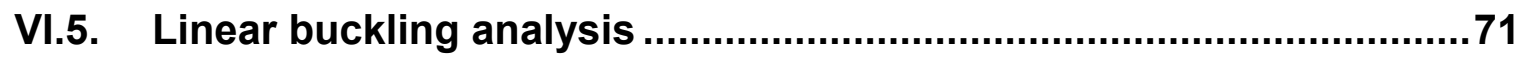


Table of Contents (continued)

Page

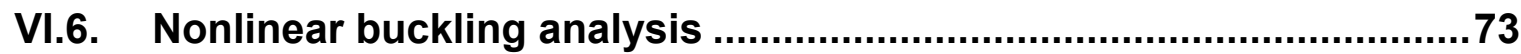

VI.7. Comparison of calculated and allowable stresses ...........................75

VI.8. Stress analysis conclusions and recommendations.........................79

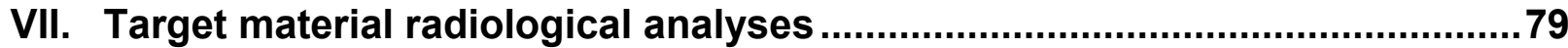

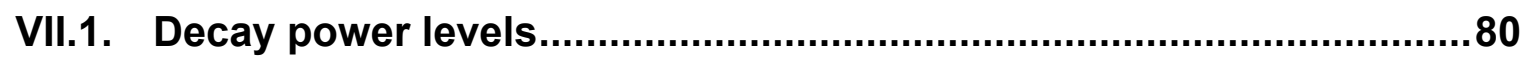

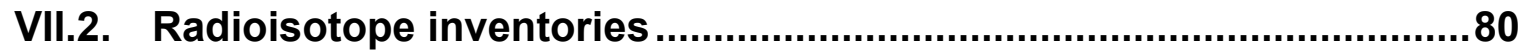

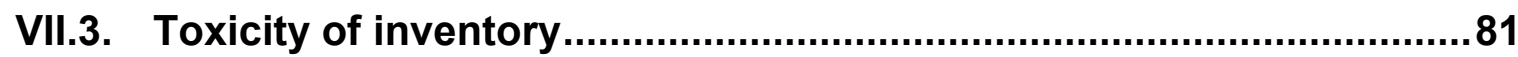

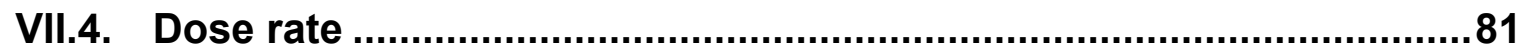

VIII. Structural material temperature during loss of flow event .........................100

VIII.1 Transient adiabatic heat-up for the LBE target ..............................102

VIII.2 Transient heat-up with radiation heat exchange with the sodium pool for the LBE target ...............................................................103

IX. Subcritical multiplier performance parameters ...........................................106

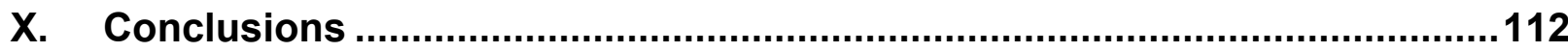

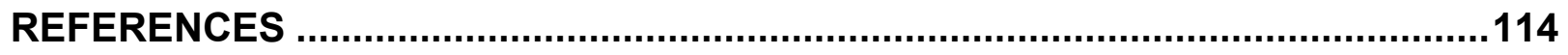

Appendix A Input file generation for ANSYS analysis ..............................115

Appendix B LBE pressure calculation at the beam window ......................117

Appendix C Critical buckling load calculation for the type 316SS target

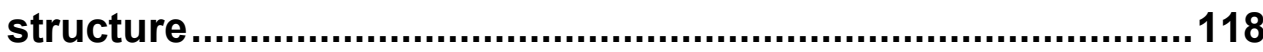

Appendix D ANSYS input file for the nonlinear buckling analysis of the hemi-spherical window .......................................................127

Appendix E Allowable HT-9 stresses ...................................................131 


\section{List of Figures}

Figure No.

Figure 1. Lead-bismuth eutectic target design ............................................. 7

Figure 2. SCM vertical cross section featuring the target system ........................ 8

Figure 3. LBE axial energy deposition ...................................................... 9

Figure 4. Number of neutrons per proton as a function of the LBE buffer thickness ......

Figure 5. Neutron source distribution as a function of the LBE buffer thickness...... 12

Figure 6. Atomic displacement in the outer buffer structure as a function of the buffer thickness for the lead-bismuth target with 5-MW beam power and $600-\mathrm{MeV}$ protons

Figure 7. Helium gas production in the outer buffer structure as a function of the buffer thickness for the lead-bismuth target with 5-MW beam power and 600-MeV protons

Figure 8. Hydrogen gas production in the outer buffer structure as a function of the buffer thickness for the lead-bismuth target with 5-MW beam power and $600-\mathrm{MeV}$ protons

Figure 9. Midplane nuclear responses in the outer buffer structure as a function of the reciprocal of the LBE outer buffer radius

Figure 10. Helium/atomic displacement ratio as a function of the buffer thickness for the LBE target

Figure 11. Spallation neutron source spectrum

Figure 12. Spallation neutron source spectrum showing the high-energy neutrons .. 16

Figure 13. Spallation neutron distribution along the beam axis

Figure 14. Cross-sectional view of the initial LBE target concept

Figure 15. LBE target concept contour plots showing (a) fluid velocity, (b) fluid temperature, and (c) structural temperature profiles for case 1

Figure 16.LBE target concept contour plots showing (a) fluid velocity, (b) fluid temperature, and (c) structural temperature profiles for case 2 . 
Figure No.

Figure 17. LBE target concept contour plots showing (a) fluid velocity, (b) fluid temperature, and (c) structural temperature profiles for case 3

Figure 18. LBE target concept contour plots showing (a) fluid velocity, (b) fluid temperature, and (c) structural temperature profiles for case 4

Figure 19. LBE target concept contour plots showing (a) fluid velocity, (b) fluid temperature, and (c) structural temperature profiles for case 5

Figure 20. LBE target concept contour plots showing (a) fluid velocity, (b) fluid temperature, and (c) structural temperature profiles for case 6

Figure 21. LBE target concept contour plots showing (a) fluid velocity, (b) fluid temperature, and (c) structural temperature profiles for case 7

Figure 22. LBE target concept contour plots showing (a) fluid velocity, (b) fluid temperature, and (c) structural temperature profiles for case 8

Figure 23. LBE target concept contour plots showing (a) fluid velocity, (b) fluid temperature, and (c) structural temperature profiles for case 9

Figure 24. LBE target concept contour plots showing (a) fluid velocity, (b) fluid temperature, and (c) structural temperature profiles for case 10

Figure 25. LBE target concept contour plots showing (a) fluid velocity, (b) fluid temperature, and (c) structural temperature profiles for case 11

Figure 26. LBE target concept contour plots showing (a) fluid velocity, (b) fluid temperature, and (c) structural temperature profiles for case 12

Figure 27. LBE target concept contour plots showing (a) fluid velocity, (b) fluid temperature, and (c) structural temperature profiles for case 13.

Figure 28. LBE target concept contour plots showing (a) fluid velocity, (b) fluid temperature, and (c) structural temperature profiles for case 14

Figure 29. LBE target concept contour plots showing (a) fluid velocity, (b) fluid temperature, and (c) structural temperature profiles for case 15

Figure 30. Comparison of predicted peak temperatures of the beam windows and middle walls for the 15 cases included in the initial parametric CFD study 
Figure No.

Figure 31. Comparison of predicted temperature distributions on the adiabatic and the wetted surfaces of the beam window of case 6 (conical window) and case 15 (hemi-spherical window)

Figure 32. Temperature difference between the adiabatic and the wetted surfaces of the beam window for varying wall thickness.....

Figure 33. LBE temperature in the inlet and outlet annular manifolds as a function of the mean temperature rise in heated region of the target

Figure 34. LBE target concept contour plots showing (a) fluid velocity, (b) fluid temperature, and (c) structural temperature profiles for case $A$

Figure 35. LBE target concept contour plots showing (a) fluid velocity, (b) fluid temperature, and (c) structural temperature profiles for case B

Figure 36. LBE target concept contour plots showing (a) fluid velocity, (b) fluid temperature, and (c) structural temperature profiles for case $\mathrm{C}$

Figure 37. LBE target concept contour plots showing (a) fluid velocity, (b) fluid temperature, and (c) structural temperature profiles for case $D$

Figure 38. Radial proton beam profiles.

Figure 39. Temperature profiles along the adiabatic surfaces of the beam window for the four radial proton beam profiles.

Figure 40. Complete axisymmetric ANSYS model of the 5-mm conical target beam window

Figure 41. Expanded view of conical section of the 5-mm conical target beam window ANSYS model.....

Figure 42. Complete axisymmetric ANSYS model of the 5-mm hemi-spherical target beam window

Figure 43. Expanded view of the hemi-spherical section of the 5-mm hemispherical target beam window ANSYS model

Figure 44. Applied external pressure and boundary conditions at both ends preventing displacement in the radial (window mid-plane) and axial directions (the end of $10 \mathrm{~cm}$-long cylinder segment)

Figure 45. Temperature distribution of the conical beam window with the 5-mm HT-9 structure, temperatures are in degrees Celsius. 
Figure No.

Figure 46. Temperature distribution of the spherical beam window with the $3.5-\mathrm{mm}$ HT-9 structure, temperatures are in degrees Celsius

Figure 47. Type 316SS Young's modulus as a function of temperature in Celsius ... 58

Figure 48. Type 316SS Poisson's ratio as a function of temperature in Celsius....... 59

Figure 49. Type 316SS thermal expansion coefficient as a function of temperature in Celsius

Figure 50. HT-9 Young's Modulus as a function of temperature in Celsius 60

Figure 51. HT-9 thermal Expansion Coefficient as a function of temperature in Celsius.

Figure 52. Stress intensity $(\mathrm{Pa})$ in the $5-\mathrm{mm}$ conical beam window during the normal operating conditions

Figure 53. Stress intensity $(\mathrm{Pa})$ in the $5-\mathrm{mm}$ conical beam window due to the LBE pressure load....

Figure 54. Stress intensity $(\mathrm{Pa})$ in the 5-mm hemi-spherical beam window during the normal operating conditions

Figure 55. Stress intensity $(\mathrm{Pa})$ in the 5-mm hemi-spherical beam window due to the LBE pressure load....

Figure 56. Maximum values of the different stress components as a function of the wall thickness for the conical window configuration, cases 1,3 , and $5 \ldots .$.

Figure 57. Maximum values of the different stress components as a function of the wall thickness for the hemi-spherical window configuration, cases 2, 4, and 6

Figure 58. Stress intensity $(\mathrm{Pa})$ in the $3.5-\mathrm{mm}$ conical beam window during the normal operating conditions

Figure 59. Stress components ( $\mathrm{MPa}$ ) along section A-A shown of Figure 58 measured from the wetted surface during the normal operating conditions

Figure 60. Total displacement $(\mathrm{cm})$ in the $3.5-\mathrm{mm}$-wall conical beam window (magnified 10 times) during the normal operating conditions 
Figure No.

Figure 61. Stress intensity $(\mathrm{Pa})$ in the $3.5-\mathrm{mm}$ conical beam window due to the LBE pressure load......

Figure 62. Stress components (MPa) along section B-B shown of Figure 61 measured from the wetted surface due to the LBE pressure load

Figure 63. Total displacement $(\mathrm{cm})$ in the $3.5-\mathrm{mm}$-wall conical beam window (magnified 100 times) due to the LBE pressure load....

Figure 64. Stress intensity $(\mathrm{Pa})$ in the $3.5-\mathrm{mm}$ conical beam window during the normal operating conditions

Figure 65. Stress components (MPa) along section A-A shown of Figure 64 measured from the wetted surface during the normal operating conditions

Figure 66. Total displacement $(\mathrm{cm})$ in the $3.5-\mathrm{mm}$ hemi-spherical beam window (magnified 10 times) during the normal operating conditions

Figure 67. Stress intensity $(\mathrm{Pa})$ in the $3.5-\mathrm{mm}$ hemi-spherical beam window due to the LBE pressure load.

Figure 68. Stress components (MPa) along section B-B shown of Figure 67 measured from the wetted surface due to the LBE pressure load

Figure 69. Total displacement $(\mathrm{cm})$ in the $3.5-\mathrm{mm}$ hemi-spherical beam window (magnified 100 times) due to the LBE pressure load.

Figure 70. Finite element model of the beam tube with hemi-spherical beam window

Figure 71. Unirradiated HT-9 stress-strain bilinear curves at different temperatures. 74

Figure 72. Irradiated HT-9 stress-strain bilinear curves with $25 \mathrm{dpa}$ at different temperatures

Figure 73. Relative displacement from the first buckling mode.

Figure 74. Total displacement $(\mathrm{cm})$ just before the structure becomes unstable at 5.74 MPa using irradiated HT-9 with $25 \mathrm{dpa}$

Figure 75. Total stress intensity (MPa) contour plot for external pressure of 5.74 MPa using irradiated HT-9 with $25 \mathrm{dpa}$

Figure 76. Schematic of the LBE system. 
Figure No.

Figure 77. Expanded view of the LBE system ................................................ 93

Figure 78. Breakup scheme of the LBE target................................................... 94

Figure 79. Buildup of decay power in a bismuth, lead, and LBE cylindrical target compared to cell 8

Figure 80. Decay of radioisotope power for cell 8 as a function of time after shutdown

Figure 81. Buildup of decay power in cell 9 as a function of irradiation time 96

Figure 82. Buildup of decay power in cell 3 as a function of irradiation time 96

Figure 83. Radioactive inhalation hazard for cell 8 as a function of irradiation time .. 97

Figure 84. Radioactive ingestion hazard for cell 8 as a function of irradiation time ... 97

Figure 85. Radioactive inhalation hazard for cell 8 as a function of decay time 98

Figure 86. Radioactive ingestion hazard for cell 8 as a function of decay time 98

Figure 87. Geometry for the dose rate calculations from the cylinder side (for Table 10).

Figure 88. Geometry for the dose rate calculations from the cylinder face (for Table 11)

Figure 89. LBE decay power as a function of time after shutdown 100

Figure 90. ADTF target design featuring the integration of the back shine shield and the other structural elements

Figure 91. Adiabatic heat-up of the LBE target system

Figure 92. Comparison of the actual decay heat loads from the radiological calculation and decay heat loads predicted by the functional fit used in heat transfer evaluations

Figure 93. Temperature of the LBE inventory as a function of time after shutdown with consideration of radiation heat exchange with the sodium pool

Figure $94 . \mathrm{SCM}-100$ fast neutron flux $(0.1$ to $20 \mathrm{MeV}) \mathrm{n} / \mathrm{cm}^{2} / \mathrm{s}$ with the leadbismuth target. 
Figure No.

Figure 95. SCM-100 high-energy neutron flux (above $20 \mathrm{MeV}$ ) n/cm $/ \mathrm{s}$ with the lead-bismuth target.

Figure 96. SCM-100 energy deposition with the lead-bismuth target, $\mathrm{W} / \mathrm{cm}^{3}{ }^{3} \ldots \ldots \ldots . .109$

Figure 97 . SCM-100 proton flux distribution with the lead-bismuth target, $\mathrm{p} / \mathrm{cm}^{2} / \mathrm{s} \ldots 110$

Figure 98. Atomic displacement rate in the grid plate per full power year as a function of the reflector zone thickness

Figure 99. Gas production rate in the grid plate per full power year as a function of the reflector zone thickness. 


\section{LIST OF TABLES}

Table No.

Table 1. Target window nuclear responses …............................................. 10

Table 2. Cases considered in the thermal hydraulic parametric study ................ 19

Table 3. Target cases considered in the ANSYS analysis ................................61 61

Table 4. Summary of stress results and associated temperatures for the conical windows.

Table 5. Summary of stress results and associated temperatures for the hemispherical windows

Table 6. Comparison of the allowable external pressure from ASME code to the LBE pressure load

Table 7. HT-9 allowable stresses for fluence up to 72 dpa ................................ 77

Table 8. Calculated stresses and HT-9 allowable stresses for the $3.5 \mathrm{~mm}$ conical beam window

Table 9. Calculated stresses and HT-9 allowable stresses for the $3.5 \mathrm{~mm}$ spherical beam window

Table 10. Details of the materials used in the LBE mode.......

Table 11. Division of the original "cell 3".

Table 12. Top 20 radioisotopes in cell 8 as a function of irradiation time 82

Table 13. Top 20 isotopes in cell 9 as a function of irradiation time

Table 14. Top 20 isotopes in cell 3 as a function of irradiation time 86

Table 15. Total activity and specific activity of all radioisotopes in the three cells at the shutdown inventory.

Table 16. Radioisotope inventory as a function of time after shutdown for cell $8 \ldots . .88$

Table 17. Radioisotope inventory as a function of time after shutdown for cell $3 \ldots . .89$

Table 18. Radioisotope inventory as a function of time after shutdown for cell 9 ..... 90 
Table No.

Table 19. Dose rate $(\mathrm{mR} / \mathrm{hr})$ calculations for the LBE cell 8 from the cylinder side at the midpoint

Table 20. Dose rate $(\mathrm{mR} / \mathrm{hr})$ calculations for the LBE cell 8 from the cylinder face at the axis

Table 21. Definition of parametric cases considered in the target temperature 103 calculation

Table 22. Comparison of predicted temperatures of the LBE inventory with and without consideration of radiation heat exchange between the LBE target and the sodium pool 


\section{Lead-Bismuth Target Design for the Subcritical Multiplier (SCM) of the Accelerator Driven Test Facility (ADTF)}

\section{Summary}

A lead-bismuth eutectic (LBE) target design concept has been developed to drive the subcritical multiplier (SCM) of the accelerator-driven test facility (ADTF). This report gives the target design description, the results from the parametric studies, and the design analyses including physics, heat-transfer, hydraulics, structural, radiological, and safety analyses.

The design is based on a coaxial geometrical configuration to minimize the target footprint and to maximize the utilization of the spallation neutrons. The target is installed vertically along the SCM axis. LBE is the target material and the target coolant. Ferritic steel (HT-9 alloy) is the selected structural material based on the current database and the design analyses. Austenitic steel (Type 316 stainless steel) is the backup choice. A uniform proton beam is employed to perform the spallation process. The proton beam has $8.33-\mathrm{mA}$ current and $8.14-\mathrm{cm}$ radius resulting in a current density of $40 \mu \mathrm{A} / \mathrm{cm}^{2}$. The beam power is $5 \mathrm{MW}$ and the proton energy is $600 \mathrm{MeV}$. The beam tube has 10$\mathrm{cm}$ radius to accommodate the halo current. A hemi-spherical geometry is used for the target window, which is connected to the beam tube. A conical target window with a rounded tip is also considered since it has a lower average temperature relative to the spherical geometry. The beam tube is enclosed inside two coaxial tubes to provide inlet and outlet manifolds for the LBE coolant. The inlet and the outlet coolant manifolds and the proton beam are entered from the top above the SCM. Several design constraints are developed and utilized for the target design process to satisfy different engineering requirements and to minimize the design development time and cost.

The geometrical configuration has been carefully designed to insure adequate coolant velocity for cooling the target structural material and to enhance the LBE flow stability. Detailed MCNPX geometrical models for the target and the subcritical multiplier have been developed to define the target and the ADTF performance parameters for the design process. Also, these models are used to generate the energy deposition and flux contour maps, to calculate the nuclear responses in the structural material, to optimize the target design parameters for satisfying the mission and the design goals of the ADTF.

The neutrons for the subcritical multiplier are generated from the spallation process driven by the $600-\mathrm{MeV}$ proton beam. A small LBE buffer between the target and the SCM is used based on design optimizations to reduce the irradiation damage in the fuel elements from the scatter protons and the high-energy neutrons, to provide an adequate manifold for the LBE coolant, and to maximize the spallation neutron fraction of the subcritical multiplier. A special attention has been given to the target window design to enhance its lifetime. The window volumetric heating is about $766 \mathrm{~W} / \mathrm{cm}^{3}$ relative to 750 $\mathrm{W} / \mathrm{cm}^{3}$ in LBE for a $40-\mu \mathrm{A} / \mathrm{cm}^{2}$ current density. The results show that the nuclear heating from the proton beam diminishes at about $32 \mathrm{~cm}$ along the beam axis of the 
LBE target material. In the structure material outside the 7-cm LBE buffer, the neutron contribution to the atomic displacement is in the range of 98 to $100 \%$ and the proton beam contribution to the helium production is less than $3.5 \%$. In the window, the neutrons are responsible for $69 \%$ of the atomic displacement and the protons are generating more than $96 \%$ of the gas production rate.

Thermal hydraulic analyses were performed to define the velocity distribution and the flow stability of the lead-bismuth eutectic as well as the temperature distribution in the target structure and the target coolant. The hydraulic results were used to update the geometrical configuration and to improve the flow stability. Parametric analyses were performed and iterated with the other design analyses to define the reference geometrical configuration. The thermal hydraulics results show that the outlet temperature of LBE is $280^{\circ} \mathrm{C}$ for an inlet temperature of $200^{\circ} \mathrm{C}$. The LBE average velocity is $2 \mathrm{~m} / \mathrm{s}$ and the total pressure drop is $\sim 32 \mathrm{psi}$. The peak temperatures on the adiabatic and the wetted surfaces of the beam window are $502{ }^{\circ} \mathrm{C}$ and $341{ }^{\circ} \mathrm{C}$, respectively, for the $3.5-\mathrm{mm}$ thick beam window.

Structural analyses were performed parametrically in conjunction with the thermal hydraulics to check the design compliance with the stress and the buckling design criteria developed for the Accelerator Production of Tritium project and the International Thermonuclear Experimental Reactor for irradiated structural materials. Also, the results are used to select the shape and the thickness of the beam window to maximize the engineering margins. The results show that the target structure including the beam window satisfies the structural design criteria for irradiated HT-9 with $72 \mathrm{dpa}$. This level of irradiation will allow the target to operate for more than full power year. However, most of the HT-9 database is obtained from fission irradiation, which needs to be confirmed for the target operating conditions including the influence of the high-energy neutron and the proton fluxes.

Radiological analyses were performed to define the spallation products. These products define the radiological toxicity and the decay heat source from LBE as function of the time after shutdown. The design analyses utilize the decay heat source to check the design performance during abnormal conditions with respect to the maximum allowed temperature for the structural material. Also, the dose rate from the gamma rays of the LBE spallation products was calculated to define the required input for calculating the appropriate time and the shielding requirements for maintaining the target system. The loss of flow analysis show that the management of the decay heat in the ADTF LBE target design does not require an active engineering system for the decay heat removal. 


\section{Introduction}

A spallation target design has been developed to generate the required neutron source for the subcritical multiplier (SCM) of the accelerator driven test facility (ADTF). The ADTF is a major nuclear research facility that will provide multiple testing and production capabilities. The main ADTF mission includes the capability to assess technology options for the transmutation of spent nuclear fuel and nuclear waste through proof-of-performance demonstrations; the ability to operate as a user facility that allows testing advanced nuclear technologies and applications, material science and research, experimental physics, and conventional nuclear engineering science applications; and the capability, through upgrades to produce radioisotopes for medical and commercial purposes.

Multiple experimental target stations are envisioned to accommodate the mission. The principal target station consists of a spallation target and a SCM with a power rating up to $100 \mathrm{MW}$. This SCM will provide the prototypic environment necessary to support the transmutation proof of performance. In addition, a target and material test station will be used to test a wide range of target designs, fuel assemblies, and coolants for developing components for the SCM. The work presented in this report is intended to cover the analyses and the design of the SCM lead-bismuth target.

The spallation target design is based on a coaxial geometrical configuration to satisfy the SCM configuration requirements for minimizing the space requirements and to maximize the SCM utilization of the spallation neutrons. The target is installed vertically along the SCM axis. Lead-Bismuth Eutectic (LBE) is the target material and the target coolant. Ferritic steel (HT-9 alloy) is the selected structural material for the target based on the current database and the design analyses. Austenitic steel (Type 316 stainless steel) is the second choice. A uniform proton beam is employed to perform the spallation process. The beam power is $5 \mathrm{MW}$ and the proton energy is 600 $\mathrm{MeV}$. The inlet and the outlet coolant manifolds and the proton beam are entered from the top above the SCM. The LBE flow cross-section area is maintained at a constant value along the axial direction to maintain a constant average velocity, which improves the target hydraulic design. The geometrical configuration has been carefully designed to insure flow stability and adequate cooling for the beam window and the structure

material. Target design objectives were defined to guide the design process. Several design constraints are defined and used in the target design process to satisfy different engineering requirements, to minimize the design development time and cost, to insure a satisfactory operating performance, and to maximize the operating lifetime of the target structural material.

Physics analyses were performed using the Monte Carlo code MCNPX [1] to account for the geometrical details, the spallation process, and the production and the transport of the spallation particles and photons. Parametric analyses were performed to study the neutron yield, the neutron energy spectrum, the buffer size between the target and the subcritical multiplier, and the nuclear responses in the beam window. Also, the neutronic performance of the SCM with MK-III EBR-II fuel (driver fuel) was 
analyzed with the target to define the SCM neutron flux, the energy deposition in the system, and the lower reflector to protect the lower SCM grid. The fast neutron flux is a key performance parameter for testing nuclear fuel. The energy deposition distribution in the different zones is also calculated.

Thermal hydraulic analyses were performed to define the velocity distribution and the flow stability of the lead-bismuth eutectic and the temperature distribution in the target structure and the target coolant. Also, the hydraulic results were used to update the geometrical configuration and to improve the flow stability. Parametric analyses were performed and iterated with the other design analyses to define the reference design.

Structural analyses were performed parametrically in conjunction with the thermal hydraulics to check the design compliance with the stress and buckling design criteria developed for the Accelerator Production of Tritium project [2] and the International Thermonuclear Experimental Reactor [3] for irradiated structural materials. Also, the results are used to select the shape and thickness of the beam window to maximize the engineering margins.

Radiological analyses were performed to define the spallation products. These products define the radiological toxicity and the decay heat source from the leadbismuth target material as function of the time after shutdown. The design analyses utilize the decay heat source to check the design performance during normal and abnormal conditions with respect to the maximum allowed temperature for the structural material. Also, the dose rate from the gamma rays of the LBE spallation products was calculated to define the required input for calculating the appropriate time and the shielding requirements for maintaining the target system.

The report describes the different studies and the obtained results as well as the reference target design. The main parameters for the target and the subcritical multiplier are defined based on detailed MCNPX analyses. The neutron flux maps, the nuclear responses, and the energy deposition distributions are generated for the target and the subcritical multiplier.

\section{Design objectives and constraints}

The main objective of the target design is to generate the required neutron source to drive the SCM. The neutrons are generated from the spallation process driven by the $600-\mathrm{MeV}$ proton beam. The beam has a total power of $5 \mathrm{MW}$ and it has a uniform spatial distribution over the beam cross-section area. The SCM design requires a small target diameter to simplify the fuel and the target replacement procedures, to reduce the neutron losses in the beam direction, to decrease the shield volume, and to lower the required number of the SCM fuel assemblies for a specific power level. However, the structural material and the heat transfer considerations require a large beam diameter to reduce the energy deposition and the irradiation damage densities in the beam window. A $40-\mu \mathrm{A} / \mathrm{cm}^{2}$ current density was selected as a compromise to satisfy the engineering 
requirements for the window design and to extend it's operating life without a significant impact on the SCM design. The other main objectives for the target design are to protect the SCM from the high-energy protons and neutrons, to contain the spallation products, to help achieving the availability goal of the facility, and to reduce the shut down time for target replacement during normal and abnormal conditions. Also, the target has to generate a uniform neutron source along the beam axis as much as possible to minimize the SCM axial power peaking.

Several design constrains are imposed on the target design process to satisfy different engineering requirements and to minimize the design development time and cost. Existing structural materials, ferritic steel (HT-9) and type 316 Stainless Steel (type 316SS) are the selected structural material for the target design. Lead-Bismuth Eutectic (LBE) is used as a target material and coolant to simplify the design. The surface temperature of the structural material in contact with the LBE is limited to less than $550^{\circ} \mathrm{C}$ to reduce erosion and corrosion concerns. This temperature limit assumes that the coolant chemistry is controlled to maintain an oxide layer on the structural material surface for corrosion protection. The stress analysis of the irradiated structural materials limits the maximum temperature to less than 550 and $600{ }^{\circ} \mathrm{C}$ for HT-9 and type $316 S S$, respectively. The average coolant velocity is limited to $\sim 2 \mathrm{~m} / \mathrm{s}$ based on the current database to avoid erosion and corrosion concerns. The coolant pressure is minimized to avoid high primary stresses in the structural material. The coolant inlet temperature is $200{ }^{\circ} \mathrm{C}$, which provides adequate design margin above the LBE melting point of $129^{\circ} \mathrm{C}$. The outlet temperature is constrained by the maximum allowable temperature for the structural material. Heat conduction to the back shine shield in the beam tube, natural convection, and radiation to the sodium pool are used for decay heat removal. These objectives and constraints are utilized to develop the current LBE target design presented in this report.

\section{Design description}

The proton beam has a total current of $8.33 \mathrm{~mA}$ distributed uniformly over a circular cross section. The beam radius is $8.14 \mathrm{~cm}$ with a current density of $40 \mu \mathrm{A} / \mathrm{cm}^{2}$. The beam tube has $10-\mathrm{cm}$ radius to accommodate the halo current. A hemi-spherical geometry is considered for the target window, which is connected to the beam tube. A conical target window with a rounded tip is also considered since it has a lower average temperature relative to the spherical geometry. The beam tube is enclosed inside two coaxial tubes to provide inlet and outlet manifolds for the LBE target coolant. The double function of the LBE as a target material and coolant does simplify the design. The radii of these tubes were adjusted to achieve the same average velocity in the inlet and the outlet manifolds. The outer manifold is used for the inlet flow to improve the coolability of the beam window. The edge of the inside tube between the inlet and the outlet flow is terminated with a rounded fairing to improve the flow stability. The fairing is tangent to the inlet side surface of the middle wall and extends into the outlet flow field. The geometrical details of the reference target design are shown in Figure 1. A guard tube is used to enclose the target design. It provides a confined space to check and contain any LBE leakage. Also, this space provides a buffer between the SCM 
sodium pool and the LBE. Helium gas at low pressure is used to fill this space. HT-9 is the selected structural material and type $316 \mathrm{SS}$ is the backup. The LBE oxygen concentration is maintained in the range of $10^{-6}$ to $10^{-4}$ at $\%$ to avoid corrosion concerns.

The beam tube enters the subcritical multiplier building horizontally as shown in Figure 2 above the subcritical multiplier. Then the beam is bended $90^{\circ}$ to reach the subcritical multiplier. The vertical section of the beam tube is $\sim 14.1 \mathrm{~m}$ after the last bending magnet. The coolant manifolds have a vertical length of about $10.1 \mathrm{~m}$ before changing direction to connect horizontally with the external section of the LBE loop. Pressurized helium gas is used to heat the target tubes before the target is filled with the LBE material. Also, helium is utilized to drain the LBE using a small vertical tube(s) of $\sim 1-\mathrm{cm}$ diameter, which reaches the target bottom section. In the target replacement procedure, the LBE is drained before the target tubes are disconnected for removal. The overhead crane is used to pull the empty target structure inside a target replacement cask.

Inside the guard tube, chemical and pressure sensors are used to check for $\mathrm{Na}$ or LBE leakage to shut down the target operation. This early warning avoids the possibility of mixing the two fluids, which reduces the maintenance down time and improves the safety performance. The beam tube vacuum is also monitored to detect any LBE leakage through the beam window. 

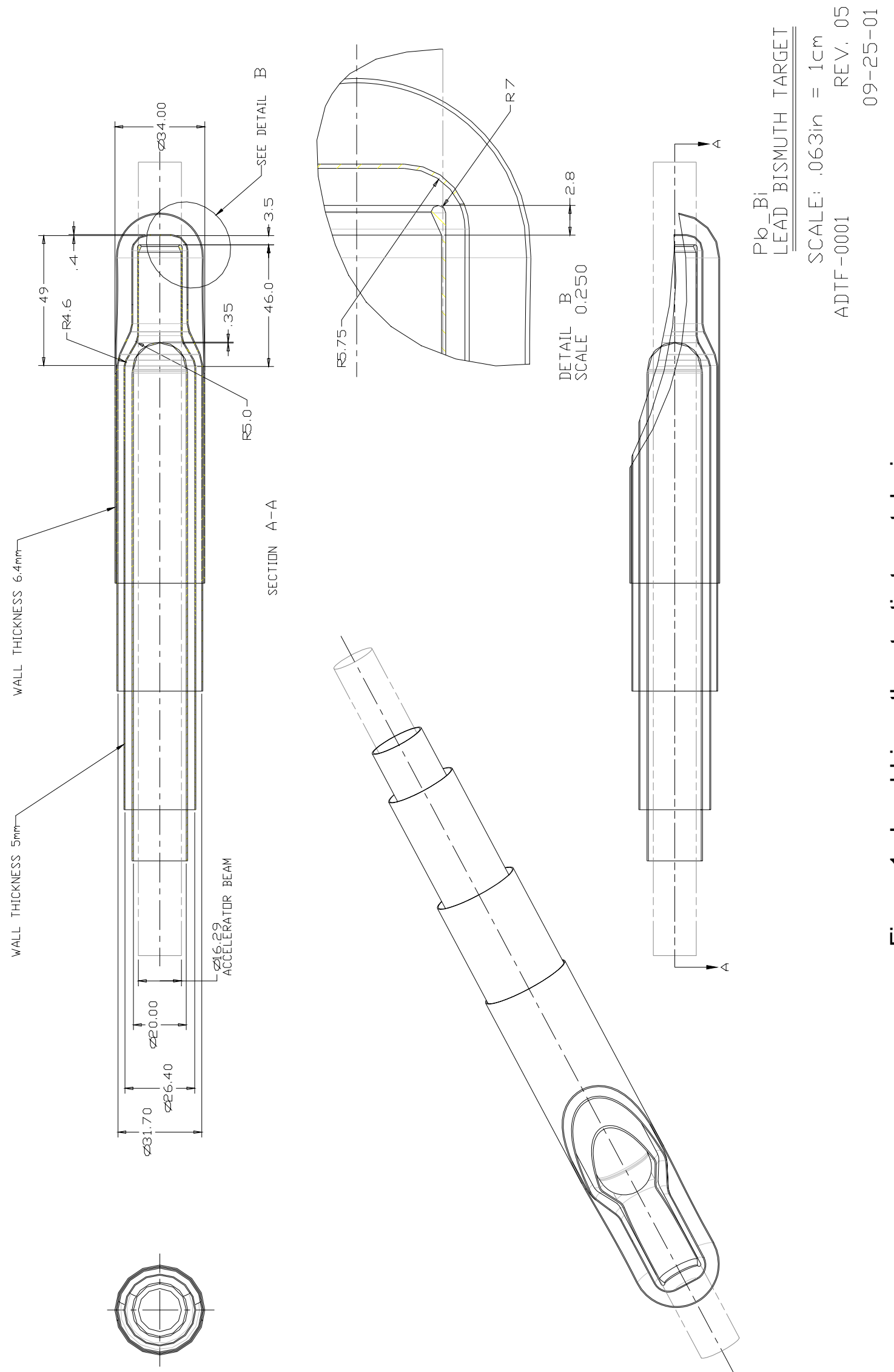

$\frac{}{0}$
$\frac{0}{9}$
$\frac{1}{0}$
$\frac{1}{0}$
$\frac{0}{7}$

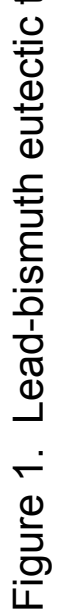

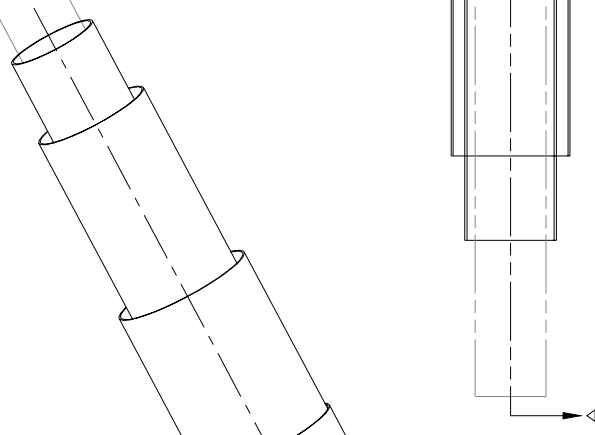

$N$ 


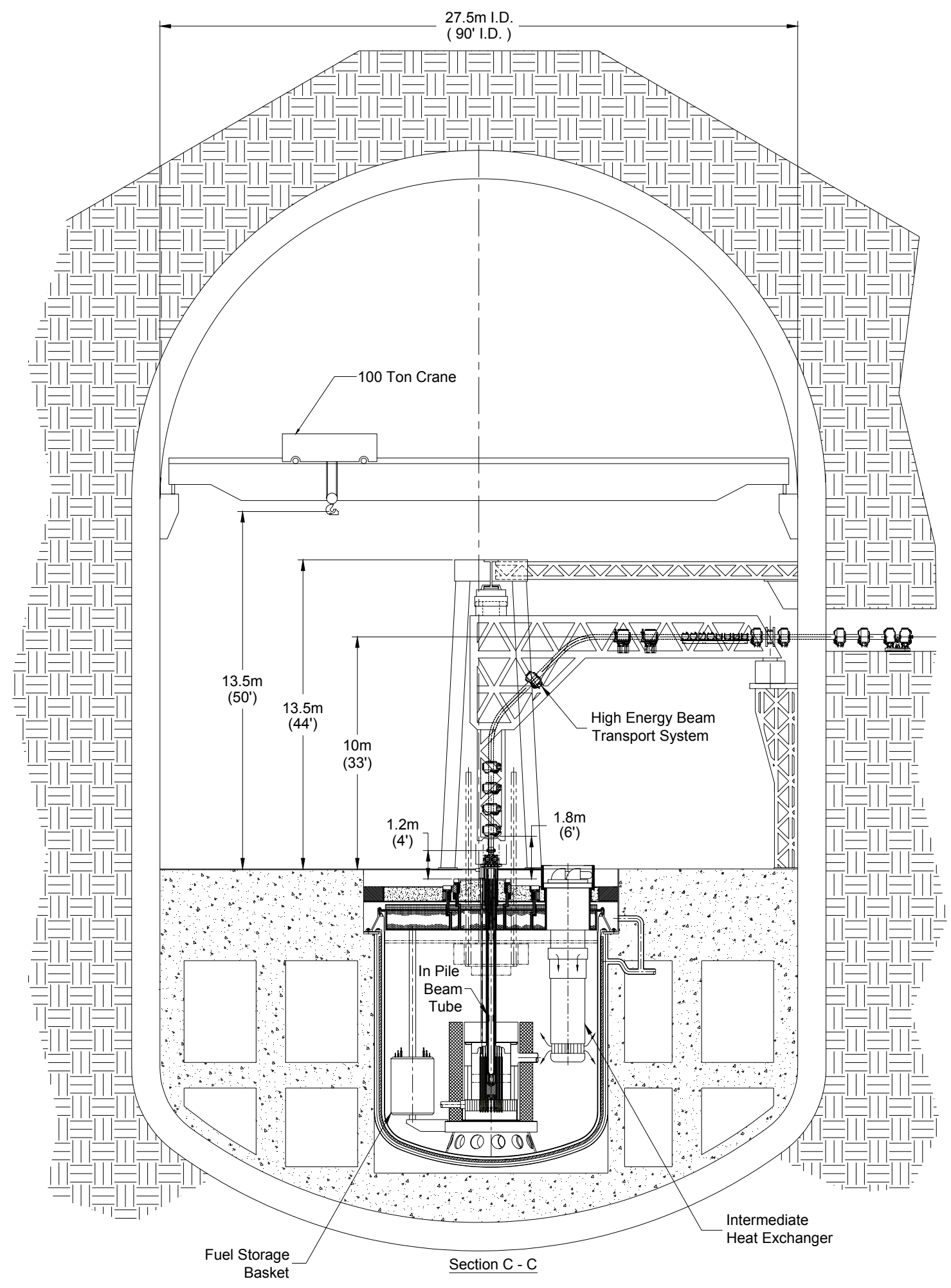

Figure 2. SCM Vertical cross section featuring the target system 


\section{Physics design}

Detailed MCNPX models were developed that include the target, the SCM, and the sodium pool to perform target, buffer, parametric, and SCM design analyses. Mark-III EBR-II driver fuel is used for the SCM. In these models, all the secondary particles from the spallation process are transported and the nuclear responses are tallied. In all the calculations, the fuel loading was adjusted to achieve a total system power of $100 \mathrm{MW}$. The proton beam power is $5 \mathrm{MW}$ and the proton energy is $600 \mathrm{MeV}$. The beam window has a current density of $40 \mu \mathrm{A} / \mathrm{cm}^{2}$.

\section{IV.1. Target length}

The first step in the analyses is to define the required target length to stop the proton beam and the axial energy deposition profile. The energy deposition profile is shown in Figure 3 as a function of the distance alone the beam axis with $0.5-\mathrm{cm}$ thick steel window. The required target material length is $\sim 32 \mathrm{~cm}$ to stop the $600-\mathrm{MeV}$ protons. The peak energy deposition is $796 \mathrm{~W} / \mathrm{cm}^{3}$ at $1.75 \mathrm{~cm}$ from the LBE surface. Table 1 gives the nuclear responses in the target window for iron, which represent a good simulation for the HT-9 alloy. In the beam window, the neutrons are responsible for $69 \%$ of the atomic displacement and the protons are generating more than $96 \%$ of the gas production rate.

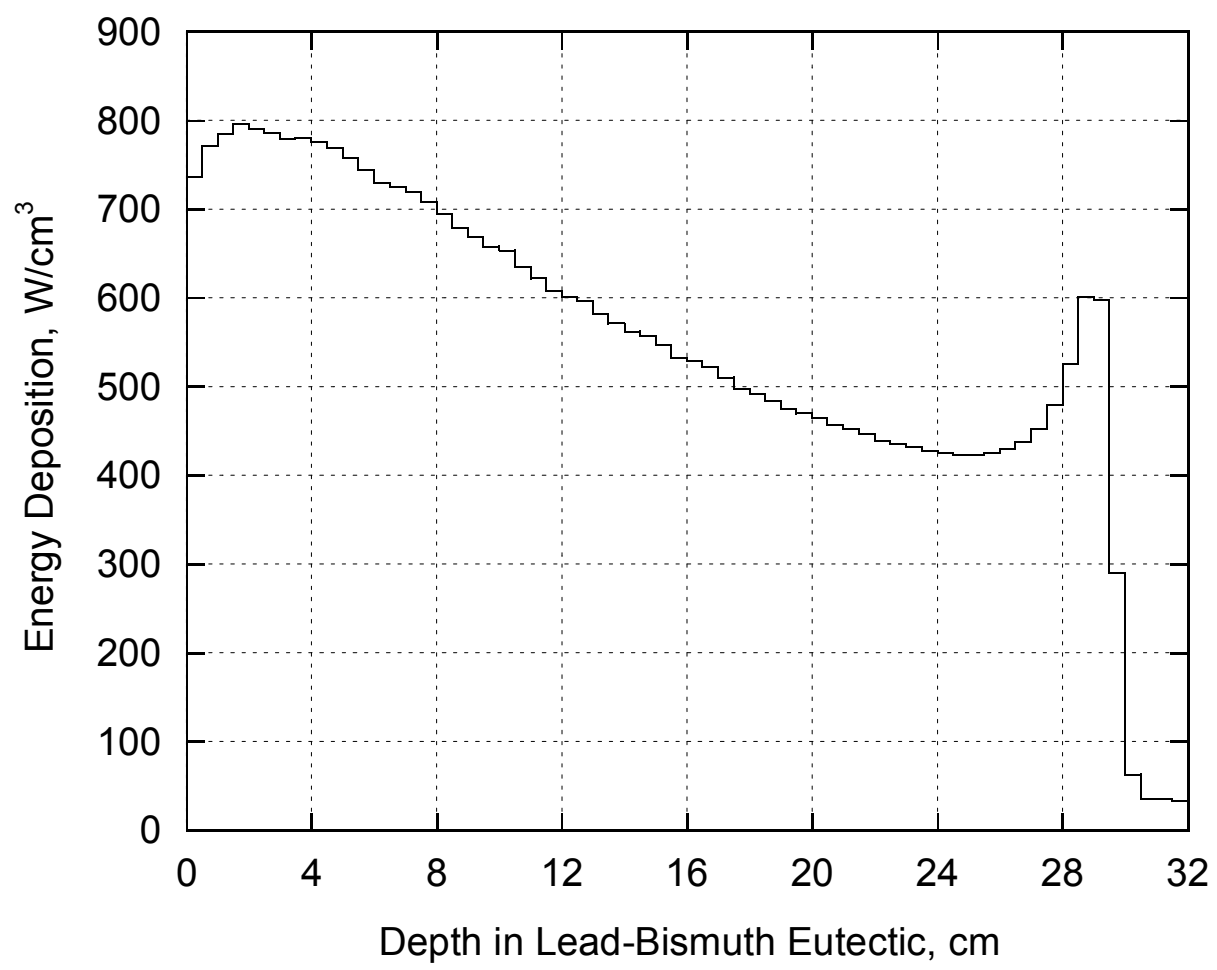

Figure 3. LBE axial energy deposition 
Table 1. Target window nuclear responses

\begin{tabular}{|lr|}
\hline Energy deposition, $\mathrm{W} / \mathrm{cm}^{3}$ & 766.49 \\
Atomic displacement, dpa/y & \\
Neutrons & 46.2 \\
Protons & 21.1 \\
Total & 67.3 \\
Helium production, appm/fpy & \\
$\quad$ Low energy neutrons $\leq 20 \mathrm{MeV}$ & 5.7 \\
High energy neutrons $>20 \mathrm{MeV}$ & 50.2 \\
Protons & 1437.3 \\
Total & 1493.2 \\
Hydrogen production, appm/fpy & \\
Low energy neutrons $\leq 20 \mathrm{MeV}$ & 6.3 \\
High energy neutrons $>20 \mathrm{MeV}$ & 1010.1 \\
Protons & 26753.1 \\
Total & 27769.5 \\
\hline
\end{tabular}

\section{IV.2. Buffer Size}

The MCNPX model was used to define the target buffer size taking into consideration the total neutron yield from the target, the spallation neutron fraction utilized by the subcritical multiplier, and the nuclear responses in the structural material next to the target. The analysis was performed as a function of the buffer thickness. The cross section areas required for the inlet and the outlet manifolds define the minimum buffer thickness, which is $7 \mathrm{~cm}$. The results show that the number of spallation neutrons per proton has low sensitivity to the buffer thickness as shown in Figure 4. It reaches a saturation value at a buffer thickness of $\sim 40 \mathrm{~cm}$. The saturation value is about 1.14 times the value obtained with the $7-\mathrm{cm}$ minimum buffer thickness. However, the number of spallation neutrons reaching the multiplier is significantly reduced as the buffer thickness is increased. This is shown in Figure 5 where this number drops from 7.8 neutrons per proton with $7-\mathrm{cm}$ buffer to $\sim 3.3$ neutrons per proton with $40-\mathrm{cm}$ buffer. The axial neutron leakage is increased as the buffer thickness is increased. This requires the target design to reduce the buffer thickness as much as possible.

The nuclear responses in the structural material outside the buffer zone are shown in Figures 6 through 8 as a function of the axial distance along the buffer boundary for different buffer sizes. For a small buffer thickness, the results show that the peak values of the different nuclear responses occur near the SCM midplane. As the buffer 
thickness increases, the peak values of the gas production, helium and hydrogen, shift to the top section of the subcritical multiplier. On the other hand, the maximum atomic displacement stays at the SCM midplane. This means that the SCM fission neutrons are causing most of the nuclear responses for the small buffer thickness. For a constant total power of $100 \mathrm{MW}$, as the buffer thickness increases, the SCM volume increases to compensate for the increased neutron leakage. Therefore, the SCM average power density and the nuclear responses, which are dominated by the fission neutrons are decreased. This explains the change in the gas production distribution as shown in Figures 7 and 8 where the contribution from the spallation neutrons are noticeable at the top of the target and decrease along the target length for the large buffer sizes. However, the atomic displacement distribution maintains the peak value at the SCM midplane because the SCM fission neutrons are the main contributor.

The nuclear responses at the SCM midplane are shown as a function of the reciprocal of the outer buffer radius in Figure 9. The results show a good linear fit because the fission neutrons dominate the reaction rates at the SCM boundary. The other important parameter for the structural material performance is the helium to atomic displacement ratio. Figure 10 shows this ratio as a function of the buffer thickness, which is in the range of 0.1 to 0.3 . This ratio is about 0.26 for HT-9 in a typical fast reactor spectrum. These results show that the $7-\mathrm{cm}$ buffer thickness protects the structural material from the nuclear responses caused by the high energy neutrons (E> $20 \mathrm{MeV}$ ), utilizes most of the spallation neutrons for driving the subcritical multiplier, and has adequate cross section area for the inlet and the outlet coolant manifolds. The lifetime of the structural material around the buffer will depend on the operating temperature, the nuclear response, and the loading conditions.

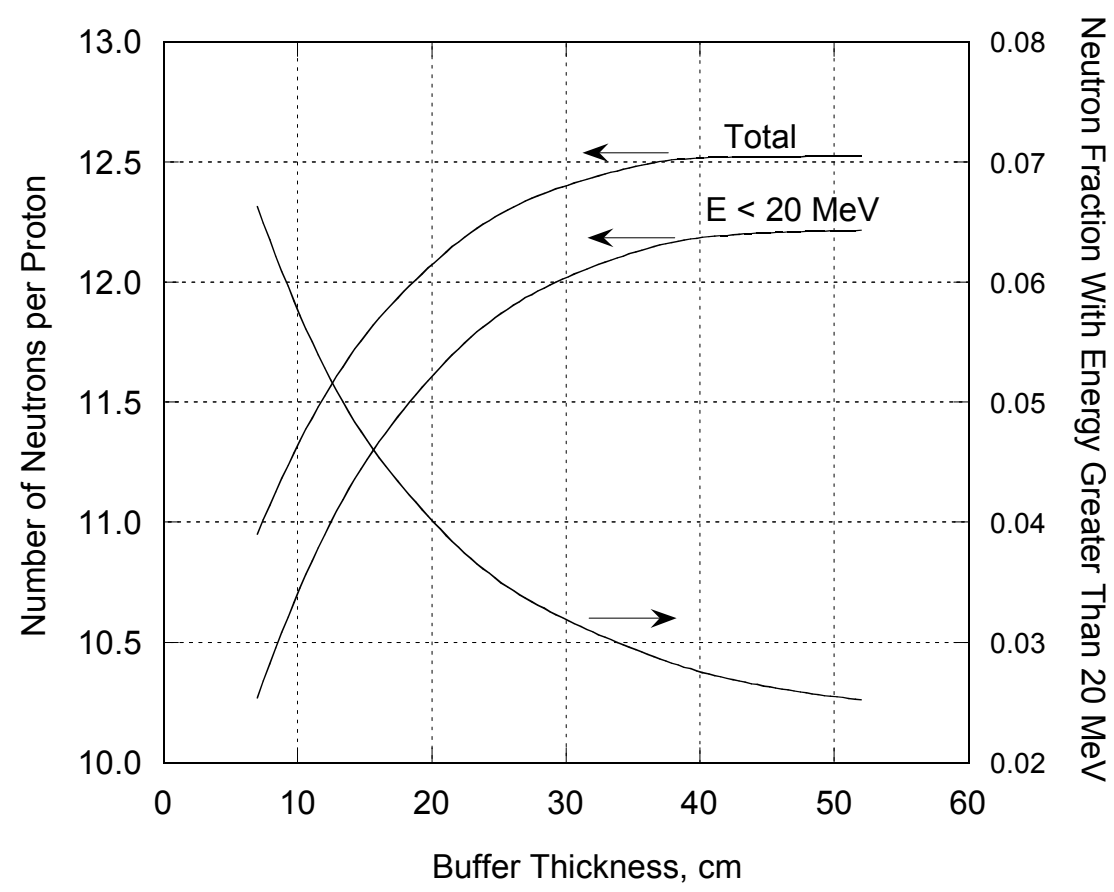

Figure 4. Number of neutrons per proton as a function of the LBE buffer thickness 


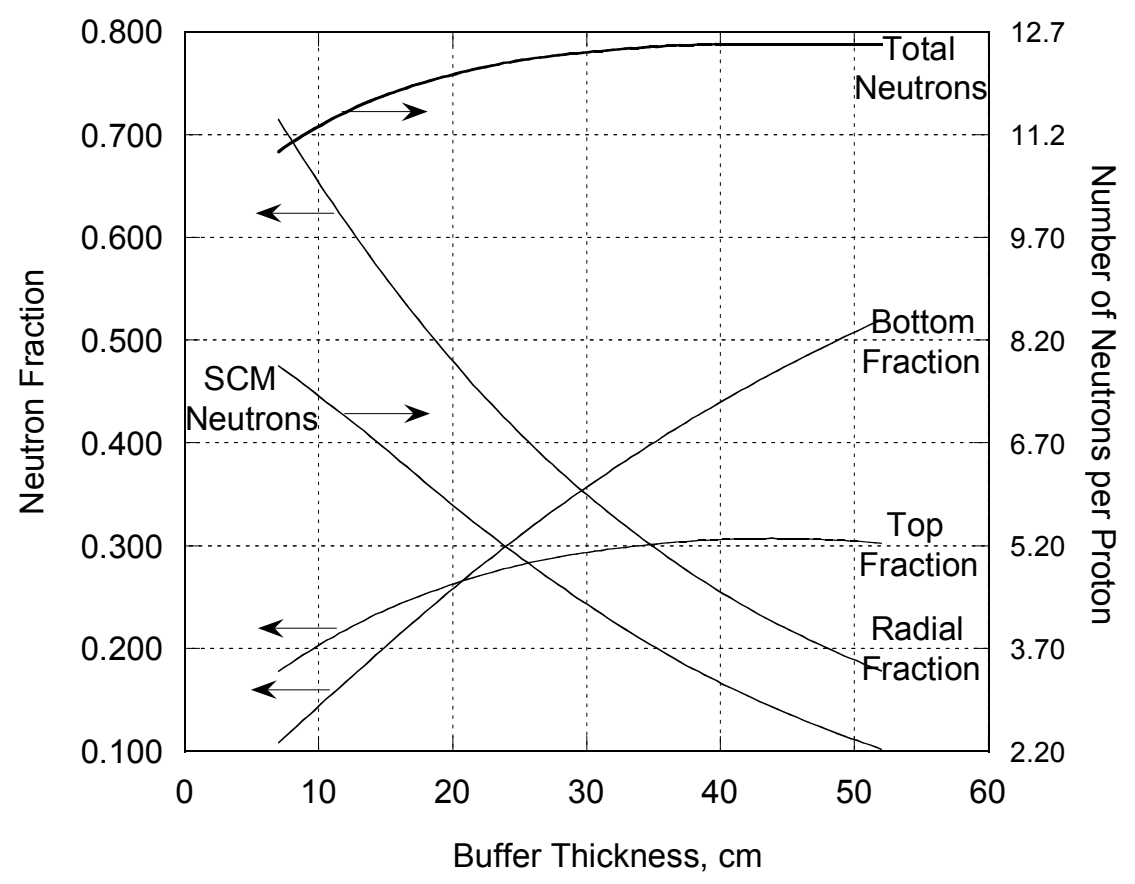

Figure 5. Neutron source distribution as a function of the LBE buffer thickness

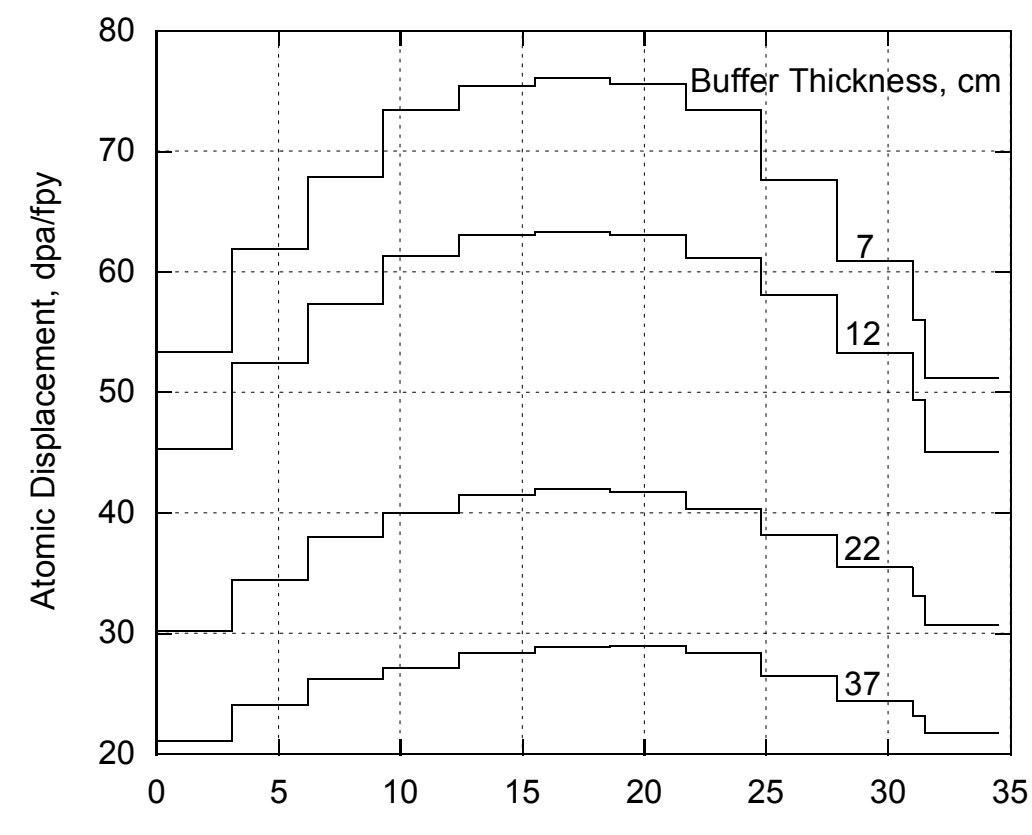

Axial Distance Along The Outer Buffer Boundary, cm

Figure 6. Atomic displacement in the outer buffer structure as a function of the buffer thickness for the lead-bismuth target with 5-MW beam power and $600-\mathrm{MeV}$ protons 


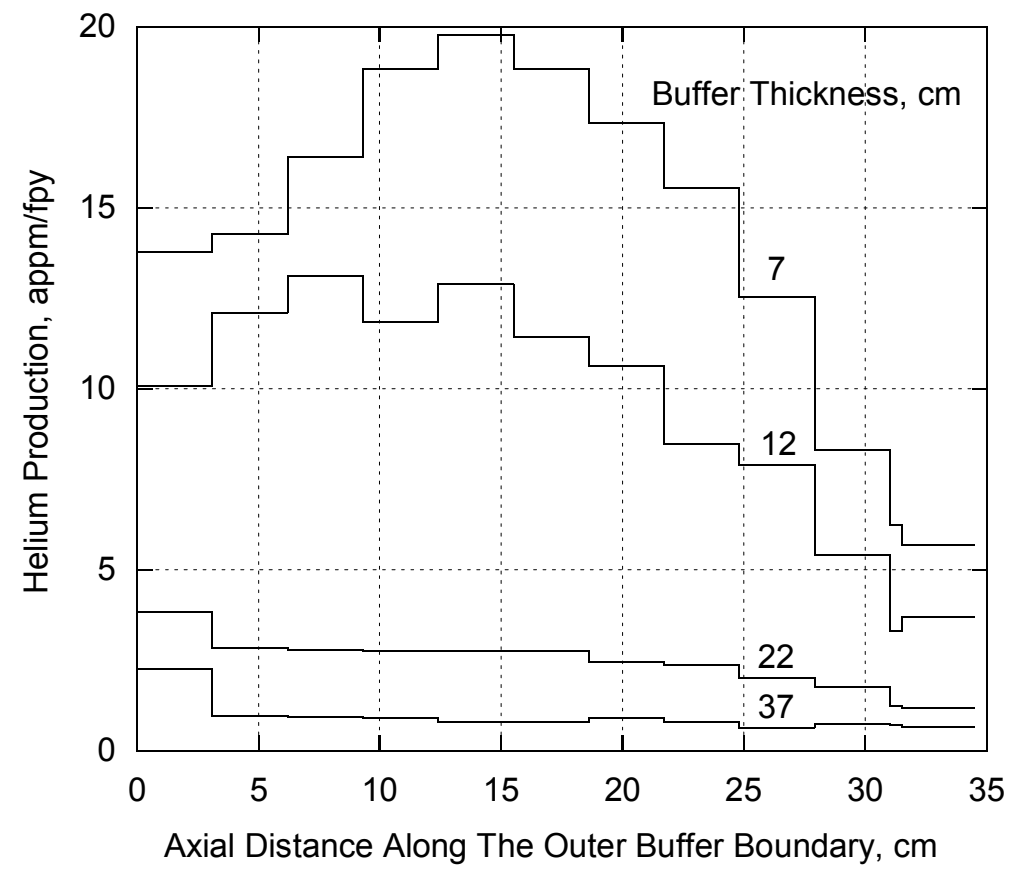

Figure 7. Helium gas production in the outer buffer structure as a function of the buffer thickness for the lead-bismuth target with 5-MW beam power and 600-MeV protons

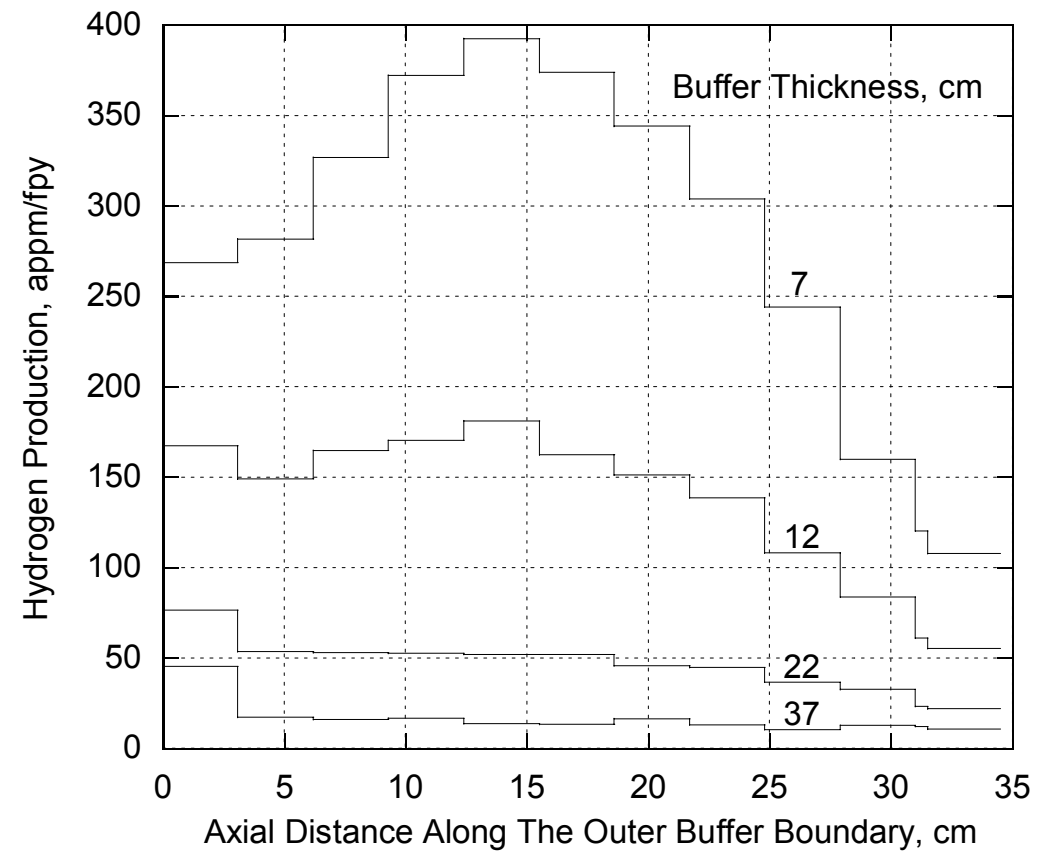

Figure 8. Hydrogen gas production in the outer buffer structure as a function of the buffer thickness for the lead-bismuth target with 5-MW beam power and $600-\mathrm{MeV}$ protons 


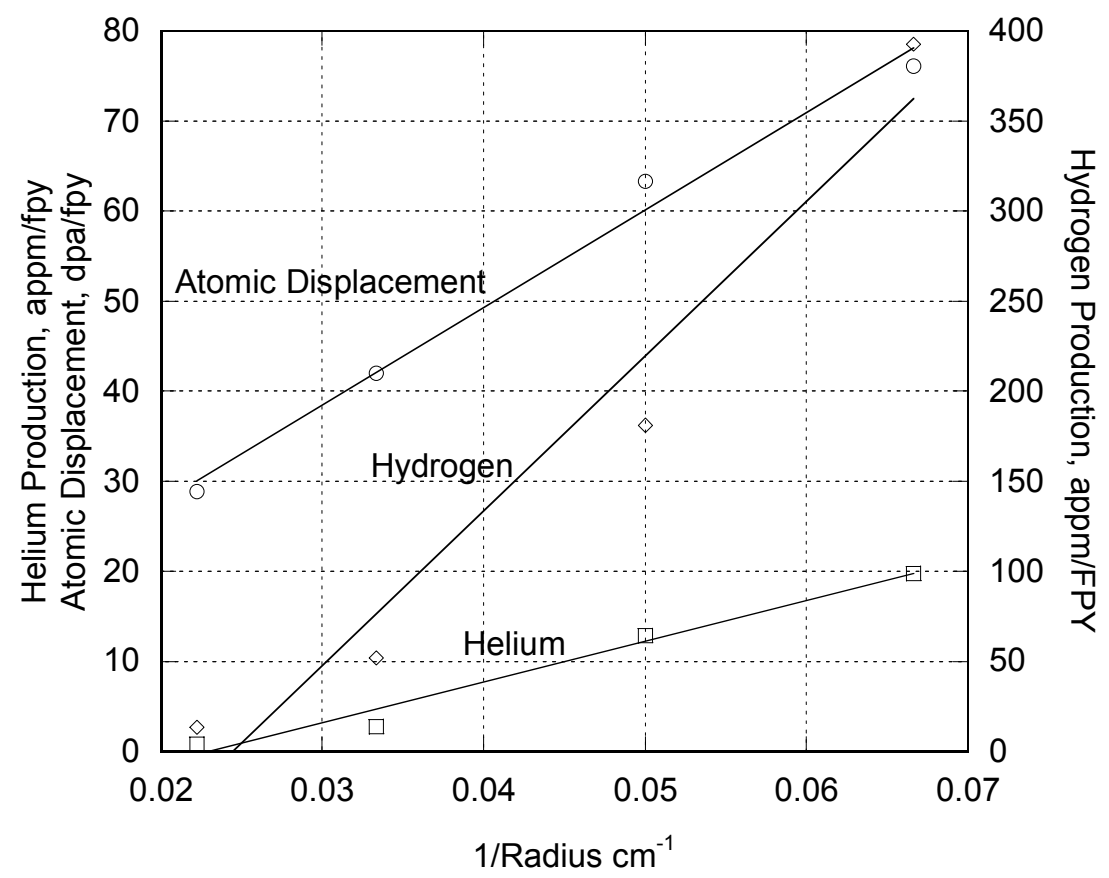

Figure 9. Midplane nuclear responses in the outer buffer structure as a function of the reciprocal of the LBE outer buffer radius

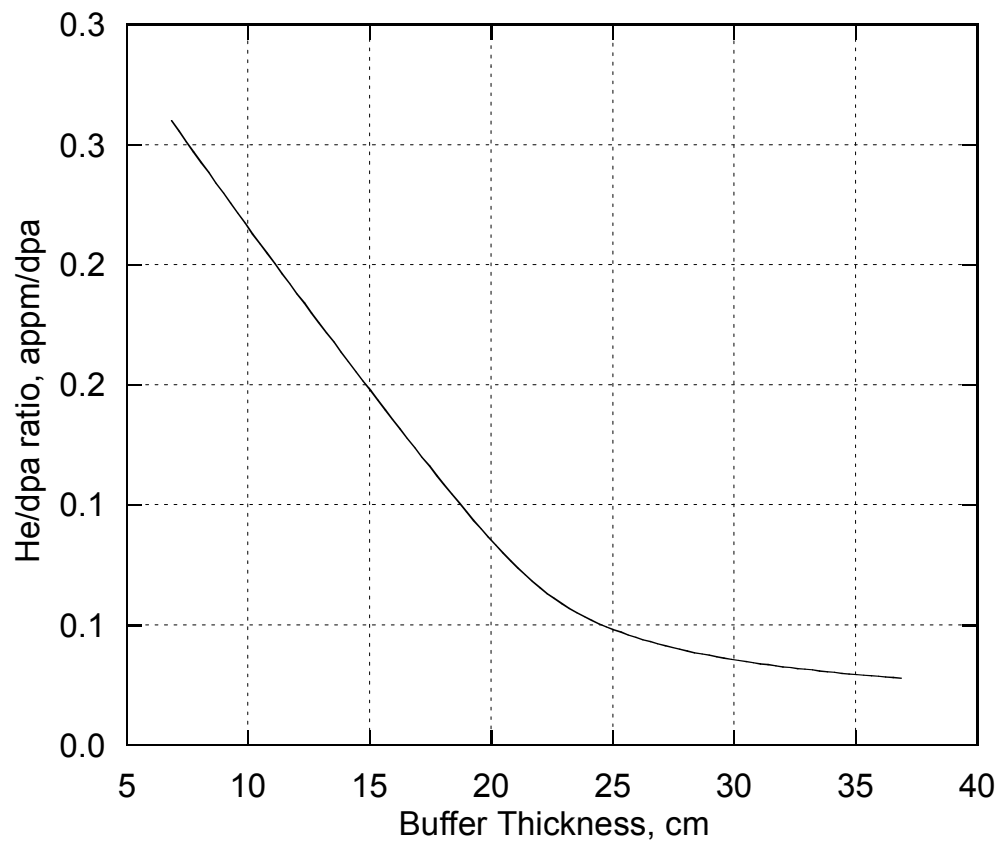

Figure 10. Helium/atomic displacement ratio as a function of the buffer thickness for the LBE target 


\section{IV.3. Reference design}

The previous analysis shows that a 7-cm thick buffer satisfies the physics and the engineering design requirements for the target design. An MCNPX analysis was performed using this buffer size to define the main characteristics of the spallation neutrons. The neutron spectrum was calculated over the radial boundary of the buffer because these neutrons drive the subcritical multiplier. The neutron spectrum peaks in the energy range of 0.6 to $0.7 \mathrm{MeV}$ as shown in Figure 11. The high-energy tail extends all the way up to $\sim 600 \mathrm{MeV}$, which is shown in Figure 12. Each proton generates a total of 10.95 neutrons including 0.68 neutrons with energy above $20 \mathrm{MeV}$. The number of neutrons reaching the subcritical multiplier is 7.61 neutrons per proton. The neutron percentage with energy above $20 \mathrm{MeV}$ entering the subcritical multiplier or leaking from the buffer top section is $6.4 \%$. On the other hand, this percentage is 12.3 for the neutrons leaving the bottom target section, which shows the forward peaking of the high-energy neutrons. The change in the slope of the neutron spectrum at $20 \mathrm{MeV}$ shown in Figure 12 may be caused by the MCNPX calculational method. Under 20 $\mathrm{MeV}, \mathrm{MCNPX}$ uses ENDF/B-VI nuclear data library for the neutron physics calculation while high-energy models are used above $20 \mathrm{MeV}$.

The spatial distribution of the spallation neutrons in the axial direction has a direct effect on the power distribution in the subcritical multiplier. Figure 13 shows the axial distribution of the spallation neutrons calculated at the radial boundary of the buffer. The total distribution peaks at $\sim 12 \mathrm{~cm}$ from the upper surface of the lead-bismuth material while the high-energy neutrons (above $20 \mathrm{MeV}$ ) peak at $\sim 14.5 \mathrm{~cm}$. The peak to the average is 1.33 and the peak to the minimum is 4.11 . The impact on the power distribution of the subcritical multiplier is shown in section VIII.

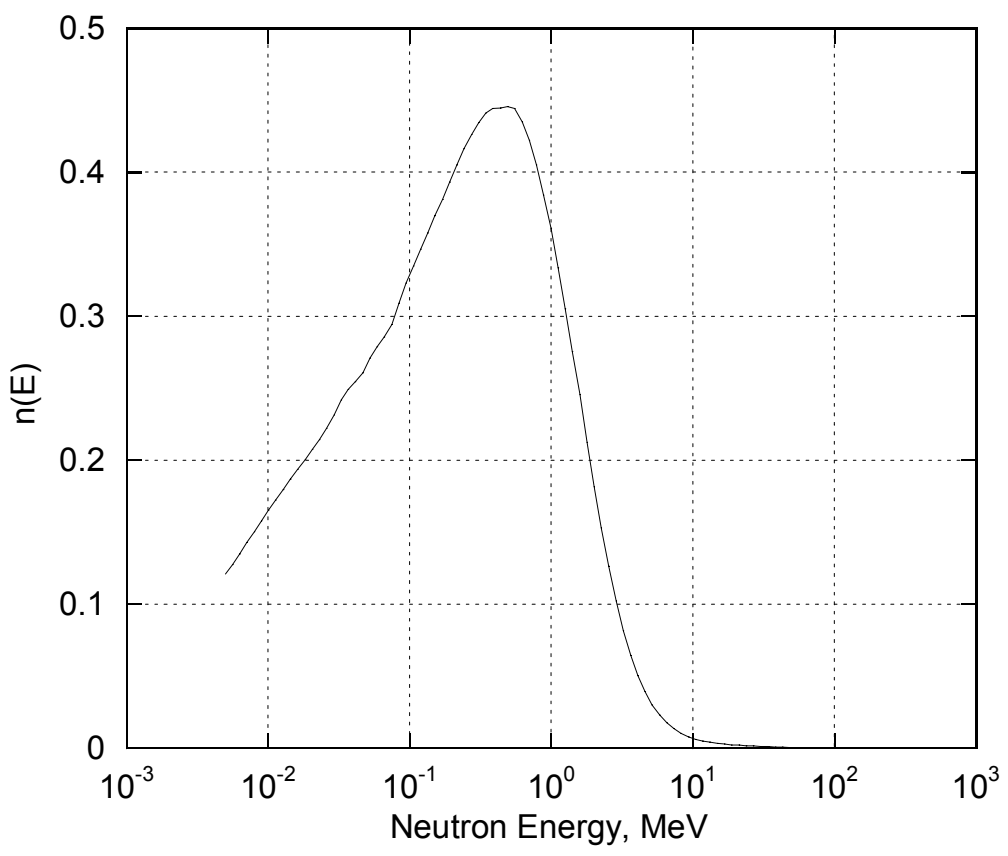

Figure 11. Spallation neutron source spectrum 


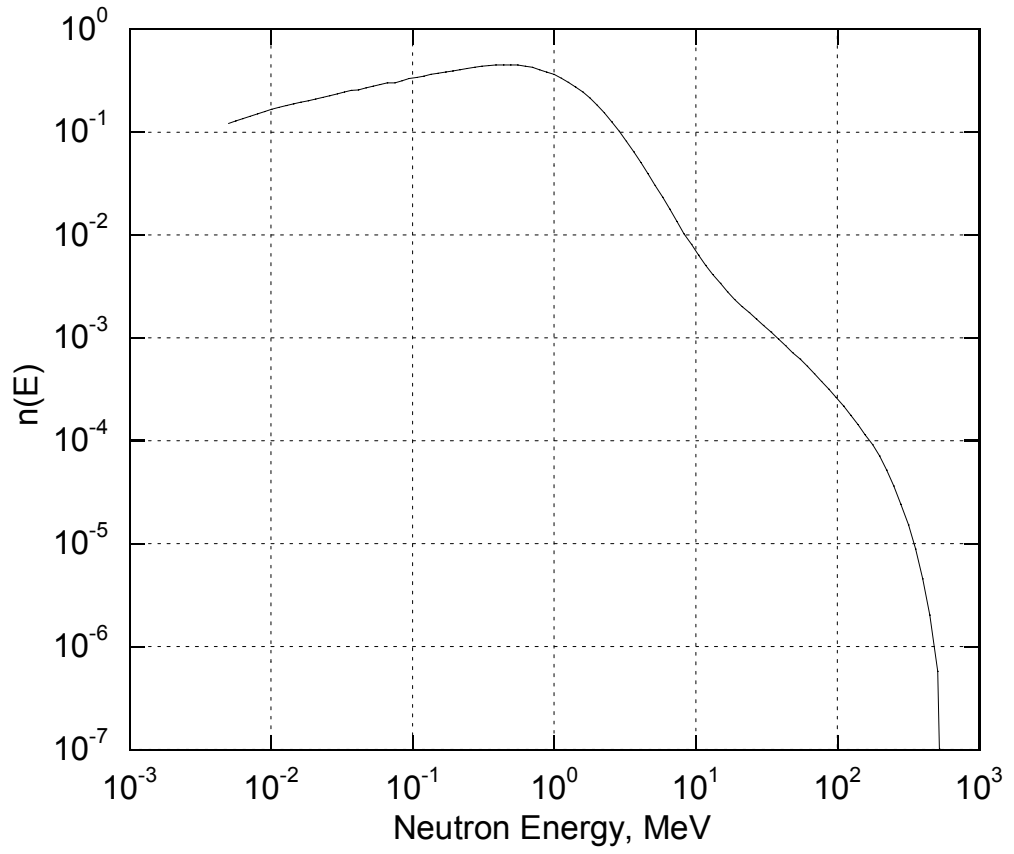

Figure 12. Spallation neutron source spectrum showing the high-energy neutrons

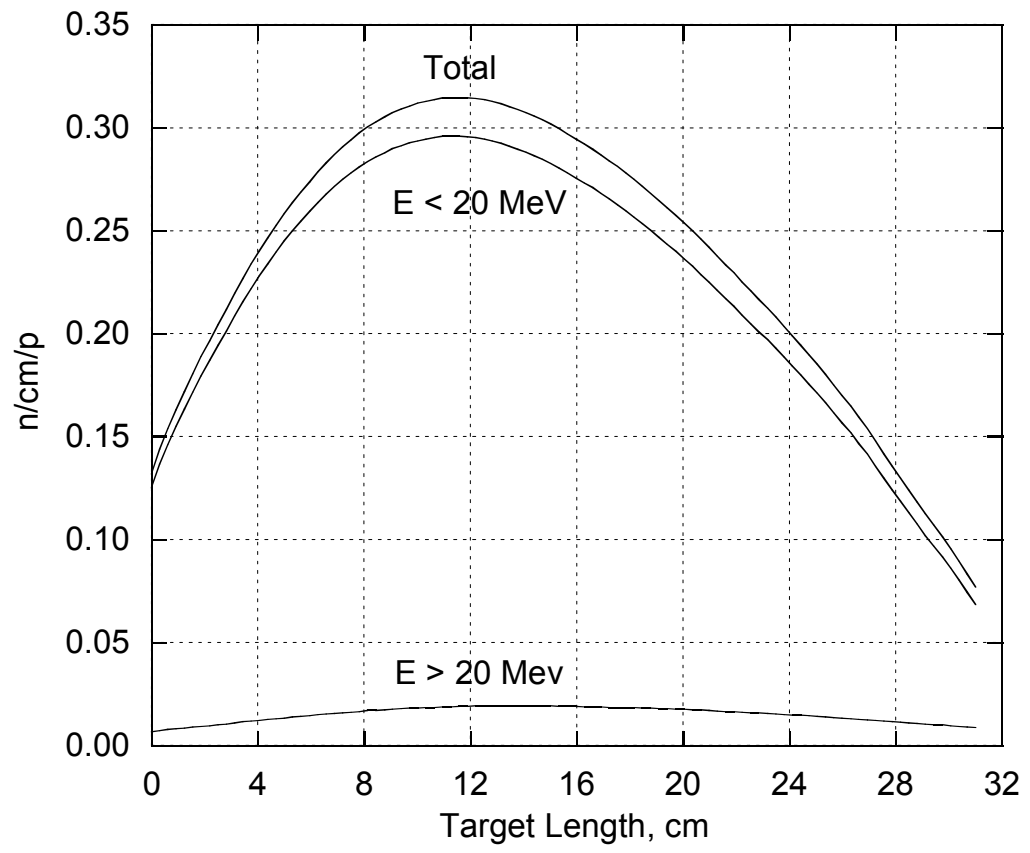

Figure 13. Spallation neutron distribution along the beam axis 


\section{Thermal hydraulic design}

First, parametric thermal hydraulic analyses were performed to determine the temperature distribution in the target materials and the velocity distribution of the leadbismuth eutectic as a function of the target design parameters. The results are used to select the target flow direction with respect to the beam window, to modify the target geometry for increasing the flow stability, and to reduce the thermal gradient in the structure material. The best two cases were selected for structural analyses to check the compliance with the structural design criteria and to define the beam window service lifetime. Then, the thermal hydraulics and the structural analyses were iterated to satisfy all the design constraints and to define the reference design. In this process, the thermal gradient and the peak structural temperature were reduced as much as possible to reduce the total stresses within the structure material and to maximize the operating lifetime of the target structure. This section gives the details of the thermal hydraulic analyses performed for this study.

As previously mentioned, the proton beam has a uniform radial distribution on the beam window. The proton beam power is of $5 \mathrm{MW}$, which results in $3.7 \mathrm{MW}$ deposited in the target materials. The axial power deposition profile in the LBE target material is shown in Figure 3, where the ordinate is the energy deposition density and the abscissa is the proton beam penetration depth. The solid structure of the liquid LBE target is fabricated from a steel alloy. The large temperature difference between the melting and the boiling temperatures of the LBE material eliminates concerns about coolant phase change since the coolant temperature increase is relatively small. On the other hand, the temperature gradient and the peak temperature of the structure material require careful considerations to satisfy the design requirements given in section II. Specifically, the peak temperature of the structural material is the main concern since the temperature gradient is set by the steel thermal conductivity for a specific heat load. The inlet coolant conditions are set to insure that the peak liquid-solid interface temperature is less than $550{ }^{\circ} \mathrm{C}$ for HT-9. Furthermore, the inlet conditions are set so that the average flow velocity does not exceed $2 \mathrm{~m} / \mathrm{s}$ to reduce erosion or corrosion concerns in the target system.

\section{V.1. Parametric analyses}

The initial LBE target concept, shown in Figure 14, is an axisymmetric annular geometry in which the central cylinder is the proton beam tube. In the initial target design, LBE enters the target through the inner annulus, moves through the bulk target region downstream of the beam window where the proton beam enters the target configuration, turns 180 degrees about the baffle cylinder, and exits the target through the outer annulus. The initial inlet temperature is $370{ }^{\circ} \mathrm{C}$ and the inlet velocity is $2 \mathrm{~m} / \mathrm{s}$ with a uniform profile. This inlet temperature is the same as the sodium inlet temperature of the SCM. The structure material is type 316SS or HT-9 with a uniform wall thickness of $5 \mathrm{~mm}$ throughout the target. This case is used as the starting case for the parametric study of the thermal hydraulic characteristics of the ADTF liquid LBE target. 


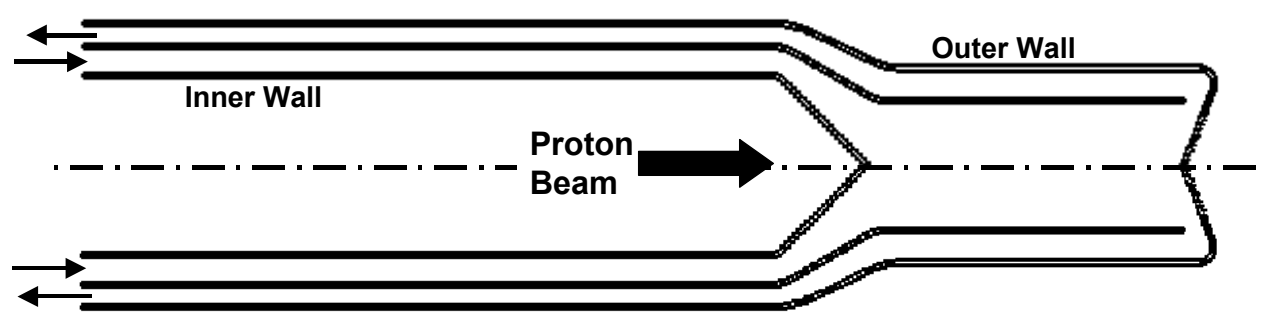

Figure 14. Cross-sectional view of the initial LBE target concept

The parametric thermal hydraulic evaluations considered the two structural materials (type 316SS and HT-9), two different inlet temperatures, two different flow paths with respect to the beam window, and geometrical variations. While type 316SS structure exhibits more desirable machining and fabrication properties, HT9 exhibits more desirable corrosion resistance properties and higher thermal conductivity. In order to insure that LBE remains liquid throughout the system, the minimum inlet temperature must be above $180{ }^{\circ} \mathrm{C}$. An inlet temperature of $200{ }^{\circ} \mathrm{C}$ is considered for the target system. Since the inlet and the outlet manifolds of the target section use coaxial tubes, the inlet LBE will be heated before it reaches the target section. In the analyses, the inlet temperature for the target section is $220^{\circ} \mathrm{C}$ to account for the heat transfer from the hot to the cold manifold. The actual inlet temperature is expected to be less than the $220{ }^{\circ} \mathrm{C}$ value used for the parametric analyses. The inlet and outlet manifolds are reversed for some cases to examine the effect on the local heat transfer coefficients in the heated region. The study also includes a number of geometric variations, with alterations made in the inclination of the inner or middle walls and the conic beam window replaced with a hemi-spherical section. The parametric cases considered are summarized in Table 2.

The thermal hydraulic characteristics of the LBE target are dominated by three primary characteristics of the proposed target design. First, energy is deposited volumetrically in the bulk target region of the flow field. Second, the energy deposition rate in the solid structure within the beam window region is significant. Finally, a compact 180-degree turn in flow direction is needed to provide a return path to the outlet. These characteristics limit the applicability of existing analytical and empirical correlations for evaluating the temperature and the velocity profiles within the system. Therefore, the primary thermal hydraulic evaluations were performed using the commercially available Computational Fluid Dynamics (CFD) software package Star-CD [4].

All the cases use the high-Reynolds number $k-\varepsilon$ turbulence model to predict turbulent flow characteristics, and the logarithmic law-of-the-wall to predict near wall characteristics. The dimensionless flow parameter $y+$ is typically used to measure the applicability of these models for a given flow distribution and computational mesh structure. Sufficient mesh refinement is used in each case to obtain $y+$ values between 30 and 300 in the heated regions, indicating that the turbulence model can provide 
reasonable predictions in these regions. Further mesh refinement is needed in the vicinity of the tip of the middle wall to obtain acceptable $y+$ values in this region since the mesh refinement used in these studies results in $y+$ values between 50 and 1200 . While further refinement of the mesh in this region appears to have little impact on the heat transfer in the heated regions of the target, the results of these studies should be used to predict general trends rather than absolute distributions at the tip of the middle wall.

Table 2. Cases considered in the thermal hydraulic parametric study

\begin{tabular}{|c|c|c|c|c|c|}
\hline Case & $\begin{array}{c}\text { Conical } \\
\text { Beam } \\
\text { Window } \\
\text { Angle } \\
\text { (degree) }\end{array}$ & $\begin{array}{c}\text { Middle Wall } \\
\text { Angle } \\
\text { (degree) }\end{array}$ & Material & $\begin{array}{c}\text { Inlet } \\
\text { Temperature } \\
\left({ }^{\circ} \mathrm{C}\right)\end{array}$ & $\begin{array}{c}\text { Flow } \\
\text { Direction }\end{array}$ \\
\hline 1 & 45 & 30 & Type 316SS & 370 & Normal \\
\hline 2 & 45 & 30 & HT9 & 370 & Normal \\
\hline 3 & 45 & 30 & HT9 & 220 & Normal \\
\hline 4 & 45 & 30 & Type 316SS & 370 & Reversed \\
\hline 5 & 45 & 30 & HT9 & 370 & Reversed \\
\hline 6 & 45 & 30 & HT9 & 220 & Reversed \\
\hline 7 & 45 & 40 & Type 316SS & 370 & Normal \\
\hline 8 & 45 & 40 & HT9 & 370 & Normal \\
\hline 9 & 45 & 40 & HT9 & 220 & Normal \\
\hline 10 & 45 & 40 & Type 316SS & 370 & Reversed \\
\hline 11 & 45 & 40 & HT9 & 370 & Reversed \\
\hline 12 & 45 & 40 & HT9 & 220 & Reversed \\
\hline 13 & 55 & 30 & HT9 & 220 & Reversed \\
\hline 14 & 65 & 30 & HT9 & 220 & Reversed \\
\hline 15 & Spherical & 30 & HT9 & 220 & Reversed \\
\hline
\end{tabular}

\section{Case 1}

The target geometry considered in this case is the initial LBE target concept with the initial parameters. The inlet temperature is $370{ }^{\circ} \mathrm{C}$, and the nominal uniform inlet flow velocity is $2 \mathrm{~m} / \mathrm{s}$. The structural material is type $316 \mathrm{SS}$ and all the structural components have $5 \mathrm{~mm}$ thickness. The thermal hydraulic behavior of this case was evaluated using an axisymmetric model consisting of 43264 cells. The calculation is 
performed as a steady state simulation using the PISO solution algorithm [4] and upwind differencing methodologies. The results of the CFD evaluation are shown as a series of contour plots in Figure 15.

The peak temperatures on the adiabatic and the wetted surfaces of the beam window are $1374{ }^{\circ} \mathrm{C}$ and $711^{\circ} \mathrm{C}$, respectively. The peak surface and internal temperatures of the middle wall, the turning baffle, are $494^{\circ} \mathrm{C}$ and $639{ }^{\circ} \mathrm{C}$, respectively. The mean fluid temperature in the portion of the target considered in the model is $407^{\circ} \mathrm{C}$. The vector velocity predictions indicate the development of a toroidal recirculation zone in the exit channel near the tip of the middle wall, or turning baffle. The development of this type of flow pattern in a steady state solution is often indicative of unsteady transient flow behavior. The pressure drop for the portion of the target considered in this model is $0.112 \mathrm{MPa}$. The predictions from this case indicate that the initial design concept does not satisfy the required temperature limits of the structural material.

\section{Case 2}

The target geometry considered in this case is the initial LBE concept. The inlet temperature is $370{ }^{\circ} \mathrm{C}$ and the uniform inlet flow velocity is $2 \mathrm{~m} / \mathrm{s}$. The structural material is HT9 instead of type 316SS with a uniform thickness of $5 \mathrm{~mm}$. The case-1 thermal hydraulic model is used for the analysis and the results from the CFD calculation are shown as a series of contour plots in Figure 16.

The peak temperatures on the adiabatic and the wetted surface of the beam window are $1204{ }^{\circ} \mathrm{C}$ and $646{ }^{\circ} \mathrm{C}$, respectively. The peak surface and the internal temperatures of the middle wall, the turning baffle, are $494^{\circ} \mathrm{C}$ and $601{ }^{\circ} \mathrm{C}$, respectively. The mean fluid temperature in the portion of the target considered in the model is $406{ }^{\circ} \mathrm{C}$. As with previous results, the vector velocity predictions indicate the development of a toroidal recirculation zone in the exit channel near the tip of the middle wall. The pressure drop for the portion of the target considered in this model is 0.112 $\mathrm{MPa}$ as in the previous case. The results from this case show a reduction in the temperature distribution within the beam window relative to the previous case with type 316SS. However the peak temperatures continue to exceed the design requirements.

\section{Case 3}

The target geometry considered in this case is the initial LBE target concept. The inlet temperature is reduced to $220^{\circ} \mathrm{C}$ to reduce the peak window temperature. As in the previous two cases the uniform inlet flow velocity is $2 \mathrm{~m} / \mathrm{s}$. Also, the structural material is HT9 steel with $5 \mathrm{~mm}$ uniform thickness. The same thermal hydraulic model of the previous two cases is used for the analysis and the results from the CFD calculation are shown as a series of contour plots in Figure 17.

The peak temperatures on the adiabatic and the wetted surfaces of the beam window are $1034{ }^{\circ} \mathrm{C}$ and $475{ }^{\circ} \mathrm{C}$, respectively. The peak surface and internal temperatures of the middle wall are $323{ }^{\circ} \mathrm{C}$ and $431{ }^{\circ} \mathrm{C}$, respectively. The mean fluid 
temperature in the portion of the target considered in the model is $256{ }^{\circ} \mathrm{C}$. As with previous results, the vector velocity predictions indicate the development of a toroidal recirculation zone in the exit channel near the tip of the middle wall. The results from this case show an improvement in the temperature distribution within the beam window relative to the previous two cases. The pressure drop did not change from the previous two cases. However the peak temperatures continue to exceed design requirements.

\section{Case 4}

The target geometry considered in this case is the initial LBE target concept. The inlet temperature is changed to the initial temperature of $370{ }^{\circ} \mathrm{C}$, and the nominal uniform inlet flow velocity is maintained at $2 \mathrm{~m} / \mathrm{s}$. However, the flow direction is reversed so that the fluid enters through the outer annulus rather than the inner annulus. The structural material is type 316SS steel with $5 \mathrm{~mm}$ uniform thickness. The same thermal hydraulic model of the previous cases is used for the analysis and the results from the CFD calculation are shown as a series of contour plots in Figure 18.

The peak temperatures on the adiabatic and the wetted surfaces of the beam window are $1035{ }^{\circ} \mathrm{C}$ and $461{ }^{\circ} \mathrm{C}$, respectively. The peak surface and internal temperatures on the middle wall are $480{ }^{\circ} \mathrm{C}$ and $645{ }^{\circ} \mathrm{C}$, respectively. The mean fluid temperature in the portion of the target considered in the model is $417^{\circ} \mathrm{C}$. Similar to the previous results, the vector velocity predictions indicate the development of a toroidal recirculation zone in the exit channel near the tip of the middle wall. The pressure drop for the portion of the target considered in this model is $0.187 \mathrm{MPa}$. The temperature results of the beam window are similar to the results from the previous case with the inlet LBE temperature of $220^{\circ} \mathrm{C}$ and HT-9 steel instead of $370^{\circ} \mathrm{C}$ and type $316 \mathrm{SS}$. This shows that reversing the flow direction reduces the peak temperate of the beam window.

\section{Case 5}

The target geometry considered in this case is the initial liquid LBE concept. The inlet temperature is $370{ }^{\circ} \mathrm{C}$, and the nominal uniform inlet flow velocity is maintained at 2 $\mathrm{m} / \mathrm{s}$ with reversed flow direction. The structural material is changed to HT9 steel with $5 \mathrm{~mm}$ uniform thickness. The same thermal hydraulic model of the previous cases is used for the analysis and the results from the CFD calculation are shown as a series of contour plots in Figure 19.

The peak temperatures on the adiabatic and the wetted surfaces of the beam window are $867{ }^{\circ} \mathrm{C}$ and $462{ }^{\circ} \mathrm{C}$, respectively. The peak surface and internal temperatures on the middle wall are $481^{\circ} \mathrm{C}$ and $608{ }^{\circ} \mathrm{C}$, respectively. Similar to the previous case, the mean fluid temperature in the portion of the target considered in the model is $417{ }^{\circ} \mathrm{C}$. Also, the vector velocity predictions indicate the development of a toroidal recirculation zone in the exit channel near the tip of the middle wall. The pressure drop for the portion of the target considered in this model is $0.187 \mathrm{MPa}$. However, the peak temperature of the window is $165{ }^{\circ} \mathrm{C}$ less than the previous case due to the use of HT-9 instead of type 316SS.

\section{Case 6}


The target geometry considered in this case is the initial LBE concept. The inlet temperature is reduced to $220^{\circ} \mathrm{C}$ and the nominal uniform inlet flow velocity of $2 \mathrm{~m} / \mathrm{s}$ is maintained. Also, the flow direction is reversed and the structural material is changed to HT-9 steel with $5 \mathrm{~mm}$ uniform thickness. The same thermal hydraulic model of the previous cases is used for the analysis and the results from the CFD calculation are shown as a series of contour plots in Figure 20.

The peak temperatures on the adiabatic and the wetted surfaces of the beam window are $697{ }^{\circ} \mathrm{C}$ and $292{ }^{\circ} \mathrm{C}$, respectively. The peak surface and internal temperatures on the middle wall are $311^{\circ} \mathrm{C}$ and $438{ }^{\circ} \mathrm{C}$, respectively. The mean fluid temperature in the portion of the target considered in the model is $246.9^{\circ} \mathrm{C}$. The results from this case provide significant improvement in the temperature distribution within the beam window structure over all cases considered up to this point.

\section{Case 7}

In this case, a modified target concept is used in which the angle of the middle wall with the centerline is increased from 30 degrees to 40 degrees to increase the average velocity at the beam window. The inlet temperature is $370{ }^{\circ} \mathrm{C}$ and the nominal uniform inlet flow velocity is $2 \mathrm{~m} / \mathrm{s}$. The flow enters the target through the inner annulus as in the initial concept. The structural material is type $316 \mathrm{SS}$ steel with a $5 \mathrm{~mm}$ uniform thickness. The thermal hydraulic model of the previous cases was updated and used for the analysis and the results from the CFD calculation are shown as a series of contour plots in Figure 21.

The peak temperatures on the adiabatic and the wetted surfaces of the beam window are $1338{ }^{\circ} \mathrm{C}$ and $664{ }^{\circ} \mathrm{C}$, respectively. The peak surface and internal temperatures on the middle wall are $1310^{\circ} \mathrm{C}$ and $534^{\circ} \mathrm{C}$, respectively. The mean fluid temperature in the portion of the target considered in the model is $426{ }^{\circ} \mathrm{C}$. As with previous results, the vector velocity predictions indicate the development of a toroidal recirculation zone in the exit channel near the tip of the middle wall. The pressure drop for the portion of the target considered in this model is $0.111 \mathrm{MPa}$. The results from this case indicate that this geometrical modification slightly reduces the beam window temperature distribution relative to the first case. However, peak temperature in the middle wall significantly increases as more heat is deposited in this component of the structure because it is moved closer to the beam window. Also, the LBE velocity in the inlet section near the middle wall is reduced, as shown in Figure 21a, which contributes to the temperature increase.

\section{Case 8}

In this case, the modified target concept is used in which the angle of the middle wall with the centerline is increased from 30 degrees to 40 degrees. The inlet temperature is $370{ }^{\circ} \mathrm{C}$ and the nominal uniform inlet flow velocity is $2 \mathrm{~m} / \mathrm{s}$. The inlet flow is through the inner annulus. The structural material is HT-9 with $5 \mathrm{~mm}$ uniform thickness. The same thermal hydraulic model of the previous cases is used for the 
analysis and the results from the CFD calculation are shown as a series of contour plots in Figure 22.

The peak temperatures on the adiabatic and the wetted surfaces of the beam window are $1180{ }^{\circ} \mathrm{C}$ and $663{ }^{\circ} \mathrm{C}$, respectively. The peak surface and internal temperatures on the middle wall are $1108{ }^{\circ} \mathrm{C}$ and $534^{\circ} \mathrm{C}$, respectively. The mean fluid temperature in the portion of the target considered in the model is $426{ }^{\circ} \mathrm{C}$. This case provides a slight improvement relative to case 7 as a result of the higher thermal conductivity of the HT9 steel. However, the peak temperature in the middle wall is significantly higher than the corresponding value of case 2 with the initial geometry.

\section{Case 9}

In this case, the modified target concept is used in which the middle wall angle is 40 degrees. The inlet temperature is $220^{\circ} \mathrm{C}$ and the nominal uniform inlet flow velocity of $2 \mathrm{~m} / \mathrm{s}$ is maintained. The inlet flow is through the inner annulus. The structural material is HT-9 with a $5 \mathrm{~mm}$ uniform thickness. The same thermal hydraulic model of the previous cases is used for the analysis and the results from the CFD calculation are shown as a series of contour plots in Figure 23.

The peak temperatures on the adiabatic and the wetted surfaces of the beam window are $1010{ }^{\circ} \mathrm{C}$ and $492{ }^{\circ} \mathrm{C}$, respectively. The peak surface and internal temperatures on the middle wall are $364{ }^{\circ} \mathrm{C}$ and $938{ }^{\circ} \mathrm{C}$, respectively. The mean fluid temperature in the portion of the target considered in the model is $256{ }^{\circ} \mathrm{C}$. The results of this case show that the peak temperature of the structural material does not satisfy the design requirements. Also, the modified geometry provides a slight reduction in the beam window temperature relative to case 3 . However, the peak temperature in the middle wall is still significantly higher than the corresponding value from case 3 .

\section{Case 10}

In this case, the modified target geometry is used in which the angle of the middle wall with the centerline is increased from 30 degrees to 40 degrees. The inlet temperature is $370{ }^{\circ} \mathrm{C}$ and the nominal uniform inlet flow velocity is $2 \mathrm{~m} / \mathrm{s}$. However, the flow direction is reversed so that the fluid enters through the outer annulus rather than the inner annulus. The structural material is type $316 \mathrm{SS}$ steel with $5 \mathrm{~mm}$ uniform thickness. The same thermal hydraulic model of the previous cases is used for the analysis and the results from the CFD calculation are shown as a series of contour plots in Figure 24.

The peak temperatures on the adiabatic and the wetted surfaces of the beam window are $1033{ }^{\circ} \mathrm{C}$ and $462{ }^{\circ} \mathrm{C}$, respectively. The peak surface and internal temperatures on the middle wall are $505^{\circ} \mathrm{C}$ and $1347^{\circ} \mathrm{C}$, respectively. The mean fluid temperature in the portion of the target considered in the model is $416{ }^{\circ} \mathrm{C}$. As with the previous results, the vector velocity predictions indicate the development of a toroidal recirculation zone in the exit channel near the tip of the middle wall. The pressure drop

for the portion of the target considered in this model is $0.185 \mathrm{MPa}$. The results show 
that reversing the flow direction in the modified target geometry results in a significant improvement in the peak beam window temperature relative to case 7 . However, the peak middle wall temperature increases slightly over the corresponding value of case 7 . Peak temperatures in both walls are well in excess of the design requirements. Also, the peak middle wall temperature is much higher than the corresponding value of case 4 while the other peak temperatures are about the same.

\section{Case 11}

In this case, the modified target geometry is used in which the angle of the middle wall with the centerline is increased from 30 degrees to 40 degrees. The inlet temperature is $370{ }^{\circ} \mathrm{C}$ and the nominal uniform inlet flow velocity is $2 \mathrm{~m} / \mathrm{s}$. The flow direction is reversed so that the fluid enters through the outer annulus rather than the inner annulus. The structural material is changed to HT-9 from the previous case with 5 $\mathrm{mm}$ uniform thickness. The same thermal hydraulic model of the previous cases is used for the analysis and the results from the CFD calculation are shown as a series of contour plots in Figure 25.

The peak temperatures on the adiabatic and the wetted surfaces of the beam window are $865{ }^{\circ} \mathrm{C}$ and $463{ }^{\circ} \mathrm{C}$, respectively. The peak surface and internal temperatures on the middle wall are $506^{\circ} \mathrm{C}$ and $1143^{\circ} \mathrm{C}$, respectively. The mean fluid temperature in the portion of the target considered in the model is $416{ }^{\circ} \mathrm{C}$. The results show that reversing the flow direction in the modified target geometry results in a significant improvement in the peak beam window temperature relative to case 8 . Again, the peak middle wall temperature increases slightly over the corresponding value of case 8. Peak temperatures in both walls are well in excess of the design requirements. Also, the peak middle wall temperature is much higher than the corresponding value of case 5 while the other peak temperatures are about the same

\section{Case 12}

In this case, the modified target geometry is used in which the angle of the middle wall with the centerline is increased from 30 degrees to 40 degrees. The inlet temperature is $220^{\circ} \mathrm{C}$, and the nominal uniform inlet flow velocity is $2 \mathrm{~m} / \mathrm{s}$. The flow direction is reversed so that the fluid enters through the outer annulus rather than the inner annulus. The structural material is HT-9 from with $5 \mathrm{~mm}$ uniform thickness. The same thermal hydraulic model of the previous cases is used for the analysis and the results from the CFD calculation are shown as a series of contour plots in Figure 26.

The peak temperatures on the adiabatic and the wetted surfaces of the beam window are $694{ }^{\circ} \mathrm{C}$ and $293{ }^{\circ} \mathrm{C}$, respectively. The peak surface and internal temperatures on the middle wall are $336{ }^{\circ} \mathrm{C}$ and $973{ }^{\circ} \mathrm{C}$, respectively. The mean fluid temperature in the portion of the target considered in the model is $246{ }^{\circ} \mathrm{C}$. The results show that reversing the flow direction in the modified target geometry results in a significant improvement in the peak beam window temperature relative to case 9 . Again, the peak middle wall temperature increases slightly over the corresponding value of case 9. Peak temperatures in both walls are well in excess of the design 
requirements. Also, the peak middle wall temperature is much higher than the corresponding value of case 6 while the other peak temperatures are about the same.

\section{Case 13}

In this case, the beam window angle with the centerline is increased from 45 degrees to 55 degrees. The inlet temperature is $220^{\circ} \mathrm{C}$ and the nominal uniform inlet flow velocity is $2 \mathrm{~m} / \mathrm{s}$. The flow enters through the outer annulus and exits through the inner annulus. The structural material is HT-9 steel with $5 \mathrm{~mm}$ uniform thickness. The same thermal hydraulic model of the previous cases is modified and used for the analysis. The results from the CFD calculation are shown as a series of contour plots in Figure 27.

The peak temperatures on the adiabatic and the wetted surfaces of the beam window are $693{ }^{\circ} \mathrm{C}$ and $288{ }^{\circ} \mathrm{C}$, respectively. The peak surface and internal temperatures on the middle wall are $309{ }^{\circ} \mathrm{C}$ and $435{ }^{\circ} \mathrm{C}$, respectively. The mean fluid temperature in the portion of the target considered in the model is $247^{\circ} \mathrm{C}$. As with the previous results, the vector velocity predictions indicate the development of a toroidal recirculation zone in the exit channel near the tip of the middle wall. The pressure drop for the portion of the target considered in this model is $0.193 \mathrm{MPa}$. The predicted peak temperatures from this simulation are nearly equal to the peak temperatures from case 6 , indicating that a 10-degree increase in the angle of the beam window has little effect on the peak temperatures in this concept.

\section{Case 14}

This case is similar to the previous case except the beam window angle with the centerline is increased from 55 degrees to 65 degrees. The same thermal hydraulic model of the previous cases is modified and used for the analysis. The results from the CFD calculation are shown as a series of contour plots in Figure 28.

The peak temperatures on the adiabatic and the wetted surfaces of the beam window are $691{ }^{\circ} \mathrm{C}$ and $287{ }^{\circ} \mathrm{C}$, respectively. The peak surface and internal temperatures on the middle wall are $308^{\circ} \mathrm{C}$ and $433{ }^{\circ} \mathrm{C}$, respectively. The mean fluid temperature in the portion of the target considered in the model is $247^{\circ} \mathrm{C}$. The pressure drop for the portion of the target considered in this model is $0.197 \mathrm{MPa}$. As with previous results, the vector velocity predictions indicate the development of a toroidal recirculation zone in the exit channel near the tip of the middle wall. The predicted peak temperatures from this simulation are nearly equal to the peak temperatures from case 6 , indicating that a 20-degree increase in the angle of the beam window has little effect on the peak temperatures in this concept.

\section{Case 15}

In this case, the cone shaped beam window is replaced with a hemi-spherical beam window. The inlet temperature is $220{ }^{\circ} \mathrm{C}$ and the nominal uniform inlet flow velocity is $2 \mathrm{~m} / \mathrm{s}$. The LBE fluid enters through the outer annulus and exits through the 
inner annulus. The structural material is HT-9 steel with $5 \mathrm{~mm}$ uniform thickness. The thermal hydraulic behavior was evaluated with an axisymmetric model consisting of 45840 cells. The calculation is performed as a transient simulation using the PISO solution algorithm and upwind differencing methodologies, although a steady state solution is obtained in this calculation. The transient method is used to minimize the effects of slight mesh distortions resulting from the implementation of the hemi-spherical beam window in the model on the convergence of the calculation. Comparisons of transient and steady state calculations for selected cases indicate little variation in predicted temperature and velocity profiles between transient and steady state evaluations. The results of the CFD evaluation are shown as a series of contour plots in Figure 29.

The peak temperature of the adiabatic and the wetted surfaces of the beam window are $692.2{ }^{\circ} \mathrm{C}$ and $367.1{ }^{\circ} \mathrm{C}$, respectively. The predicted peak surface and internal temperatures in the middle wall are $363.5^{\circ} \mathrm{C}$ and $439.3^{\circ} \mathrm{C}$, respectively. The mean fluid temperature in the portion of the system considered is $247.9{ }^{\circ} \mathrm{C}$. As with previous results, the vector velocity predictions indicate the development of a toroidal recirculation zone near the tip of the middle wall, the turning baffle. The pressure drop for the portion of the target considered in this model is $0.192 \mathrm{MPa}$. The results from this case are very close to the results of case 6.

\section{Comparison of the results from the parametric study}

Since structural temperature distributions are used in the design criteria of this conceptual design phase, the peak surface and peak structural temperatures for the beam window and the middle wall are compared. The results of the 15 cases included in the initial parametric study are summarized in Figure 30. None of the cases considered in this initial study clearly satisfy the maximum temperature design limit. However, general trends from the parametric study provide vital information needed to develop a conceptual design that satisfies the limit. Cases with the flow enter in the outer annulus show lower peak temperatures relative to the other cases. Cases with the middle wall angle increased provide small reduction in the beam window temperature distribution while the middle wall peak temperatures are significantly increased. For conical beam windows, changing the cone angle has little impact on the temperature distribution. The use of $220^{\circ} \mathrm{C}$ inlet temperature is essential to reduce the temperature distribution in the target structure. A small difference is observed between the temperature distribution of the conical (case 6) and the hemi-spherical (case 15) beam windows. A detailed comparison of the adiabatic and the wetted surfaces temperatures on the beam windows of the two cases is shown in Figure 31. While the stagnation point at the centerline of the hemi-spherical beam window in case 15 raises the temperatures in that region above those seen in the cone-shaped beam window of case 6 , the remainder of the temperature distributions along both surfaces of the each beam window geometry are nearly identical. Therefore, both concepts can be considered for developing a reference design. 


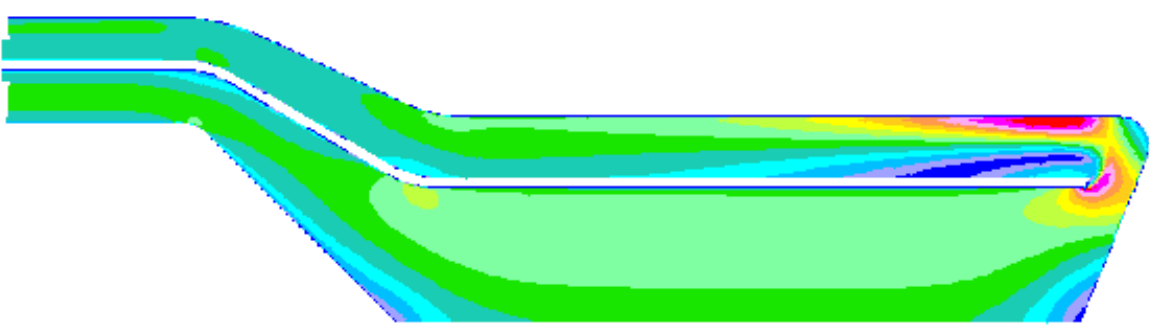

\begin{tabular}{|c|}
5.818 \\
\hline 5.403 \\
4.987 \\
4.572 \\
4.156 \\
\hline 3.740 \\
\hline 3.325 \\
\hline 2.909 \\
\hline 2.494 \\
\hline 2.078 \\
\hline 1.662 \\
\hline 1.247 \\
0.8312 \\
\hline 0.4156 \\
\hline 0.
\end{tabular}

(a)

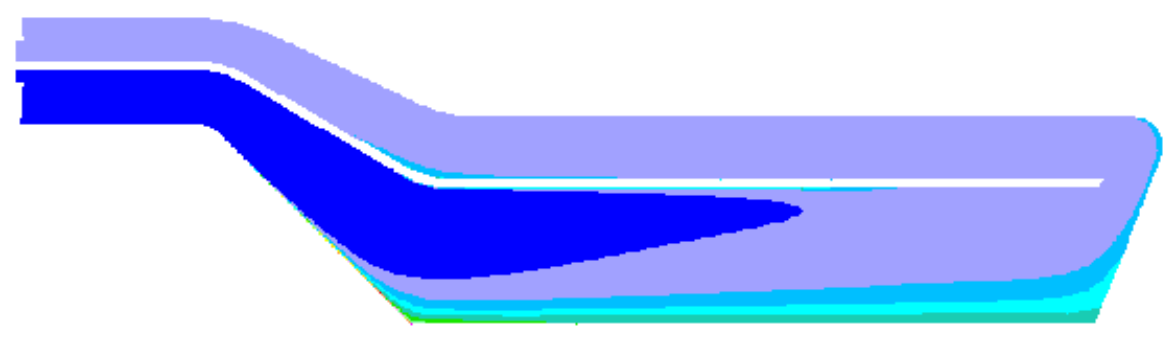

TEMPERATURE ABSOLUTE KELVIN

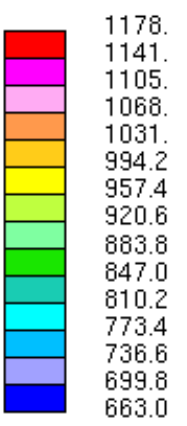

(b)

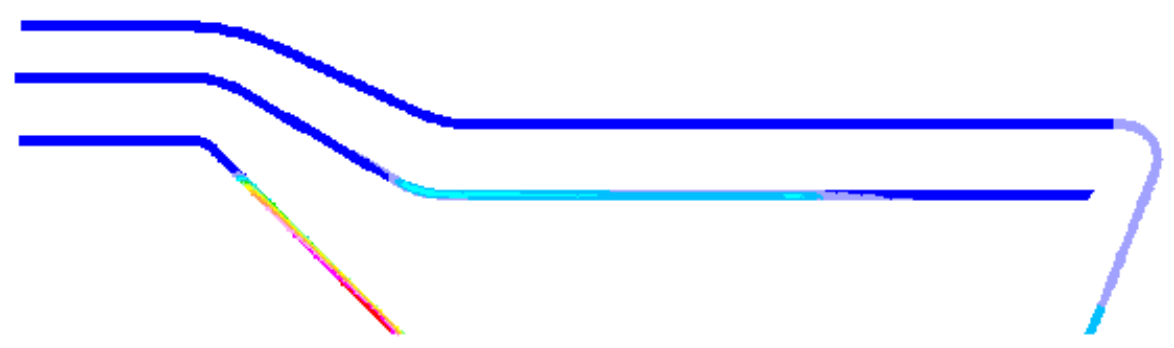

TEMPERATURE ABSOLUTE KELVIN

\begin{tabular}{|l}
1639. \\
1569. \\
1500. \\
1430. \\
1360. \\
1290. \\
1221. \\
1151. \\
1081. \\
1012. \\
\hline 941.9 \\
\hline 872.1 \\
\hline 802.4 \\
\hline 732.7 \\
\hline 663.0
\end{tabular}

(c)

Figure 15. LBE target concept contour plots showing (a) fluid velocity, (b) fluid temperature, and (c) structural temperature profiles for case 1 


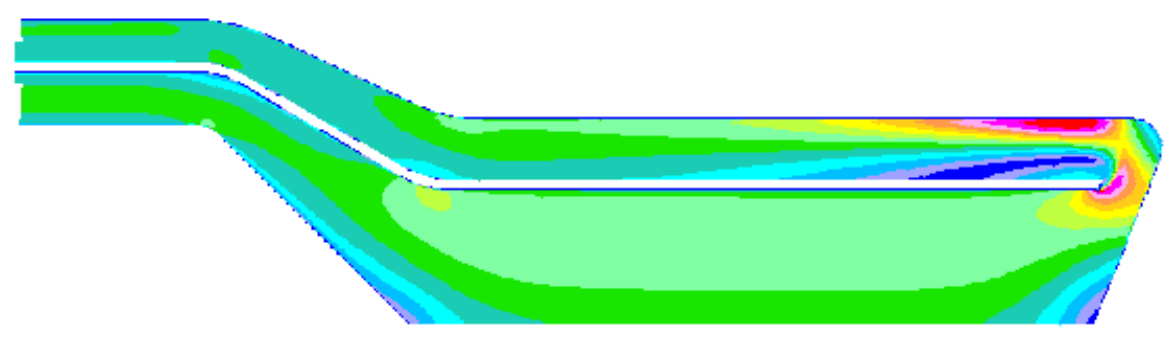

VELOCITY MAGNITUDE $\mathrm{M} / \mathrm{S}$

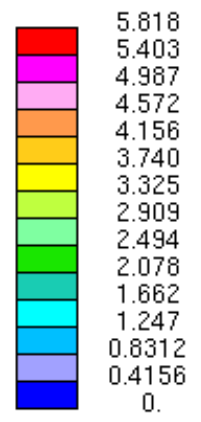

(a)

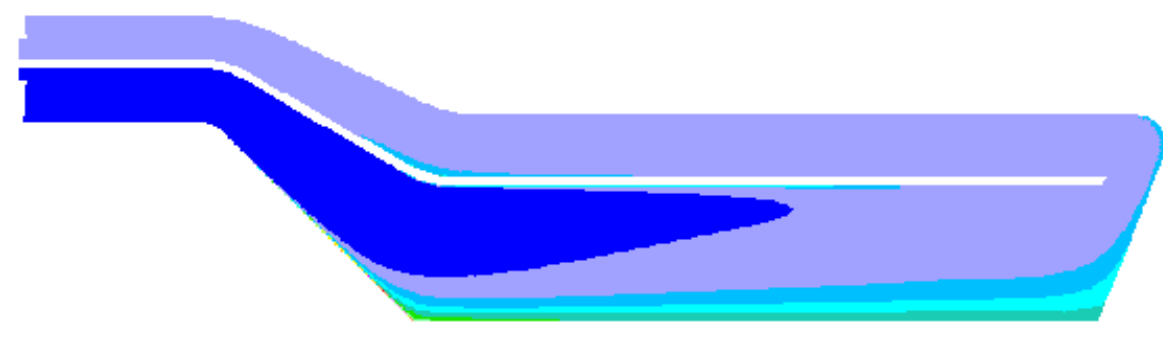

TEMPERATURE ABSOLUTE KELVIN

\begin{tabular}{|l}
1176. \\
1139. \\
1103. \\
1066. \\
1029. \\
992.7 \\
956.0 \\
919.4 \\
\hline 882.8 \\
\hline 846.1 \\
\hline 809.5 \\
772.9 \\
736.3 \\
699.6 \\
\hline 663.0
\end{tabular}

(b)

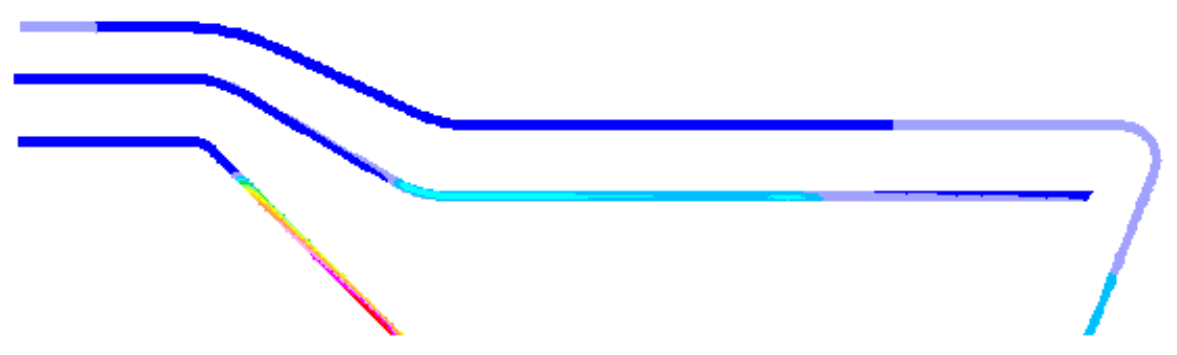

TEMPERATURE ABSOLUTE KELVIN

\begin{tabular}{|l}
1477. \\
1419. \\
1361. \\
1303. \\
1245. \\
1186. \\
1128. \\
1070. \\
1012. \\
\hline 953.8 \\
\hline 895.6 \\
837.5 \\
779.3 \\
721.2 \\
\hline 663.0
\end{tabular}

(c)

Figure 16. LBE target concept contour plots showing (a) fluid velocity, (b) fluid temperature, and (c) structural temperature profiles for case 2 


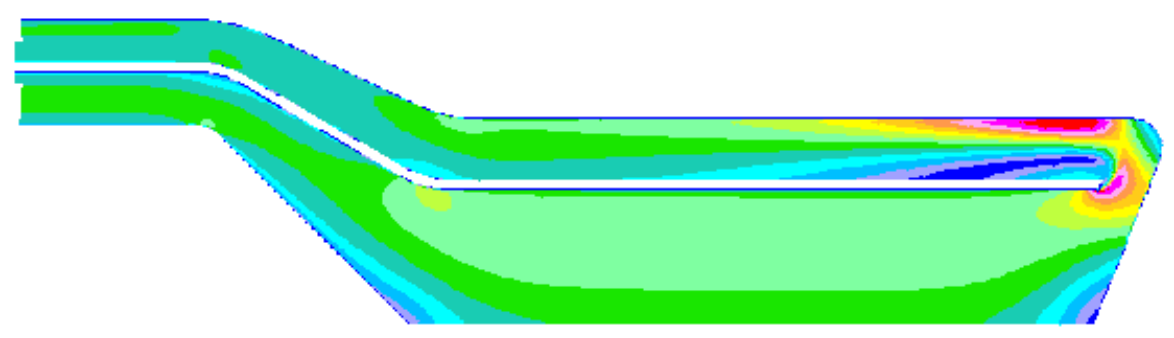

VELOCITY MAGNITUDE $\mathrm{M} / \mathrm{S}$

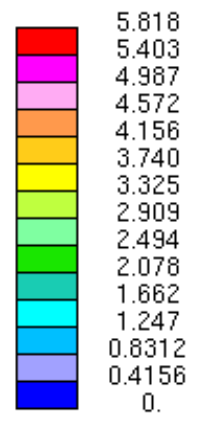

(a)

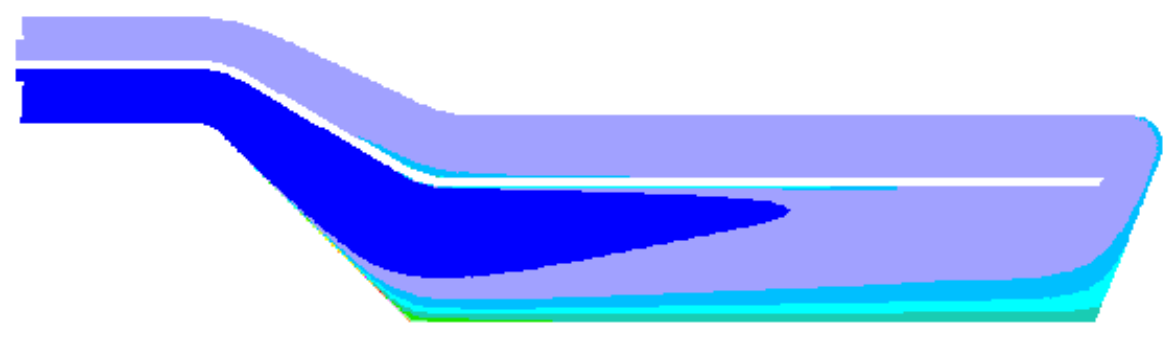

TEMPERATURE ABSOLUTE KELVIN

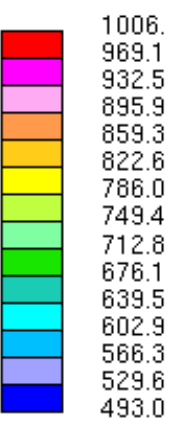

(b)

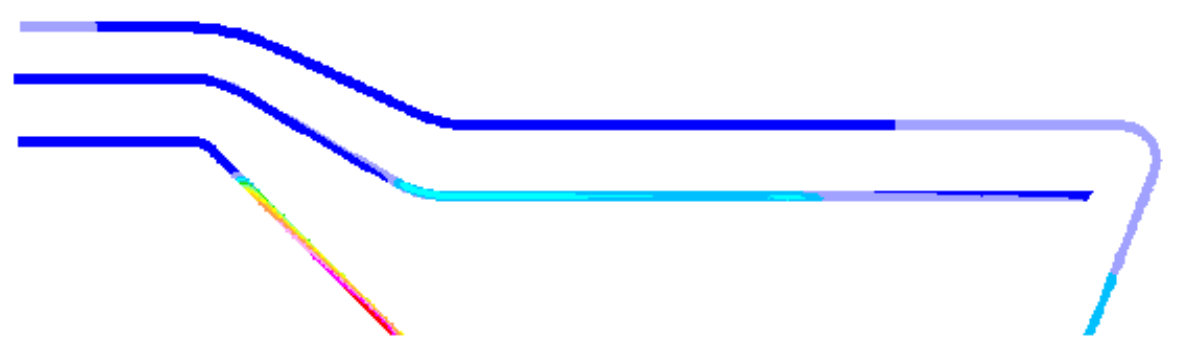

TEMPERATURE ABSOLUTE KELVIN

\begin{tabular}{|l}
1307. \\
1249. \\
1191. \\
1133. \\
1075. \\
1016. \\
958.2 \\
900.1 \\
\hline 841.9 \\
783.8 \\
725.6 \\
667.5 \\
609.3 \\
551.2 \\
493.0 \\
\hline
\end{tabular}

(c)

Figure 17. LBE target concept contour plots showing (a) fluid velocity, (b) fluid temperature, and (c) structural temperature profiles for case 3 

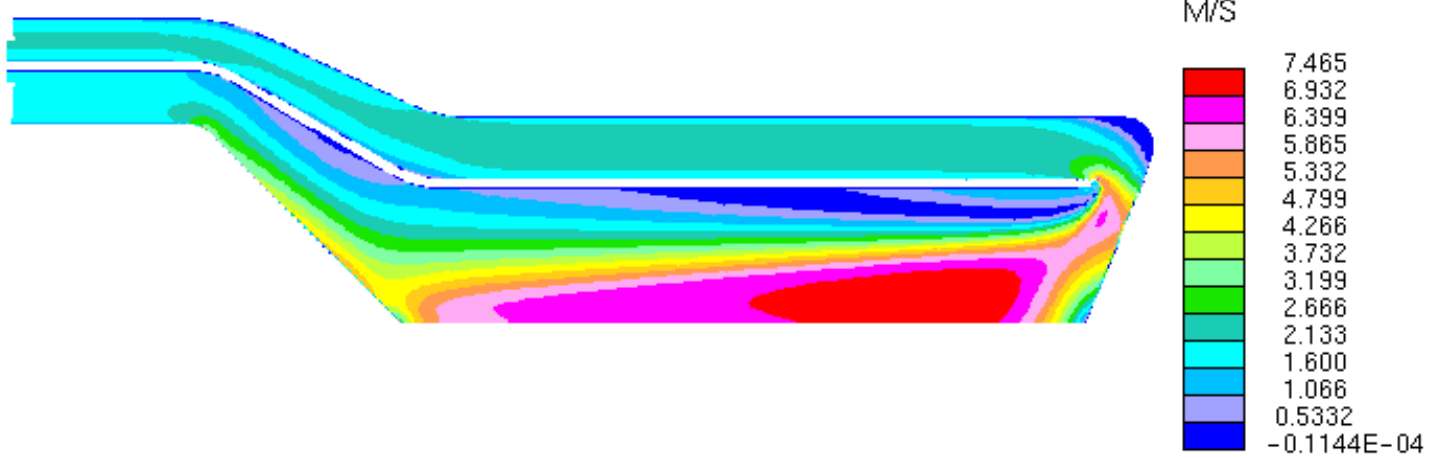

(a)

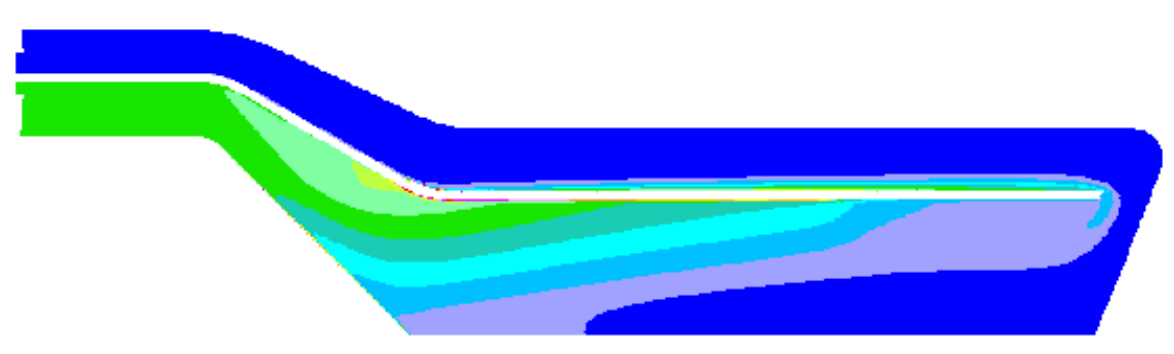

TEMPERATURE ABSOLUTE KELVIN

\begin{tabular}{|r}
808.1 \\
797.7 \\
787.4 \\
777.0 \\
766.6 \\
\hline 756.3 \\
745.9 \\
\hline 735.5 \\
\hline 725.2 \\
\hline 714.8 \\
\hline 704.5 \\
\hline 694.1 \\
\hline 683.7 \\
673.4 \\
\hline 663.0
\end{tabular}

(b)

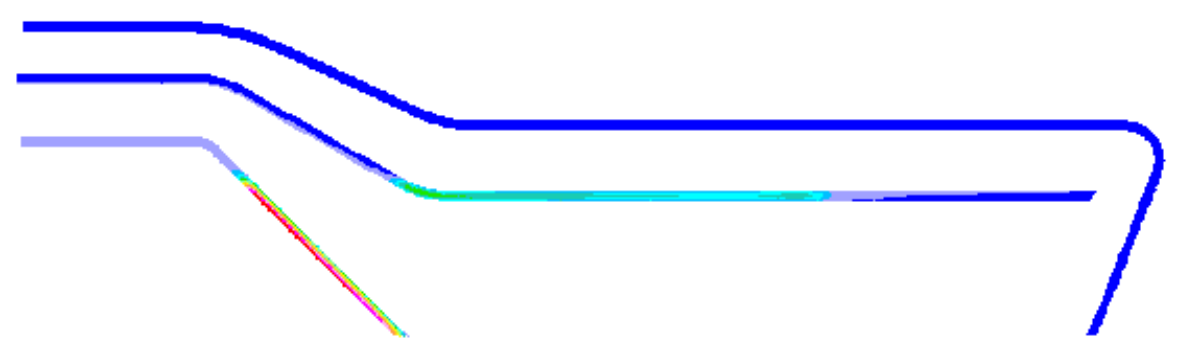

TEMPERATURE ABSOLUTE KELVIN

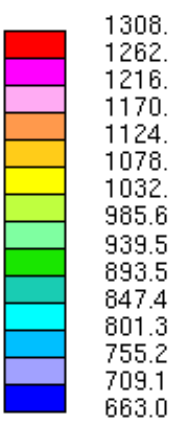

(c)

Figure 18. LBE target concept contour plots showing (a) fluid velocity, (b) fluid temperature, and (c) structural temperature profiles for case 4 


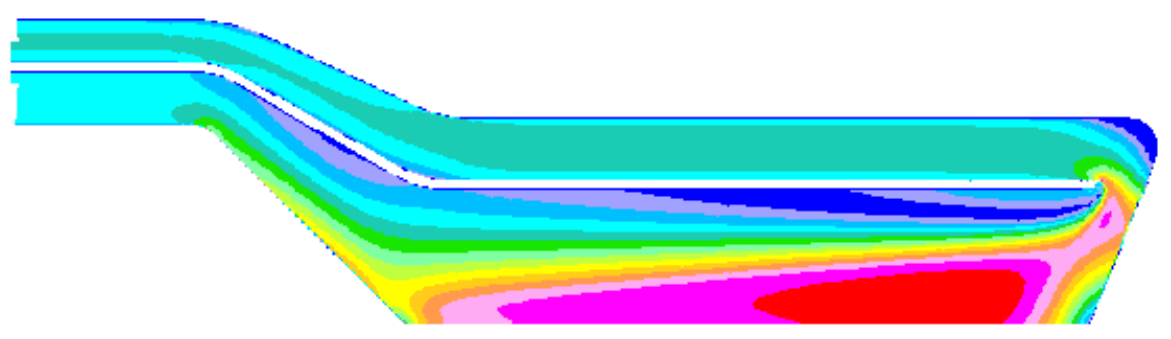

VELOCITY MAGNITUDE Mis

\begin{tabular}{|c|c|}
\hline & 7.465 \\
6.932 \\
6.399 \\
5.865 \\
5.332 \\
4.799 \\
4.266 \\
3.732 \\
\hline 3.199 \\
2.666 \\
2.133 \\
\hline 1.600 \\
\hline 1.066 \\
\hline 0.5332 \\
\hline$-0.1144 \mathrm{E}-04$ \\
\hline
\end{tabular}

(a)

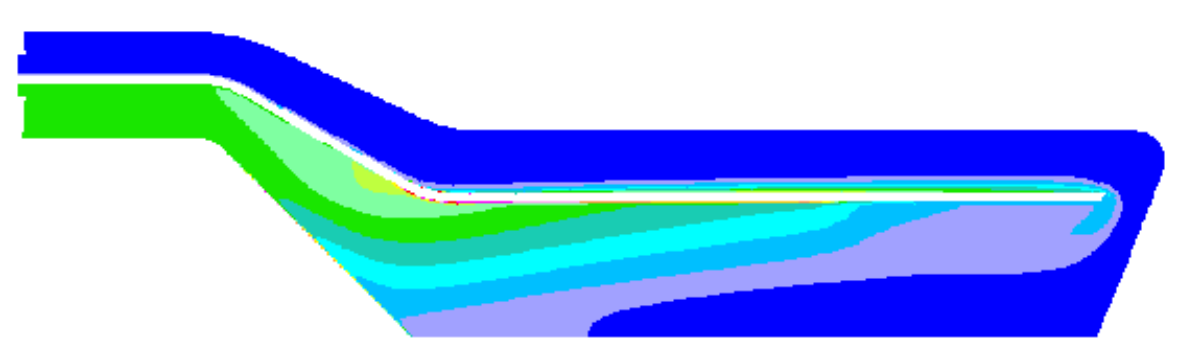

TEMPERATURE ABSOLUTE KELVIN

\begin{tabular}{r}
808.1 \\
797.7 \\
787.4 \\
777.0 \\
766.6 \\
\hline 756.3 \\
\hline 745.9 \\
\hline 735.6 \\
\hline 725.2 \\
\hline 714.8 \\
\hline 704.5 \\
694.1 \\
683.7 \\
673.4 \\
663.0
\end{tabular}

(b)

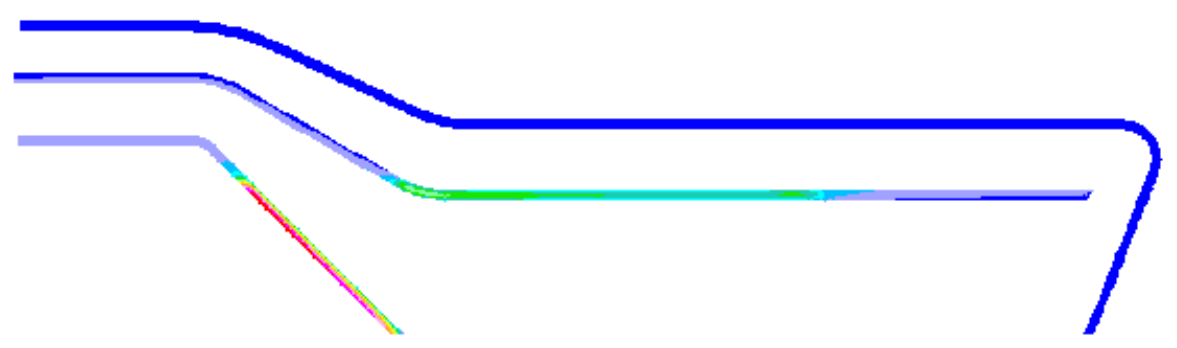

TEMPERATURE ABSOLUTE KELVIN

\begin{tabular}{|l}
1140. \\
1106. \\
1072. \\
1038. \\
1004. \\
969.5 \\
935.4 \\
901.4 \\
\hline 867.3 \\
\hline 833.3 \\
799.2 \\
765.2 \\
7331.1 \\
697.1 \\
\hline 663.0
\end{tabular}

(c)

Figure 19. LBE target concept contour plots showing (a) fluid velocity, (b) fluid temperature, and (c) structural temperature profiles for case 5 


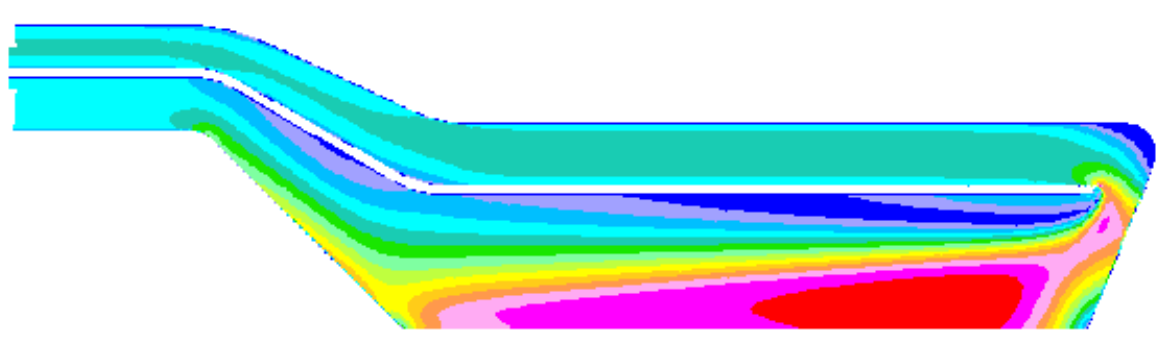

VELOCITY MAGNITUDE

Mis

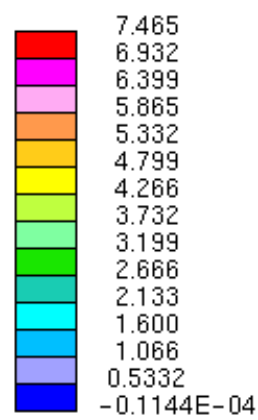

(a)

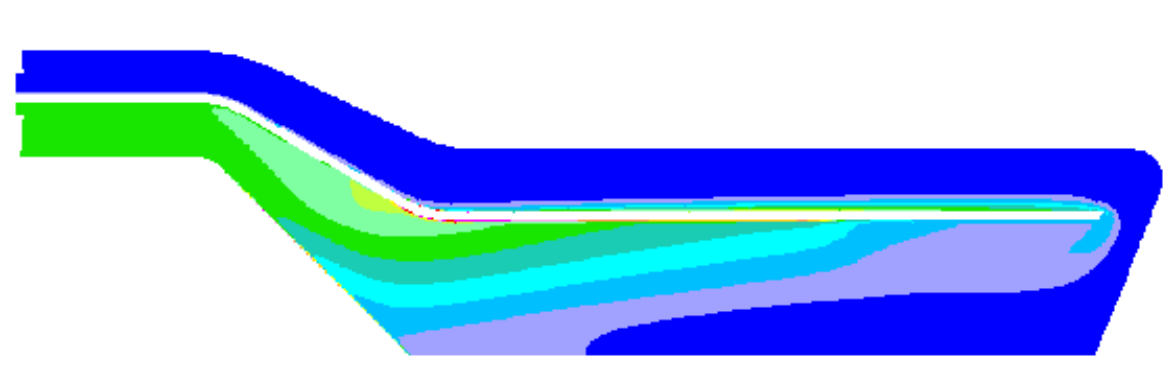

TEMPERATURE ABSOLUTE KELVIN

\begin{tabular}{|r}
638.1 \\
627.7 \\
617.4 \\
607.0 \\
596.6 \\
586.3 \\
\hline 575.9 \\
\hline 565.6 \\
\hline 555.2 \\
544.8 \\
\hline 534.5 \\
524.1 \\
513.7 \\
503.4 \\
\hline 493.0
\end{tabular}

(b)

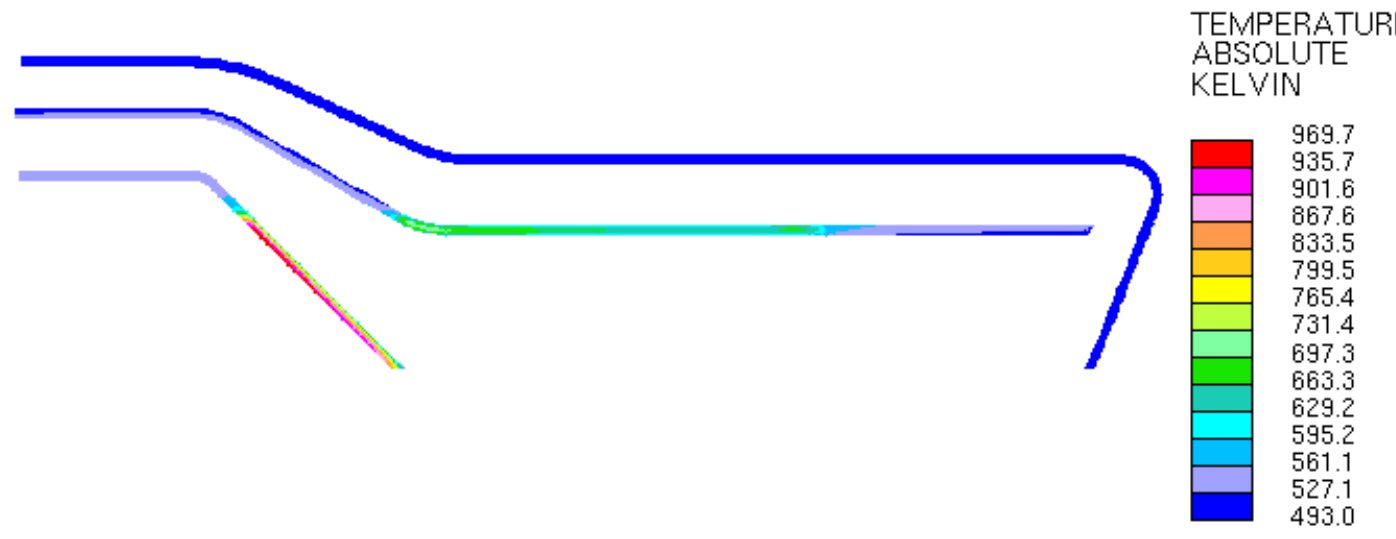

(c)

Figure 20. LBE target concept contour plots showing (a) fluid velocity, (b) fluid temperature, and (c) structural temperature profiles for case 6 
VELOCITYMAGNITUDE
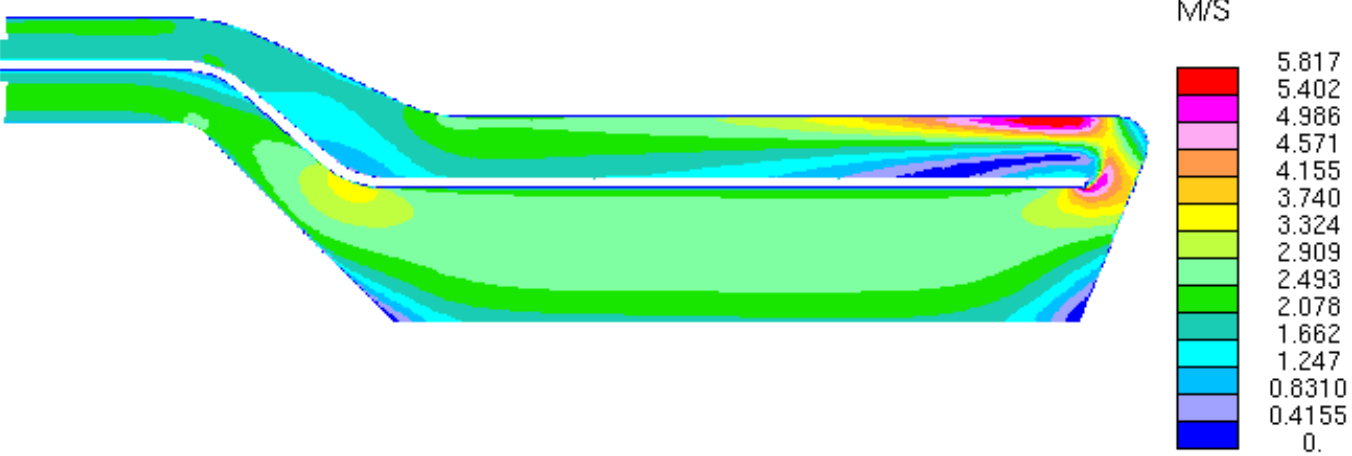

(a)

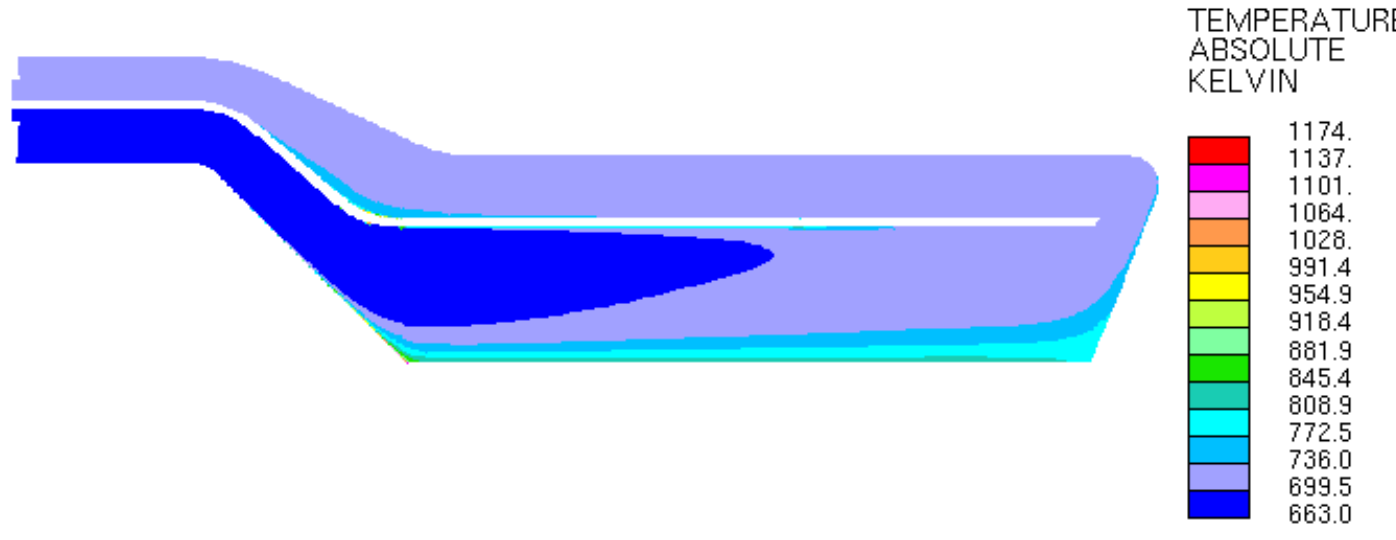

(b)

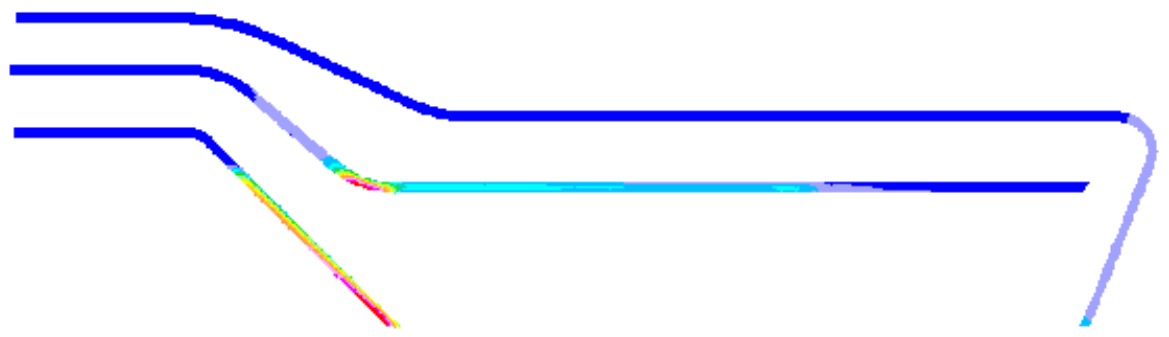

TEMPERATURE ABSOLUTE KELVIN

\begin{tabular}{|l}
1611. \\
1543. \\
1475. \\
1408. \\
1340. \\
1272. \\
1205. \\
1137. \\
1069. \\
1001. \\
933.8 \\
\hline 866.1 \\
798.4 \\
\hline 730.7 \\
663.0
\end{tabular}

(c)

Figure 21. LBE target concept contour plots showing (a) fluid velocity, (b) fluid temperature, and (c) structural temperature profiles for case 7 


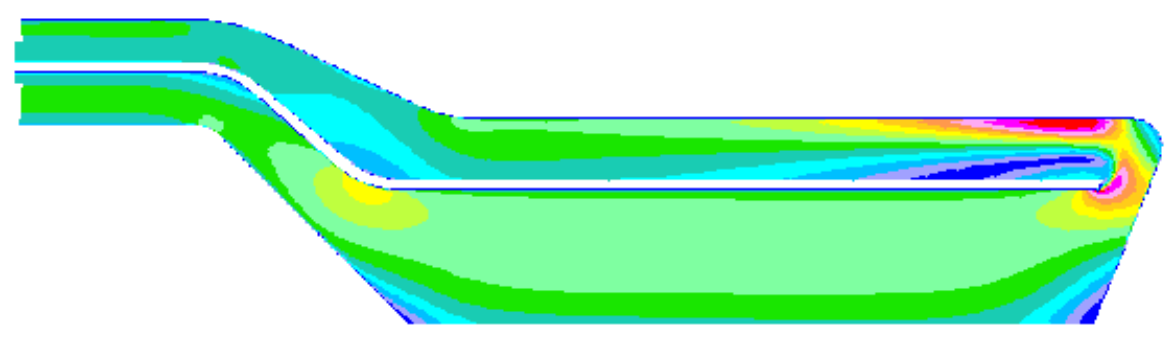

VELOCITY MAGNITUDE $\mathrm{M} / \mathrm{S}$

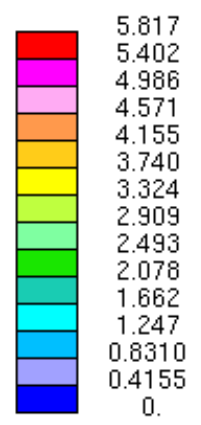

(a)

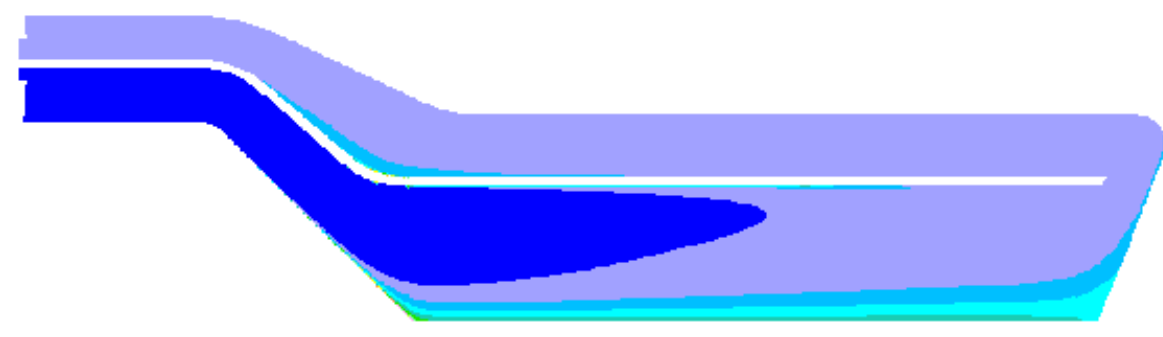

TEMPERATURE ABSOLUTE KELVIN

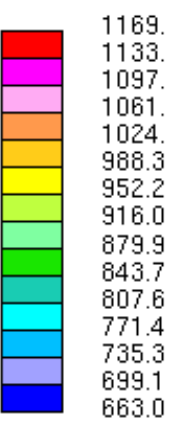

(b)

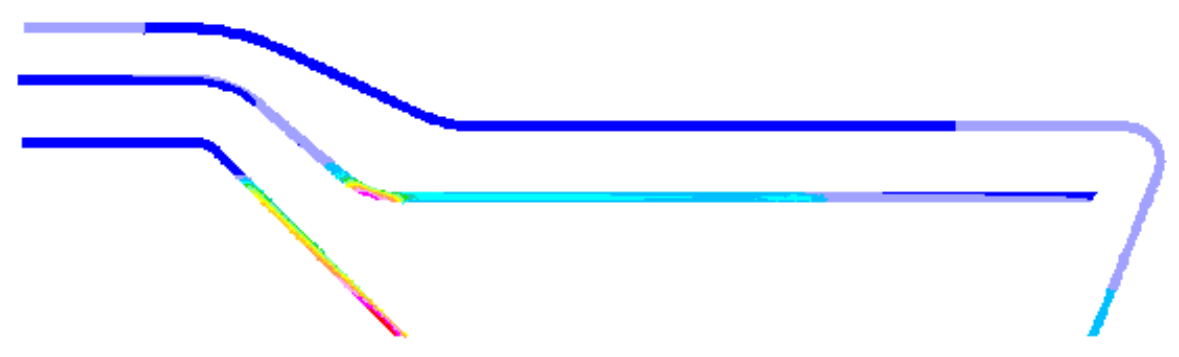

TEMPERATURE ABSOLUTE KELVIN

\begin{tabular}{|l}
1452. \\
1395. \\
1339. \\
1283. \\
1226. \\
1170. \\
1114. \\
1057. \\
1001. \\
\hline 944.7 \\
\hline 888.4 \\
\hline 832.0 \\
\hline 775.7 \\
\hline 719.4 \\
\hline 663.0
\end{tabular}

(c)

Figure 22. LBE target concept contour plots showing (a) fluid velocity, (b) fluid temperature, and (c) structural temperature profiles for case 8 


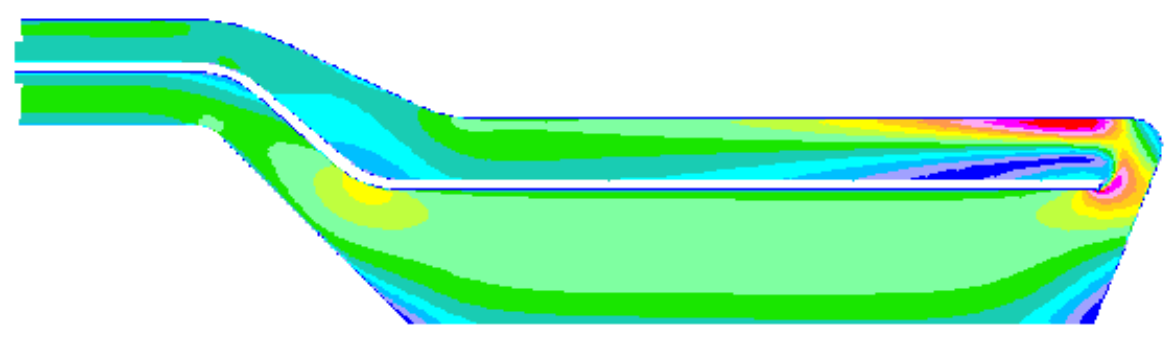

VELOCITY MAGNITUDE $\mathrm{M} / \mathrm{S}$

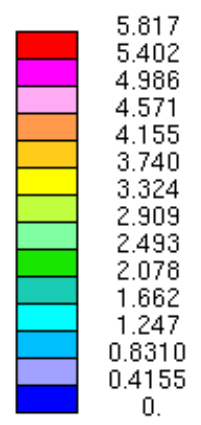

(a)

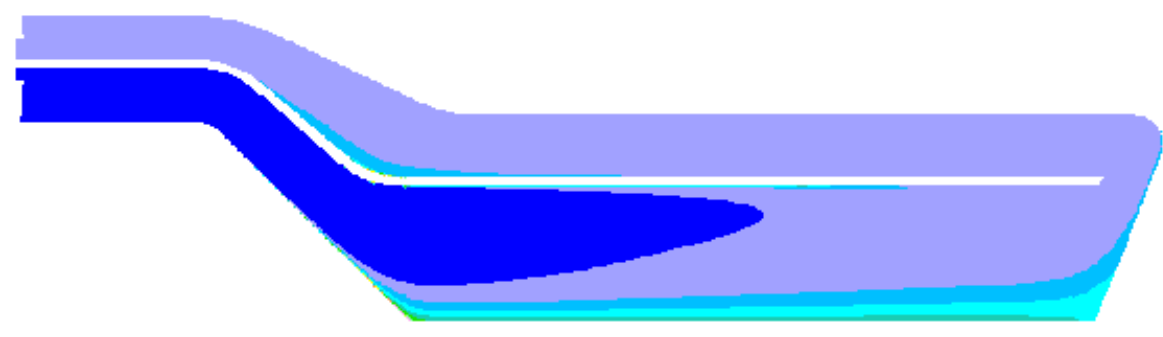

TEMPERATURE ABSOLUTE KELVIN

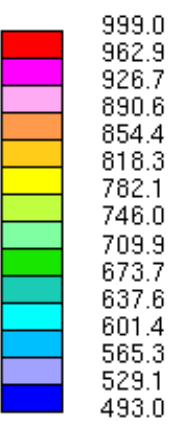

(b)

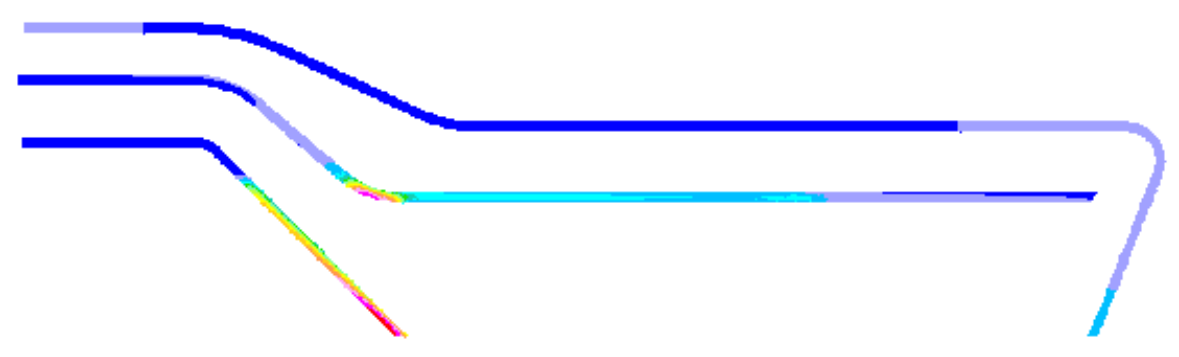

TEMPERATURE ABSOLUTE KELVIN

\begin{tabular}{|l}
1282. \\
1225. \\
1169. \\
1113. \\
1056. \\
1000. \\
\hline 943.7 \\
887.4 \\
831.0 \\
\hline 774.7 \\
\hline 718.4 \\
\hline 662.0 \\
605.7 \\
\hline 549.3 \\
\hline 493.0
\end{tabular}

(c)

Figure 23. LBE target concept contour plots showing (a) fluid velocity, (b) fluid temperature, and (c) structural temperature profiles for case 9 


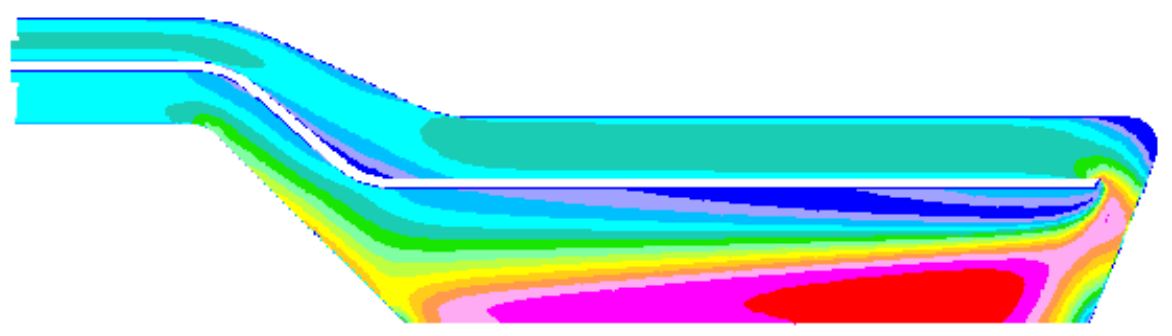

VELOCITY MAGNITUDE $\mathrm{M} / \mathrm{S}$

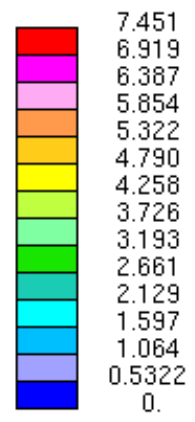

(a)

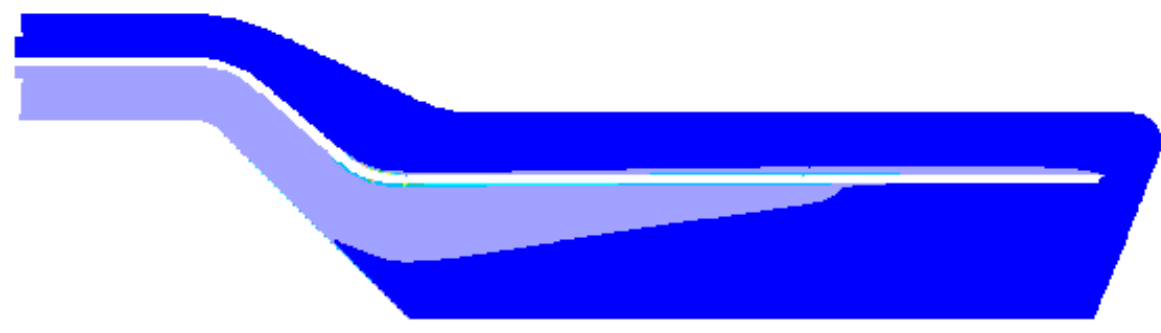

TEMPERATURE ABSOLUTE KELVIN

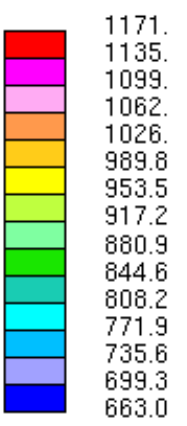

(b)

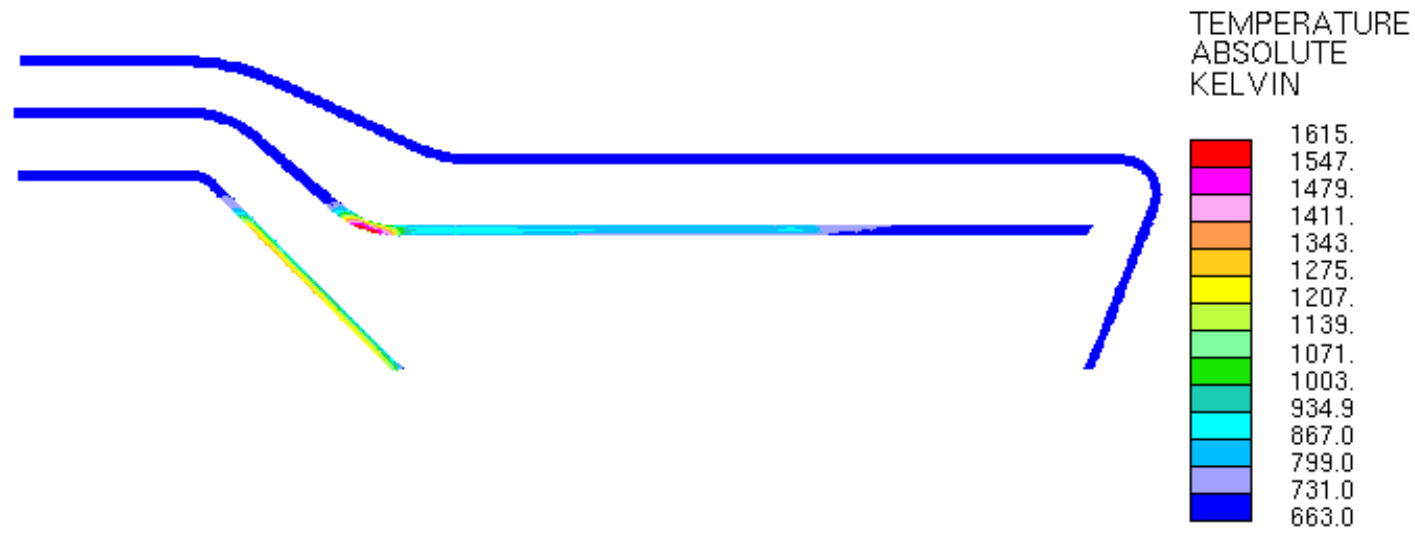

(c)

Figure 24. LBE target concept contour plots showing (a) fluid velocity, (b) fluid temperature, and (c) structural temperature profiles for case 10 


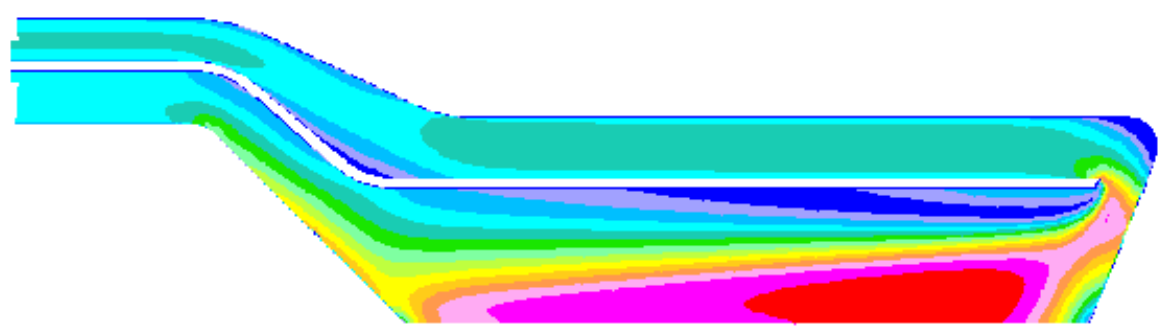

VELOCITY MAGNITUDE $\mathrm{M} / \mathrm{S}$

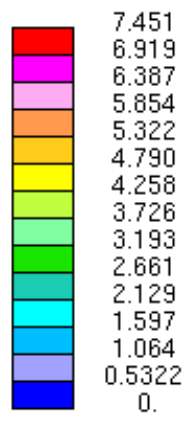

(a)

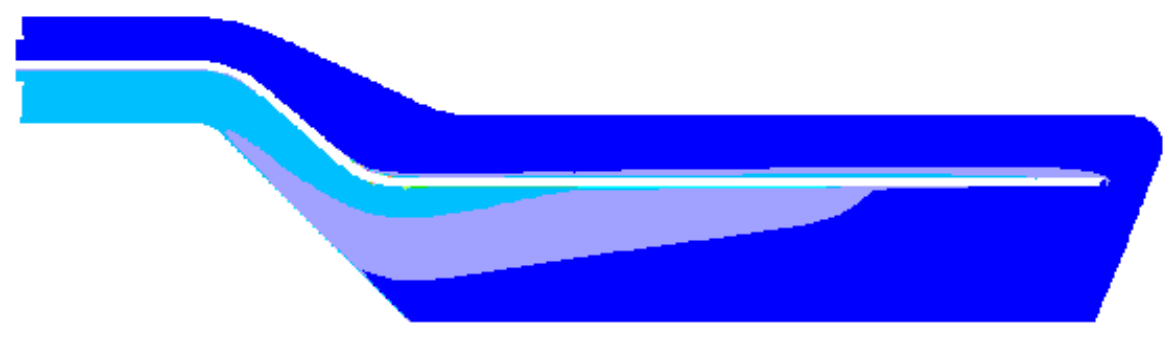

TEMPERATURE ABSOLUTE KELVIN

\begin{tabular}{|l}
1073. \\
1044. \\
1014 \\
985.1 \\
\hline 955.8 \\
\hline 926.5 \\
\hline 897.2 \\
868.0 \\
\hline 838.7 \\
\hline 809.4 \\
780.1 \\
\hline 750.8 \\
\hline 721.6 \\
692.3 \\
\hline 663.0
\end{tabular}

(b)

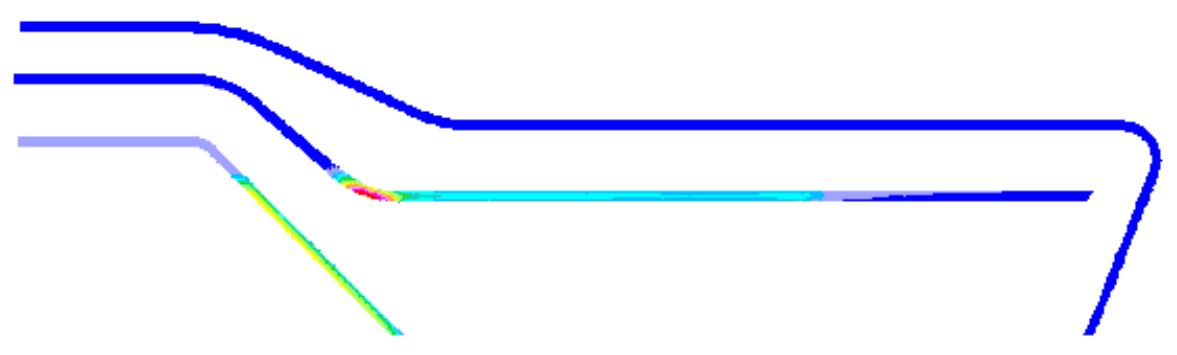

TEMPERATURE ABSOLUTE KELVIN

\begin{tabular}{|l}
1414. \\
1360. \\
1307. \\
1253. \\
1199. \\
1146. \\
1092. \\
1038. \\
984.8 \\
\hline 931.2 \\
\hline 877.6 \\
\hline 823.9 \\
\hline 770.3 \\
\hline 716.7 \\
\hline 663.0
\end{tabular}

(c)

Figure 25. LBE target concept contour plots showing (a) fluid velocity, (b) fluid temperature, and (c) structural temperature profiles for case 11 


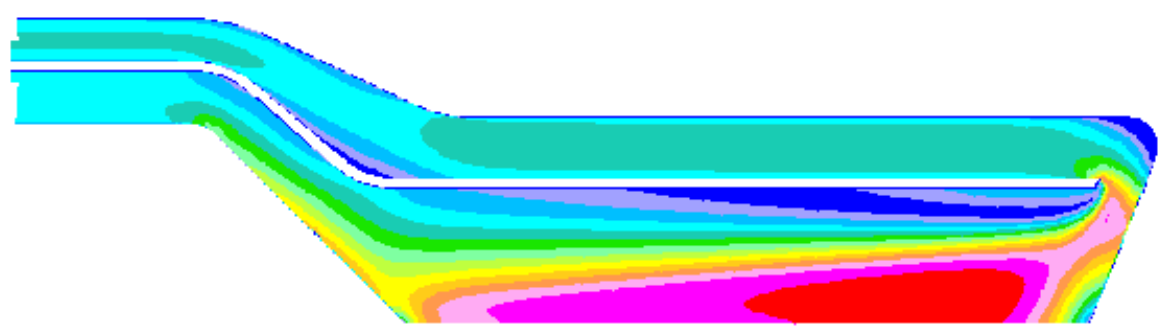

VELOCITY MAGNITUDE $\mathrm{M} / \mathrm{S}$

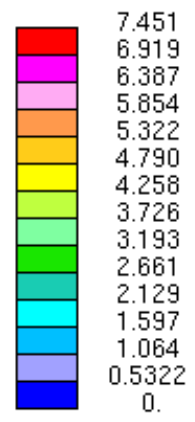

(a)

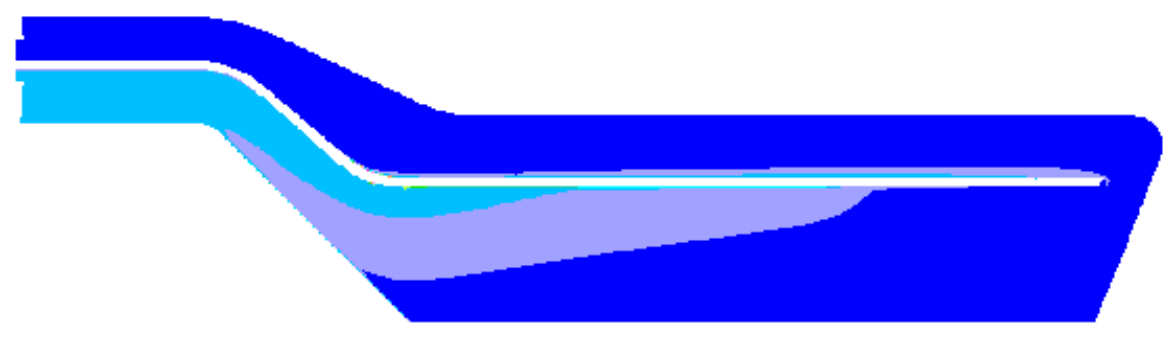

TEMPERATURE ABSOLUTE KELVIN

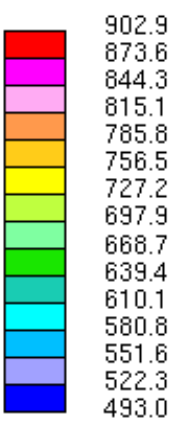

(b)

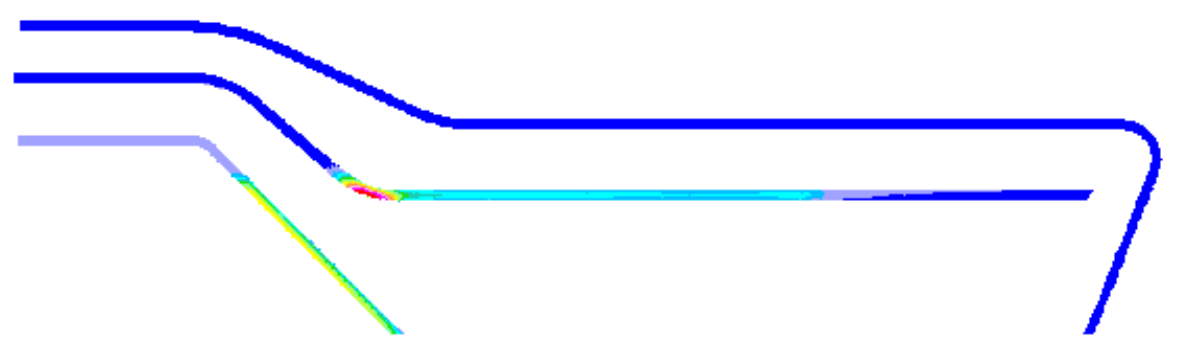

TEMPERATURE ABSOLUTE KELVIN

\begin{tabular}{|l}
1244. \\
1190. \\
1137. \\
1083. \\
1029. \\
\hline 975.7 \\
\hline 922.1 \\
\hline 868.5 \\
\hline 814.8 \\
\hline 761.2 \\
\hline 707.6 \\
\hline 653.9 \\
\hline 600.3 \\
\hline 546.6 \\
\hline 493.0
\end{tabular}

(c)

Figure 26. LBE target concept contour plots showing (a) fluid velocity, (b) fluid temperature, and (c) structural temperature profiles for case 12 


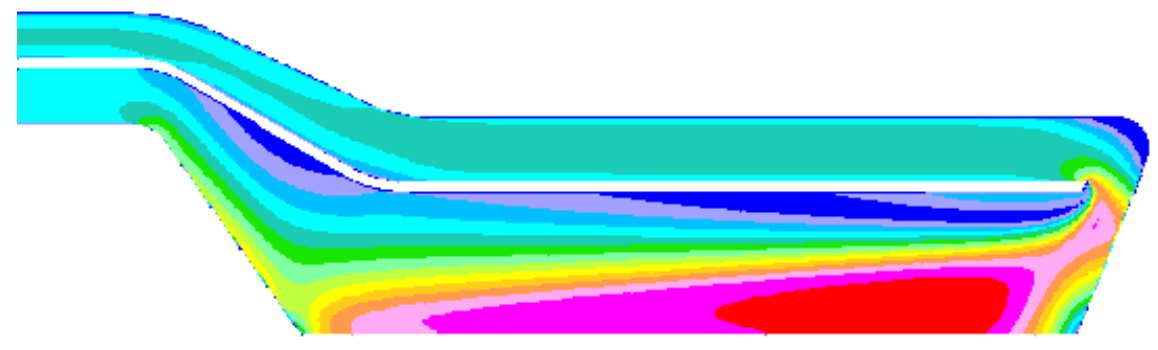

VELOCITY MAGNITUDE $\mathrm{M} / \mathrm{S}$

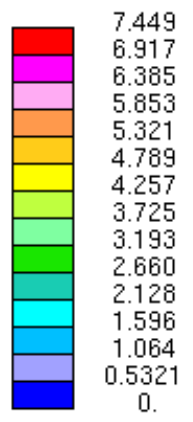

(a)

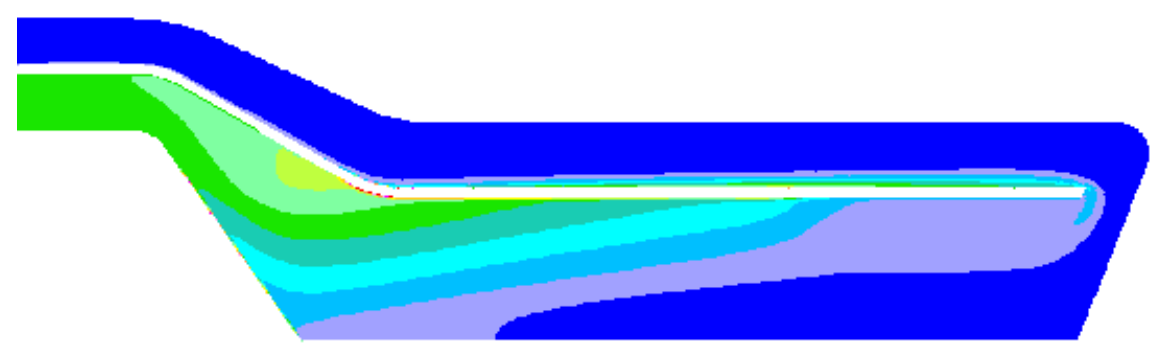

TEMPERATURE ABSOLUTE KELVIN

\begin{tabular}{|l}
637.3 \\
627.0 \\
616.7 \\
606.4 \\
5596.1 \\
\hline 585.8 \\
\hline 575.5 \\
565.1 \\
\hline 554.8 \\
\hline 544.5 \\
\hline 534.2 \\
\hline 523.9 \\
513.6 \\
503.3 \\
493.0
\end{tabular}

(b)
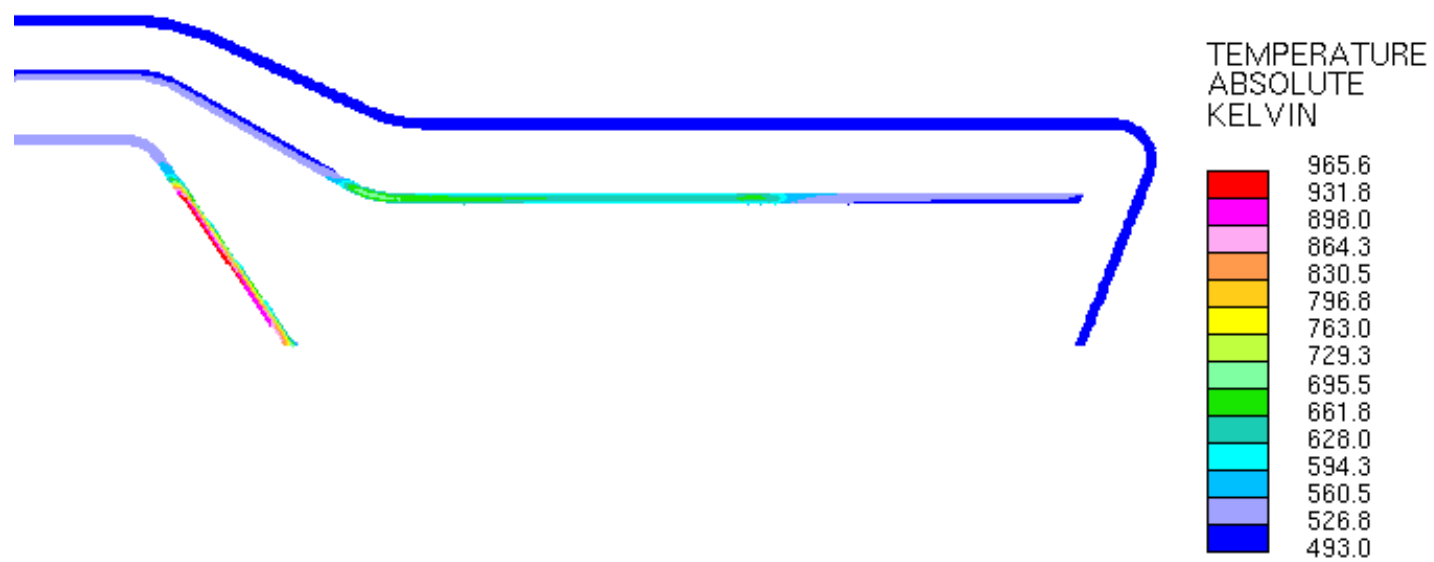

(c)

Figure 27. LBE target concept contour plots showing (a) fluid velocity, (b) fluid temperature, and (c) structural temperature profiles for case 13 


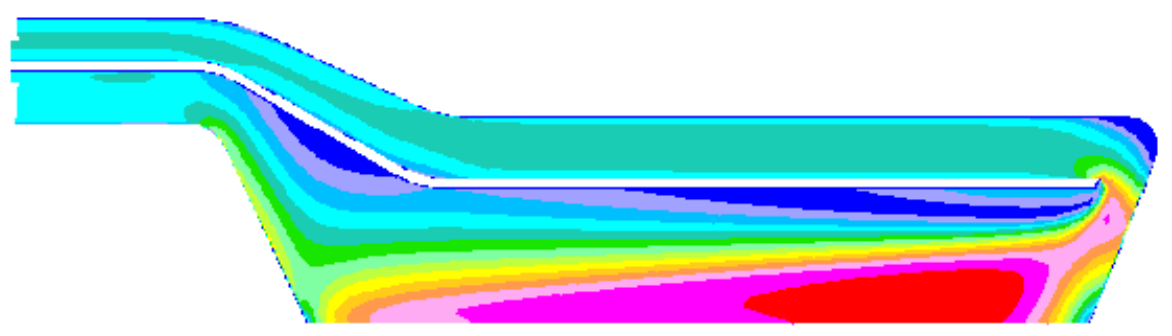

VELOCITY MAGNITUDE $\mathrm{M} / \mathrm{S}$

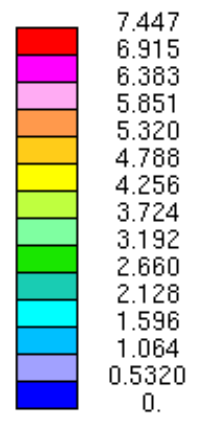

(a)

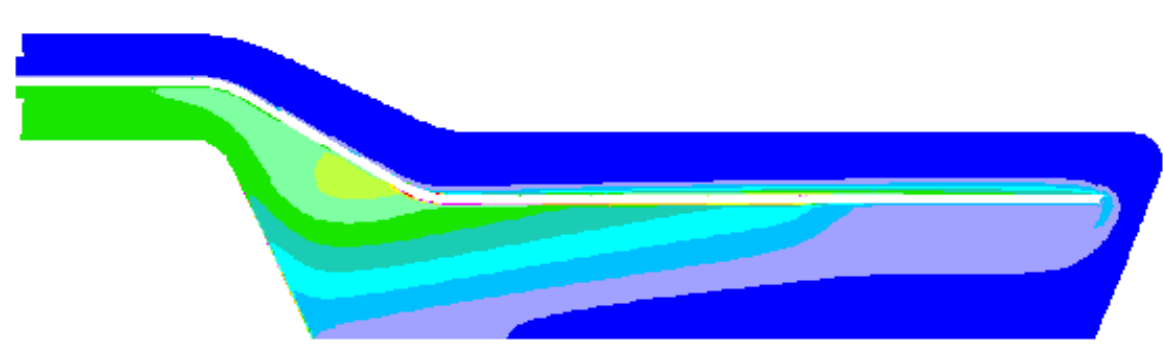

TEMPERATURE ABSOLUTE KELVIN

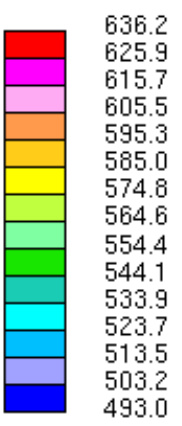

(b)

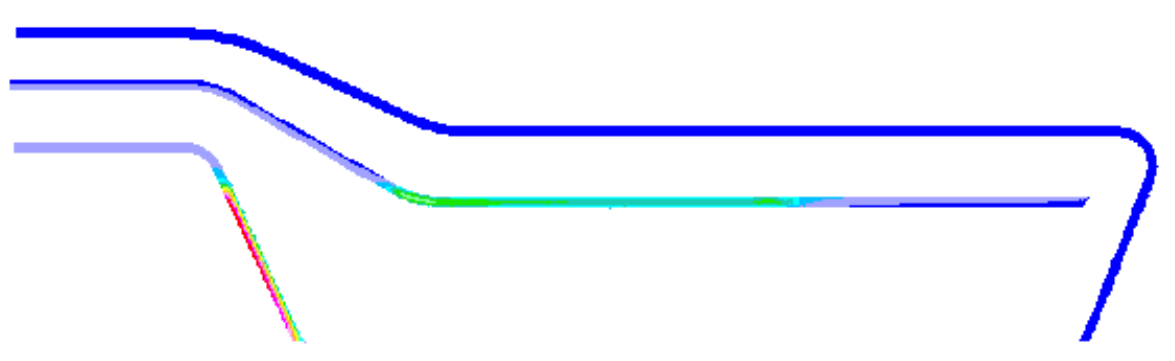

TEMPERATURE ABSOLUTE KELVIN

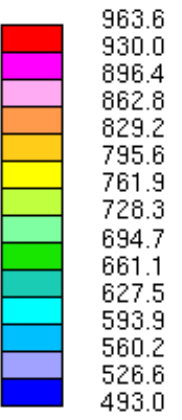

(c)

Figure 28. LBE target concept contour plots showing (a) fluid velocity, (b) fluid temperature, and (c) structural temperature profiles for case 14 


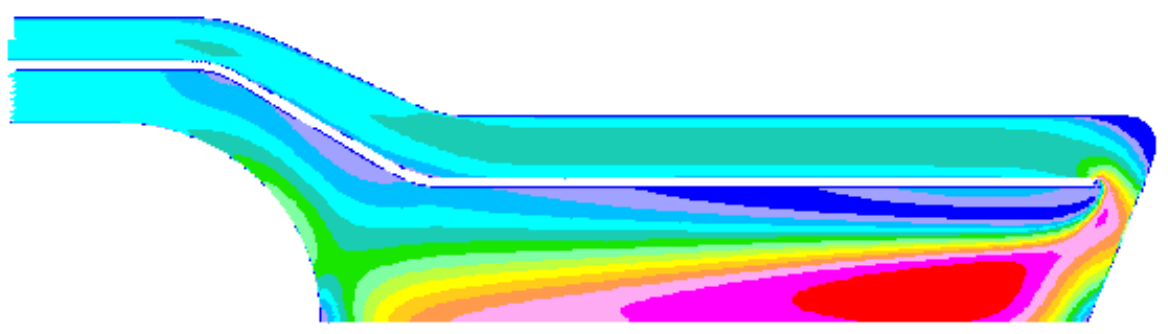

VELOCITY MAGNITUDE

$\mathrm{M} / \mathrm{S}$

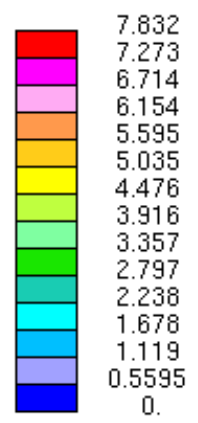

(a)

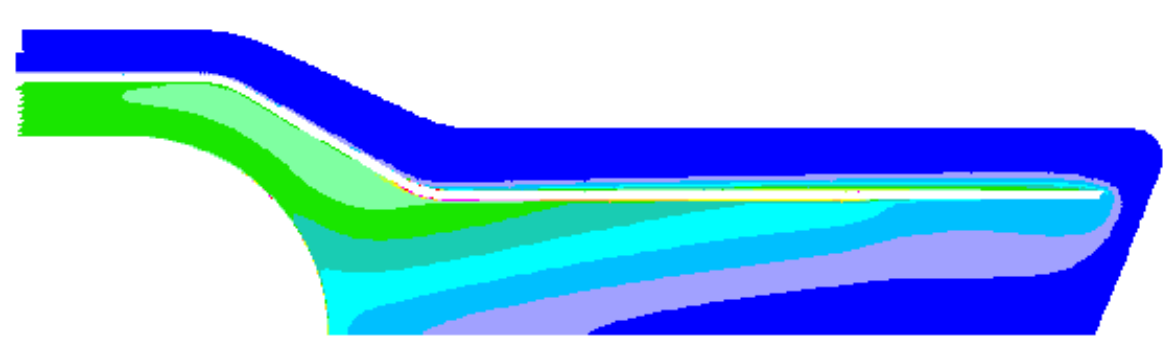

TEMPERATURE ABSOLUTE KELVIN

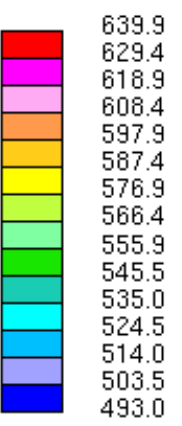

(b)

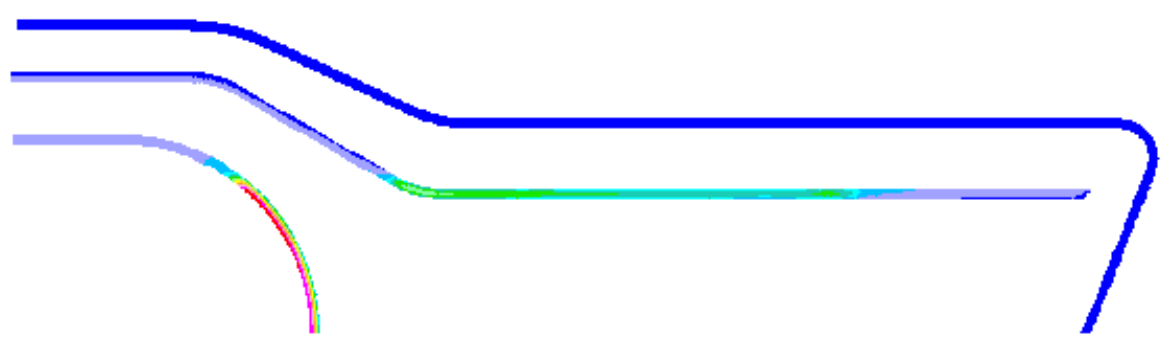

TEMPERATURE ABSOLUTE KELVIN

\begin{tabular}{|l}
965.0 \\
931.3 \\
\hline 897.6 \\
863.8 \\
\hline 830.1 \\
\hline 796.4 \\
\hline 762.7 \\
729.0 \\
695.3 \\
661.6 \\
627.9 \\
594.1 \\
\hline 560.4 \\
526.7 \\
493.0
\end{tabular}

(c)

Figure 29. LBE target concept contour plots showing (a) fluid velocity, (b) fluid temperature, and (c) structural temperature profiles for case 15 


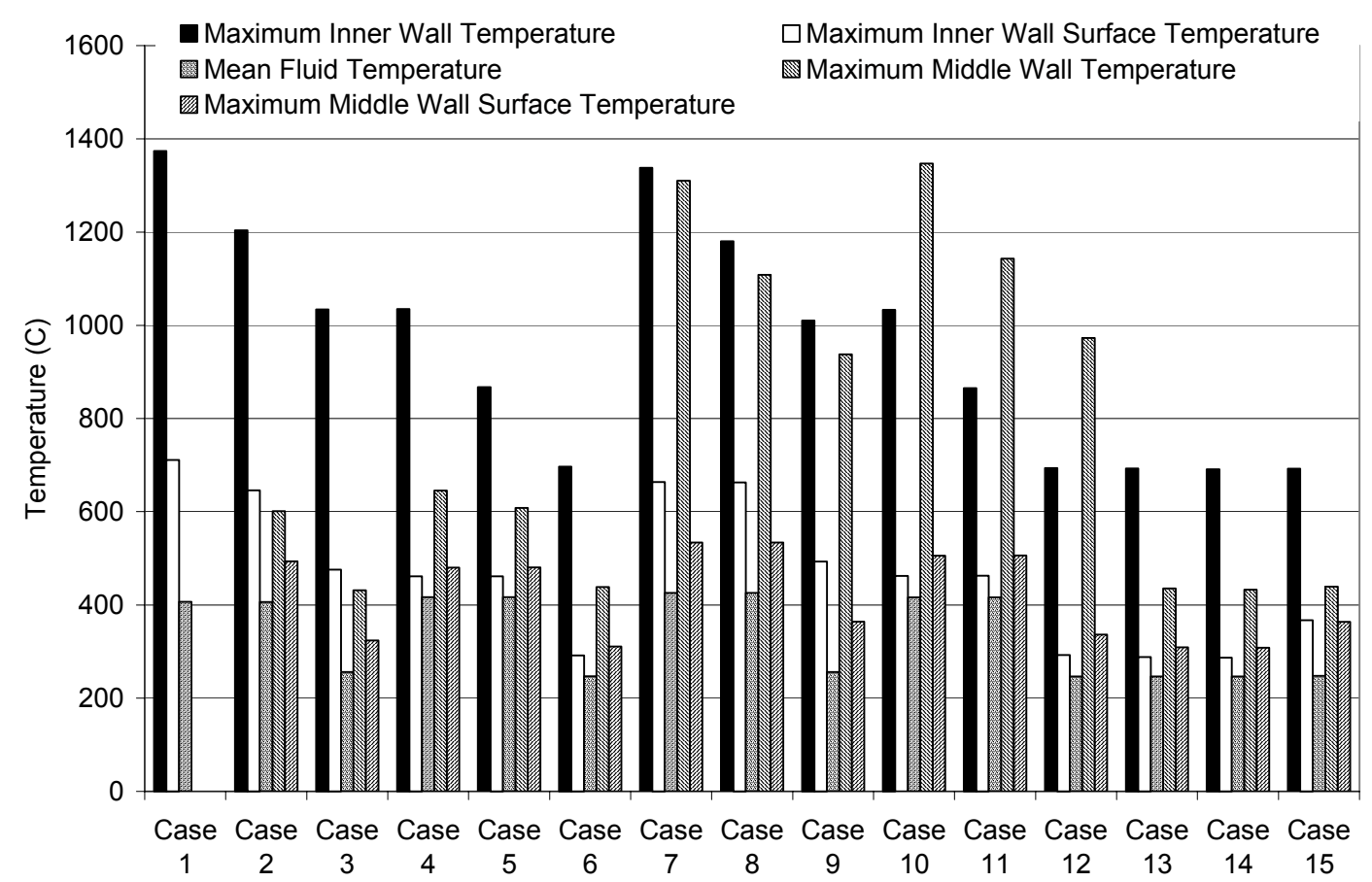

Figure 30. Comparison of the predicted peak temperatures for the beam windows and middle walls of the 15 cases included in the initial parametric CFD study

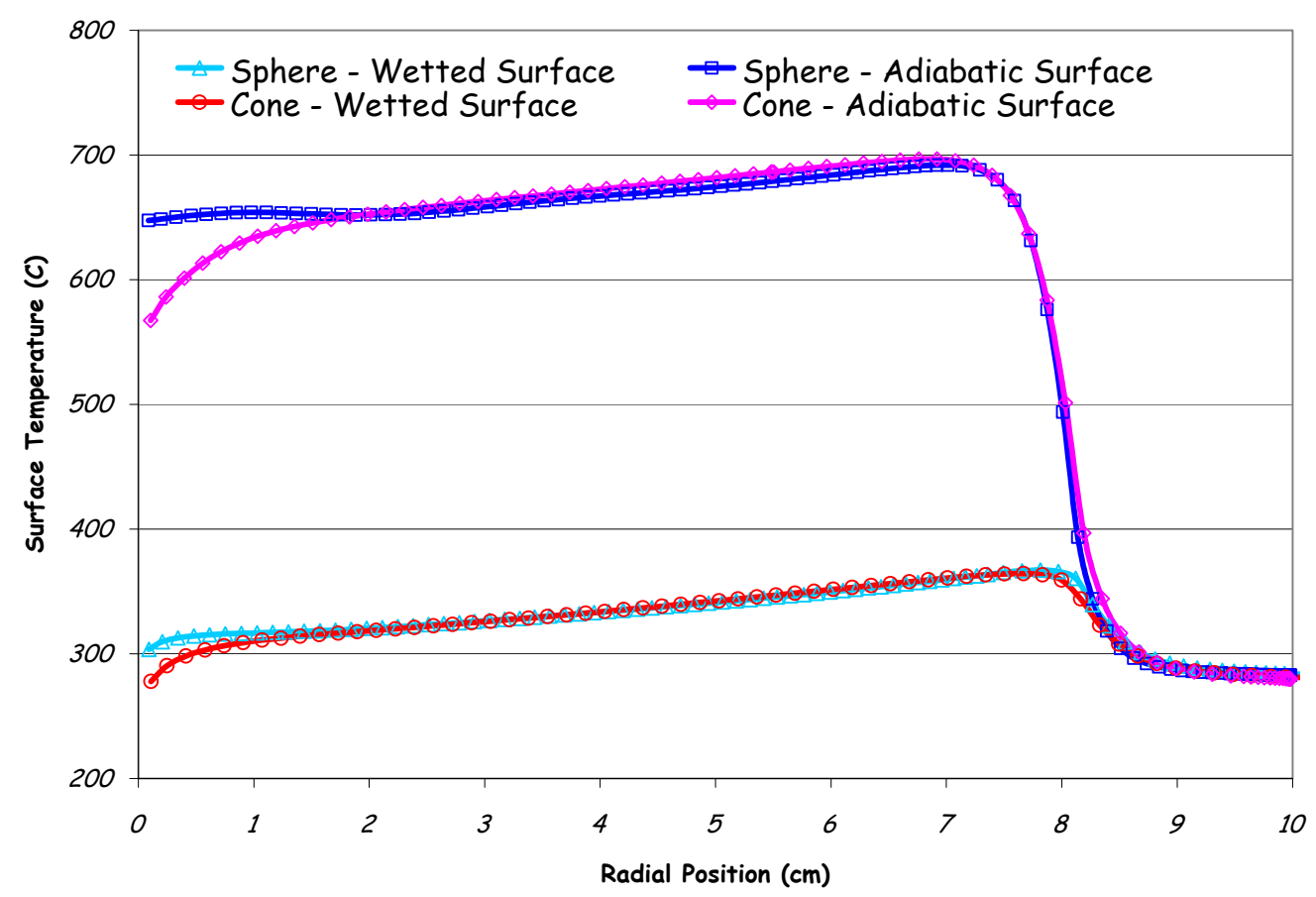

Figure 31. Comparison of predicted temperature distributions on the adiabatic and the wetted surfaces of the beam window of case 6 (conical window) and case 15 (hemi-spherical window) 


\section{V.2. Beam window thickness}

In the parametric study, none of the cases considered satisfy the peak temperature limit. A reduction in the beam window thickness is needed to satisfy this design constraint. Based upon the solution of the one-dimensional conduction equation for a slab geometry,

$$
T=-\frac{q^{\prime \prime \prime}}{2 k} x^{2}-C_{1} x+C_{2},
$$

the temperature difference between the adiabatic and the wetted surfaces of a slab of material of thickness $L$ is given by

$$
\Delta \mathrm{T}_{\text {slab }}=\frac{\mathrm{q}^{\prime \prime \prime}}{2 \mathrm{k}} \mathrm{L}^{2} .
$$

Using this relation, the temperature difference between the adiabatic and the wetted surfaces of a slab is shown in Figure 32 for the two steel alloys under consideration. From these calculations, the CFD results can be extrapolated for different beam window thicknesses. For cases 6 and 15, a reduction in wall thickness of 1 or $2 \mathrm{~mm}$ will reduce the peak temperature to $\sim 550$ or $500{ }^{\circ} \mathrm{C}$, respectively. This extrapolation does not account for changes in heat flux through the wetted surface and the resulting changes in surface temperature that result from reducing the wall thickness. Consideration of these neglected factors in a more thorough analysis would tend to result in a further reduction in the peak temperature on the adiabatic surface as the thickness is reduced.

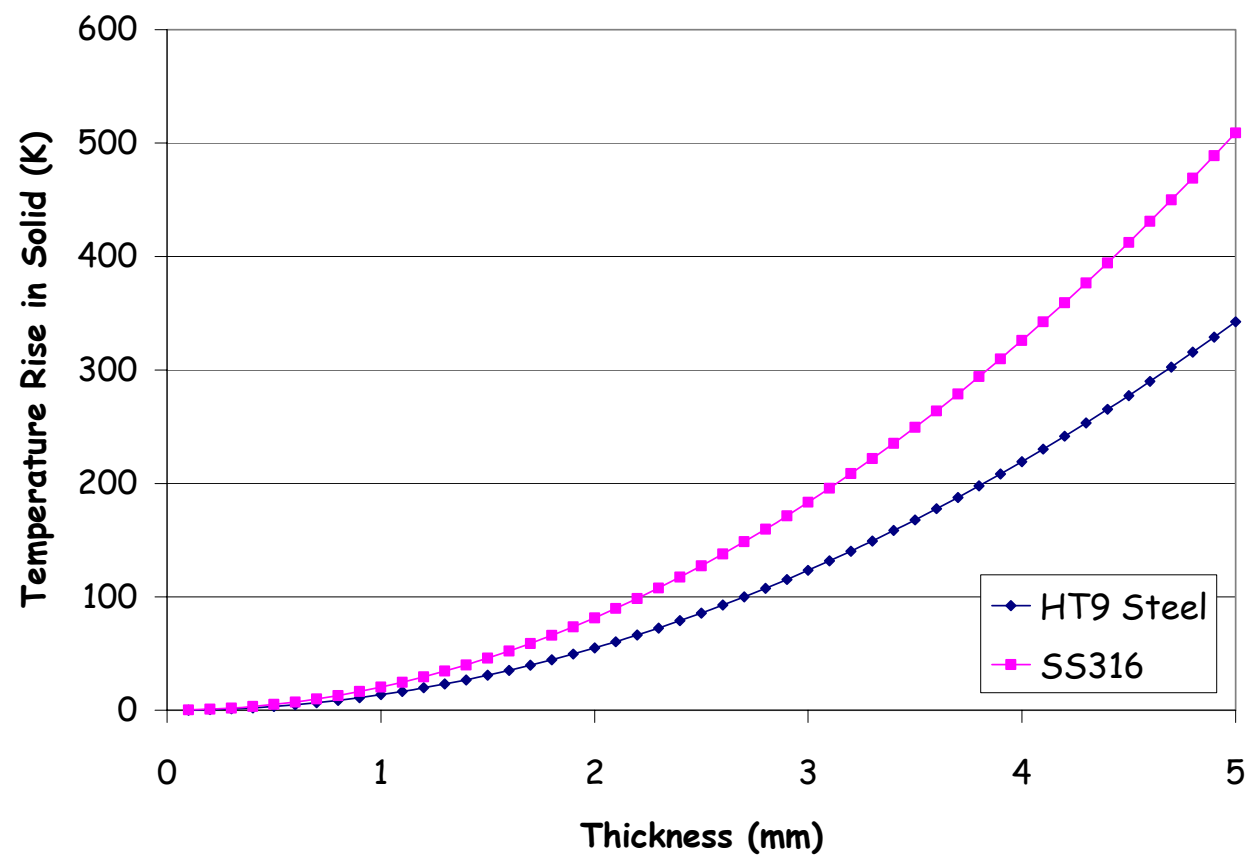

Figure 32. Temperature difference between the adiabatic and the wetted surfaces of the beam window for varying wall thickness 


\section{V.3. Coaxial geometry effect on the LBE inlet temperature}

In each of the cases considered in the parametric study, only a segment of the total manifold length of the inlet and outlet are included in the model. This segment is sufficiently long to insure fully developed velocity and turbulence profiles in the inlet and outlet manifolds. However, it is not sufficiently long to account for the total heat transfer between the cold and the hot LBE flowing through the coaxial manifolds. Using the mean temperature rise obtained from the target parametric study, the heat transfer between the inlet and outlet manifolds can be estimated using standard annular flow heat transfer correlations.

For a counter-current, concentric tube heat exchanger, the heat transfer between the two channels is given by:

$$
\mathrm{Q}=\dot{\mathrm{m}}_{\text {hot }} \mathrm{C}_{\mathrm{p}} \Delta \mathrm{T}_{\text {hot }}=\dot{\mathrm{m}}_{\text {cold }} \mathrm{C}_{\mathrm{p}} \Delta \mathrm{T}_{\text {cold }}=\mathrm{UA}_{H \mathrm{~T}} \Delta \mathrm{T}_{\mathrm{Im}},
$$

where $U$ is the overall heat transfer coefficient, given by:

$$
\mathrm{U} \cong 1 / \frac{1}{\mathrm{~h}_{\text {in }}}+\mathrm{R}_{\mathrm{w}}+\frac{1}{\mathrm{~h}_{\text {out }}}
$$

and $\Delta \mathrm{T}_{\mathrm{Im}}$ is the log mean temperature difference, given by [5]:

$$
\Delta T_{\text {Im }}=\frac{\left(T_{\text {hot,in }}-T_{\text {cold,out }}\right)-\left(T_{\text {hot,out }}-T_{\text {cold, in }}\right)}{\ln \left(\frac{T_{\text {hot, in }}-T_{\text {cold, out }}}{T_{\text {hot,out }}-T_{\text {cold, in }}}\right)}
$$

The local heat transfer coefficients, $h_{\text {cold }}$ and $h_{\text {hot }}$, are calculated using the correlation of Sabin [6],

$$
\mathrm{Nu}=5.8+0.02 \mathrm{Pe}^{0.8},
$$

which is valid for liquid metal coolants in narrow concentric tube annuli with a constant heat flux conditions at the heat transfer surface. The overall heat transfer coefficient between the inlet and outlet flow paths of the ADTF target is predicted to be approximately $5700 \mathrm{~W} / \mathrm{m}^{2} \mathrm{C}$.

The mean temperature rise in the target portion included in the CFD model is approximately $58.2{ }^{\circ} \mathrm{C}$ for all cases in the parametric study. Using equation 4 , the expected temperature rise in the inlet manifold of the target can be evaluated as a function of the mean temperature rise in the target portion included in the CFD model as shown in Figure 33 for HT-9 steel tubes. The estimated temperature rise in the cold manifold of the target is approximately $34.6{ }^{\circ} \mathrm{C}$ for HT-9 steel and $32.6{ }^{\circ} \mathrm{C}$ for type 316SS. These estimates assume perfect conduction at the interface between liquid and solid and take no account for the surface conditions. In this system, an oxygen level will 
be maintained to avoid corrosion concerns by forming oxide coating on the steel surfaces, which will increase the thermal resistance of these tubes. An inlet temperature rise of $20^{\circ} \mathrm{C}$ was assumed for the parametric study for all the cases. Because of the oxide formation and the assumed $20{ }^{\circ} \mathrm{C}$ increase in the inlet temperature, the peak temperatures predicted in the parametric study will not increase further due to the heat transfer in the manifold section of the target system.

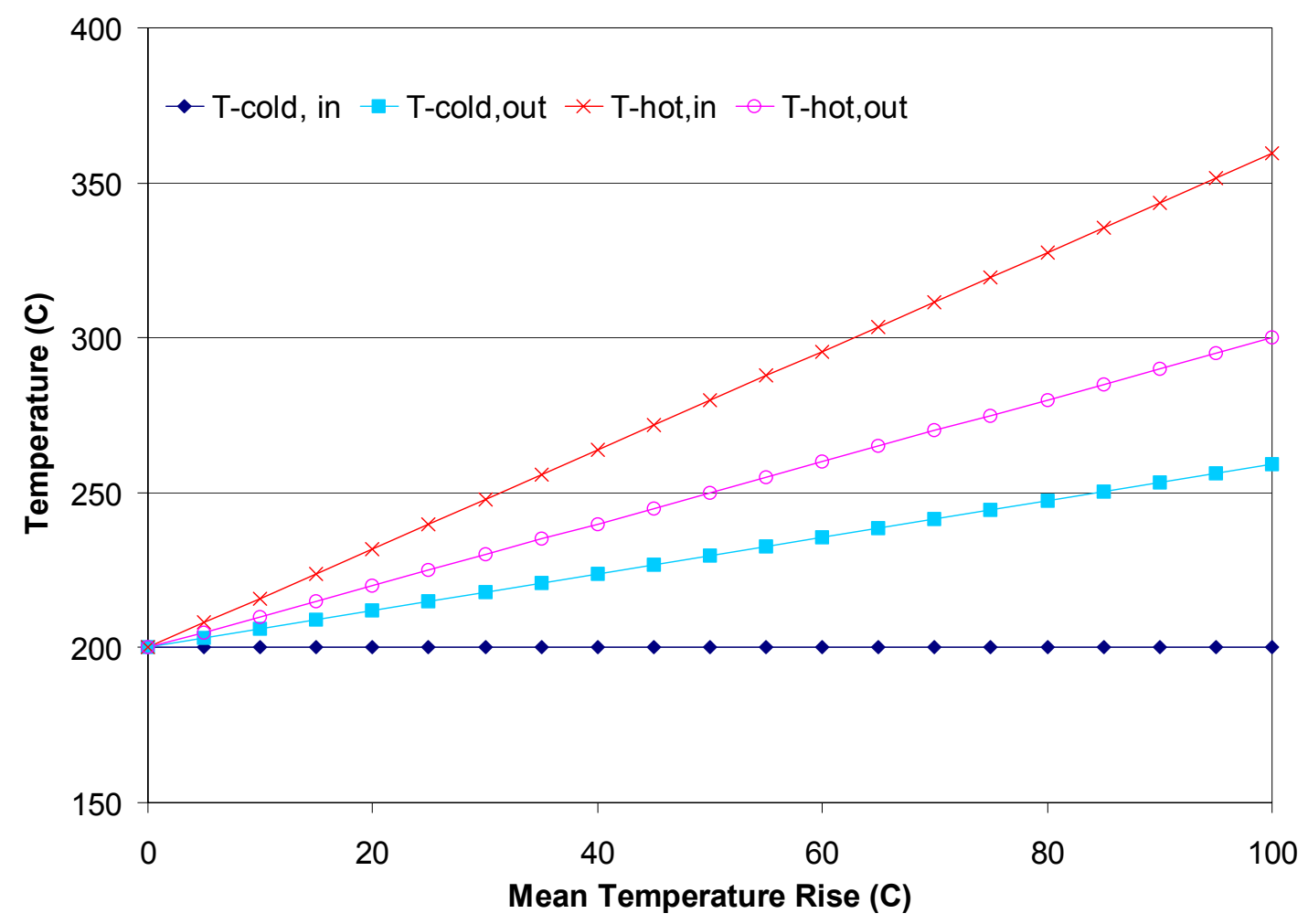

Figure 33. LBE temperature in the inlet and outlet annular manifolds as a function of the mean temperature rise in heated region of the target

\section{V.4. Geometrical modifications for flow stability}

In all the cases of the parametric study, the formation of a toroidal recirculation zone was predicted as the fluid turns around the middle wall. Since toroidal recirculation zones do not exist in a stable state, this prediction is likely an indication of a local transient instability in the region near the predicted recirculation zone. Indeed, it is well known that 180 degrees annular turns about a thin walled baffle induce instability in the exit flow channel. Idelchik [7] recommends several control strategies for reducing the severity of the instability resulting from annular turn geometries. However, it should be noted that these guidelines do not insure a fully stable flow field. They insure only that the impact of the instability on the temperature and pressure distributions within the system is minimized. 
To increase the stability of the flow field in the target area, the middle wall should be modified so that it's leading edge near the end cap terminates in a rounded fairing with a radius of at least $0.7 \mathrm{~cm}$ at the tip. The fairing should be tangent to the inlet side surface of the middle wall and extend into the outlet flow field. Additionally, the radius of curvature of the outer wall in the region near the 180 degrees turn should be in the range of 3.89 to $7.57 \mathrm{~cm}$. Finally, the distance between the leading edge of the middle wall and the end cap should be in the range of 3.12 to $4.27 \mathrm{~cm}$.

Using the results of the parametric study and the above geometrical recommendations, an ADTF liquid LBE target concept, shown in Figure 1 was developed. While altering the shape of the middle wall effects the target temperature distribution, the shape of the beam window region can be altered as needed to meet mechanical and thermal stress requirements with little impact on the temperature distribution in the target. The wall thickness of the beam window should be in the range of 3.5 to $4 \mathrm{~mm}$ to satisfy the thermal hydraulic design requirements assuming an inlet temperature of $200{ }^{\circ} \mathrm{C}$. Also, the LBE fluid should enter the target through the outer annulus and exits through the inner annulus. For stability reasons, a rounded fairing should be added to the entire circumference of the inner surface of the middle wall. Since the conic shape of the end cap provides no significant benefit to flow stability, it can be replaced with a simple end cap. This replacement reduces the complexity of the design, simplifies the fabrication procedure, and enhances the structural performance of the target design.

\section{V.5. Reference design}

Design iterations including thermal hydraulics, thermal stresses, and structural analyses were performed to define the reference target design. The thermal hydraulic characteristics of the evaluated target geometries were simulated using the commercially available CFD code Star-CD [4], and the temperature distribution of the target structure was transferred to the structural analyses. Four cases were analyzed based on the results from the thermal hydraulic parametric study and the structural analyses. The first case, case A, considers the reference design with a cone-shaped beam window region that has a uniform thickness of $4 \mathrm{~mm}$. Also, the beam tube wall has a uniform thickness of $4 \mathrm{~mm}$ and the remaining walls have a thickness of $5 \mathrm{~mm}$. The second case, case $B$, is based upon the first case, with the beam tube wall thickness and the beam window thickness reduced to $3.5 \mathrm{~mm}$. The third case, case ${ }^{\circ} \mathrm{C}$, replaces the cone-shaped beam window of the second case with a hemi-spherical beam window that has a uniform thickness of $3.5 \mathrm{~mm}$. The final case, case $\mathrm{D}$, considers the $3.5 \mathrm{~mm}$ thick hemi-spherical beam window with a $5 \mathrm{~mm}$ thick beam tube.

In all cases, the simulation uses a uniform inlet velocity of $2 \mathrm{~m} / \mathrm{s}$ and an inlet temperature of $220{ }^{\circ} \mathrm{C}$. Sufficient inlet and outlet manifold length is included to insure fully developed velocity and temperature profiles. The PISO solution algorithm is used with upwind differencing methodologies to obtain a steady state solution for the velocity, turbulence, pressure, and temperature fields. Velocity and temperature profiles for the four cases are shown in Figures 34 through 37. 
VELOCITYMAGNITUDE

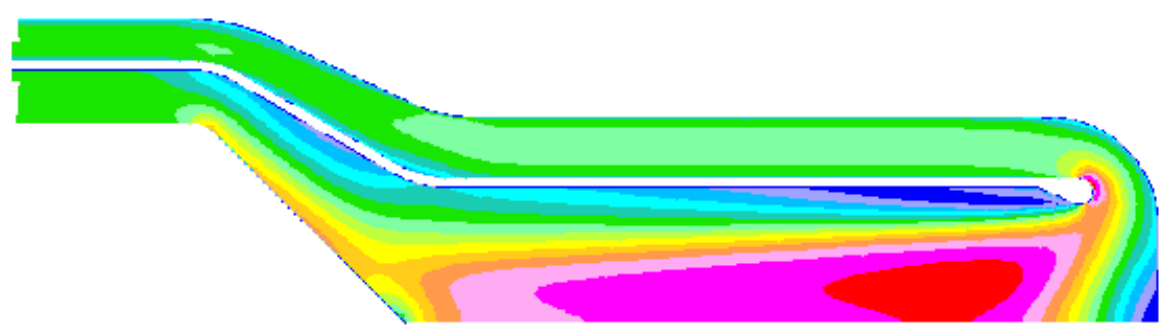

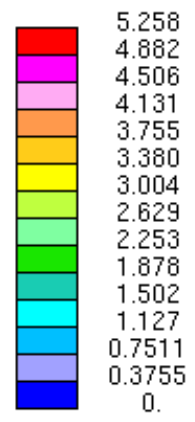

(a)

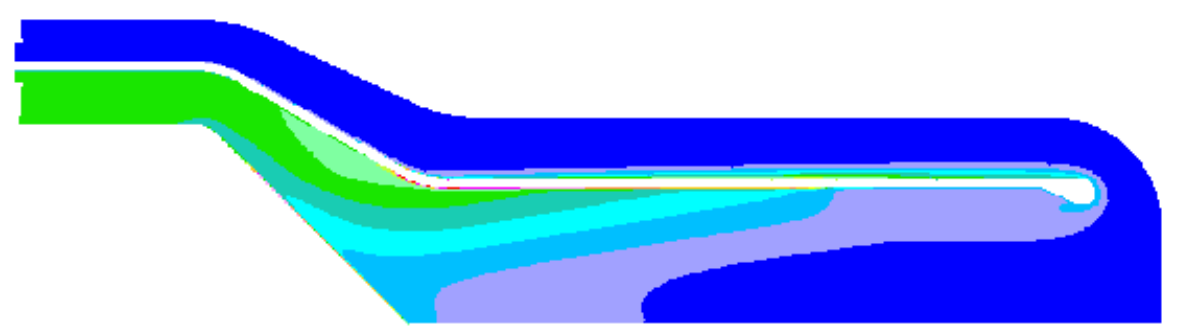

TEMPERATURE ABSOLUTE KELVIN

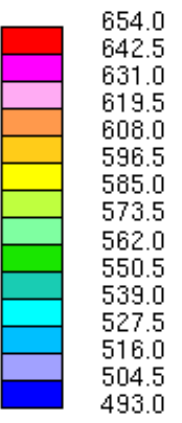

(b)

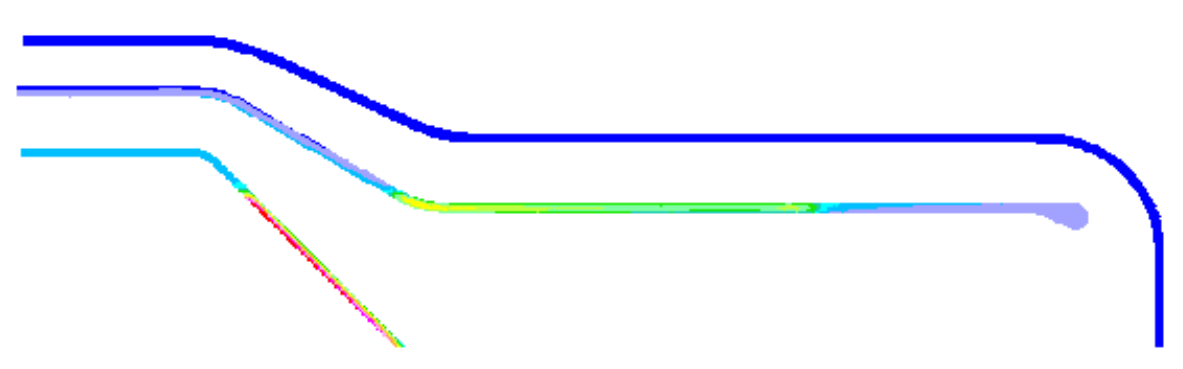

TEMPERATURE ABSOLUTE KELVIN

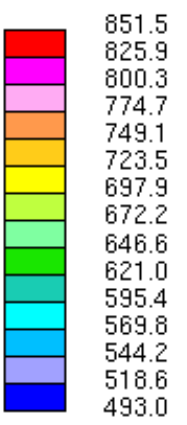

(c)

Figure 34. LBE target concept contour plots showing (a) fluid velocity, (b) fluid temperature, and (c) structural temperature profiles for case $A$ 
VELOCITYMAGNITUDE

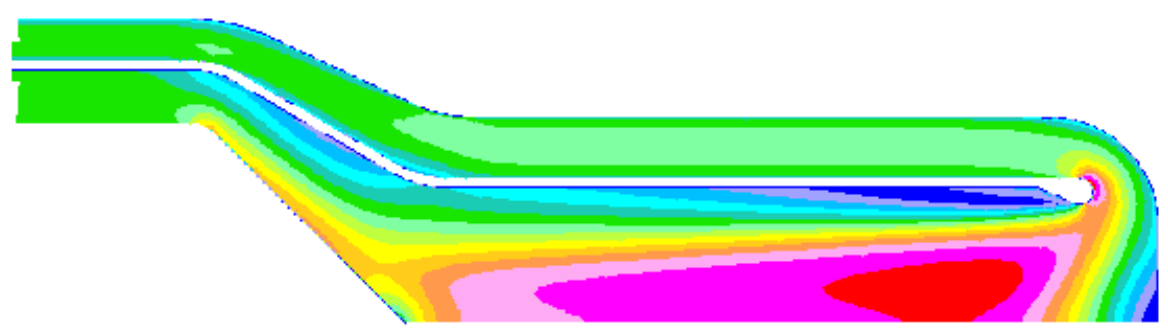

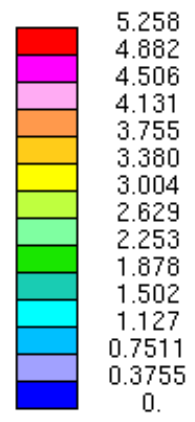

(a)

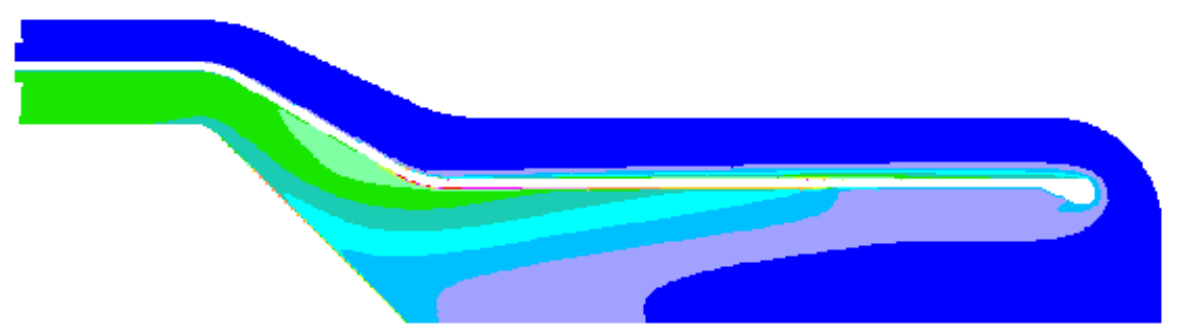

TEMPERATURE ABSOLUTE KELVIN

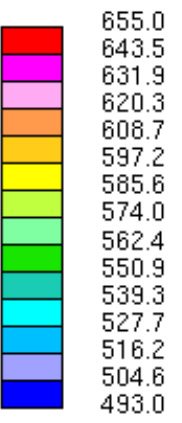

(b)

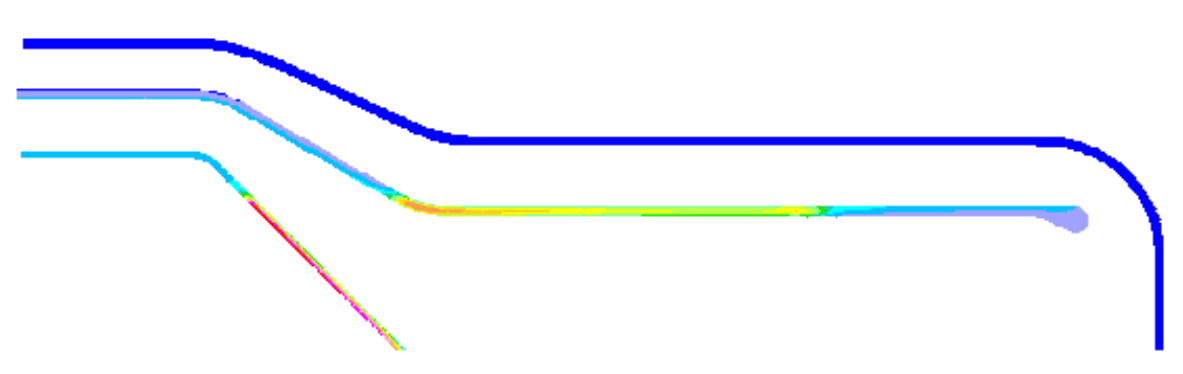

TEMPERATURE ABSOLUTE KELVIN

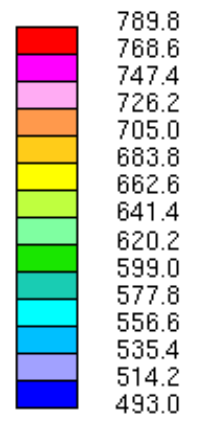

(c)

Figure 35. LBE target concept contour plots showing (a) fluid velocity, (b) fluid temperature, and (c) structural temperature profiles for case B 


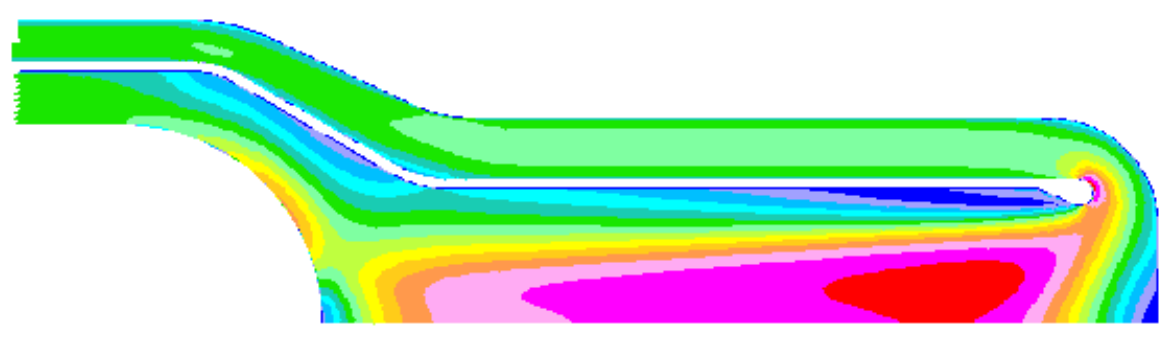

VELOCITY MAGNITUDE $\mathrm{M} / \mathrm{S}$

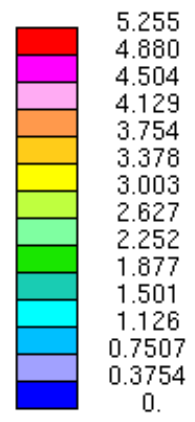

(a)

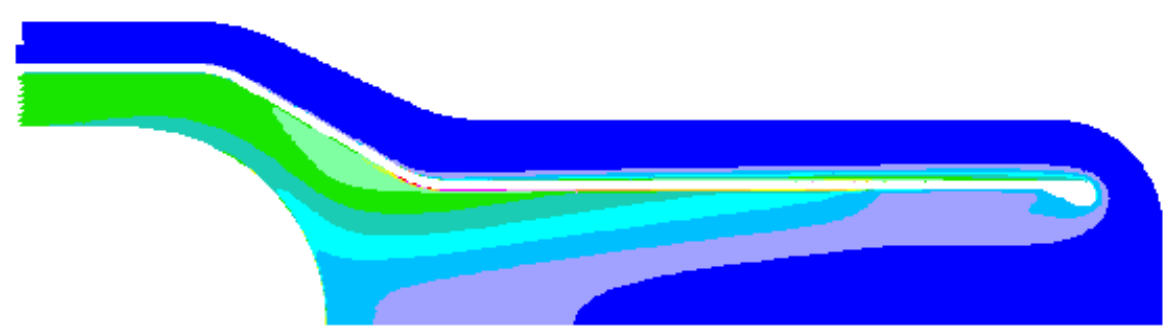

TEMPERATURE ABSOLUTE KELVIN

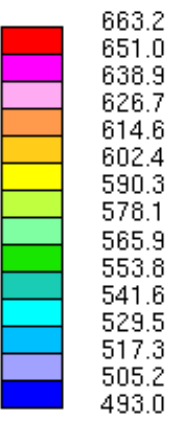

(b)

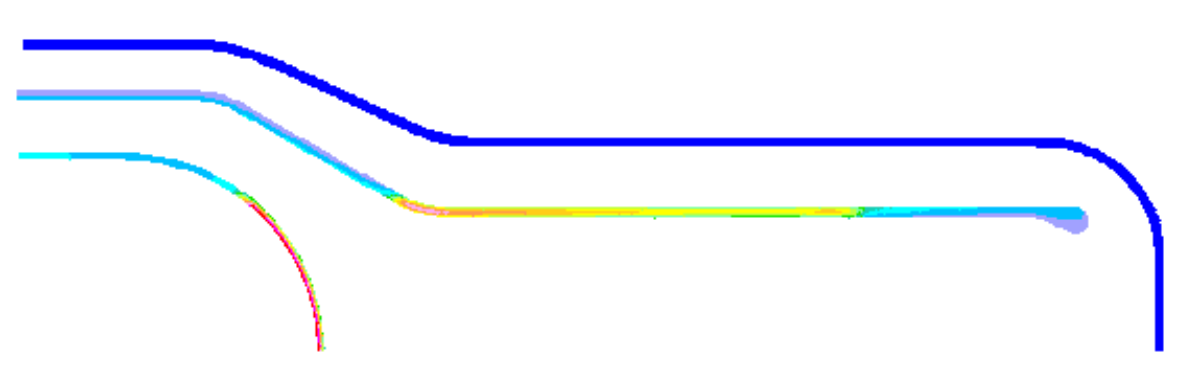

TEMPERATURE ABSOLUTE KELVIN

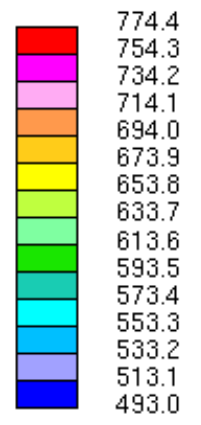

(c)

Figure 36. LBE target concept contour plots showing (a) fluid velocity, (b) fluid temperature, and (c) structural temperature profiles for case $\mathrm{C}$ 


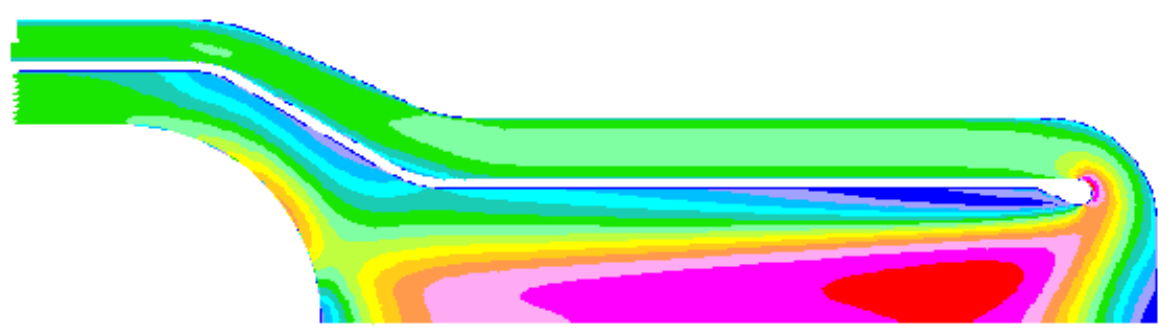

VELOCITY MAGNITUDE $\mathrm{M} / \mathrm{S}$

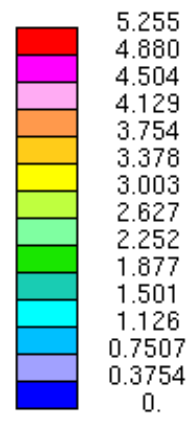

(a)

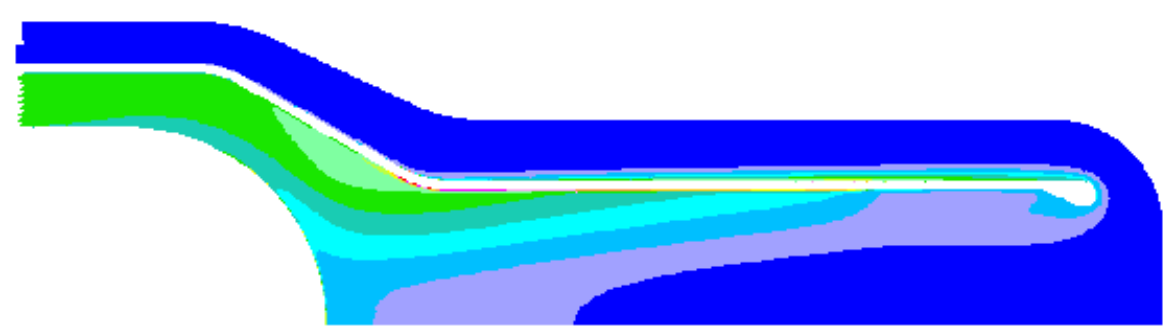

TEMPERATURE ABSOLUTE KELVIN

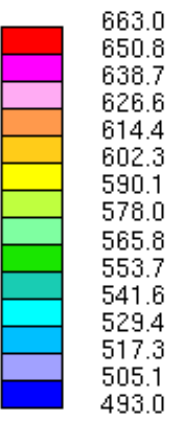

(b)

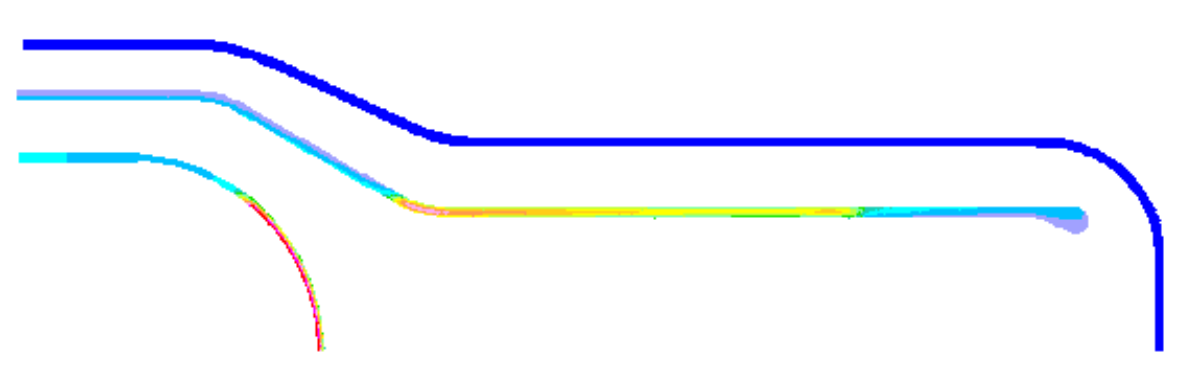

TEMPERATURE ABSOLUTE KELVIN

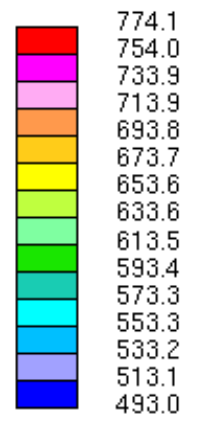

(c)

Figure 37. LBE target concept contour plots showing (a) fluid velocity, (b) fluid temperature, and (c) structural temperature profiles for case $D$ 
The four cases considered in this iteration satisfy the temperature limits specified for both the peak and the surface temperatures. For each case, temperature distributions in the beam window and beam tube were utilized for the structural analyses for analyzing thermal and mechanical stresses in those regions. Based upon these studies, the beam window thickness of $3.5 \mathrm{~mm}$ was selected to reduce the thermal stresses. Furthermore, the hemi-spherical configuration is preferable to the conical configuration because of higher margin for buckling as shown in the stress analysis section. Additionally, the thickness of the cylindrical beam tube is $5 \mathrm{~mm}$ to insure adequate margin for buckling. Case $D$ represents the current reference target design.

\section{V.6. Beam profile effect on the peak window temperature}

In all cases considered, the radial distributions of the proton beam, therefore the thermal energy deposition in the beam window is assumed to have uniform profiles. Since it possible to have different proton beam profiles, three alternative radial distributions were considered in separate thermal hydraulic analysis using the target geometry of case $\mathrm{B}$ from the design iteration process. The distributions considered are:

1. A uniform distribution

2. A clipped elliptic paraboloid distribution with a peak to average ratio of 1.2

3. A full-width elliptic paraboloid distribution with a peak to average ratio of 1.5

4. An offset parabolic distribution rotated about the centerline with a peak to average ratio of 1.5

The four normalized distributions are shown in Figure 38 . Temperature distributions of the adiabatic surfaces of the four beam windows are compared in Figure 39. Clearly, the uniform distribution (Distribution 1) provides the lowest peak temperature of the four profiles considered. However, the other distributions relax the temperature gradient at the edge of the heated region where the peak thermal stress occurs for the current reference design. This approach can be used to reduce further the thermal stresses within the beam window. Optimization of the beam profile may be desirable for future revisions of the current reference target design.

\section{V.7. Target diameter effect on the peak window temperature}

A thermal hydraulic analysis has been performed to study the impact of expanding the radius of the middle cylinder that serves as a baffle between the inlet and outlet flow paths so that it is located outside the proton beam path. In order to maintain flow stability, the diameter of the outer cylinder must be expanded proportionally. Expansion of the target region without increasing the inlet flow rate results in a substantial decrease in the velocity at the central region. This reduction in the flow velocity leads to a significant reduction in the heat transfer at the surface of the beam window. While the turbulence characteristics and the size of the recirculation zone are not significantly effected by these geometrical modifications, thermal design criteria are exceeded by as much as $450{ }^{\circ} \mathrm{C}$ as a result of the reduced flow velocity in the central region. Further studies of this approach are not warranted. 


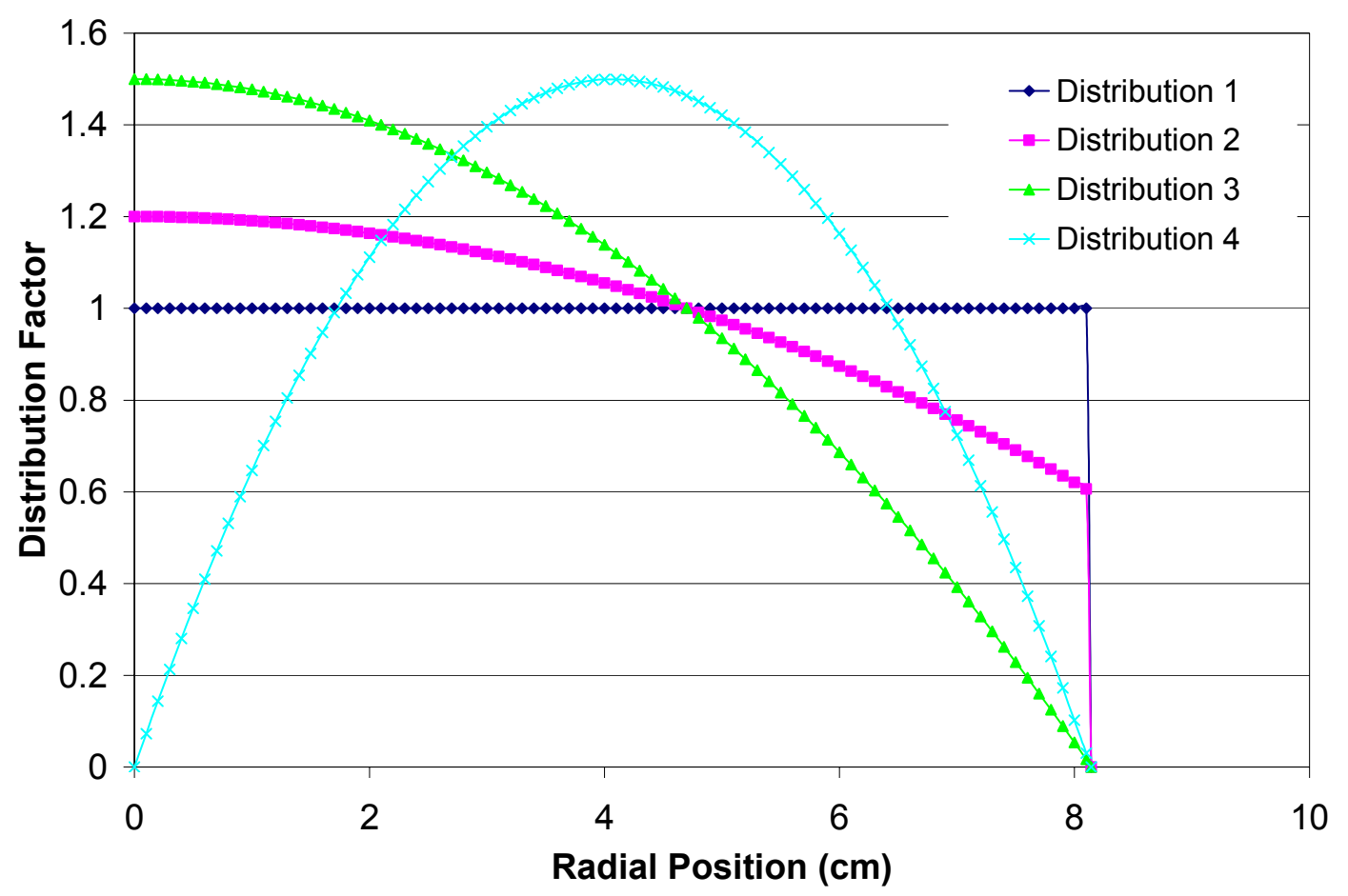

Figure 38. Radial proton beam profiles

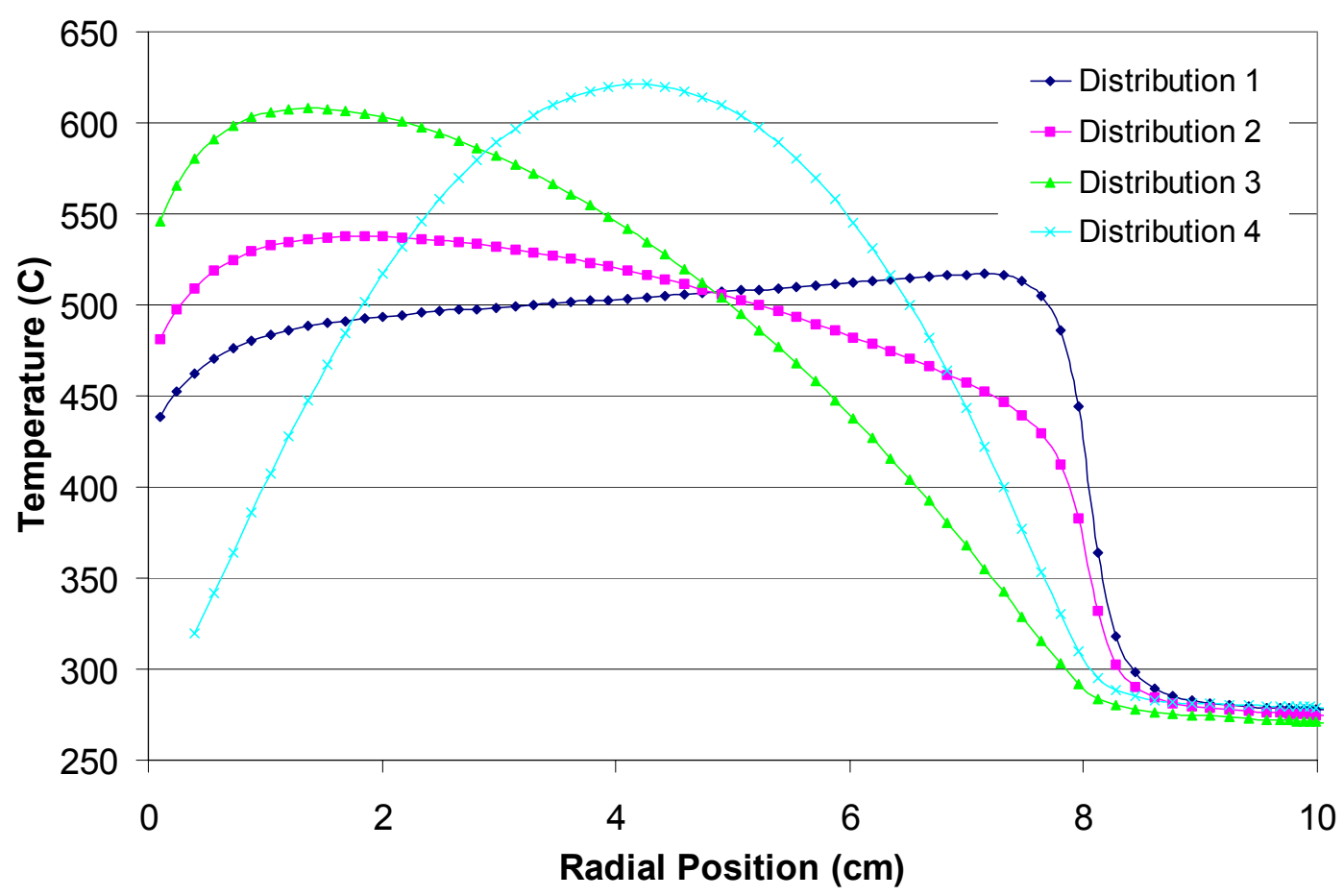

Figure 39. Temperature profiles along the adiabatic surfaces of the beam window for the four radial proton beam profiles 


\section{Structural design}

The ability of the beam tube to withstand the mechanical and thermal loads is determined by comparing the calculated stresses to allowable stresses defined in the APT supplemental structural design requirements [2], the international thermonuclear experimental reactor [3], and the ASME Code. A stress analysis was performed on various beam window configurations under normal operating conditions. The analysis was aimed to develop a beam window configuration, which would satisfy the stress and the buckling criteria.

The ANSYS general-purpose finite element code [8] was used with a twodimensional axisymmetric finite element model for the target tube. The LBE hydrostatic pressure load and the thermal stresses caused by the temperature gradient in the target structure were used in the ANSYS analysis. The buckling capabilities of the structure were initially evaluated using the ASME code. Then, a nonlinear buckling analysis was performed using ANSYS code.

\section{VI.1. Finite element models for stress analysis}

Two beam window configurations were considered. The first has a conical geometry as shown in Figures 40 and 41 and the second utilize a hemi-spherical geometry shown in Figures 42 and 43 . The models used for the stress evaluation consist of the target beam window and a $10-\mathrm{cm}$-long section of the beam tube.

The finite element models of the stress analysis were generated from Excel files obtained from the thermal hydraulic analyses. These files contained nodal coordinates and corresponding temperatures generated from the CFD analysis. An example of FORTRAN program used to generate the finite element model of conical window used for the stress analysis is shown in Appendix A. Later the constant material properties are replaced with the temperature-dependent ones. The materials properties are discussed in the section VI.3.

The structure stiffness was modeled with 2-D plane elements with axisymmetric capability (ANSYS PLANE 42 element). The finite element grid was identical to the grid used in thermal hydraulic analysis. It is a map-mesh, which consists of 1768 nodes and 1648 rectangular elements in an array of 16 rows across the wall thickness with 103 elements per row for the conical window concept.

The second beam window concept analyzed replaces the conical geometry with a hemi-spherical geometry using $5 \mathrm{~mm}$-thick wall as shown in Figures 42 and 43 . The finite element model consists of 2108 nodes and 1968 elements ordered in 16 rows across the wall thickness with 123 elements per row. Additional finite element models of beam window configurations are generated from the models shown in Figures 41 and 43 by decreasing the wall thickness as follows: 


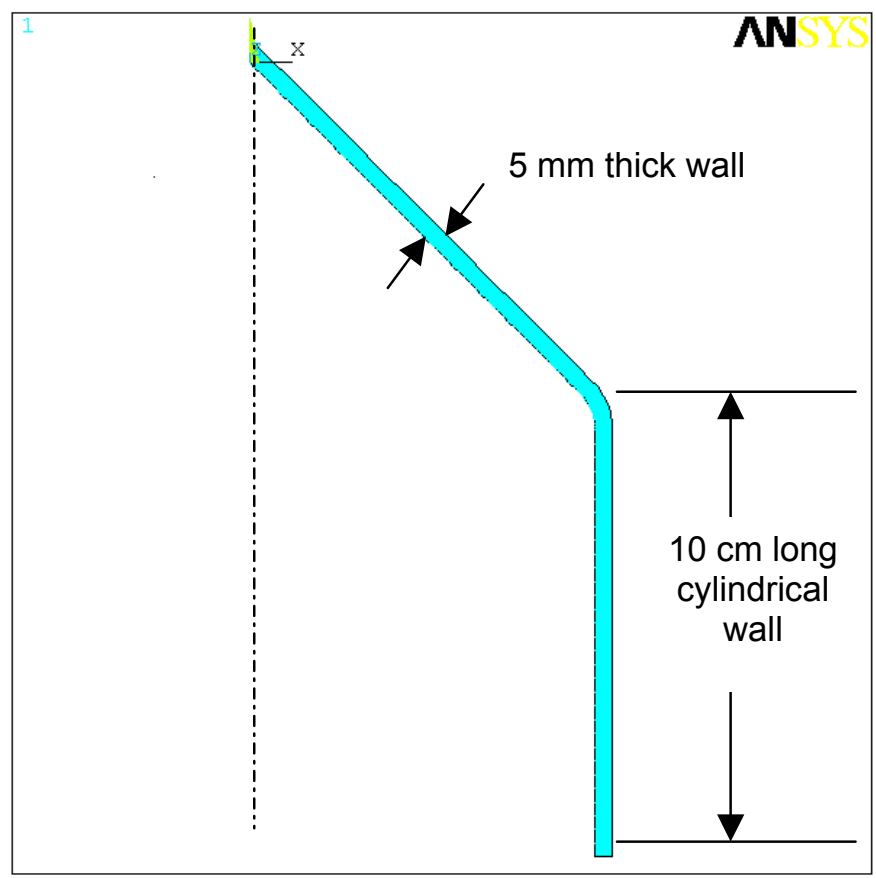

Figure 40. Complete axisymmetric ANSYS model of the 5-mm conical target beam window

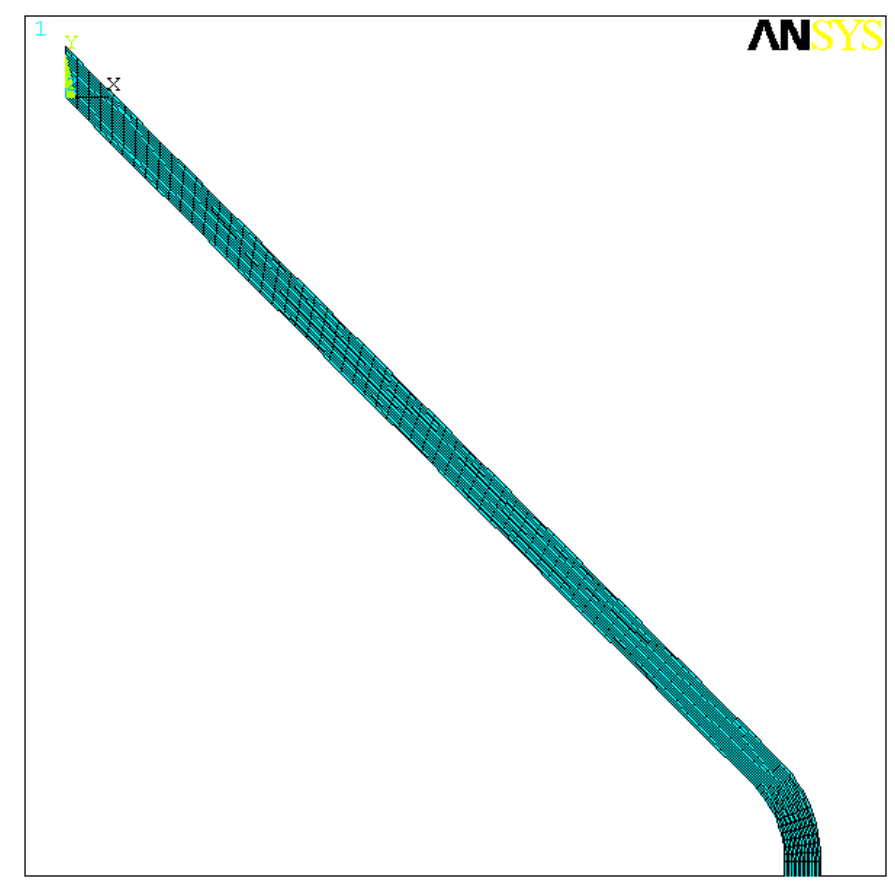

Figure 41. Expanded view of conical section of the 5-mm conical target beam window ANSYS model 


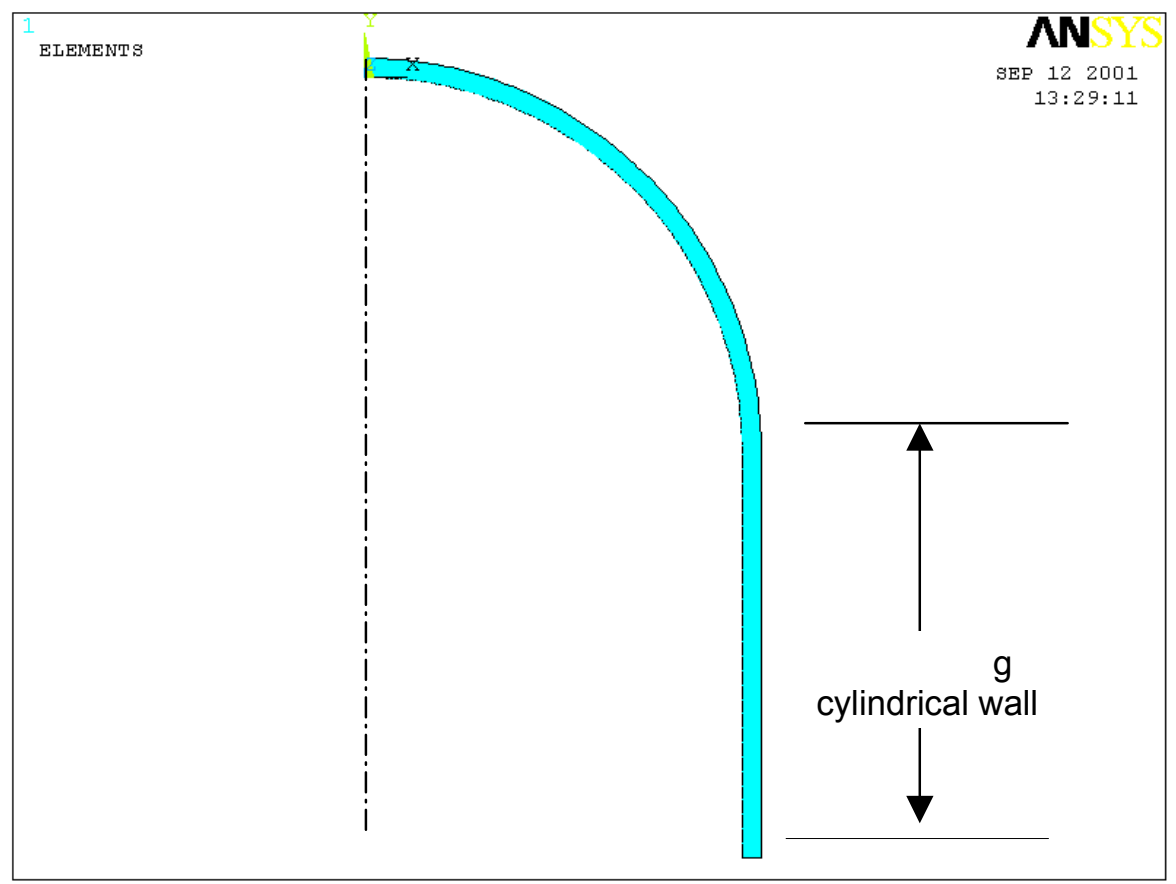

Figure 42. Complete axisymmetric ANSYS model of the 5-mm hemi-spherical target beam window

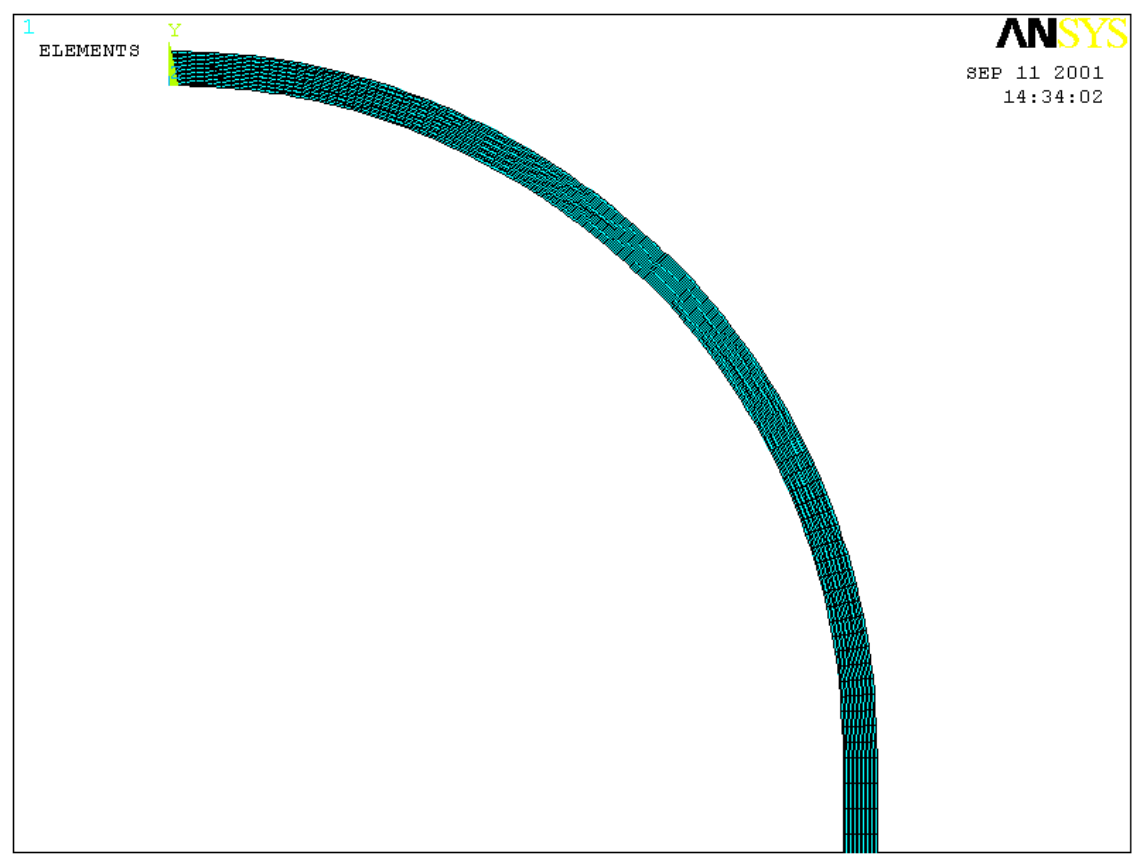

Figure 43. Expanded view of the hemi-spherical section of the 5-mm hemi-spherical target beam window ANSYS model 
- $4 \mathrm{~mm}(4.060 \mathrm{~mm}$ actual) thick wall - conical and hemi-spherical configurations

- $3 \mathrm{~mm}$ (3.125mm actual) thick wall - conical and hemi-spherical configurations

- $3.5 \mathrm{~mm}$ thick wall - conical and hemi-spherical configurations

The $4 \mathrm{~mm}$ and $3 \mathrm{~mm}$ thick beam windows were generated from the $5 \mathrm{~mm}$ beam window by deleting three and six rows of elements across the thickness respectively, starting from the adiabatic window surface.

\section{VI.2. Loads and boundary conditions}

Under the normal operating conditions the beam window is exposed to mechanical and thermal loads. The mechanical load is the external pressure due to the hydraulic head from the liquid lead-bismuth eutectic in the target system. The pressure load is calculated to be $0.79 \mathrm{MPa}$ as shown in Figure 44. The main parameters used to calculate the pressure load are given in Appendix B. The temperature distribution of the beam tube including the window from the thermal hydraulic analysis is shown in Figure 45 for the conical configuration. The temperature distribution was calculated for HT-9 structure, however the same temperature distribution was used in the structural analysis for the type 316SS. This approximation was done to understand the effect of different geometrical configurations and the window thickness on the structural performance of the beam tube without considering the absolute value of the results. In fact, type 316SS temperature gradient would be larger than that of the HT-9 because type 316SS thermal conductivity is lower than that of HT-9. The temperature distribution across the beam window for the 3-mm and 4-mm configurations was obtained by removing elements from the adiabatic surface of the 5-mm configuration to reduce the thickness to the appropriate value. After the initial evaluation described above, the temperature distribution across the beam window wall for the $3.5-\mathrm{mm}$ configurations was obtained from the thermal hydraulic analysis to calculate the window thermal stresses. In the $3.5 \mathrm{~mm}$ case, both the thermal input and the stress model used the HT-9 material properties. Figure 46 shows the temperature distribution for the hemi-spherical configuration.

\section{VI.3. Material properties}

The mechanical properties are evaluated over a wide temperature range for performing the structural analysis. Figures 47 to 49 show the temperature dependence of Young's modulus, Poisson's ratio and the thermal expansion coefficient for type $316 S S$ used in the analysis [9]. Figures 50 and 51 show temperature dependence of Young's modulus and the thermal expansion coefficient for HT-9. The temperature dependence of Poisson's ratio for type 316SS was used for HT-9 steel. 


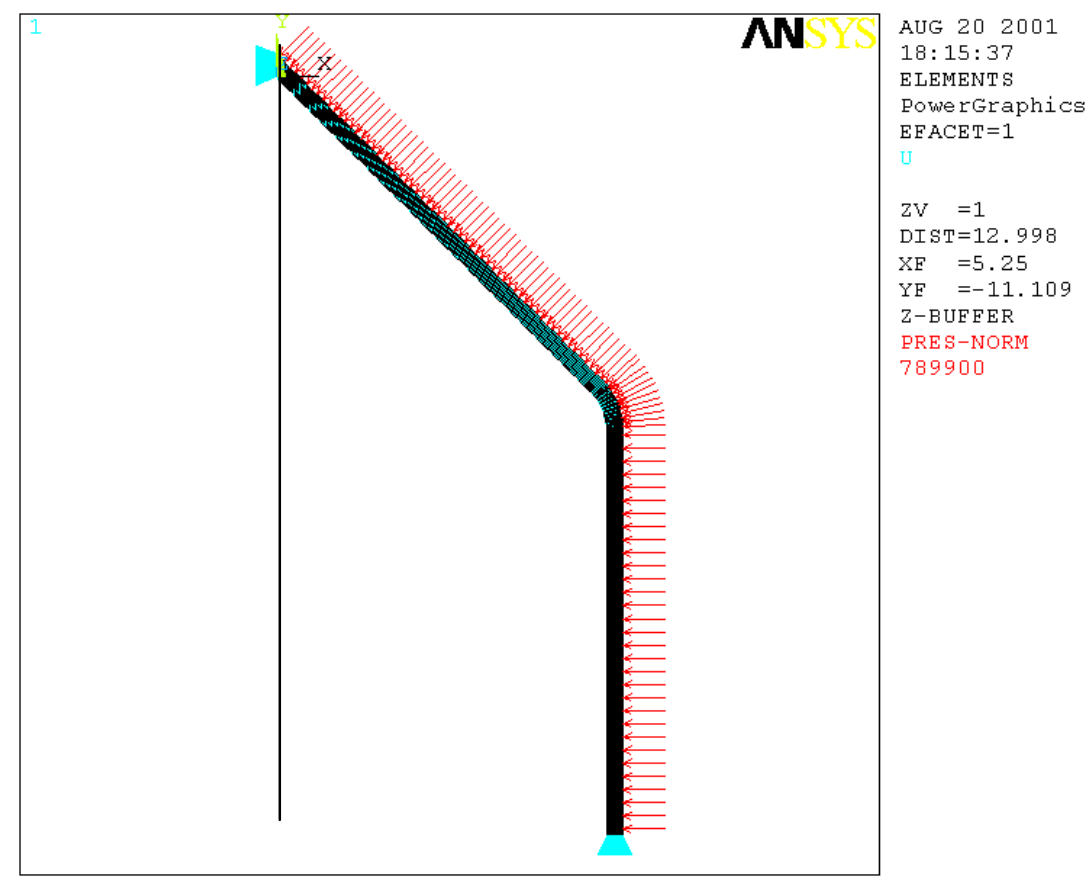

Figure 44. Applied external pressure and boundary conditions at both ends preventing displacement in the radial (window centerline) and axial directions (the end of $10 \mathrm{~cm}$-long cylinder segment)

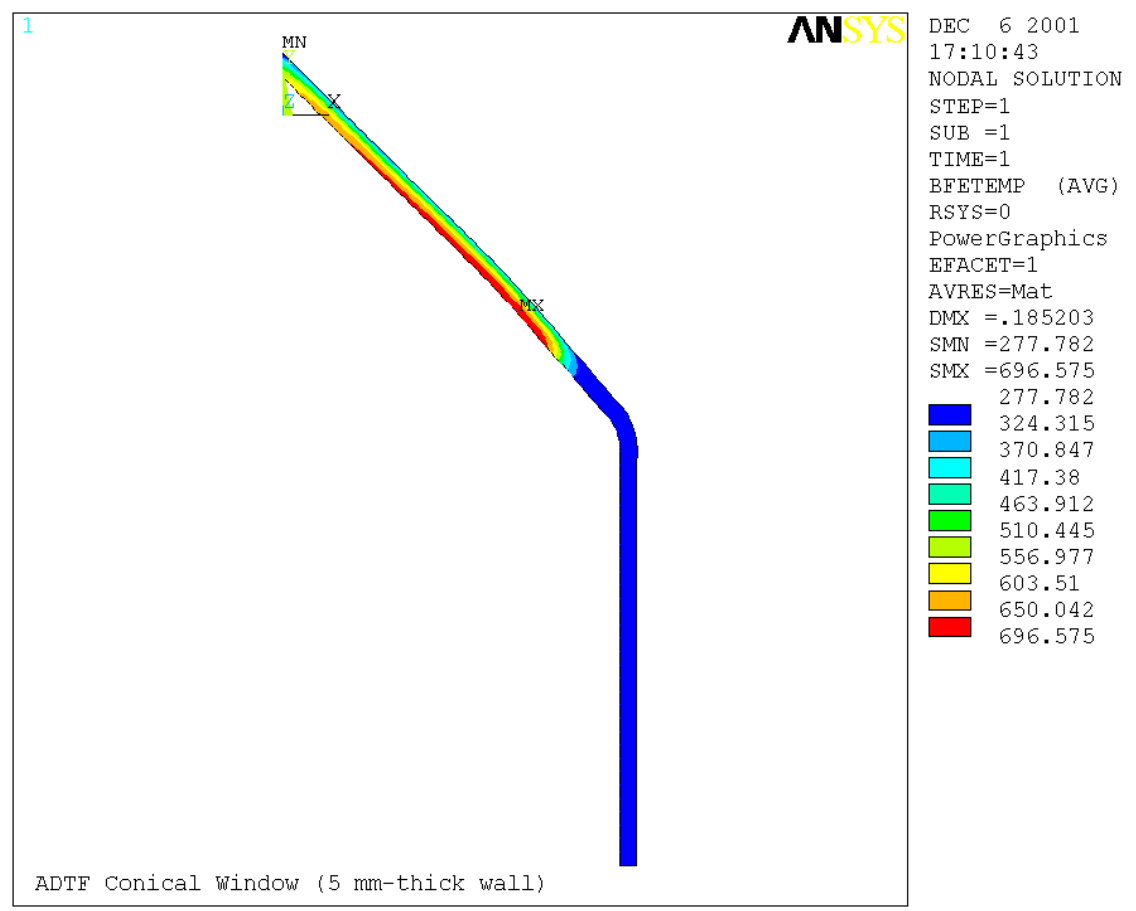

Figure 45. Temperature distribution of the conical beam window with the 5-mm HT-9 structure, temperatures are in degrees Celsius 


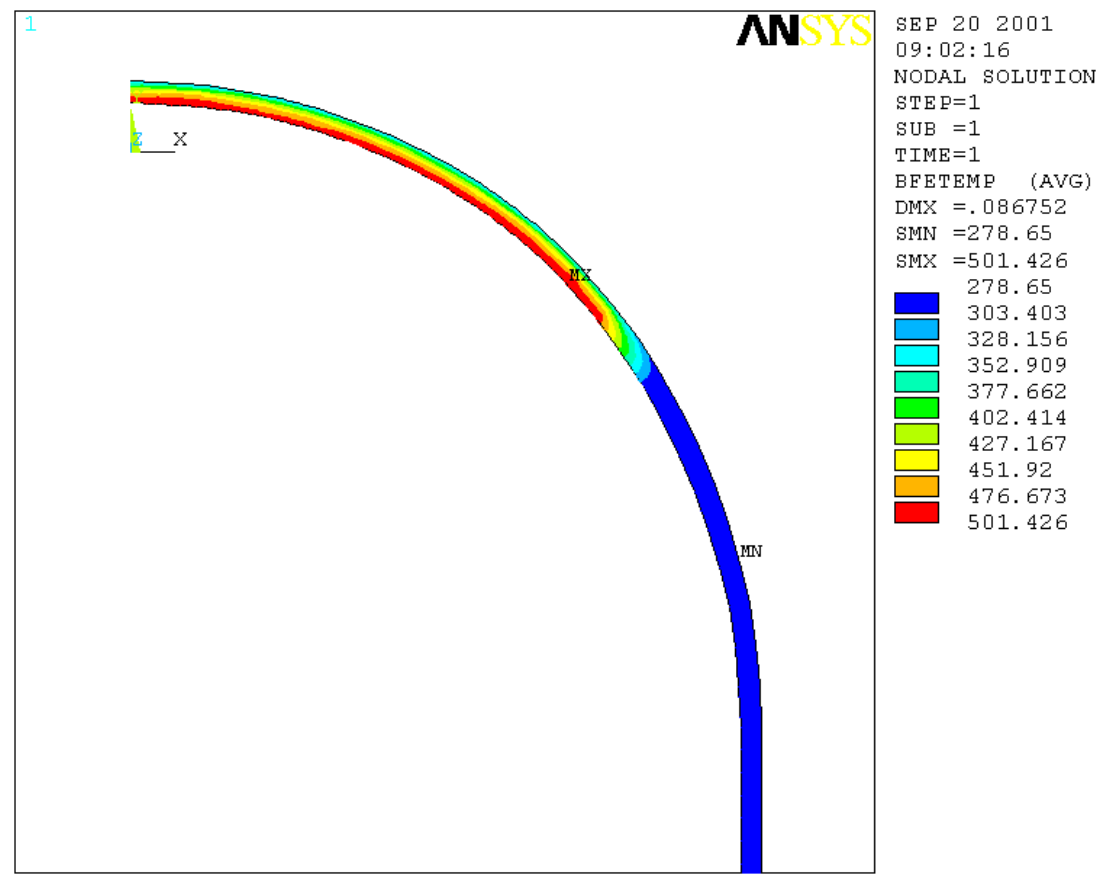

Figure 46. Temperature distribution of the spherical beam window with $3.5 \mathrm{~mm} \mathrm{HT}-9$ structure, temperatures are in degrees Celsius.

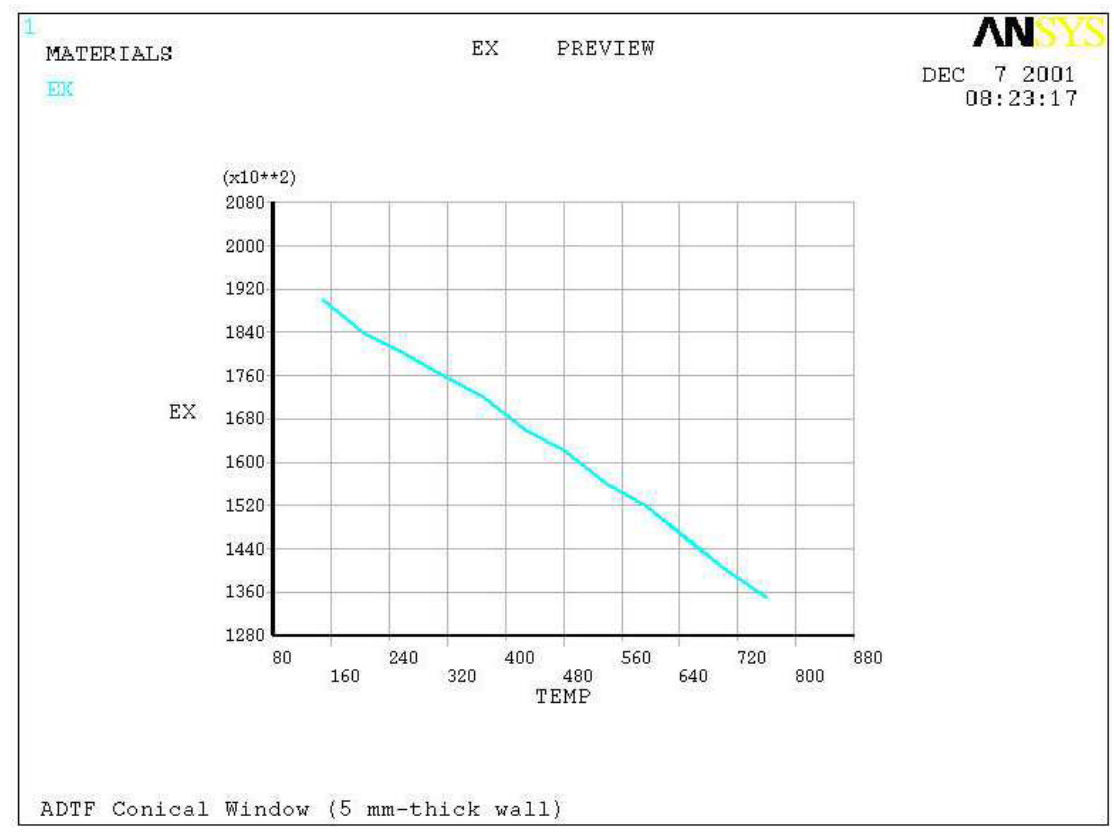

Figure 47. Type 316SS Young's modulus as a function of temperature in Celsius 


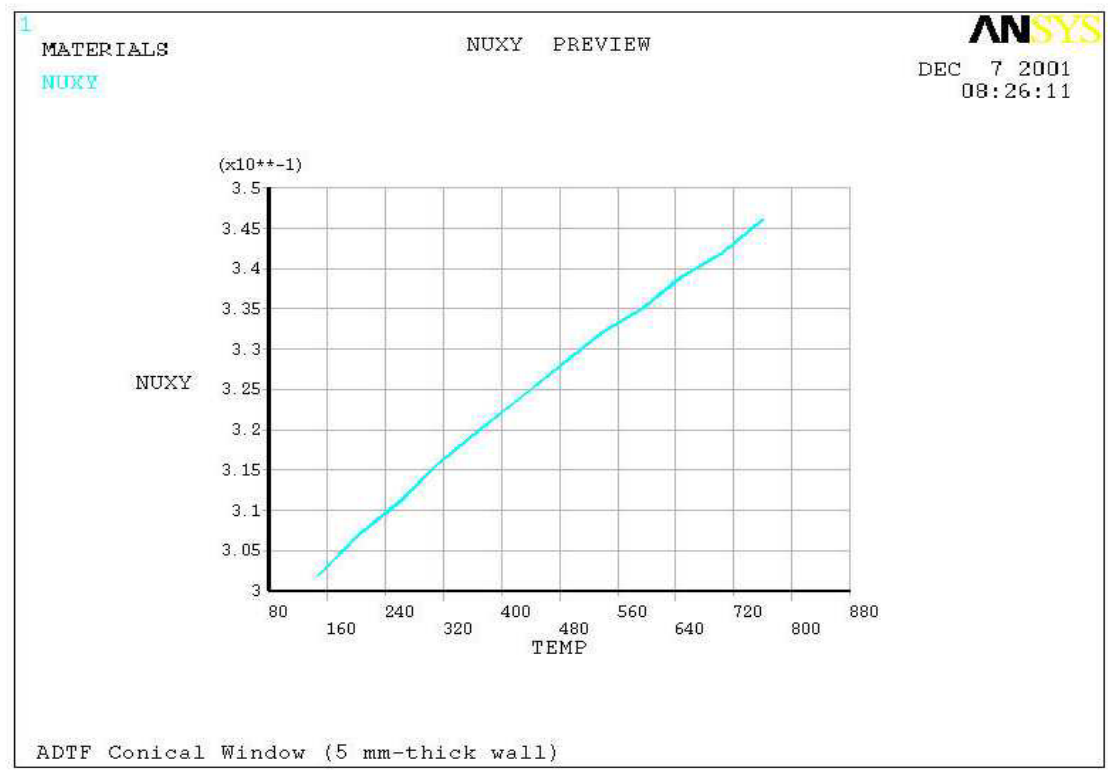

Figure 48. Type 316SS Poisson's ratio as a function of temperature in Celsius

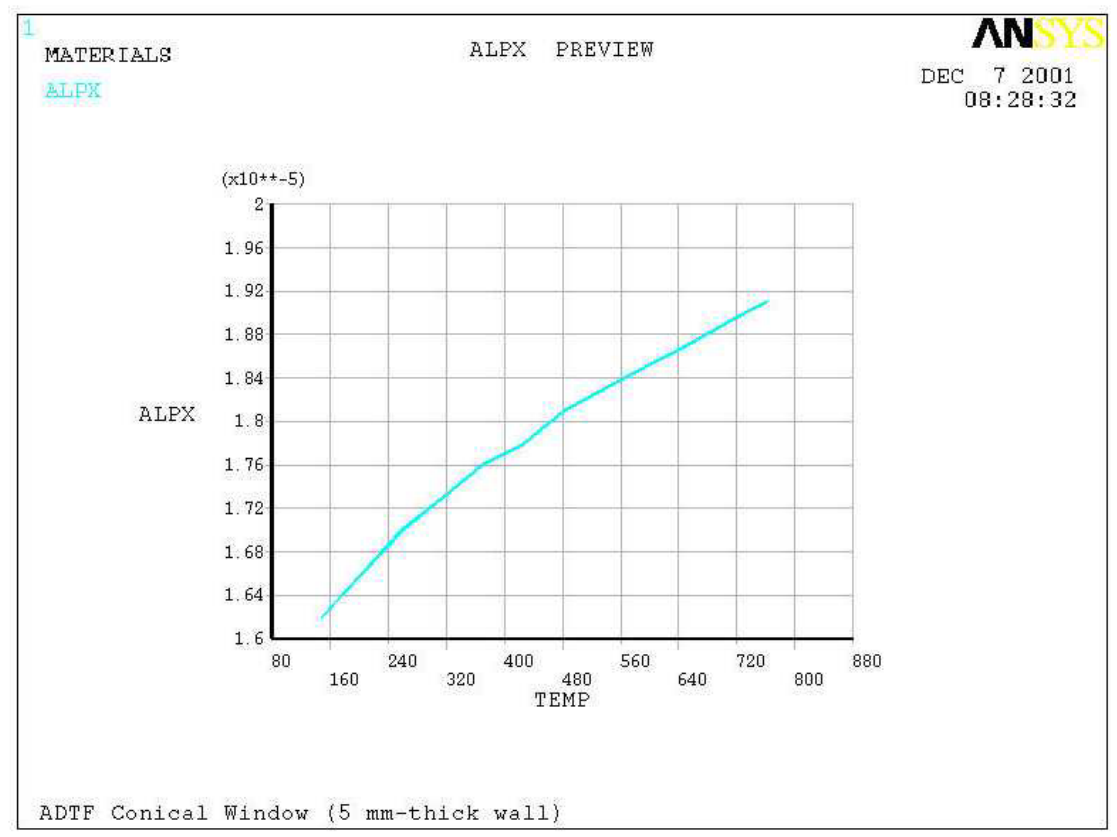

Figure 49. Type 316SS thermal expansion coefficient as a function of temperature in Celsius 


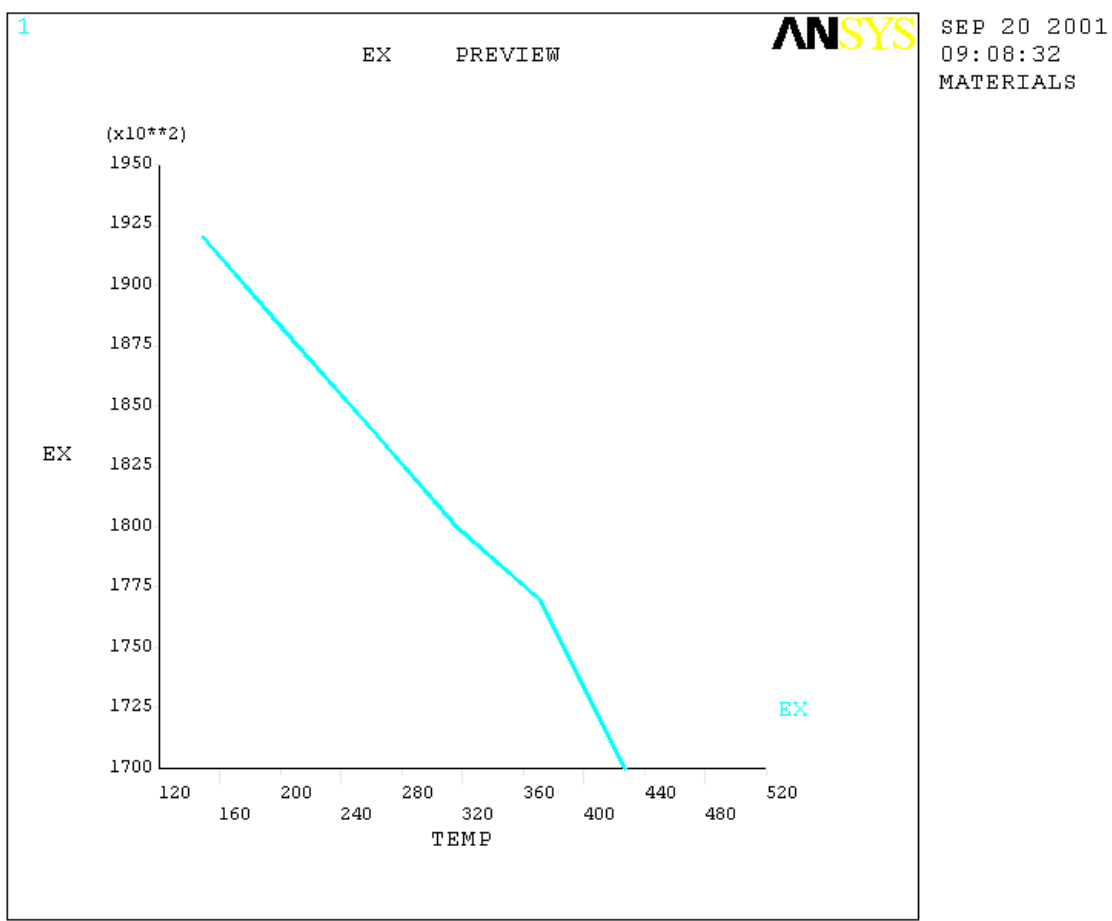

Figure 50. HT-9 Young's Modulus as a function of temperature in Celsius

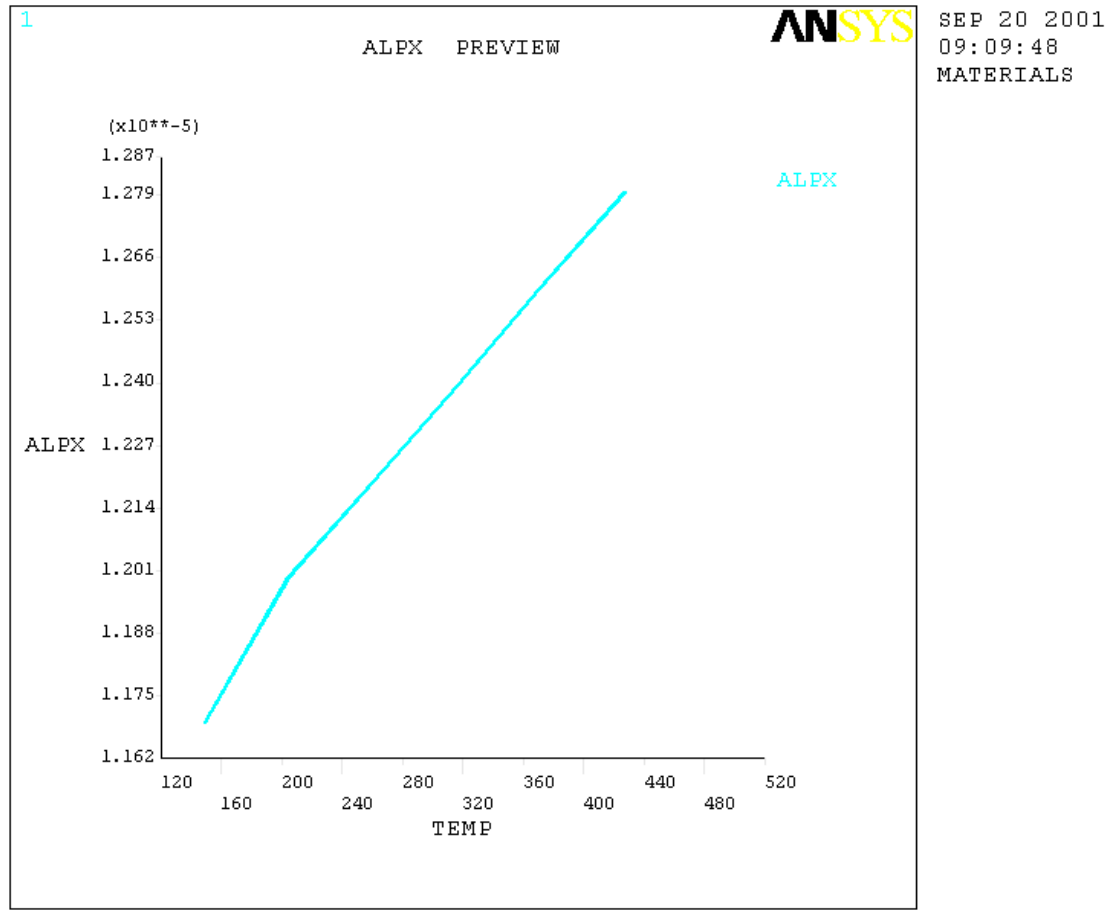

Figure 51. HT-9 thermal Expansion Coefficient as a function of temperature in Celsius 


\section{VI.4. ANSYS stress results}

A parametric stress analysis was performed to study the effect of the window wall thickness and the window geometry on the generated stresses during the normal operation. The window wall thickness was parametrically changed for the conical and spherical geometries. Table 3 gives the details of the analyzed cases and the method used for generating the temperature distribution for each case.

The results for the 5-mm wall thickness are shown in Figures 52 through 55 for the conical and spherical geometries in the form of stress intensity contour plots. The first contour plot gives the stresses caused by the LBE pressure and the temperature gradient during the normal operation. The second contour plot gives the stresses caused only by the LBE pressure load. The peak stress occurs close to the intersection of the proton beam boundary with the window on the wetted surface as shown in figures 52 and 54.

Table 3. Target cases considered in the ANSYS analysis

\begin{tabular}{|c|c|c|c|c|}
\hline $\begin{array}{c}\text { Case } \\
\text { Number }\end{array}$ & $\begin{array}{c}\text { Window } \\
\text { Geometry }\end{array}$ & $\begin{array}{c}\text { Window Wall } \\
\text { Thickness, } \mathrm{mm}\end{array}$ & $\begin{array}{c}\text { Window } \\
\text { Material }\end{array}$ & $\begin{array}{c}\text { Temperature } \\
\text { Distribution }\end{array}$ \\
\hline 1 & Conical & 5 & Type 316 SS* & $\begin{array}{c}\text { Thermal Hydraulic } \\
\text { Analysis }\end{array}$ \\
\hline 2 & Hemi-spherical & 5 & Type 316 SS* & $\begin{array}{c}\text { Thermal Hydraulic } \\
\text { Analysis }\end{array}$ \\
\hline 3 & Conical & 4 & Type 316 SS* & $\begin{array}{c}\text { Generated from } \\
\text { Case 1 }\end{array}$ \\
\hline 5 & Hemi-spherical & 4 & Type 316 SS* & $\begin{array}{c}\text { Generated from } \\
\text { Case 2 }\end{array}$ \\
\hline 6 & Conical & 3 & Type 316 SS* & $\begin{array}{c}\text { Generated from } \\
\text { Case 1 }\end{array}$ \\
\hline 7 & Conical & 3.5 & HT-9 Alloy & $\begin{array}{c}\text { Thermal Hydraulic } \\
\text { Analysis } \\
\text { Case 2 }\end{array}$ \\
\hline 8 & Hemi-spherical & 3.5 & HT-9 Alloy & $\begin{array}{c}\text { Thermal Hydraulic } \\
\text { Analysis }\end{array}$ \\
\hline
\end{tabular}

* The thermal hydraulic analysis was performed with HT-9 while the stress analysis assumed type 316SS, see the loads and boundary conditions section. 
The maximum stresses from the parametric study are summarized in Figures 56 and 57, and Tables 4 and 5 for the conical and spherical window configurations as a function of the wall thickness. Stress results are broken down into stress components, which are required for the structural design criteria defined in the Supplemental Structural Design Requirements [2].

Based on the results from the parametric study and the allowable stresses for the HT-9 structure, a 3.5-mm window wall thickness was selected. The thermal hydraulics and structural analyses were performed for the two geometrical configurations with this thickness to obtain the temperature distribution, the stress components, and the displacement during the normal operation. The results are shown in Figures 58 through 63 for the conical configuration and a summary of the results is given in Table 4 . The corresponding results for the hemi-spherical configuration are shown in Figures 64 through 69 and the summary is given in Table 5. Again, the peak stress occurs near the intersection of the proton beam boundary with the beam window. The peak stress values of the two geometrical configurations are very close during the normal operation, which qualify both designs for further consideration.

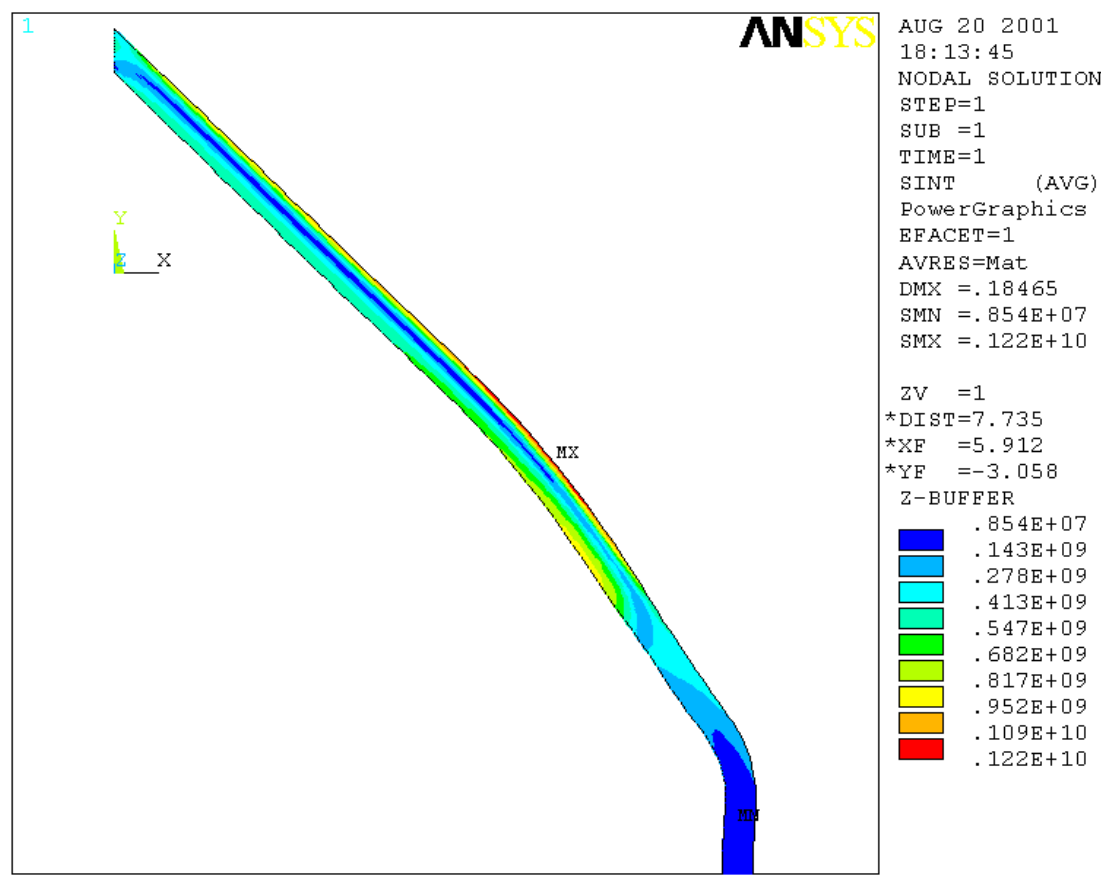

Figure 52. Stress intensity $(\mathrm{Pa})$ in the $5-\mathrm{mm}$ conical beam window during the normal operating conditions 


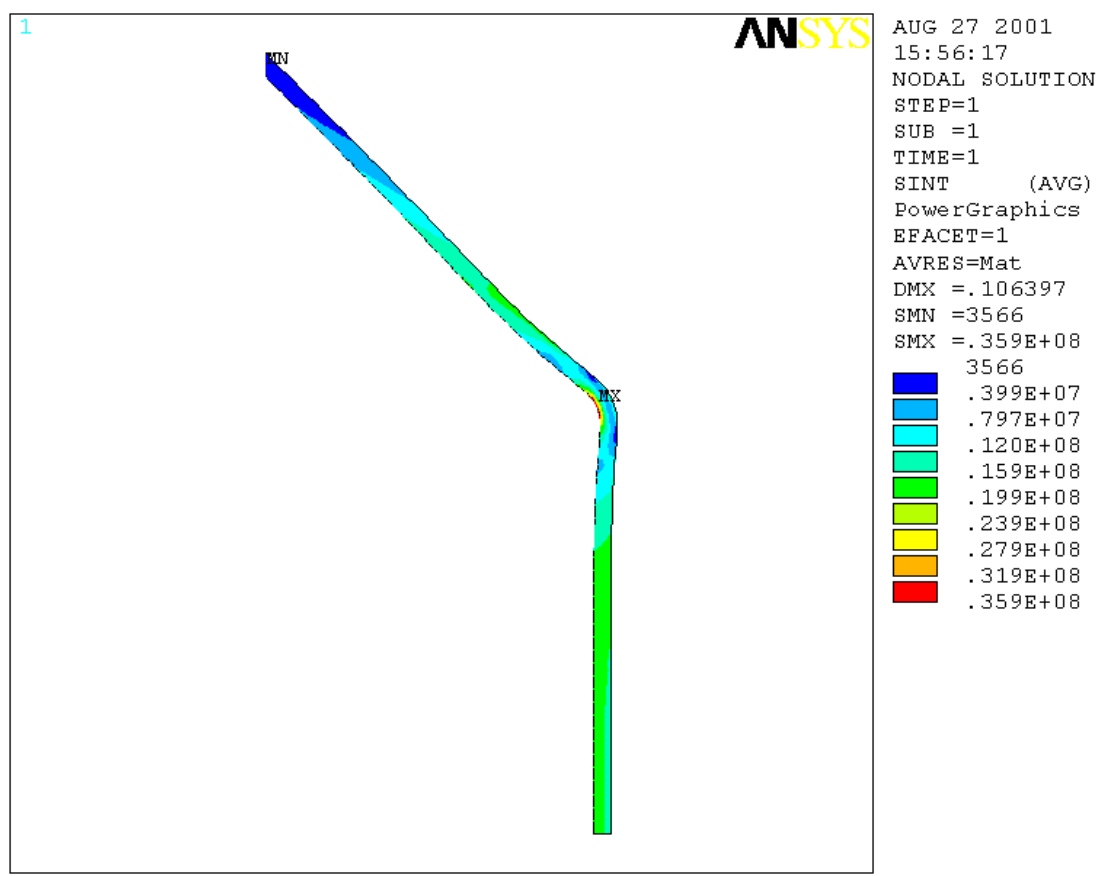

Figure 53. Stress intensity $(\mathrm{Pa})$ in the $5-\mathrm{mm}$ conical beam window due to the LBE pressure load

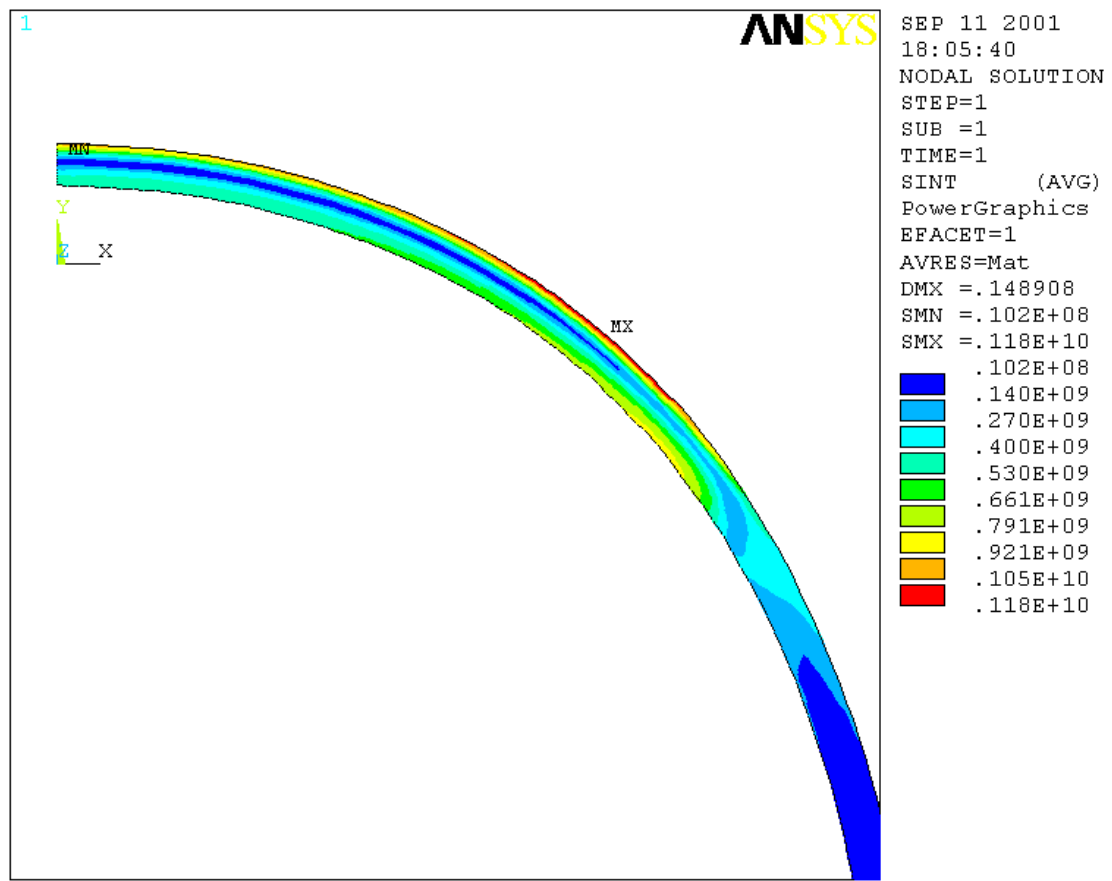

Figure 54. Stress intensity $(\mathrm{Pa})$ in the $5-\mathrm{mm}$ hemi-spherical beam window during the normal operating conditions 


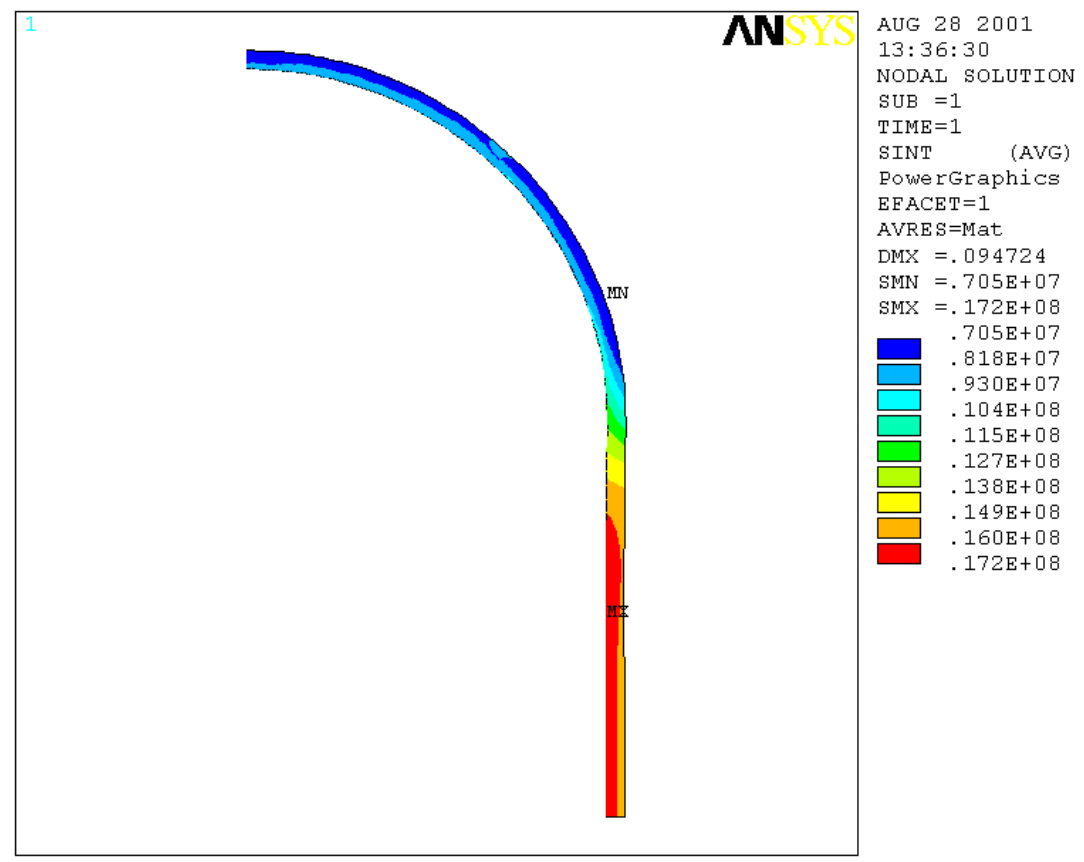

Figure 55. Stress intensity $(\mathrm{Pa})$ in the 5-mm hemi-spherical beam window due to the LBE pressure load

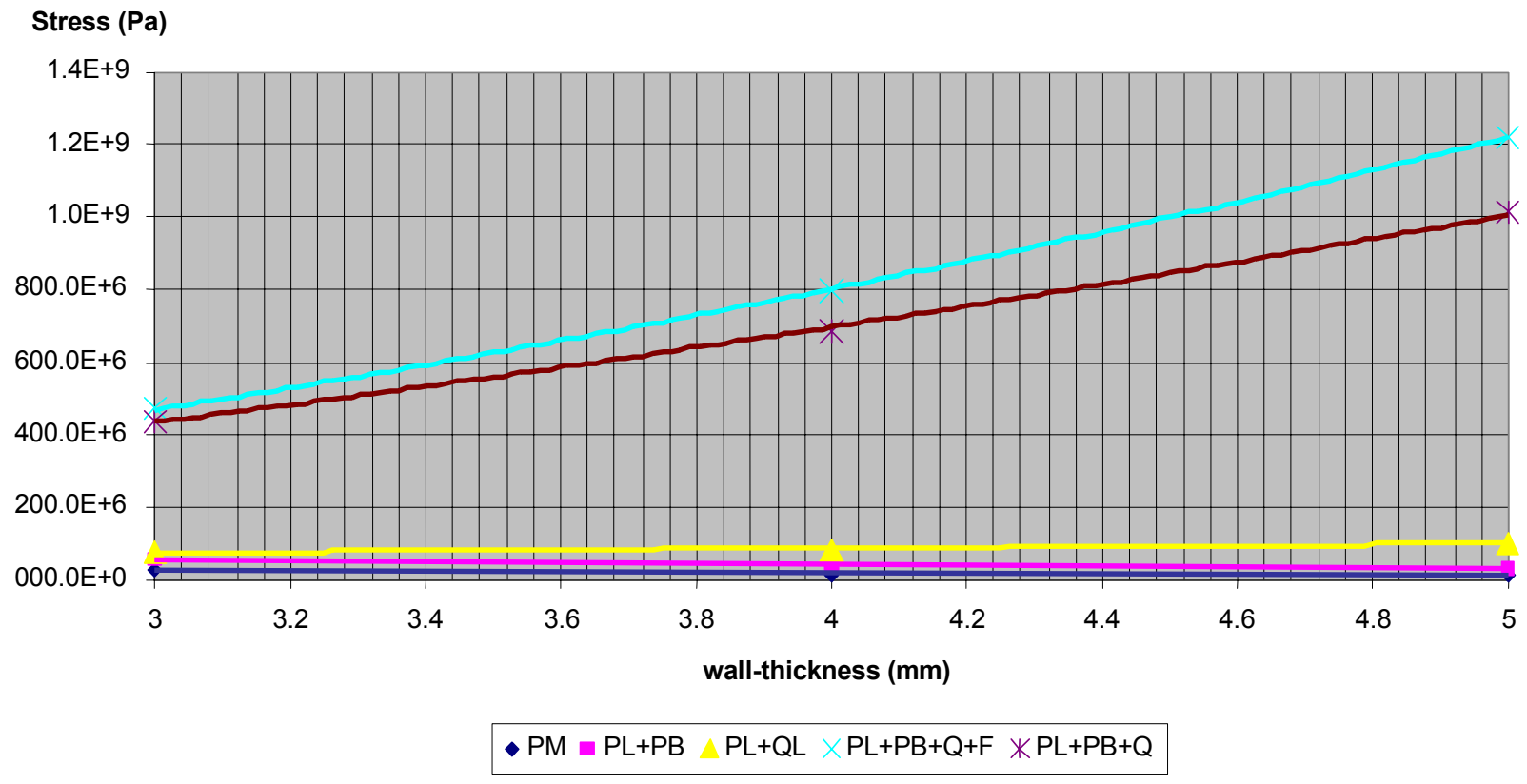

Figure 56. Maximum values of the different stress components as a function of the wall thickness for the conical window configuration, cases 1,3 , and 5 


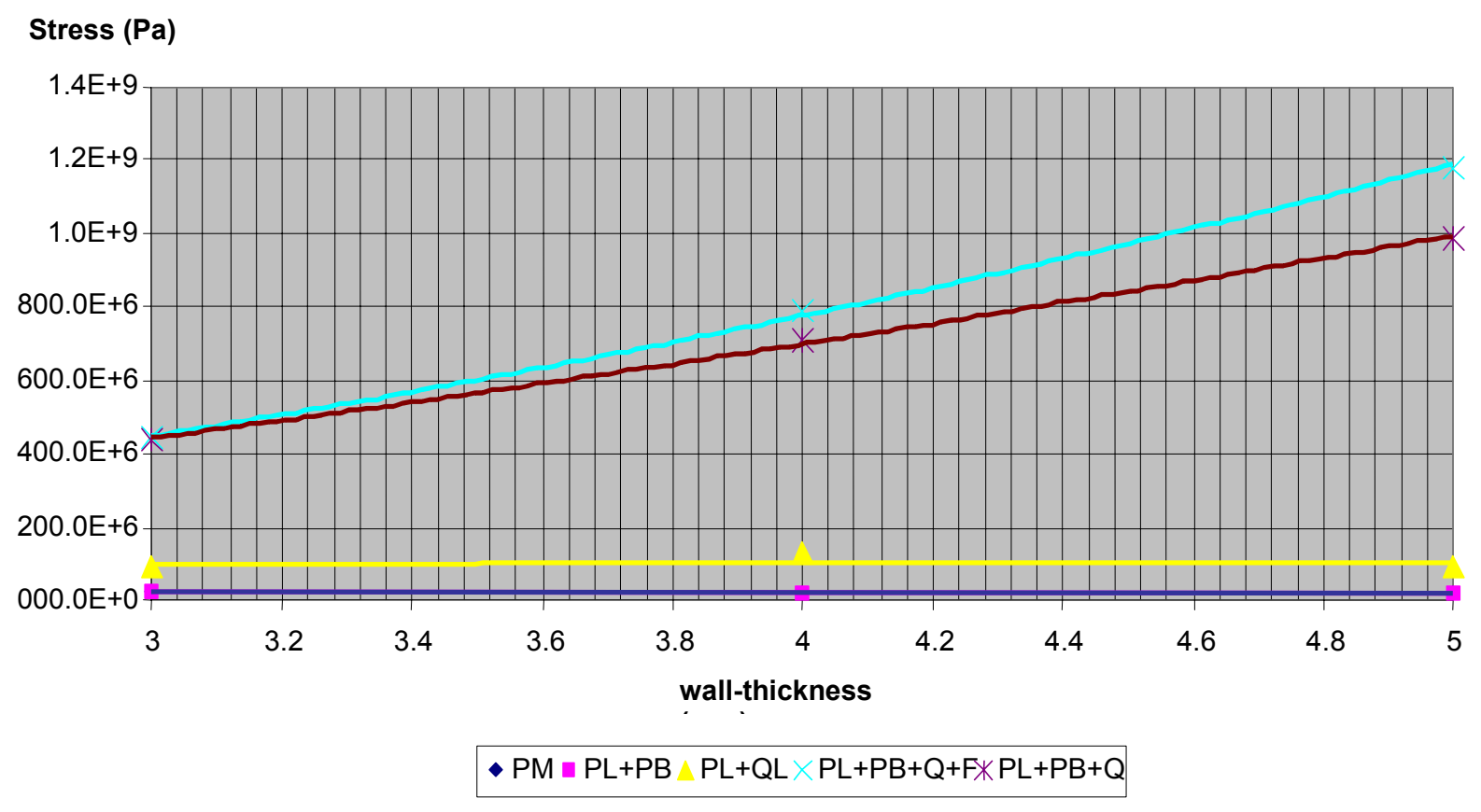

Figure 57. Maximum values of the different stress components as a function of the wall thickness for the spherical window configuration, cases 2,4 , and 6

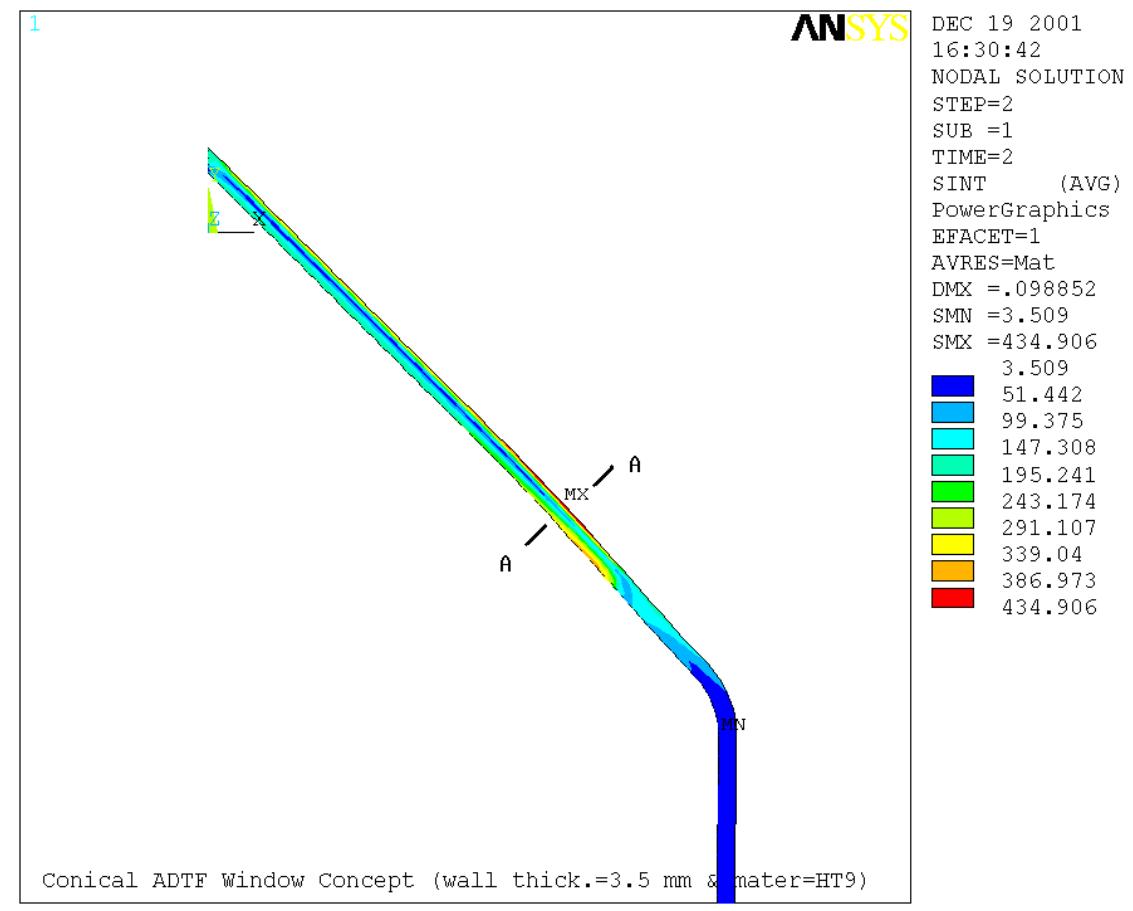

Figure 58. Stress intensity $(\mathrm{Pa})$ in the $3.5-\mathrm{mm}$ conical beam window during the normal operating conditions 


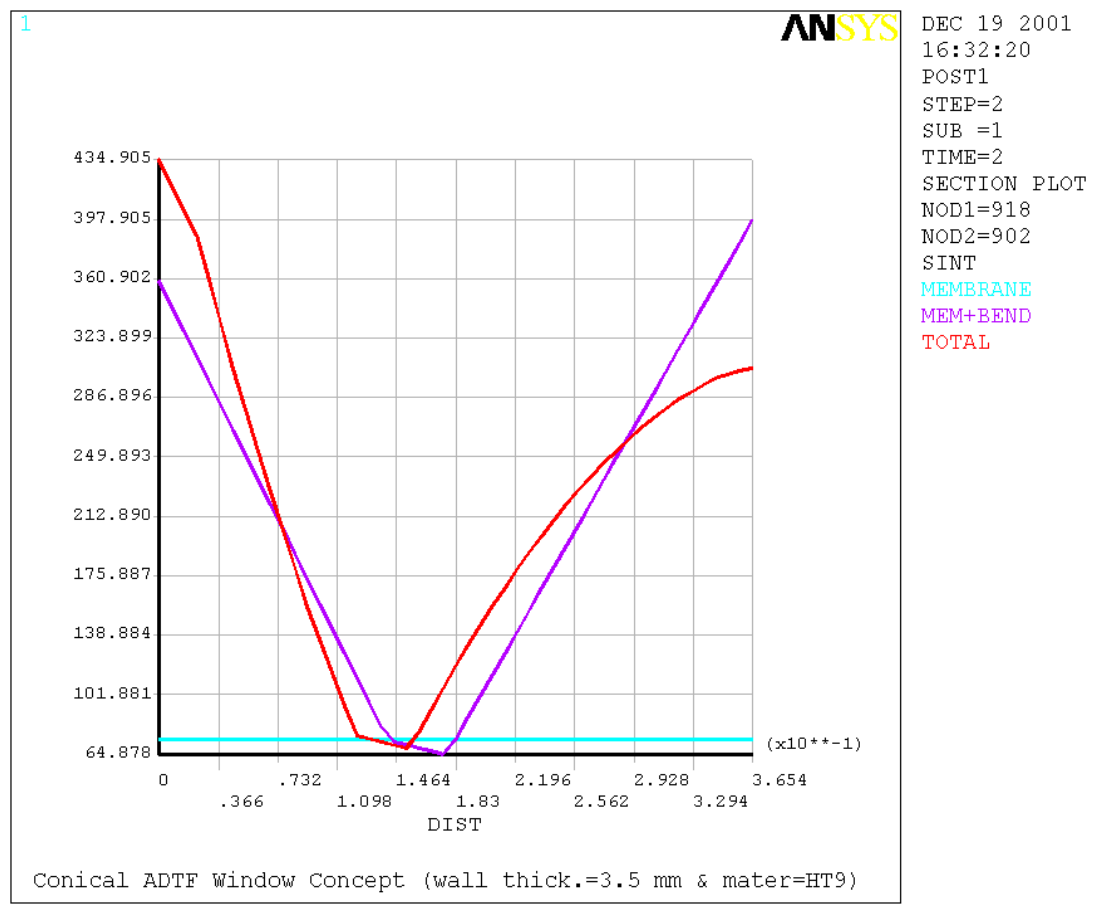

Figure 59. Stress components (MPa) along section A-A shown of Figure 58 measured from the wetted surface during the normal operating conditions

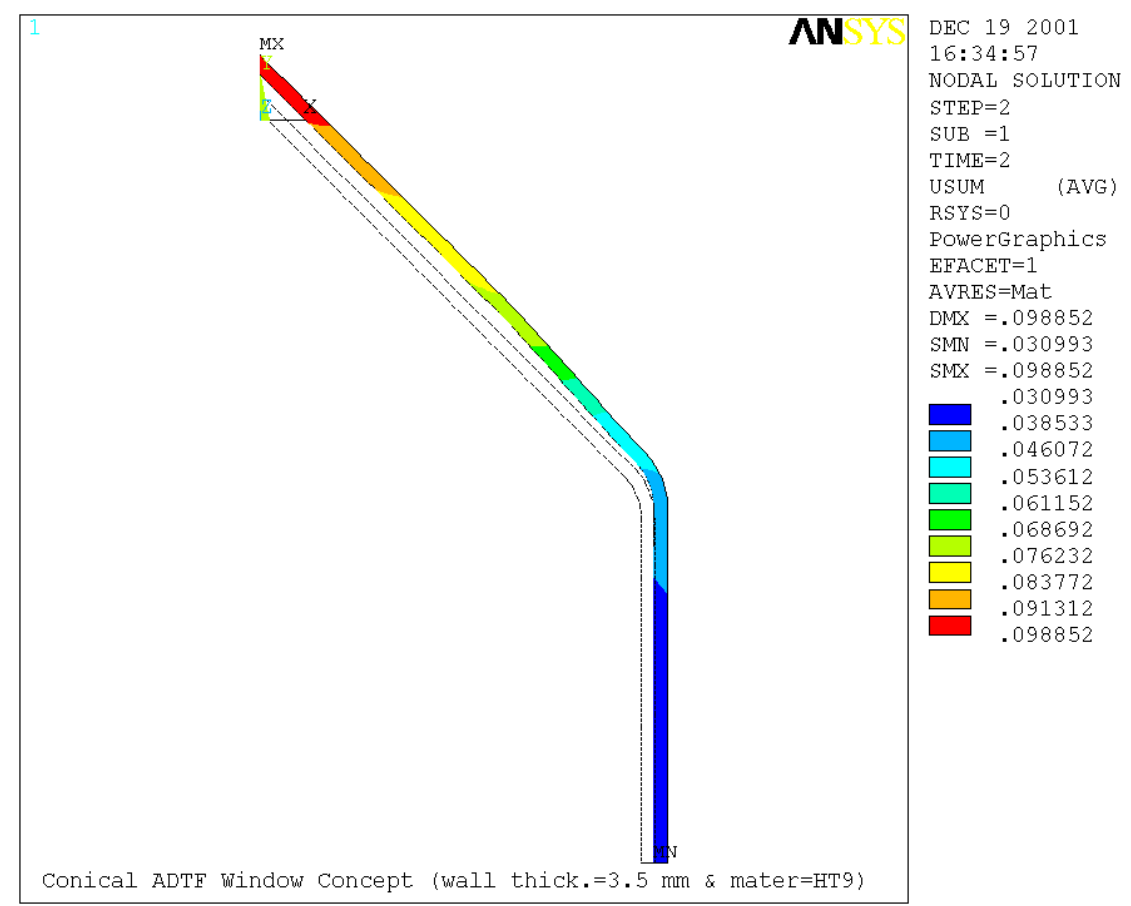

Figure 60. Total displacement $(\mathrm{cm})$ in the $3.5-\mathrm{mm}$-wall conical beam window (magnified 10 times) during the normal operating conditions 


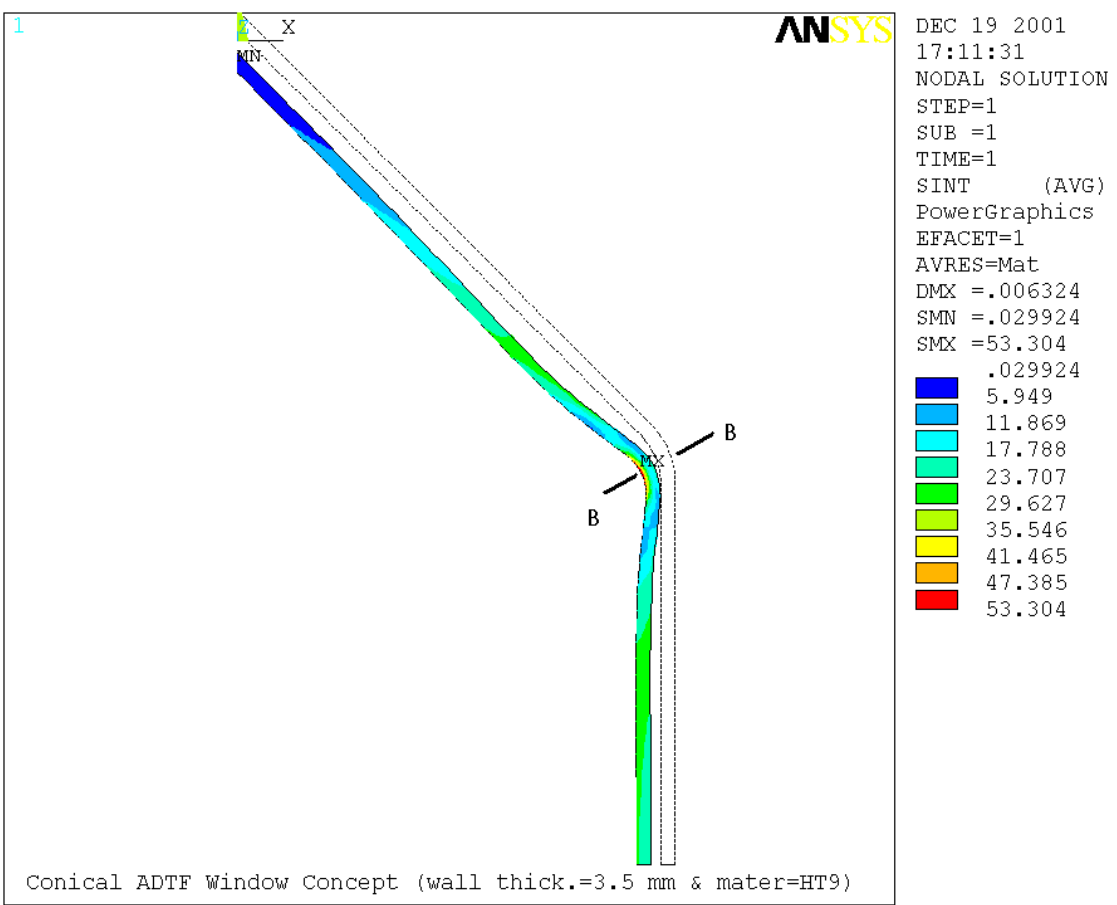

Figure 61. Stress intensity $(\mathrm{Pa})$ in the $3.5-\mathrm{mm}$ conical beam window due to the LBE pressure load

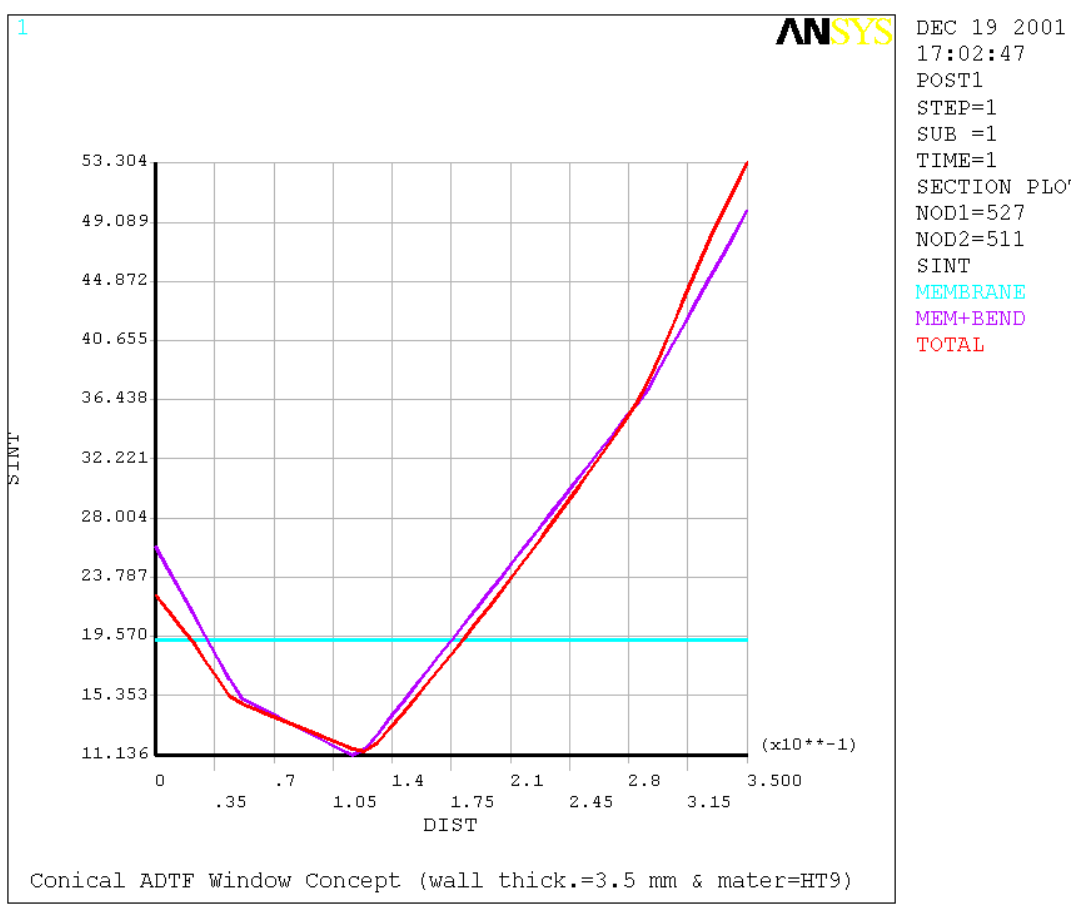

Figure 62. Stress components (MPa) along section B-B shown of Figure 61 measured from the wetted surface due to the LBE pressure load 


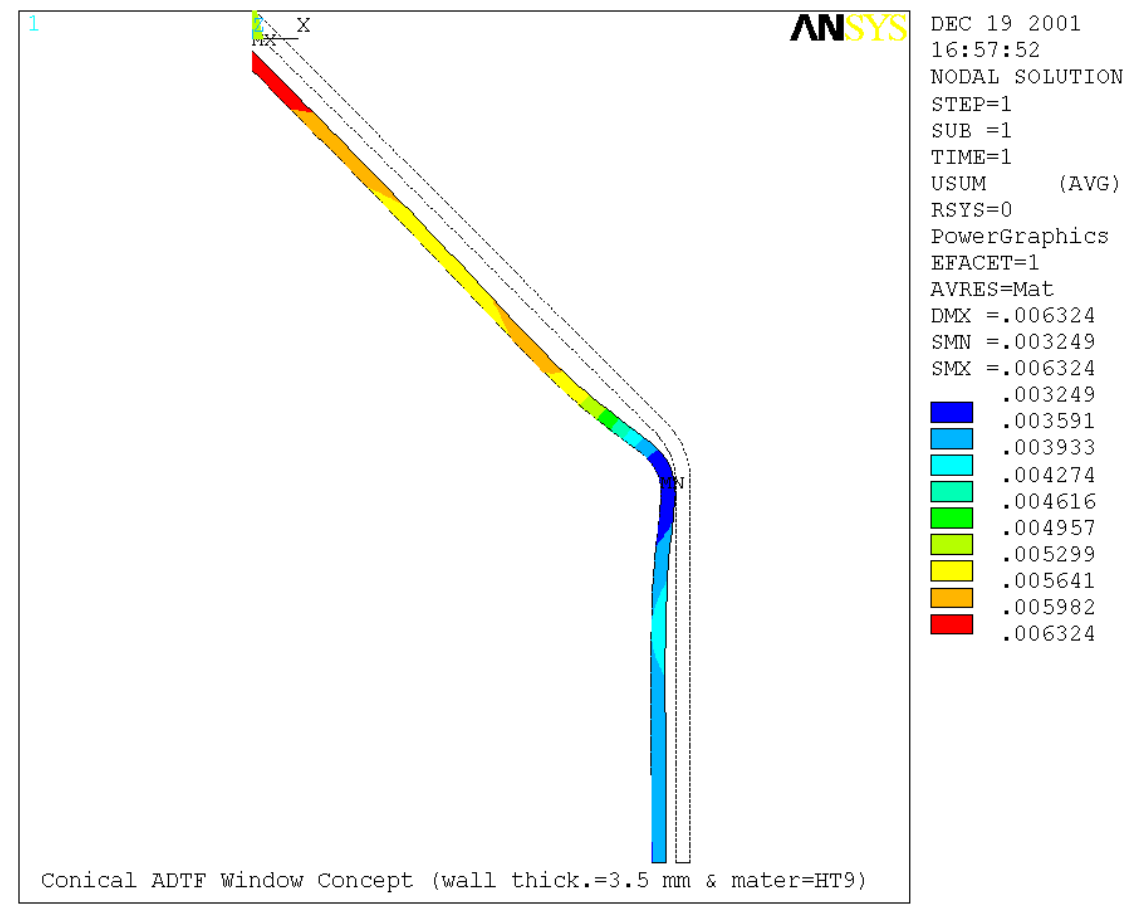

Figure 63. Total displacement $(\mathrm{cm})$ in the 3.5-mm-wall conical beam window (magnified 100 times) due to the LBE pressure load
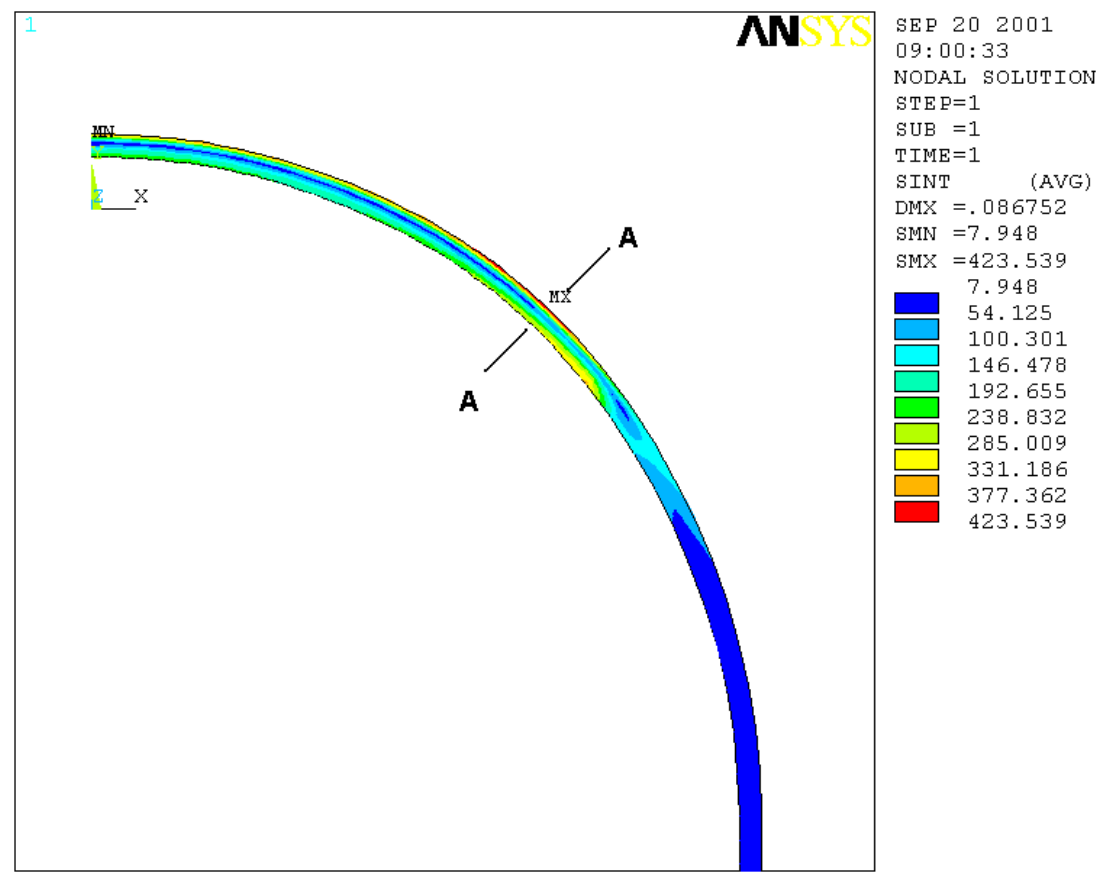

Figure 64. Stress intensity $(\mathrm{Pa})$ in the $3.5-\mathrm{mm}$ hemi-spherical beam window during the normal operating conditions 


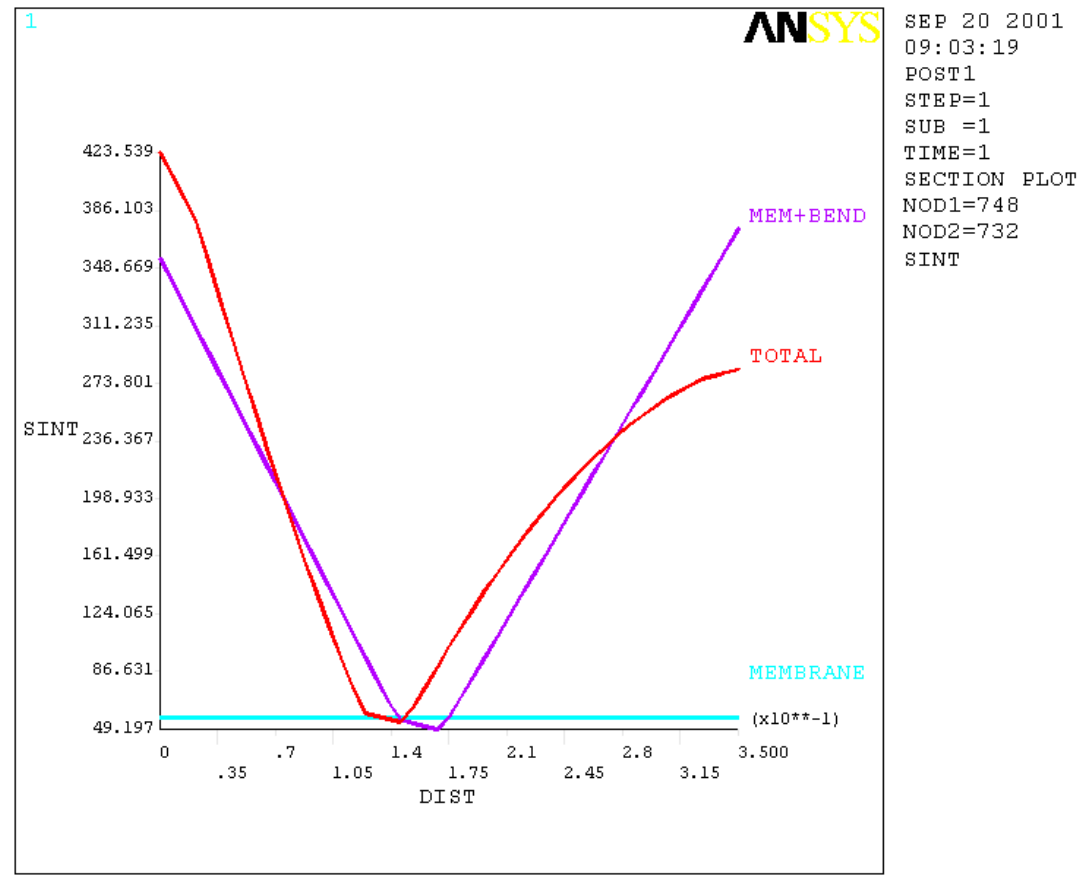

Figure 65. Stress components (MPa) along section A-A shown of Figure 64 measured from the wetted surface during the normal operating conditions

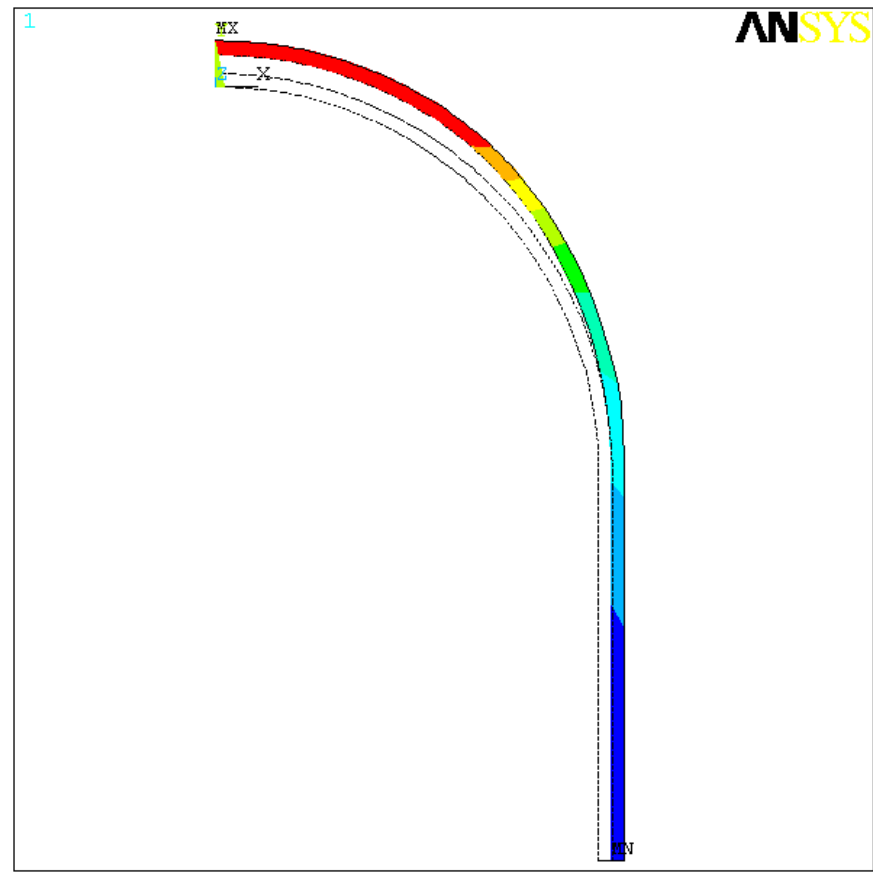

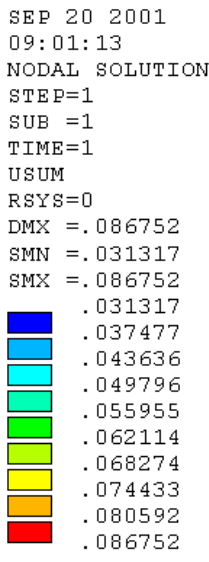

Figure 66. Total displacement $(\mathrm{cm})$ in the $3.5-\mathrm{mm}$ hemi-spherical beam window (magnified 10 times) during the normal operating conditions 


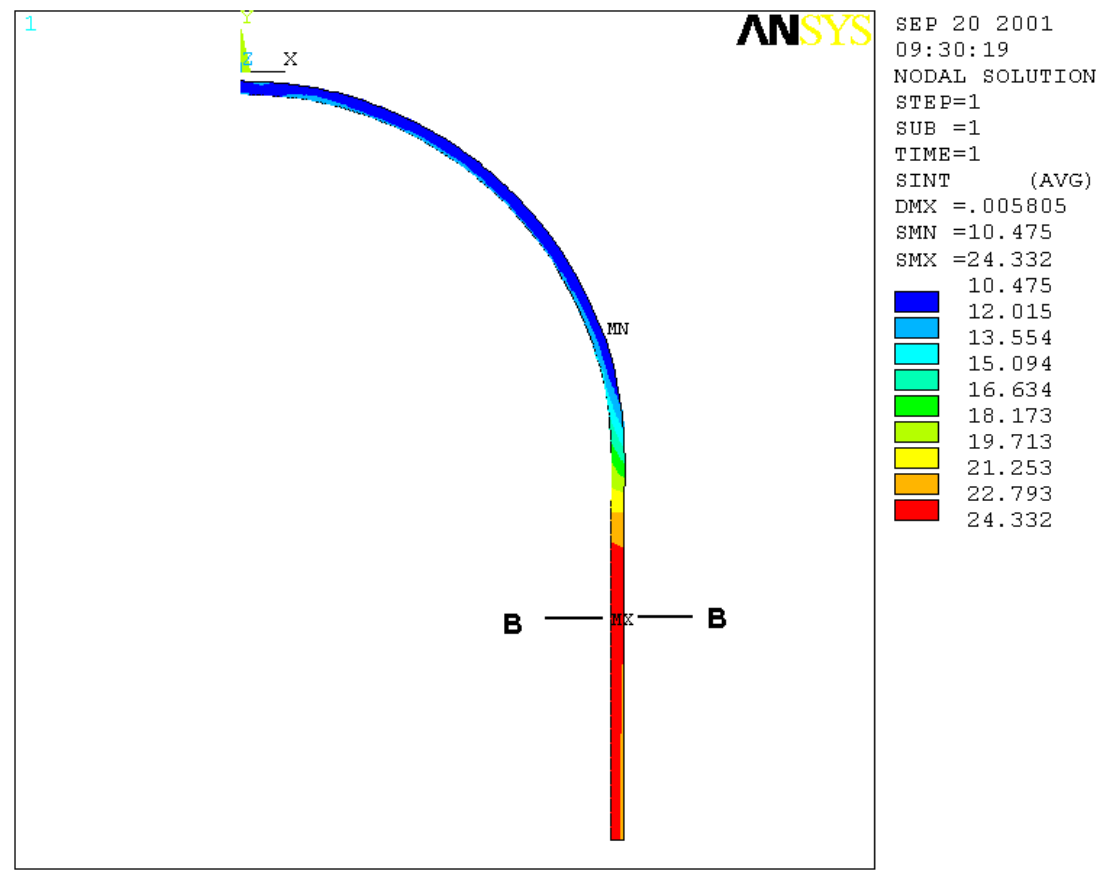

Figure 67. Stress intensity $(\mathrm{Pa})$ in the $3.5-\mathrm{mm}$ hemi-spherical beam window due to the LBE pressure load

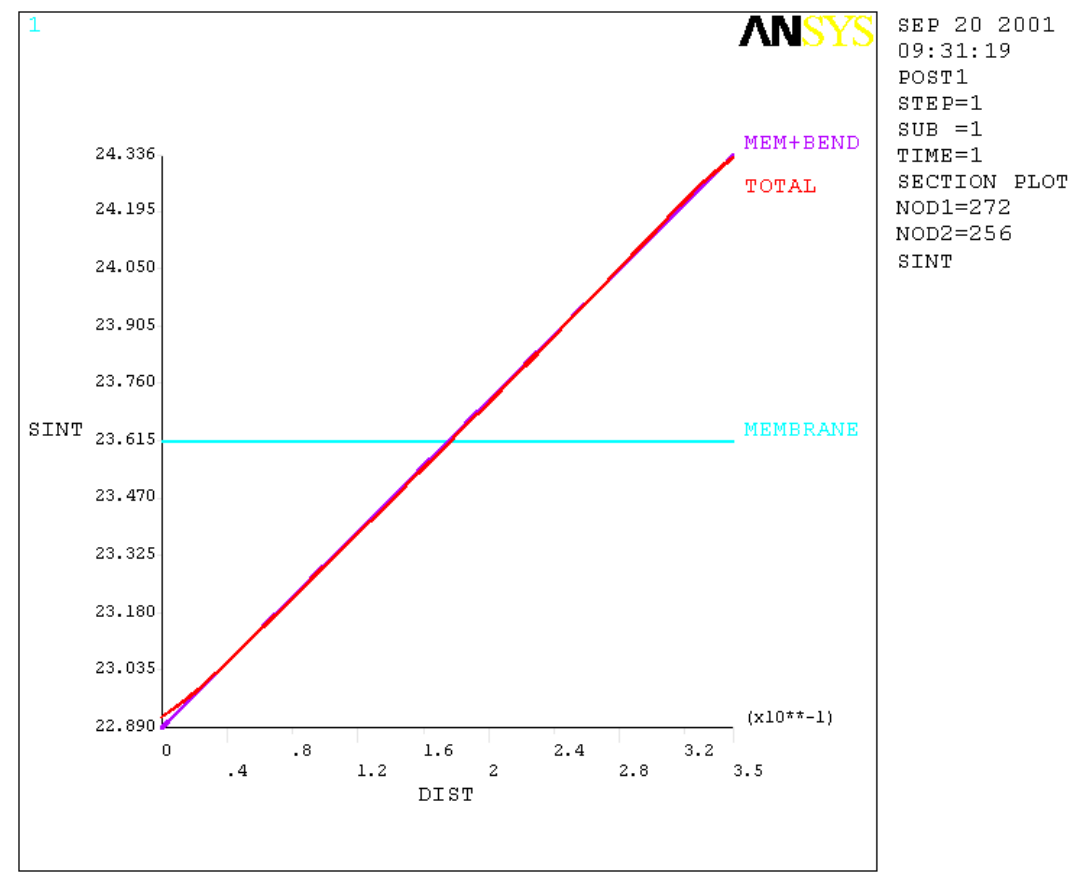

Figure 68. Stress components (MPa) along section B-B shown of Figure 67 measured from the wetted surface due to the LBE pressure load 


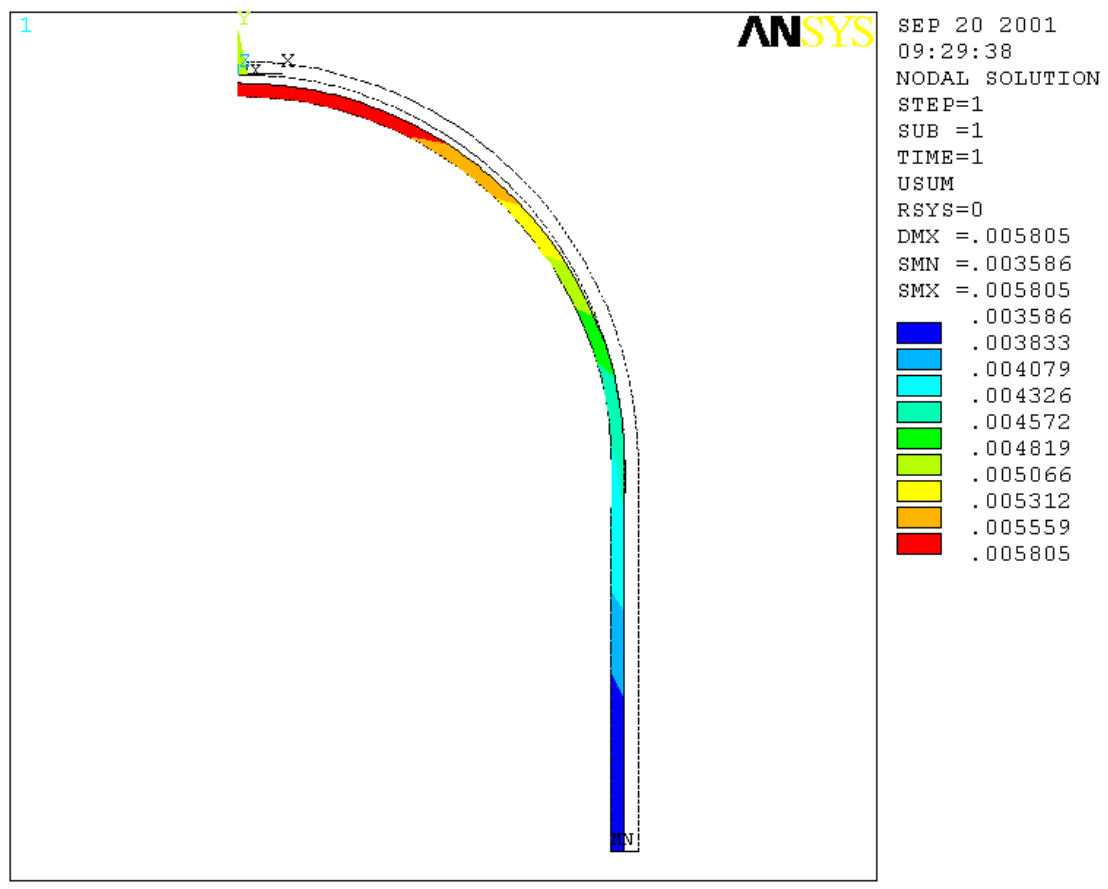

Figure 69. Total displacement $(\mathrm{cm})$ in the $3.5-\mathrm{mm}$ hemi-spherical beam window (magnified 100 times) due to the LBE pressure load

\section{VI.5. Linear buckling analysis}

Linear Buckling Analysis was carried out for the beam tube as a function of the wall thickness for the beam window and the cylindrical section assuming type 316SS. Appendix $\mathrm{C}$ gives the assumptions and the procedure used in the evaluation. The liquid lead-bismuth eutectic generates the external load. The analysis used the methods presented in Article D-3 of the ASME Code Section VIII, Division 2, Shells of Revolution Under External Pressure [10]. The results are summarized in Table 6.

This results shows that for type 316SS, the cylindrical section of the beam tube should be at least $5 \mathrm{~mm}$ thick to meet the ASME code. For the conical and hemispherical beam window configurations, the 3-mm thick window satisfies ASME code. For the same window thickness, the hemi-spherical configuration has a larger margin against buckling than the conical. In this evaluation, the radiation and temperature effects were not included. 

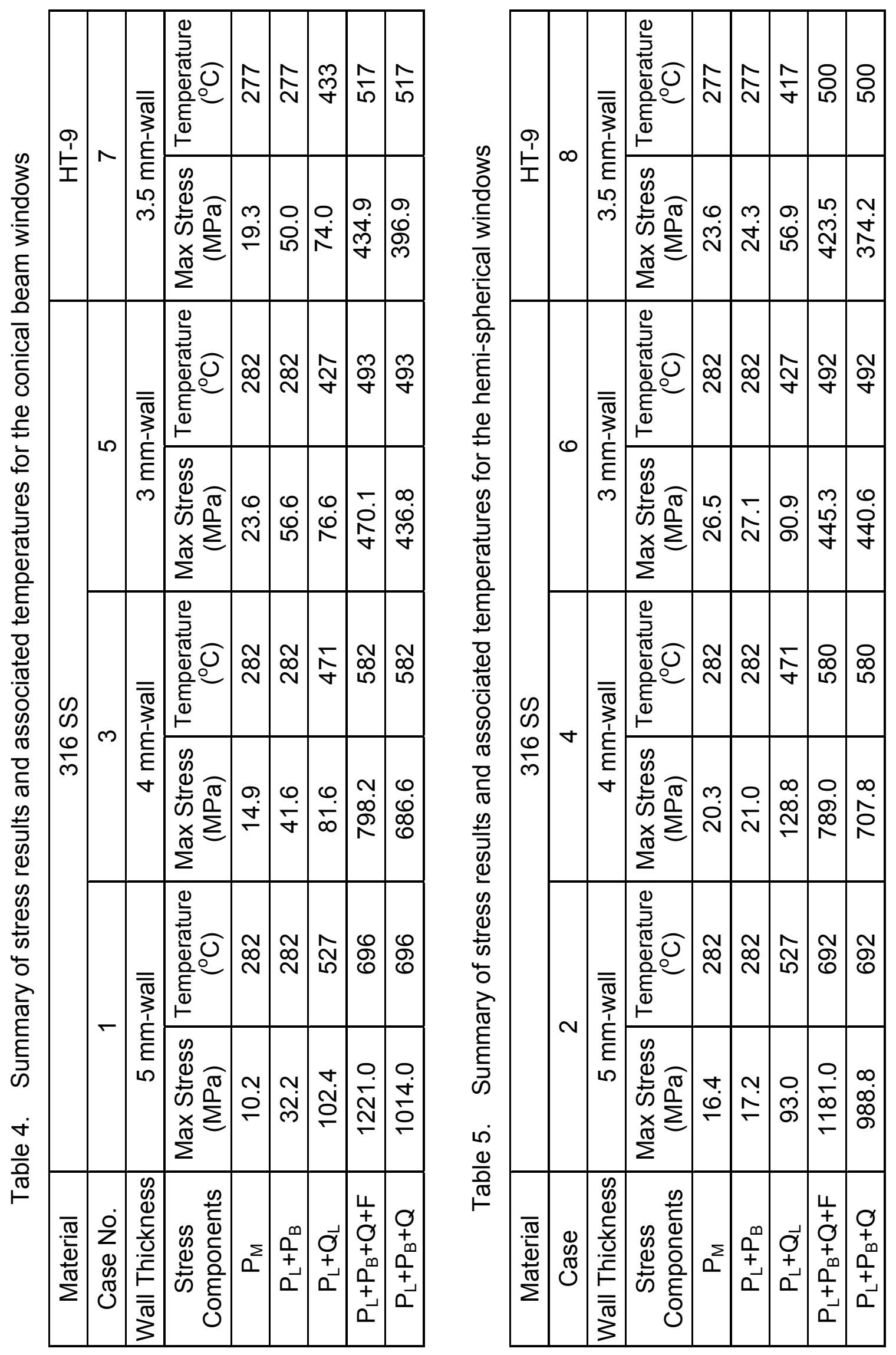
Table 6. Comparison of the allowable external pressure from ASME code to the LBE pressure load

\begin{tabular}{|c|c|c|c|c|}
\hline $\begin{array}{c}\text { Wall Thickness } \\
(\mathrm{mm})\end{array}$ & Beam Tube Section & $\begin{array}{c}\mathrm{P}_{\text {allowed }}(\mathrm{MPa}) \\
\text { SS316 }\end{array}$ & Tavg $\left({ }^{\circ} \mathrm{C}\right)$ & $\begin{array}{c}\text { Design Margin } \\
\left(\mathrm{P}_{\text {allowed }} / 0.79\right)\end{array}$ \\
\hline \multirow{2}{*}{5} & Conical window & 1.544 & 527 & 1.95 \\
\cline { 2 - 5 } & Spherical Window & 3.119 & 527 & 3.95 \\
\hline \multirow{2}{*}{4} & Conical window & 1.288 & 471 & 1.63 \\
\cline { 2 - 5 } & Spherical Window & 2.587 & 471 & 3.27 \\
\hline \multirow{2}{*}{3} & Conical window & 0.975 & 427 & 1.23 \\
\cline { 2 - 5 } & Spherical Window & 1.921 & 427 & 2.43 \\
\hline 5 & $8 m-l o n g$ Cylinder & 1.543 & 277 & 1.95 \\
\hline 4 & $8 m-l o n g$ Cylinder & 0.496 & 277 & 0.63 \\
\hline 3 & $8 m-l o n g$ Cylinder & 0.372 & 277 & 0.47 \\
\hline
\end{tabular}

\section{VI.6. Nonlinear buckling analysis}

Non-linear buckling analysis was carried out for the HT-9 beam tube with spherical beam window. Based on the initial results obtained from the linear buckling analysis presented above and the stress analysis during normal operation, the thickness of the different sections of the beam tube was defined. The beam window thickness is $3.5 \mathrm{~mm}$ and the wall thickness of the cylindrical section is $5 \mathrm{~mm}$. This beam tube configuration was used for the nonlinear finite element buckling analysis to define the critical buckling load. In the finite element model, the $3.5 \mathrm{~mm}$ spherical beam window with $5 \mathrm{~mm}$ thick wall cylindrical section was modeled with 4-node shell elements (ANSYS Shell 181) as shown in Figure 70. In the finite element model, an effective length of $2.1 \mathrm{~m}$ is used for the beam tube instead of the whole length, which is adequate according to Article D-3, Figure $\mathrm{G}$ of Reference 10. The complete ANSYS input file is enclosed in the Appendix D. The transition from the $3.5 \mathrm{~mm}$ to $5 \mathrm{~mm}$ was made over $20-\mathrm{mm}$ length. At the open end of the beam tube, the three translations are constrained and the normal operating temperature distribution is used for the finite element model. A uniform external pressure of $10 \mathrm{MPa}$ was applied gradually during the solution process. Also, a small percentage of the first linear buckling mode shape is added to the model as an initial geometrical imperfection to obtain the critical buckling load. The magnitude of the external pressure load causing the structure to become unstable represents the first critical buckling load. The influence of irradiation on the critical buckling load was evaluated by running the analysis with the unirradiated and irradiated HT-9 and the stress-strain data used in the analyses are shown in Figures 71 and 72 , respectively. 


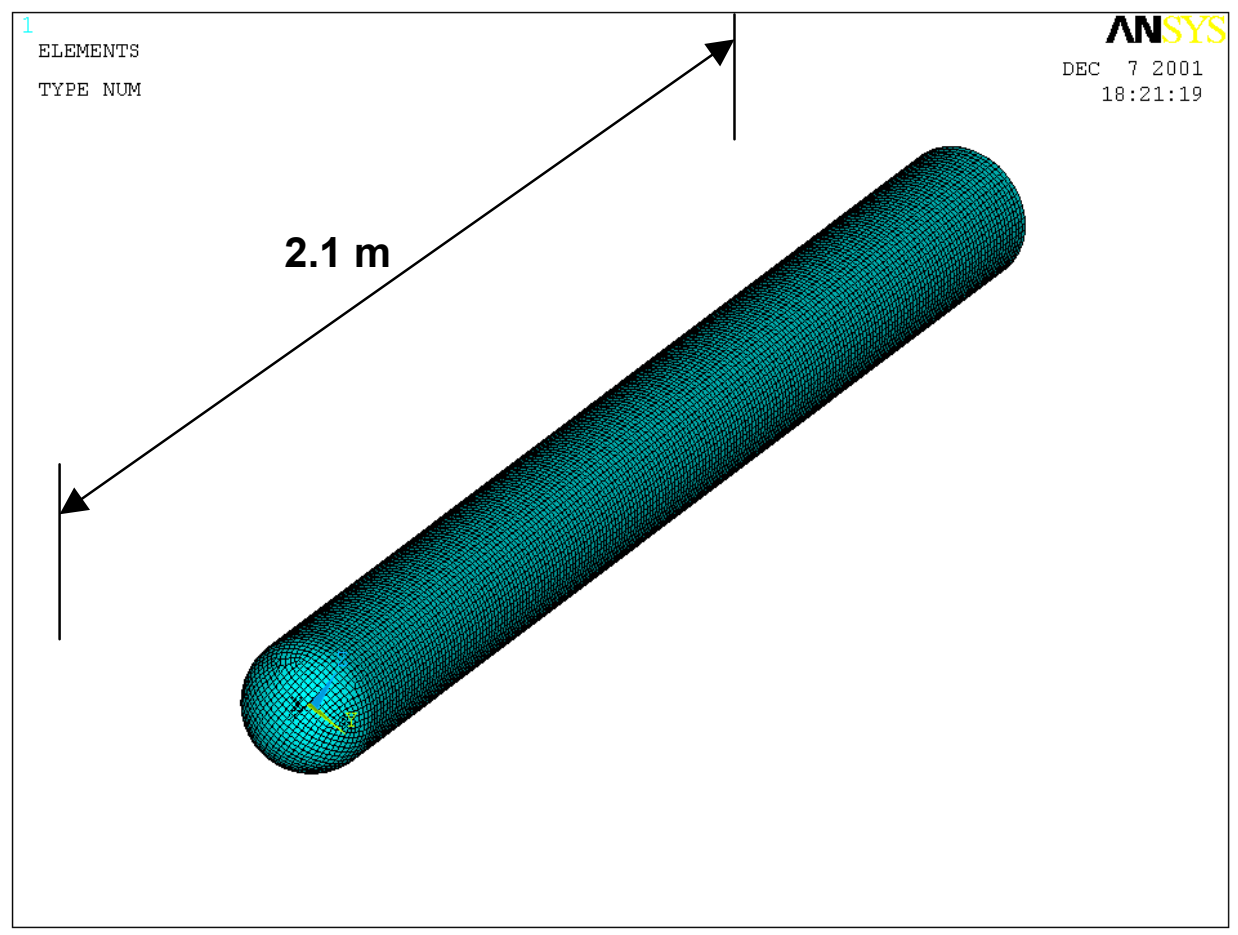

Figure 70. Finite element model of the beam tube with hemi-spherical beam window

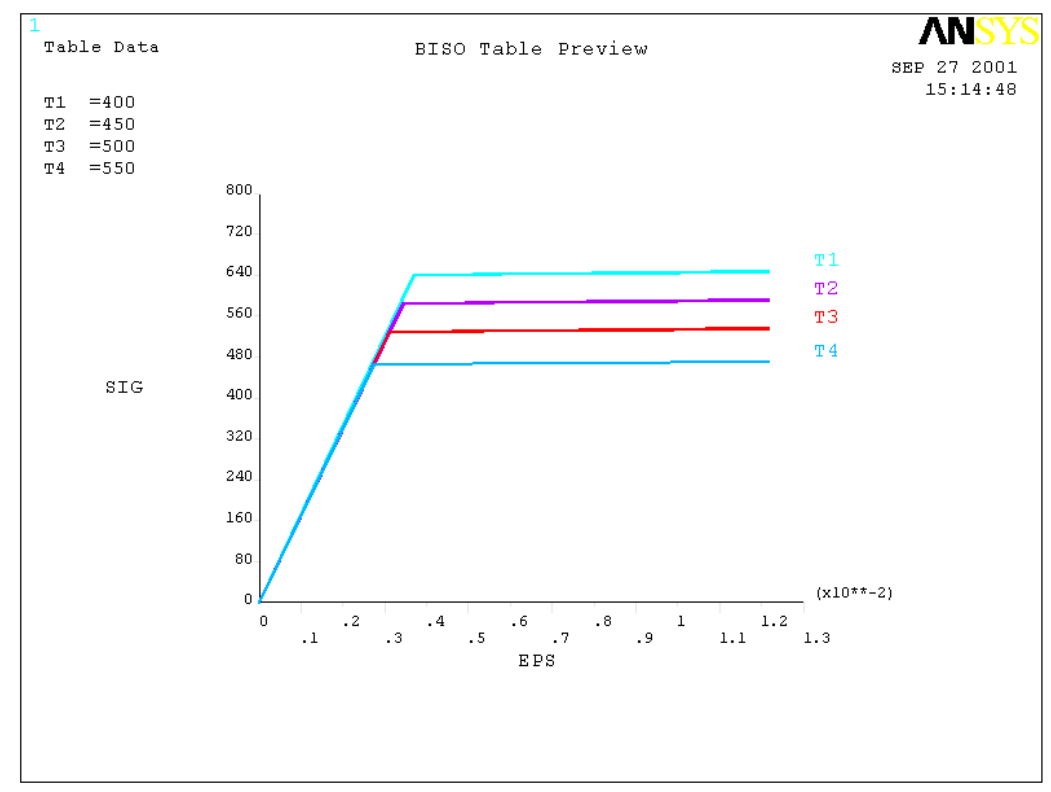

Figure 71. Unirradiated HT-9 stress-strain bilinear curves for at different temperatures 


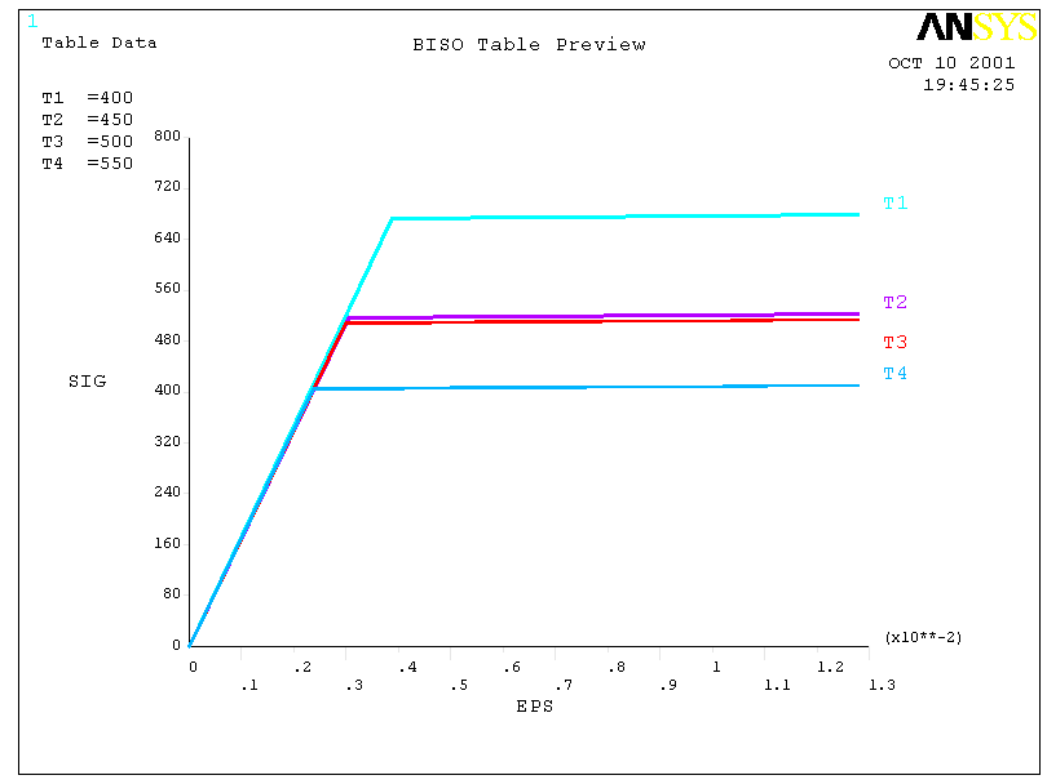

Figure 72. Irradiated HT-9 stress-strain bilinear curves with 25 dpa at different temperatures

The results show a large safety margin against buckling for the beam tube under consideration for both unirradiated and irradiated HT-9. The critical load levels for those two cases are 5.64 and 5.74MPa, respectively, which are much higher than the working external pressure of $0.79 \mathrm{MPa}$. The relative displacement of the beam tube from the first buckling mode is shown in Figure 73 for the unirradiated HT-9. The analysis shows that the beam tube has a large margin against buckling under the normal loading conditions. The total displacement and the total stress intensity due to the critical load of $5.74 \mathrm{MPa}$ are shown in Figures 74 and 75 for the irradiated HT-9 with 25 dpa, respectively.

\section{VI.7. Comparison of the calculated and the allowable stresses}

The Supplemental Structural Design Requirements [2] contains structural design rules for the APT target and blanket components. These rules consider the irradiation affects on the material properties, which are not included in the ASME Code. Irradiation conditions similar to the APT target are expected in the beam tube, however the operating temperature will be higher than that of the APT target. The material database of the APT target-blanket covers only the temperature range of 80 to $200{ }^{\circ} \mathrm{C}$ [11]. Therefore, other databases covering higher temperatures were considered for the analyses, mainly fission and fusion databases. These databases need to be confirmed for higher energy neutrons and protons expected during the operation. 


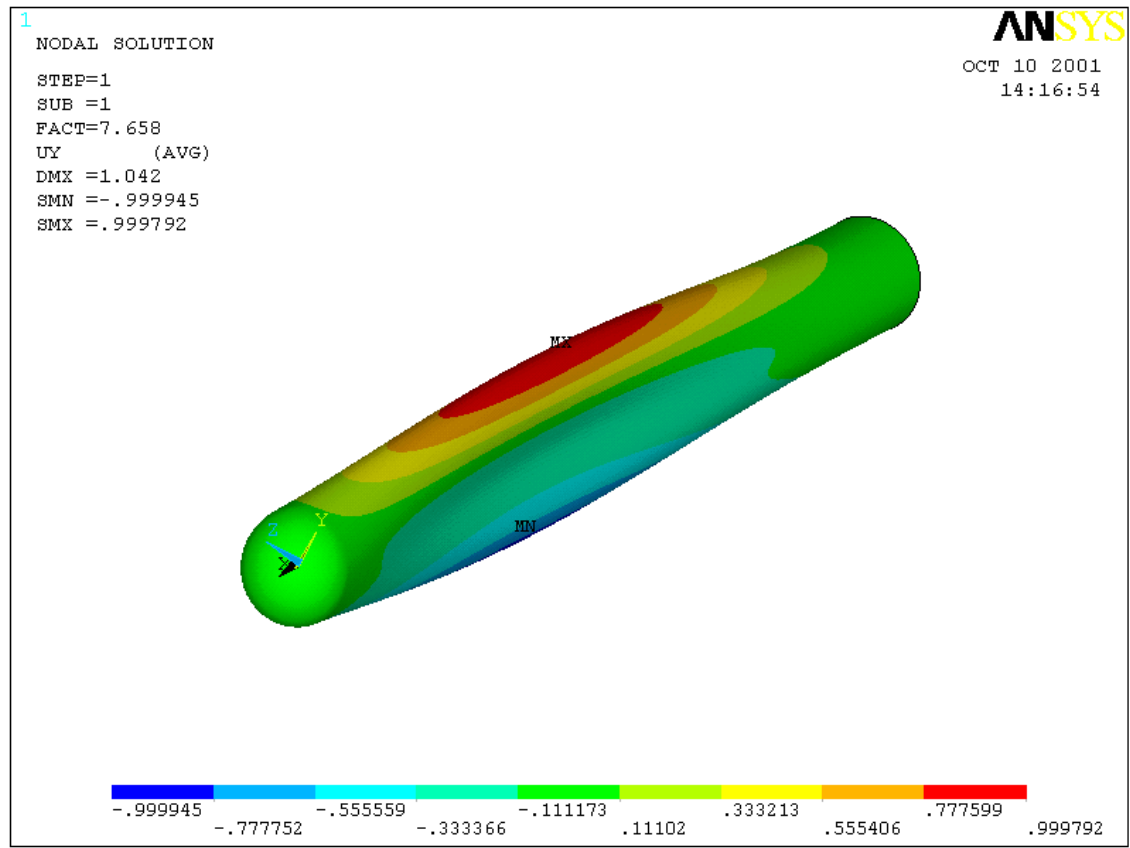

Figure 73. Relative displacement from the first buckling mode

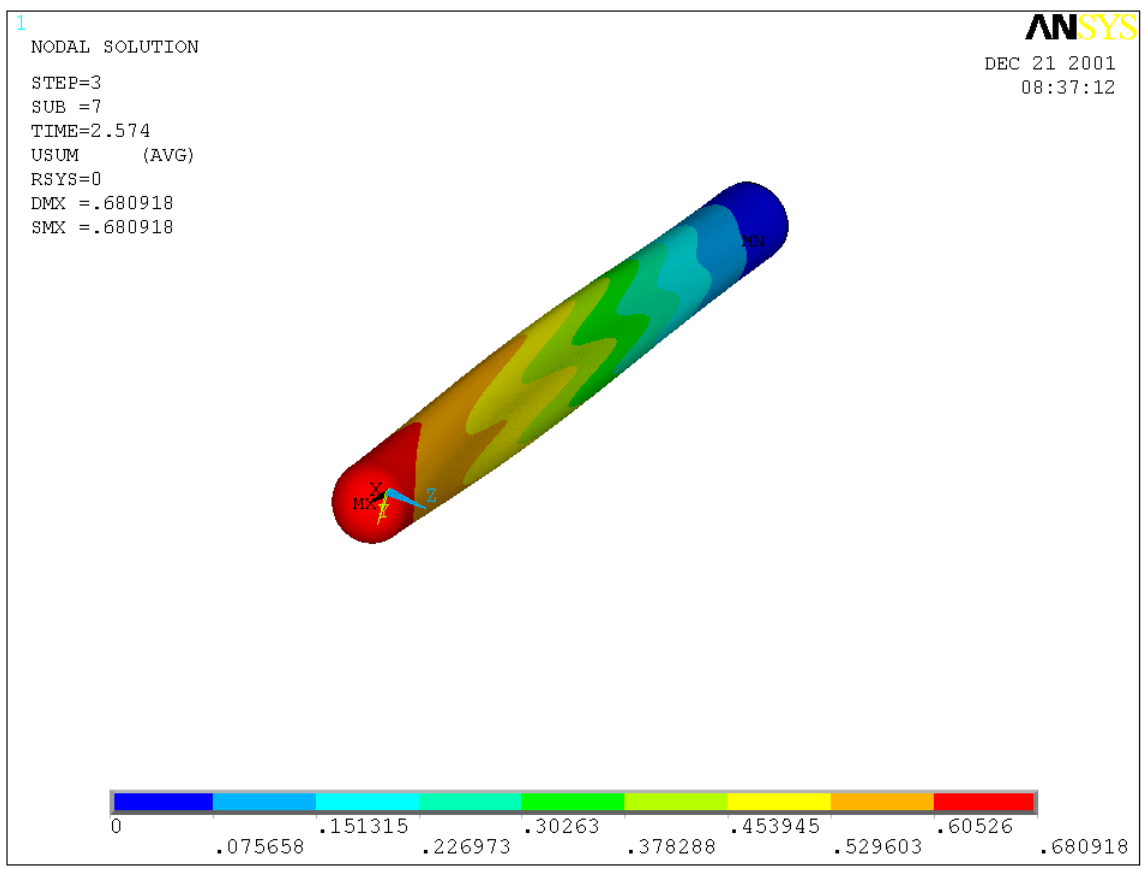

Figure 74. Total displacement $(\mathrm{cm})$ just before the structure becomes unstable at 5.74 MPa using irradiated HT-9 with 25 dpa 


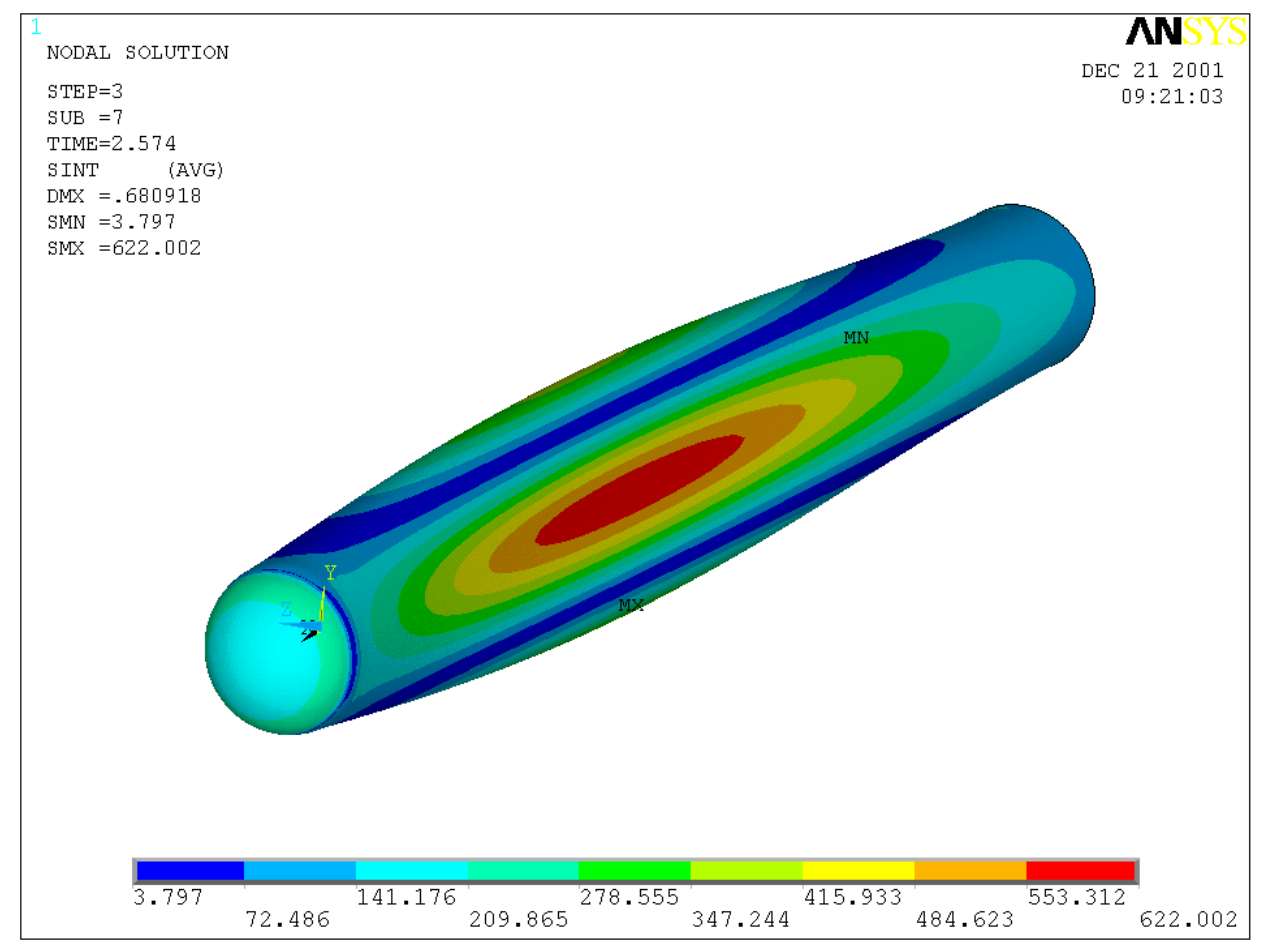

Figure 75. Total Stress Intensity (MPa) contour plot for external pressure of $5.74 \mathrm{MPa}$ using irradiated HT-9 with 25 dpa

Unirradiated HT-9 has very low ductility, the minimum uniform elongation is $\sim 2.5 \%$. Therefore it is reasonable to assume that small fluence will reduce the uniform elongation below $2 \%$. The allowable HT-9 stresses were calculated assuming no ductility left due to irradiation effects. The calculated allowable HT-9 stresses are given in Table 7. Appendix $\mathrm{E}$ contains the explanation of the basic assumptions used for calculating these allowable stresses.

Table 7. HT-9 allowable stresses for fluence up to $72 \mathrm{dpa}$

\begin{tabular}{|c|c|c|c|}
\hline Temp $^{\circ} \mathrm{C}$ & 371 & 450 & 1022 \\
\hline $\mathrm{S}_{\mathrm{m}}$ & 180.6 & 204.6 & 160.1 \\
\hline $\mathrm{S}_{\mathrm{e}}$ & 180.6 & 204.6 & 160.1 \\
\hline $\mathrm{S}_{\mathrm{d} 2}$ & 361.2 & 409.2 & 320.1 \\
\hline
\end{tabular}

The calculated stresses for the $3.5 \mathrm{~mm}$ wall thickness for the conical and the spherical beam windows at the appropriate temperature for each stress component are given in Tables 8 and 9. Also, the allowable stress for each stress component is given 
to compare with the calculated values. All the stress values are less than the allowable stresses except the $\left(P_{L}+P_{B}+Q\right)$ stress component for the conical window geometry, which slightly exceeds the allowable stress $\left(S_{d 2}\right)$. Reducing the thickness to $3 \mathrm{~mm}$ instead of the $3.5 \mathrm{~mm}$ can satisfy this stress component. The hemi-spherical window satisfies all allowable stresses.

Table 8. Calculated stresses and HT-9 allowable stresses for the $3.5 \mathrm{~mm}$ conical beam window

\begin{tabular}{|c|c|c|c|c|}
\hline $\begin{array}{c}\text { Stress } \\
\text { Component }\end{array}$ & $\begin{array}{c}\text { Allowable } \\
\text { stress }\end{array}$ & $\begin{array}{c}\text { Calculated } \\
\text { Stress (MPa) }\end{array}$ & $\begin{array}{c}\text { HT-9 } \\
\text { Allowable } \\
\text { Stresses } \\
\text { (MPa) }\end{array}$ & $\begin{array}{c}\text { Temperature } \\
(\mathrm{C})\end{array}$ \\
\hline $\mathrm{P}_{\mathrm{M}}$ & $\mathrm{S}_{\mathrm{m}}$ & 19.3 & $182^{*}$ & 277 \\
\hline $\mathrm{P}_{\mathrm{L}}+\mathrm{P}_{\mathrm{B}}$ & $\mathrm{K}_{\mathrm{eff}} \mathrm{S}_{\mathrm{m}}$ & 50.0 & $-^{* *}$ & 277 \\
\hline $\mathrm{P}_{\mathrm{L}}+\mathrm{Q}_{\mathrm{L}}$ & $\mathrm{S}_{\mathrm{e}}$ & 74.0 & 182 & 433 \\
\hline $\mathrm{P}_{\mathrm{L}}+\mathrm{P}_{\mathrm{B}}+\mathrm{Q}+\mathrm{F}$ & $\mathrm{S}_{\mathrm{d} 1}$ & 434.9 & -- $^{* * *}$ & 517 \\
\hline $\mathrm{P}_{\mathrm{L}}+\mathrm{P}_{\mathrm{B}}+\mathrm{Q}$ & $\mathrm{S}_{\mathrm{d} 2}$ & 396.9 & 363 & 517 \\
\hline
\end{tabular}

* The allowable is calculated at the maximum temperature $(433 \mathrm{C})$ to be on the conservative side since the $S_{m}$ value is not available at $277 \mathrm{C}$

** Larger or equal to Sm

*** Larger than $\mathrm{S}_{\mathrm{d} 2}$

Table 9. Calculated stresses and HT-9 allowable stresses for the $3.5 \mathrm{~mm}$ spherical beam window

\begin{tabular}{|c|c|c|c|c|}
\hline $\begin{array}{c}\text { Stress } \\
\text { Component }\end{array}$ & $\begin{array}{c}\text { Allowable } \\
\text { stress }\end{array}$ & $\begin{array}{c}\text { Calculated } \\
\text { Stress (MPa) }\end{array}$ & $\begin{array}{c}\mathrm{HT}-9 \\
\text { Allowable } \\
(\mathrm{MPa})\end{array}$ & $\begin{array}{c}\text { Temperature } \\
\left({ }^{\circ} \mathrm{C}\right)\end{array}$ \\
\hline $\mathrm{P}_{\mathrm{M}}$ & $\mathrm{S}_{\mathrm{m}}$ & 23.6 & $181^{*}$ & 277 \\
\hline $\mathrm{P}_{\mathrm{L}}+\mathrm{P}_{\mathrm{B}}$ & $\mathrm{K}_{\mathrm{eff}} \mathrm{S}_{\mathrm{m}}$ & 24.3 & $-^{* *}$ & 277 \\
\hline $\mathrm{P}_{\mathrm{L}}+\mathrm{Q}_{\mathrm{L}}$ & $\mathrm{S}_{\mathrm{e}}$ & 56.9 & 181 & 417 \\
\hline $\mathrm{P}_{\mathrm{L}}+\mathrm{P}_{\mathrm{B}}+\mathrm{Q}+\mathrm{F}$ & $\mathrm{S}_{\mathrm{d} 1}$ & 423.5 & $-^{* * *}$ & 500 \\
\hline $\mathrm{P}_{\mathrm{L}}+\mathrm{P}_{\mathrm{B}}+\mathrm{Q}$ & $\mathrm{S}_{\mathrm{d} 2}$ & 374.2 & 386 & 500 \\
\hline
\end{tabular}

* The allowable is calculated at the maximum temperature $(417 \mathrm{C})$ to be on the conservative side since the $S_{m}$ value is not available at $277 \mathrm{C}$

** Larger or equal to $\mathrm{Sm}$

*** Larger than $\mathrm{S}_{\mathrm{d} 2}$ 


\section{VI.8. Stress analysis conclusions and recommendations}

The stress analysis reached the following recommendations and conclusions:

1. The beam tube with the $3.5-\mathrm{mm}$ hemi-spherical window and the $5-\mathrm{mm}$ wall thickness satisfies the structural design rules for irradiated material.

2. The structural analyses used allowable stresses for Irradiated HT-9 with 72 dpa, which allow the target to operate more than full power year.

3. The material database used in the analysis need to be confirmed to account for the high-energy neutrons and protons expected during the operation.

4. The maximum stresses occur in the beam window at the edge of the beam footprint, which can be reduced by smoothing the beam profile at the edge.

5. The existing HT-9 database does not provide the necessary information to perform the analysis as a function of the operating fluence or at higher fluence. Further experiments are required to defining the allowable stresses at high fluence, which may allow the target to operate beyond the 72 dpa used in the current analysis.

\section{Target material radiological analyses}

Radiological analyses have been performed for the LBE reference target design of the ADTF. The analyses are based on the MCNPX model developed for the physics analyses, coupled with the ORIGEN2-S code for the evaluation of isotopic production/destruction and decay. The MCNPX model is divided into 7 cells as shown in Figure 76. Table 10 shows the details of the materials used in the 7 regions. The cell numbers in Table 10 match the red numbers of Figure 76 . Figure 77 shows an expanded section of Figure 76 so one can observe how the system fits together. The proton beam ( $600 \mathrm{MeV}, 8.33 \mathrm{~mA}, 8.143 \mathrm{~cm}$ radius) enters in cell 1 and strikes cell 2 in the direction of cell 3 .

With this geometry, cell 3 receives most of the beam power in the lower section, which is surrounded by cell 5 . However, cell 3 also extends to the top of cell 7 . The fraction of cell 3 that takes the beam is only $13.76 \%$ of the total LBE inventory in the model. Therefore cell 3 was divided into 3 sections: (1) the lower solid cylinder which receives the actual beam; (2) the mid section which is a hollow cylinder between the lower solid cylinder and the top of cell 6; and (3) the upper section which is a hollow cylinder between the top of cell 6 and the top of the sodium. The cells have been labeled 8, 9, and 3, respectively. They are shown in Figure 78 and their relative sizes are summarized in Table 11. Since the proton beam strikes cell 8 in this new scheme, most of the activation will occur there. If the LBE is a flowing liquid target, the radiological inventory must be diluted by the entire inventory of LBE in the facility not just in cells 3,8 and 9 . 


\section{VII.1. Decay power levels}

Since the actual make-up of the LBE can be adjusted over a range of lead and bismuth mixtures, the overall decay power from the LBE is compared to lead and bismuth individually. In this assessment a composition of $44.5 \% \mathrm{~Pb}$ and $55.5 \% \mathrm{Bi}$ was used for the LBE. In accelerator applications, the activation of the target is extremely geometry dependent, so a bare cylinder of lead is compared to a bare cylinder of bismuth and to a bare cylinder of LBE. The cylinders used in this analysis have the same geometry as cell 8 in the model, but had no other surrounding materials. Figure 79 shows a comparison of the buildup of radioisotope decay power for these three materials as a function of irradiation time, up to one year. Also included in this figure is the decay power in the "cell 8", which is the LBE surrounded by the rest of the system: the fuel, reflector, and sodium regions. The difference between the power in "cell 8" and "LBE" on this figure is from particles entering the LBE from the surroundings.

The decay power of the radioactive isotopes after shutdown is plotted in Figure 80. The buildup of the decay power from the other two LBE cells 3 and 9 are shown in Figures 81 and 82 . The maximum power levels that each cell reaches along with the power per gram of material are included in Table 11. If there is no mixing of material, cell 8 reaches a power density of $0.133 \mathrm{w} / \mathrm{g}$, but when the entire LBE mass of the calculational model is included the overall power density is $1.95 \mathrm{E}-5 \mathrm{w} / \mathrm{g}$. If the total LBE mass of the target loop is considered, this power density will be reduced further.

\section{VII.2. Radioisotope inventories}

In order to understand the make-up of the decay power, we must consider the activity of the radioisotopes. Table 12 shows, for 11 different irradiation times, the top 20 radioisotopes (by activity) for cell 8 . Table 13 is the same as Table 12, but for cell 9 , and Table 14 likewise for cell 3. If we look at the shutdown inventory of these three cells, we note that cells 3 and 9 are dominated by $\mathrm{Bi}-210$, Po-210, and Pb-207m. In cell 3 these three isotopes account for $96 \%$ of the total activity and in cell 9 they account of $84 \%$ of the total activity. However, in cell 8 , they account for $12 \%$ of the total activity. These three isotopes are most probably produced by neutron interactions. The other isotopes shown for cell 8 are most likely due to the proton interactions. The total activity and specific activity of all isotopes at shutdown are shown in Table 15 for the three cells.

The shutdown activity presents information concerning the maximum heat load and maximum radiological hazard. However, it does not provide any information concerning maintenance, for one must allow the target to decay before it can be approached. The isotope that rapidly becomes the dominant radioisotope during irradiation is $\mathrm{Pb}-207 \mathrm{~m}$, which has a $0.8 \mathrm{sec}$ half-life. It will rapidly decay to $\mathrm{Pb}-207$, which is stable, at shutdown. The minimum time that one will have to wait before the area can be entered will probably be no less than one hour. Therefore Tables 16, 17, and 18 show the activity of the top 20 radioisotopes, by activity, after 1 hour, 8 hours, 1 day, 1 week, 2 weeks, 1 month and $1 / 2$ year of decay time. 


\section{VII.3. Toxicity of inventory}

The calculated radiological toxicity for ingestion and inhalation are shown in Figures 83 and 84 , as a function of irradiation time and in Figures 85 and 86 as a function of decay time for cell 8 . The values for cell 9 were approximately three orders of magnitude lower and for cell 3 approximately four orders of magnitude lower.

\section{VII.4. Dose rate}

The gamma rays dose rate from cell 8 was calculated using the MicroShield V5.05 computer program. MicroShield does not support some of the isotopes that are significant in this problem, so the gamma ray emission rates from the ORIGEN2-S calculation at specific times were used as the inputs. The MicroShield model assumed that the LBE was pure lead with the LBE density. It used cylindrical geometry and the dose rate at one set of points was calculated from the mid plane of the cylinder (in the radial direction), as shown in Figure 87, and the other was from the end flat surfaces of the cylinder as shown in Figure 88. The distances were 1, 30, 60, 90, 120 and $150 \mathrm{~cm}$ from the LBE. No shielding was assumed. It should be noted that if the LBE is a flowing target, the actual dose rate would be reduced by the ratio of the mass of the material that is not struck with the beam. The dose rates in $\mathrm{mR} / \mathrm{hr}$ are shown in Tables 19 and 20 for the six distances and five decay periods.

Table 10. Details of the materials used in the LBE mode

\begin{tabular}{|c|c|c|c|c|}
\hline Cell & Material & Density $(\mathrm{g} / \mathrm{cc})$ & Volume $(\mathrm{cc})$ & Mass $(\mathrm{g})$ \\
\hline 1 & Void & 0.0 & $1.282 \mathrm{E}+05$ & 0.0 \\
\hline 2 & Steel lining & 7.87 & $1.331 \mathrm{E}+04$ & $1.48 \mathrm{E}+05$ \\
\hline 3 & LBE & 10.24 & $1.488 \mathrm{E}+05$ & $1.524 \mathrm{E}+06$ \\
\hline 4 & Steel lining & 7.87 & $2.072 \mathrm{E}+04$ & $1.631 \mathrm{E}+05$ \\
\hline 5 & Fuel-Na-clad & 6.556 & $4.398 \mathrm{E}+04$ & $2.884 \mathrm{E}+05$ \\
\hline 6 & Na-Steel reflector & 6.902 & $2.282 \mathrm{E}+06$ & $1.575 \mathrm{E}+07$ \\
\hline 7 & Na & 8.513 & $4.501 \mathrm{E}+08$ & $3.832 \mathrm{E}+08$ \\
\hline
\end{tabular}

Table 11. Division of the original "Cell 3"

\begin{tabular}{|c|c|c|c|c|c|c|}
\hline Cell & Description & Volume (cc) & Mass (g) & $\begin{array}{c}\text { Fraction of } \\
\text { mass }\end{array}$ & $\begin{array}{c}\text { Max. Power } \\
\text { Level }(\mathrm{kW})\end{array}$ & $\begin{array}{c}\text { Power } \\
\text { Density } \\
(\mathrm{W} / \mathrm{g})\end{array}$ \\
\hline 3 & Top region & $1.12 \mathrm{E}+05$ & $1.14 \mathrm{E}+06$ & 0.7495 & 0.53 & $4.65 \mathrm{E}-4$ \\
\hline 8 & Bottom region & $2.05 \mathrm{E}+04$ & $2.10 \mathrm{E}+05$ & 0.1376 & 27.94 & $1.33 \mathrm{E}-1$ \\
\hline 9 & Mid region & $1.68 \mathrm{E}+04$ & $1.72 \mathrm{E}+05$ & 0.1129 & 1.67 & $9.71 \mathrm{E}-3$ \\
\hline Total & & $1.49 \mathrm{E}+05$ & $1.52 \mathrm{E}+06$ & 1.0000 & & $1.95 \mathrm{E}-5$ \\
\hline
\end{tabular}


Table 12. Top 20 radioisotopes in cell 8 as a function of irradiation time

\begin{tabular}{|c|c|c|c|c|c|c|c|c|c|c|c|}
\hline \multicolumn{3}{|c|}{$1.0 \mathrm{mi}$} & \multicolumn{3}{|c|}{$1.0 \mathrm{hr}$} & \multicolumn{3}{|c|}{$1.0 \mathrm{~d}$} & \multicolumn{3}{|c|}{$3.0 \mathrm{~d}$} \\
\hline Isotope & $\begin{array}{l}\text { Activity } \\
\text { (Ci) }\end{array}$ & $\begin{array}{c}\text { Fraction } \\
\text { of total }\end{array}$ & Isotope & $\begin{array}{l}\text { Activity } \\
\text { (Ci) }\end{array}$ & $\begin{array}{c}\text { Fraction } \\
\text { of total }\end{array}$ & Isotope & $\begin{array}{l}\text { Activity } \\
\text { (Ci) }\end{array}$ & $\begin{array}{c}\text { Fraction } \\
\text { of total }\end{array}$ & Isotope & $\begin{array}{l}\text { Activity } \\
\text { (Ci) }\end{array}$ & $\begin{array}{c}\text { Fraction } \\
\text { of total }\end{array}$ \\
\hline All & $3.20 \mathrm{E}+05$ & & All & $9.33 \mathrm{E}+05$ & & All & $2.02 \mathrm{E}+06$ & & All & $2.41 \mathrm{E}+06$ & \\
\hline pb207m & $2.20 \mathrm{E}+05$ & 0.687 & pb207m & $2.20 \mathrm{E}+05$ & 0.235 & pb207m & $2.20 \mathrm{E}+05$ & 0.109 & pb207m & $2.20 \mathrm{E}+05$ & 0.091 \\
\hline bi207m & $8.96 \mathrm{E}+03$ & 0.028 & pb197 & $2.70 \mathrm{E}+04$ & 0.029 & pb201 & $6.61 \mathrm{E}+04$ & 0.033 & pb201 & $8.09 \mathrm{E}+04$ & 0.034 \\
\hline t1206 & $3.85 E+03$ & 0.012 & t1206 & $2.62 \mathrm{E}+04$ & 0.028 & tl199 & $6.22 \mathrm{E}+04$ & 0.031 & pb203 & $7.98 \mathrm{E}+04$ & 0.033 \\
\hline t|207 & $3.02 \mathrm{E}+03$ & 0.009 & t|207 & $2.24 \mathrm{E}+04$ & 0.024 & t|198 & $5.77 \mathrm{E}+04$ & 0.029 & tl199 & $7.08 \mathrm{E}+04$ & 0.029 \\
\hline pb197 & $1.47 \mathrm{E}+03$ & 0.005 & pb196 & $1.80 \mathrm{E}+04$ & 0.019 & bi204 & $5.31 \mathrm{E}+04$ & 0.026 & bi204 & $6.95 \mathrm{E}+04$ & 0.029 \\
\hline t|207m & $1.43 E+03$ & 0.004 & tl194 & $1.50 \mathrm{E}+04$ & 0.016 & tl197 & $5.12 \mathrm{E}+04$ & 0.025 & pb200 & $6.33 \mathrm{E}+04$ & 0.026 \\
\hline hg188 & $1.28 \mathrm{E}+03$ & 0.004 & bi200 & $1.48 \mathrm{E}+04$ & 0.016 & pb199 & $4.72 \mathrm{E}+04$ & 0.023 & tl198 & $6.19 \mathrm{E}+04$ & 0.026 \\
\hline ir180 & $1.03 E+03$ & 0.003 & pb199 & $1.43 E+04$ & 0.015 & tl196 & $4.54 \mathrm{E}+04$ & 0.022 & t|200 & $5.99 \mathrm{E}+04$ & 0.025 \\
\hline os181 & $9.96 \mathrm{E}+02$ & 0.003 & bi199 & $1.38 \mathrm{E}+04$ & 0.015 & bi203 & $4.42 \mathrm{E}+04$ & 0.022 & bi203 & $5.76 \mathrm{E}+04$ & 0.024 \\
\hline nb 98 & $8.96 \mathrm{E}+02$ & 0.003 & tl193 & $1.35 E+04$ & 0.014 & pb198 & $4.28 \mathrm{E}+04$ & 0.021 & tl197 & $5.14 \mathrm{E}+04$ & 0.021 \\
\hline ir181 & $7.39 \mathrm{E}+02$ & 0.002 & hg190 & $1.34 \mathrm{E}+04$ & 0.014 & bi202 & $3.91 \mathrm{E}+04$ & 0.019 & pb199 & $4.72 \mathrm{E}+04$ & 0.020 \\
\hline nb 99 & $7.23 \mathrm{E}+02$ & 0.002 & tl195 & $1.25 E+04$ & 0.013 & pb200 & $3.77 \mathrm{E}+04$ & 0.019 & t|201 & $4.64 \mathrm{E}+04$ & 0.019 \\
\hline hg189 & $7.13 E+02$ & 0.002 & au188 & $1.25 E+04$ & 0.013 & bi201 & $3.43 E+04$ & 0.017 & tl196 & $4.55 E+04$ & 0.019 \\
\hline ir178 & $7.04 \mathrm{E}+02$ & 0.002 & au189 & $1.22 \mathrm{E}+04$ & 0.013 & hg195 & $3.29 \mathrm{E}+04$ & 0.016 & pb198 & $4.28 \mathrm{E}+04$ & 0.018 \\
\hline nb100 & $6.99 \mathrm{E}+02$ & 0.002 & bi202 & $1.14 \mathrm{E}+04$ & 0.012 & tl195 & $3.09 \mathrm{E}+04$ & 0.015 & hg195 & $4.12 \mathrm{E}+04$ & 0.017 \\
\hline hg187 & $6.91 \mathrm{E}+02$ & 0.002 & bi201 & $1.04 \mathrm{E}+04$ & 0.011 & pb203 & $2.99 \mathrm{E}+04$ & 0.015 & bi202 & $3.91 \mathrm{E}+04$ & 0.016 \\
\hline y 96 & $6.55 \mathrm{E}+02$ & 0.002 & hg191 & $1.03 E+04$ & 0.011 & hg193 & $2.84 \mathrm{E}+04$ & 0.014 & bi206 & $3.60 \mathrm{E}+04$ & 0.015 \\
\hline hg186 & $5.93 E+02$ & 0.002 & au190 & $1.02 \mathrm{E}+04$ & 0.011 & pb197 & $2.78 \mathrm{E}+04$ & 0.014 & bi201 & $3.43 E+04$ & 0.014 \\
\hline tl191 & $5.54 \mathrm{E}+02$ & 0.002 & pb198 & $1.02 \mathrm{E}+04$ & 0.011 & pb196 & $2.70 \mathrm{E}+04$ & 0.013 & tl195 & $3.09 \mathrm{E}+04$ & 0.013 \\
\hline pt182 & $5.27 \mathrm{E}+02$ & 0.002 & os181 & $1.01 \mathrm{E}+04$ & 0.011 & t1206 & $2.63 E+04$ & 0.013 & hg197 & $3.06 \mathrm{E}+04$ & 0.013 \\
\hline
\end{tabular}

\begin{tabular}{|c|c|c|c|c|c|c|c|c|c|c|c|}
\hline \multicolumn{3}{|c|}{$7.0 \mathrm{~d}$} & \multicolumn{3}{|c|}{$14.0 \mathrm{~d}$} & \multicolumn{3}{|c|}{ 30.0d } & \multicolumn{3}{|c|}{ 60.0d } \\
\hline isotope & $\begin{array}{c}\text { Activity } \\
\text { (Ci) }\end{array}$ & $\begin{array}{l}\text { Fraction } \\
\text { of total }\end{array}$ & isotope & $\begin{array}{c}\text { Activity } \\
\text { (Ci) }\end{array}$ & $\begin{array}{c}\text { Fraction } \\
\text { of total }\end{array}$ & isotope & $\begin{array}{c}\text { Activity } \\
\text { (Ci) }\end{array}$ & $\begin{array}{c}\text { Fraction } \\
\text { of total }\end{array}$ & isotope & $\begin{array}{c}\text { Activity } \\
\text { (Ci) }\end{array}$ & $\begin{array}{l}\text { Fraction } \\
\text { of total }\end{array}$ \\
\hline all & $2.67 \mathrm{E}+06$ & & all & $2.84 \mathrm{E}+06$ & & all & $2.97 \mathrm{E}+06$ & & all & $3.05 \mathrm{E}+06$ & \\
\hline pb207m & $2.20 \mathrm{E}+05$ & 0.082 & pb207m & $2.20 \mathrm{E}+05$ & 0.077 & pb207m & $2.19 \mathrm{E}+05$ & 0.074 & pb207m & $2.19 E+05$ & 0.072 \\
\hline pb203 & $1.23 E+05$ & 0.046 & pb203 & $1.38 \mathrm{E}+05$ & 0.048 & pb203 & $1.39 \mathrm{E}+05$ & 0.047 & bi206 & $1.40 \mathrm{E}+05$ & 0.046 \\
\hline tl200 & $8.59 E+04$ & 0.032 & bi206 & $1.04 \mathrm{E}+05$ & 0.037 & bi206 & $1.32 \mathrm{E}+05$ & 0.044 & pb203 & $1.39 \mathrm{E}+05$ & 0.046 \\
\hline tl201 & $8.21 \mathrm{E}+04$ & 0.031 & $t \mid 201$ & $1.01 \mathrm{E}+05$ & 0.035 & t/201 & $1.05 \mathrm{E}+05$ & 0.035 & t/201 & $1.05 E+05$ & 0.034 \\
\hline pb201 & $8.11 E+04$ & 0.030 & tl200 & 8.91E+04 & 0.031 & tl200 & 8.91E+04 & 0.030 & bi205 & 1.01E+05 & 0.033 \\
\hline tl199 & $7.09 \mathrm{E}+04$ & 0.027 & pb201 & $8.11 \mathrm{E}+04$ & 0.029 & bi210 & $8.51 \mathrm{E}+04$ & 0.029 & t1200 & $8.91 \mathrm{E}+04$ & 0.029 \\
\hline bi204 & $7.04 \mathrm{E}+04$ & 0.026 & bi210 & $7.40 \mathrm{E}+04$ & 0.026 & pb201 & $8.11 E+04$ & 0.027 & bi210 & $8.64 E+04$ & 0.028 \\
\hline bi206 & $6.98 E+04$ & 0.026 & tl199 & 7.09E+04 & 0.025 & bi205 & $8.03 E+04$ & 0.027 & pb201 & $8.11 \mathrm{E}+04$ & 0.027 \\
\hline pb200 & $6.98 \mathrm{E}+04$ & 0.026 & bi204 & $7.04 E+04$ & 0.025 & tl199 & $7.10 E+04$ & 0.024 & tl199 & $7.10 \mathrm{E}+04$ & 0.023 \\
\hline tl198 & $6.18 \mathrm{E}+04$ & 0.023 & pb200 & $7.00 \mathrm{E}+04$ & 0.025 & bi204 & $7.04 \mathrm{E}+04$ & 0.024 & bi204 & $7.04 \mathrm{E}+04$ & 0.023 \\
\hline bi203 & $5.84 \mathrm{E}+04$ & 0.022 & tl198 & $6.19 E+04$ & 0.022 & pb200 & $7.00 \mathrm{E}+04$ & 0.024 & pb200 & $7.01 \mathrm{E}+04$ & 0.023 \\
\hline bi210 & $5.36 \mathrm{E}+04$ & 0.020 & bi203 & $5.84 \mathrm{E}+04$ & 0.021 & tl198 & $6.19 E+04$ & 0.021 & tl198 & $6.19 \mathrm{E}+04$ & 0.020 \\
\hline tl197 & $5.14 \mathrm{E}+04$ & 0.019 & hg197 & $5.75 \mathrm{E}+04$ & 0.020 & hg197 & $5.87 \mathrm{E}+04$ & 0.020 & hg197 & $5.89 \mathrm{E}+04$ & 0.019 \\
\hline hg197 & $4.95 \mathrm{E}+04$ & 0.019 & tl197 & $5.14 \mathrm{E}+04$ & 0.018 & bi203 & $5.84 E+04$ & 0.020 & bi203 & $5.84 \mathrm{E}+04$ & 0.019 \\
\hline pb199 & $4.72 \mathrm{E}+04$ & 0.018 & bi205 & $5.08 \mathrm{E}+04$ & 0.018 & tl197 & $5.14 \mathrm{E}+04$ & 0.017 & tl197 & $5.14 E+04$ & 0.017 \\
\hline tl196 & $4.55 \mathrm{E}+04$ & 0.017 & pb199 & $4.72 \mathrm{E}+04$ & 0.017 & pb199 & $4.72 \mathrm{E}+04$ & 0.016 & pb199 & $4.72 \mathrm{E}+04$ & 0.015 \\
\hline pb198 & $4.28 \mathrm{E}+04$ & 0.016 & tl196 & $4.55 \mathrm{E}+04$ & 0.016 & tl196 & $4.55 \mathrm{E}+04$ & 0.015 & tl196 & \begin{tabular}{|l}
$4.55 \mathrm{E}+04$ \\
\end{tabular} & 0.015 \\
\hline hg195 & $4.14 \mathrm{E}+04$ & 0.015 & pb198 & $4.28 \mathrm{E}+04$ & 0.015 & pb198 & $4.28 E+04$ & 0.014 & pb198 & $4.28 \mathrm{E}+04$ & 0.014 \\
\hline bi202 & $3.91 \mathrm{E}+04$ & 0.015 & hg195 & $4.14 \mathrm{E}+04$ & 0.015 & hg195 & $4.14 \mathrm{E}+04$ & 0.014 & hg195 & $4.15 E+04$ & 0.014 \\
\hline bi201 & $3.43 E+04$ & 0.013 & bi202 & $3.91 \mathrm{E}+04$ & 0.014 & bi202 & $3.91 \mathrm{E}+04$ & 0.013 & bi202 & $3.91 \mathrm{E}+04$ & 0.013 \\
\hline
\end{tabular}


Table 12. Top 20 radioisotopes in cell 8 as a function of irradiation time (Continued)

\begin{tabular}{|c|c|c|c|c|c|c|c|c|}
\hline \multicolumn{3}{|c|}{$90.0 \mathrm{~d}$} & \multicolumn{3}{|c|}{$182.0 \mathrm{~d}$} & \multicolumn{3}{|c|}{$1.0 \mathrm{yr}$} \\
\hline isotope & $\begin{array}{c}\text { Activity } \\
\text { (Ci) }\end{array}$ & $\begin{array}{c}\text { Fraction } \\
\text { of total }\end{array}$ & isotope & $\begin{array}{c}\text { Activity } \\
\text { (Ci) }\end{array}$ & $\begin{array}{c}\text { Fraction } \\
\text { of total }\end{array}$ & isotope & $\begin{array}{c}\text { Activity } \\
\text { (Ci) }\end{array}$ & $\begin{array}{c}\text { Fraction } \\
\text { of total }\end{array}$ \\
\hline all & $3.09 E+06$ & & all & $3.15 E+06$ & & all & $3.22 \mathrm{E}+06$ & \\
\hline pb207m & $2.19 \mathrm{E}+05$ & 0.071 & pb207m & $2.19 \mathrm{E}+05$ & 0.070 & pb207m & $2.19 \mathrm{E}+05$ & 0.068 \\
\hline bi206 & $1.40 \mathrm{E}+05$ & 0.045 & bi206 & $1.40 \mathrm{E}+05$ & 0.045 & bi206 & $1.41 \mathrm{E}+05$ & 0.044 \\
\hline pb203 & $1.39 E+05$ & 0.045 & pb203 & $1.40 \mathrm{E}+05$ & 0.044 & pb203 & $1.40 \mathrm{E}+05$ & 0.043 \\
\hline bi205 & $1.06 \mathrm{E}+05$ & 0.034 & bi205 & $1.08 \mathrm{E}+05$ & 0.034 & bi205 & $1.08 \mathrm{E}+05$ & 0.034 \\
\hline tl201 & $1.05 \mathrm{E}+05$ & 0.034 & tl201 & $1.05 \mathrm{E}+05$ & 0.033 & tl201 & $1.05 \mathrm{E}+05$ & 0.033 \\
\hline tl200 & $8.91 E+04$ & 0.029 & tl200 & $8.92 E+04$ & 0.028 & tl200 & $8.92 E+04$ & 0.028 \\
\hline bi210 & $8.63 E+04$ & 0.028 & bi210 & $8.62 \mathrm{E}+04$ & 0.027 & bi210 & $8.61 \mathrm{E}+04$ & 0.027 \\
\hline pb201 & $8.11 E+04$ & 0.026 & pb201 & $8.12 \mathrm{E}+04$ & 0.026 & pb201 & $8.12 E+04$ & 0.025 \\
\hline tl199 & $7.10 \mathrm{E}+04$ & 0.023 & tl199 & $7.10 \mathrm{E}+04$ & 0.023 & tl199 & $7.10 \mathrm{E}+04$ & 0.022 \\
\hline bi204 & $7.04 \mathrm{E}+04$ & 0.023 & bi204 & $7.04 \mathrm{E}+04$ & 0.022 & po210 & $7.10 \mathrm{E}+04$ & 0.022 \\
\hline pb200 & $7.01 E+04$ & 0.023 & pb200 & $7.01 \mathrm{E}+04$ & 0.022 & bi204 & 7.04E+04 & 0.022 \\
\hline tl198 & $6.19 \mathrm{E}+04$ & 0.020 & tl198 & $6.19 \mathrm{E}+04$ & 0.020 & pb200 & $7.01 \mathrm{E}+04$ & 0.022 \\
\hline hg197 & $5.91 \mathrm{E}+04$ & 0.019 & hg197 & $5.96 \mathrm{E}+04$ & 0.019 & tl198 & $6.19 \mathrm{E}+04$ & 0.019 \\
\hline bi203 & $5.84 \mathrm{E}+04$ & 0.019 & bi203 & $5.84 \mathrm{E}+04$ & 0.019 & hg197 & $6.07 E+04$ & 0.019 \\
\hline tl197 & $5.14 \mathrm{E}+04$ & 0.017 & tl197 & $5.14 \mathrm{E}+04$ & 0.016 & bi203 & $5.84 \mathrm{E}+04$ & 0.018 \\
\hline pb199 & $4.72 \mathrm{E}+04$ & 0.015 & po210 & $5.03 \mathrm{E}+04$ & 0.016 & tl197 & $5.14 \mathrm{E}+04$ & 0.016 \\
\hline tl196 & $4.55 \mathrm{E}+04$ & 0.015 & pb199 & $4.72 \mathrm{E}+04$ & 0.015 & pb199 & $4.72 \mathrm{E}+04$ & 0.015 \\
\hline pb198 & $4.28 \mathrm{E}+04$ & 0.014 & tl196 & $4.55 \mathrm{E}+04$ & 0.014 & tl196 & $4.55 \mathrm{E}+04$ & 0.014 \\
\hline hg195 & $4.15 \mathrm{E}+04$ & 0.013 & pb198 & $4.28 \mathrm{E}+04$ & 0.014 & pb198 & $4.28 \mathrm{E}+04$ & 0.013 \\
\hline bi202 & $3.91 \mathrm{E}+04$ & 0.013 & hg195 & $4.16 \mathrm{E}+04$ & 0.013 & hg195 & $4.19 E+04$ & 0.013 \\
\hline
\end{tabular}


Table 13. Top 20 isotopes in cell 9 as a function of irradiation time

\begin{tabular}{|c|c|c|c|c|c|c|c|c|c|c|c|}
\hline \multicolumn{3}{|c|}{$1.0 \mathrm{mi}$} & \multicolumn{3}{|c|}{$1.0 \mathrm{hr}$} & \multicolumn{3}{|c|}{$1.0 \mathrm{~d}$} & \multicolumn{3}{|c|}{$3.0 \mathrm{~d}$} \\
\hline isotope & $\begin{array}{l}\text { Activity } \\
\text { (Ci) }\end{array}$ & $\begin{array}{c}\text { Fraction } \\
\text { of total }\end{array}$ & isotope & $\begin{array}{c}\text { Activity } \\
\text { (Ci) }\end{array}$ & \begin{tabular}{|c|} 
Fraction \\
of total
\end{tabular} & isotope & $\begin{array}{c}\text { Activity } \\
\text { (Ci) }\end{array}$ & $\begin{array}{l}\text { Fraction } \\
\text { of total }\end{array}$ & isotope & $\begin{array}{l}\text { Activity } \\
\text { (Ci) }\end{array}$ & $\begin{array}{c}\begin{array}{c}\text { Fraction } \\
\text { of total }\end{array} \\
\end{array}$ \\
\hline all & $1.90 \mathrm{E}+04$ & & all & $2.18 \mathrm{E}+04$ & & all & $3.39 \mathrm{E}+04$ & & all & $4.65 E+04$ & \\
\hline pb207m & $1.82 \mathrm{E}+04$ & 0.9569 & pb207m & $1.82 E+04$ & 0.8356 & pb207m & $1.82 \mathrm{E}+04$ & 0.5375 & pb207m & $1.82 E+04$ & 0.3916 \\
\hline bi207m & $4.54 \mathrm{E}+02$ & 0.0239 & t1206 & $6.67 \mathrm{E}+02$ & 0.0306 & bi210 & $5.88 E+03$ & 0.0270 & bi210 & $1.55 \mathrm{E}+04$ & 0.3324 \\
\hline t1206 & $9.73 E+01$ & 0.0051 & pb209 & $5.21 \mathrm{E}+02$ & 0.0239 & pb209 & $2.70 \mathrm{E}+03$ & 0.0124 & pb209 & $2.72 \mathrm{E}+03$ & 0.0584 \\
\hline tl207m & $7.10 \mathrm{E}+01$ & 0.0037 & t|207 & $4.98 \mathrm{E}+02$ & 0.0229 & bi204 & $8.45 E+02$ & 0.0388 & pb203 & $1.36 \mathrm{E}+03$ & 0.0292 \\
\hline t1207 & $6.74 \mathrm{E}+01$ & 0.0035 & bi207m & $4.54 \mathrm{E}+02$ & 0.0208 & $\mathrm{t} \mid 206$ & $6.68 \mathrm{E}+02$ & 0.0307 & bi206 & $1.11 \mathrm{E}+03$ & 0.0239 \\
\hline tl208 & $2.23 E+01$ & 0.0012 & bi210 & $2.61 \mathrm{E}+02$ & 0.0120 & pb203 & $5.49 \mathrm{E}+02$ & 0.0252 & bi204 & $1.08 \mathrm{E}+03$ & 0.0233 \\
\hline hg205 & $1.53 \mathrm{E}+01$ & 0.0008 & hg205 & $1.23 E+02$ & 0.0056 & pb201 & $5.20 \mathrm{E}+02$ & 0.0239 & tl206 & $6.68 \mathrm{E}+02$ & 0.0144 \\
\hline rb 95 & $1.41 \mathrm{E}+01$ & 0.0007 & tl208 & $1.10 \mathrm{E}+02$ & 0.0050 & tl207 & $4.98 E+02$ & 0.0229 & pb201 & $6.31 \mathrm{E}+02$ & 0.0136 \\
\hline zr100 & $1.40 \mathrm{E}+01$ & 0.0007 & pb204m & $8.72 \mathrm{E}+01$ & 0.0040 & bi207m & $4.54 \mathrm{E}+02$ & 0.0208 & bi203 & $5.54 \mathrm{E}+02$ & 0.0119 \\
\hline nb100 & $1.40 \mathrm{E}+01$ & 0.0007 & bi202 & $8.60 \mathrm{E}+01$ & 0.0039 & bi203 & $4.26 E+02$ & 0.0196 & tl207 & $4.98 \mathrm{E}+02$ & 0.0107 \\
\hline sr 95 & $1.04 \mathrm{E}+01$ & 0.0005 & $\mathrm{t} \mid 207 \mathrm{~m}$ & $7.10 \mathrm{E}+01$ & 0.0037 & bi206 & $4.12 \mathrm{E}+02$ & 0.0217 & bi207m & $4.54 \mathrm{E}+02$ & 0.0239 \\
\hline pb209 & $9.62 \mathrm{E}+00$ & 0.0005 & bi204 & $6.42 \mathrm{E}+01$ & 0.0034 & bi202 & $2.53 E+02$ & 0.0133 & tl201 & $3.59 \mathrm{E}+02$ & 0.0189 \\
\hline bi210 & $4.37 \mathrm{E}+00$ & 0.0002 & bi201 & $5.39 \mathrm{E}+01$ & 0.0028 & pb200 & $2.12 \mathrm{E}+02$ & 0.0112 & pb200 & $3.56 \mathrm{E}+02$ & 0.0187 \\
\hline hg206 & $2.29 \mathrm{E}+00$ & 0.0001 & pb199 & $4.97 \mathrm{E}+01$ & 0.0026 & tl199 & $1.97 \mathrm{E}+02$ & 0.0104 & tl200 & $3.17 \mathrm{E}+02$ & 0.0167 \\
\hline pb204m & $1.94 \mathrm{E}+00$ & 0.0001 & pb196 & $4.75 \mathrm{E}+01$ & 0.0025 & pb204m & $1.88 \mathrm{E}+02$ & 0.0099 & bi205 & $2.95 \mathrm{E}+02$ & 0.0155 \\
\hline pb197 & $1.92 \mathrm{E}+00$ & 0.0001 & pb197 & $4.07 \mathrm{E}+01$ & 0.0021 & bi201 & $1.69 \mathrm{E}+02$ & 0.0089 & bi202 & $2.53 \mathrm{E}+02$ & 0.0133 \\
\hline bi202 & $1.75 \mathrm{E}+00$ & 0.0001 & bi200 & $3.83 E+01$ & 0.0020 & pb199 & $1.55 \mathrm{E}+02$ & 0.0081 & tl199 & $2.25 E+02$ & 0.0118 \\
\hline pb196 & $1.31 \mathrm{E}+00$ & 0.0001 & pb201 & $3.53 E+01$ & 0.0019 & hg205 & $1.23 E+02$ & 0.0065 & pb204m & $1.88 \mathrm{E}+02$ & 0.0099 \\
\hline bi204 & $1.10 \mathrm{E}+00$ & 0.0001 & bi199 & $3.32 \mathrm{E}+01$ & 0.0017 & tl208 & $1.10 \mathrm{E}+02$ & 0.0058 & bi201 & $1.69 \mathrm{E}+02$ & 0.0089 \\
\hline bi201 & $1.08 \mathrm{E}+00$ & 0.0001 & bi203 & $3.22 \mathrm{E}+01$ & 0.0017 & tl201 & $1.05 \mathrm{E}+02$ & 0.0055 & pb199 & $1.55 \mathrm{E}+02$ & 0.0081 \\
\hline
\end{tabular}

\begin{tabular}{|c|c|c|c|c|c|c|c|c|c|c|c|}
\hline \multicolumn{3}{|c|}{$7.0 \mathrm{~d}$} & \multicolumn{3}{|c|}{$14.0 \mathrm{~d}$} & \multicolumn{3}{|c|}{$30.0 \mathrm{~d}$} & \multicolumn{3}{|c|}{$60.0 d$} \\
\hline isotope & $\begin{array}{l}\text { Activity } \\
\text { (Ci) }\end{array}$ & $\begin{array}{l}\text { Fraction } \\
\text { of total }\end{array}$ & isotope & $\begin{array}{l}\text { Activity } \\
\text { (Ci) }\end{array}$ & $\begin{array}{c}\text { Fraction } \\
\text { of total }\end{array}$ & isotope & $\begin{array}{l}\text { Activity } \\
\text { (Ci) }\end{array}$ & $\begin{array}{c}\text { Fraction } \\
\text { of total }\end{array}$ & isotope & $\begin{array}{l}\text { Activity } \\
\text { (Ci) }\end{array}$ & \begin{tabular}{|c|} 
Fraction \\
of total
\end{tabular} \\
\hline all & $6.23 E+04$ & & all & $7.61 \mathrm{E}+04$ & & all & $8.66 \mathrm{E}+04$ & & all & $9.36 \mathrm{E}+04$ & \\
\hline bi210 & $2.82 E+04$ & 0.4531 & bi210 & $3.89 E+04$ & 0.5116 & bi210 & $4.48 \mathrm{E}+04$ & 0.5171 & bi210 & $4.55 \mathrm{E}+04$ & 0.4723 \\
\hline pb207m & $1.82 \mathrm{E}+04$ & 0.2922 & pb207m & $1.82 \mathrm{E}+04$ & 0.2392 & pb207m & $1.82 \mathrm{E}+04$ & 0.2102 & pb207m & $1.82 \mathrm{E}+04$ & 0.1890 \\
\hline pb209 & $2.72 \mathrm{E}+03$ & 0.0436 & bi206 & $3.10 \mathrm{E}+03$ & 0.0407 & po210 & $4.90 \mathrm{E}+03$ & 0.0566 & po210 & $1.05 \mathrm{E}+04$ & 0.1094 \\
\hline bi206 & $2.12 \mathrm{E}+03$ & 0.0341 & pb209 & $2.72 E+03$ & 0.0357 & bi206 & $3.79 \mathrm{E}+03$ & 0.0438 & bi206 & $3.93 E+03$ & 0.0408 \\
\hline pb203 & $2.03 E+03$ & 0.0326 & pb203 & $2.27 \mathrm{E}+03$ & 0.0298 & pb209 & $2.72 E+03$ & 0.0314 & pb209 & $2.72 E+03$ & 0.0282 \\
\hline bi204 & $1.10 \mathrm{E}+03$ & 0.0176 & po210 & $1.73 \mathrm{E}+03$ & 0.0228 & pb203 & $2.29 \mathrm{E}+03$ & 0.0265 & pb203 & $2.29 \mathrm{E}+03$ & 0.0238 \\
\hline tl206 & $6.68 \mathrm{E}+02$ & 0.0107 & bi204 & $1.10 \mathrm{E}+03$ & 0.0144 & bi205 & $1.72 \mathrm{E}+03$ & 0.0199 & bi205 & $2.17 \mathrm{E}+03$ & 0.0225 \\
\hline $\mathrm{t} \mid 201$ & $6.35 \mathrm{E}+02$ & 0.0102 & bi205 & $1.09 \mathrm{E}+03$ & 0.0143 & bi204 & $1.10 \mathrm{E}+03$ & 0.0127 & bi204 & $1.10 \mathrm{E}+03$ & 0.0114 \\
\hline pb201 & $6.33 E+02$ & 0.0102 & $\mathrm{t} \mid 201$ & $7.80 \mathrm{E}+02$ & 0.0103 & $t \mid 201$ & $8.16 \mathrm{E}+02$ & 0.0094 & $t \mid 201$ & $8.15 \mathrm{E}+02$ & 0.0085 \\
\hline bi205 & $6.30 \mathrm{E}+02$ & 0.0101 & tl206 & $6.68 \mathrm{E}+02$ & 0.0088 & $\mathrm{t} \mid 206$ & $6.68 \mathrm{E}+02$ & 0.0077 & $\mathrm{t} \mid 206$ & $6.68 \mathrm{E}+02$ & 0.0069 \\
\hline po210 & $5.66 \mathrm{E}+02$ & 0.0298 & pb201 & $6.33 E+02$ & 0.0333 & pb201 & $6.33 E+02$ & 0.0333 & pb201 & $6.33 E+02$ & 0.0333 \\
\hline bi203 & $5.63 E+02$ & 0.0296 & bi203 & $5.63 E+02$ & 0.0296 & bi203 & $5.63 \mathrm{E}+02$ & 0.0296 & bi203 & $5.63 \mathrm{E}+02$ & 0.0296 \\
\hline t|207 & $4.98 \mathrm{E}+02$ & 0.0262 & t1207 & $4.98 \mathrm{E}+02$ & 0.0262 & t|207 & $4.99 \mathrm{E}+02$ & 0.0262 & t|207 & $4.99 \mathrm{E}+02$ & 0.0262 \\
\hline $\mathrm{t} \mid 200$ & $4.60 \mathrm{E}+02$ & 0.0242 & tl200 & $4.78 \mathrm{E}+02$ & 0.0251 & tl200 & $4.78 \mathrm{E}+02$ & 0.0251 & $\mathrm{t} 1200$ & $4.78 \mathrm{E}+02$ & 0.0251 \\
\hline bi207m & $4.54 \mathrm{E}+02$ & 0.0239 & bi207m & $4.54 \mathrm{E}+02$ & 0.0239 & bi207m & $4.54 \mathrm{E}+02$ & 0.0239 & bi207m & $4.54 \mathrm{E}+02$ & 0.0239 \\
\hline pb200 & $3.92 \mathrm{E}+02$ & 0.0206 & pb200 & $3.94 \mathrm{E}+02$ & 0.0207 & pb200 & $3.94 \mathrm{E}+02$ & 0.0207 & pb200 & $3.94 \mathrm{E}+02$ & 0.0207 \\
\hline bi202 & $2.53 E+02$ & 0.0133 & bi202 & $2.53 E+02$ & 0.0133 & bi202 & $2.53 E+02$ & 0.0133 & bi202 & $2.53 \mathrm{E}+02$ & 0.0133 \\
\hline tl199 & $2.25 \mathrm{E}+02$ & 0.0118 & tl199 & $2.25 \mathrm{E}+02$ & 0.0118 & tl199 & $2.25 \mathrm{E}+02$ & 0.0118 & tl199 & $2.25 \mathrm{E}+02$ & 0.0118 \\
\hline pb204m & $1.88 \mathrm{E}+02$ & 0.0099 & pb204m & $1.89 \mathrm{E}+02$ & 0.0099 & pb204m & $1.89 \mathrm{E}+02$ & 0.0099 & $\mathrm{t} \mid 202$ & $2.04 \mathrm{E}+02$ & 0.0107 \\
\hline bi201 & $1.69 \mathrm{E}+02$ & 0.0089 & bi201 & $1.69 \mathrm{E}+02$ & 0.0089 & tl202 & $1.72 \mathrm{E}+02$ & 0.0091 & pb204m & $1.89 \mathrm{E}+02$ & 0.0099 \\
\hline
\end{tabular}


Table 13. Top 20 isotopes in cell 9 as a function of irradiation time (continued)

\begin{tabular}{|c|c|c|c|c|c|c|c|c|}
\hline \multicolumn{3}{|c|}{$90.0 d$} & \multicolumn{3}{|c|}{$182.0 \mathrm{~d}$} & \multicolumn{3}{|c|}{$1.0 \mathrm{yr}$} \\
\hline isotope & $\begin{array}{l}\text { Activity } \\
\text { (Ci) }\end{array}$ & $\begin{array}{c}\text { Fraction } \\
\text { of total }\end{array}$ & isotope & $\begin{array}{l}\text { Activity } \\
\text { (Ci) }\end{array}$ & $\begin{array}{l}\text { Fraction } \\
\text { of total }\end{array}$ & isotope & $\begin{array}{c}\text { Activity } \\
\text { (Ci) }\end{array}$ & $\begin{array}{c}\text { Fraction } \\
\text { of total }\end{array}$ \\
\hline all & $9.87 E+04$ & & all & $1.10 \mathrm{E}+05$ & & all & $1.21 \mathrm{E}+05$ & \\
\hline bi210 & $4.55 \mathrm{E}+04$ & 0.4610 & bi210 & $4.55 \mathrm{E}+04$ & 0.4135 & bi210 & $4.55 \mathrm{E}+04$ & 0.3752 \\
\hline pb207m & $1.82 \mathrm{E}+04$ & 0.1844 & po210 & $2.65 \mathrm{E}+04$ & 0.2411 & po210 & $3.75 \mathrm{E}+04$ & 0.3096 \\
\hline po210 & $1.54 \mathrm{E}+04$ & 0.1562 & pb207m & $1.82 \mathrm{E}+04$ & 0.1655 & pb207m & $1.82 \mathrm{E}+04$ & 0.1502 \\
\hline bi206 & $3.94 E+03$ & 0.0399 & bi206 & $3.94 \mathrm{E}+03$ & 0.0358 & bi206 & $3.94 \mathrm{E}+03$ & 0.0325 \\
\hline pb209 & $2.72 E+03$ & 0.0275 & pb209 & $2.71 \mathrm{E}+03$ & 0.0247 & pb209 & $2.71 \mathrm{E}+03$ & 0.0224 \\
\hline pb203 & $2.29 E+03$ & 0.0232 & bi205 & $2.32 \mathrm{E}+03$ & 0.0211 & bi205 & $2.32 E+03$ & 0.0191 \\
\hline bi205 & $2.28 \mathrm{E}+03$ & 0.0231 & pb203 & $2.29 \mathrm{E}+03$ & 0.0209 & pb203 & $2.30 \mathrm{E}+03$ & 0.0189 \\
\hline bi204 & $1.10 \mathrm{E}+03$ & 0.0111 & bi204 & $1.10 \mathrm{E}+03$ & 0.0100 & bi204 & $1.10 \mathrm{E}+03$ & 0.0091 \\
\hline tl201 & $8.15 E+02$ & 0.0083 & tl201 & $8.16 \mathrm{E}+02$ & 0.0074 & $\mathrm{t} \mid 201$ & $8.16 \mathrm{E}+02$ & 0.0067 \\
\hline tl206 & $6.68 \mathrm{E}+02$ & 0.0068 & tl206 & $6.68 \mathrm{E}+02$ & 0.0061 & t1206 & $6.68 \mathrm{E}+02$ & 0.0055 \\
\hline pb201 & $6.33 E+02$ & 0.0333 & pb201 & $6.33 E+02$ & 0.0333 & pb201 & $6.33 E+02$ & 0.0333 \\
\hline bi203 & $5.63 \mathrm{E}+02$ & 0.0296 & bi203 & $5.63 \mathrm{E}+02$ & 0.0296 & bi203 & $5.63 E+02$ & 0.0296 \\
\hline tl207 & $4.99 E+02$ & 0.0263 & t|207 & $5.01 \mathrm{E}+02$ & 0.0263 & t|207 & $5.04 \mathrm{E}+02$ & 0.0265 \\
\hline tl200 & $4.78 \mathrm{E}+02$ & 0.0251 & t1200 & $4.78 \mathrm{E}+02$ & 0.0251 & t1200 & $4.78 \mathrm{E}+02$ & 0.0251 \\
\hline bi207m & $4.54 \mathrm{E}+02$ & 0.0239 & bi207m & $4.54 \mathrm{E}+02$ & 0.0239 & bi207m & $4.54 \mathrm{E}+02$ & 0.0239 \\
\hline pb200 & $3.94 \mathrm{E}+02$ & 0.0207 & pb200 & $3.94 \mathrm{E}+02$ & 0.0207 & pb200 & $3.94 \mathrm{E}+02$ & 0.0207 \\
\hline bi202 & $2.53 E+02$ & 0.0133 & bi202 & $2.53 \mathrm{E}+02$ & 0.0133 & bi207 & $2.84 \mathrm{E}+02$ & 0.0149 \\
\hline tl199 & $2.25 \mathrm{E}+02$ & 0.0118 & tl199 & $2.25 \mathrm{E}+02$ & 0.0118 & bi202 & $2.53 E+02$ & 0.0133 \\
\hline $\mathrm{t} \mid 202$ & $2.10 \mathrm{E}+02$ & 0.0110 & $\mathrm{t} \mid 202$ & $2.11 \mathrm{E}+02$ & 0.0111 & tl199 & $2.25 \mathrm{E}+02$ & 0.0118 \\
\hline pb204m & $1.89 \mathrm{E}+02$ & 0.0100 & pb204m & $1.90 \mathrm{E}+02$ & 0.0100 & tl202 & $2.11 \mathrm{E}+02$ & 0.0111 \\
\hline
\end{tabular}


Table 14. Top 20 isotopes in cell 3 as a function of irradiation time

\begin{tabular}{|c|c|c|c|c|c|c|c|c|c|c|c|}
\hline \multicolumn{3}{|c|}{$1.0 \mathrm{mi}$} & \multicolumn{3}{|c|}{$1.0 \mathrm{hr}$} & \multicolumn{3}{|c|}{$1.0 \mathrm{~d}$} & \multicolumn{3}{|c|}{$3.0 \mathrm{~d}$} \\
\hline isotope & $\begin{array}{c}\text { Activity } \\
\text { (Ci) }\end{array}$ & \begin{tabular}{|c|}
$\begin{array}{c}\text { Fraction } \\
\text { of total }\end{array}$ \\
\end{tabular} & isotope & $\begin{array}{c}\text { Activity } \\
\text { (Ci) }\end{array}$ & \begin{tabular}{|c|} 
Fraction \\
of total
\end{tabular} & isotope & $\begin{array}{c}\text { Activity } \\
\text { (Ci) }\end{array}$ & \begin{tabular}{|c|}
$\begin{array}{c}\text { Fraction } \\
\text { of total }\end{array}$ \\
\end{tabular} & isotope & $\begin{array}{c}\text { Activity } \\
\text { (Ci) }\end{array}$ & $\begin{array}{c}\begin{array}{c}\text { Fraction } \\
\text { of total }\end{array} \\
\end{array}$ \\
\hline all & $1.13 \mathrm{E}+03$ & & all & $1.34 \mathrm{E}+03$ & & all & $3.96 \mathrm{E}+03$ & & all & $7.90 \mathrm{E}+03$ & \\
\hline pb207m & $1.10 \mathrm{E}+03$ & 0.9673 & pb207m & $1.10 \mathrm{E}+03$ & 0.8173 & bi210 & $2.28 \mathrm{E}+03$ & 0.5762 & bi210 & $6.01 \mathrm{E}+03$ & 0.7601 \\
\hline bi207m & $2.40 \mathrm{E}+01$ & 0.0212 & bi210 & $1.02 E+02$ & 0.0758 & pb207m & $1.10 \mathrm{E}+03$ & 0.2765 & pb207m & $1.10 \mathrm{E}+03$ & 0.1387 \\
\hline t|207m & $3.88 \mathrm{E}+00$ & 0.0034 & pb209 & $5.05 \mathrm{E}+01$ & 0.0377 & pb209 & $2.62 E+02$ & 0.0660 & pb209 & $2.63 E+02$ & 0.0333 \\
\hline tl206 & $2.88 \mathrm{E}+00$ & 0.0025 & bi207m & $2.40 \mathrm{E}+01$ & 0.0179 & pb203 & $4.81 \mathrm{E}+01$ & 0.0121 & pb203 & $1.17 \mathrm{E}+02$ & 0.0148 \\
\hline bi210 & $1.70 \mathrm{E}+00$ & 0.0015 & t1206 & $1.90 \mathrm{E}+01$ & 0.0142 & bi203 & $3.19 \mathrm{E}+01$ & 0.0081 & bi206 & $7.57 \mathrm{E}+01$ & 0.0096 \\
\hline tl208 & $1.22 \mathrm{E}+00$ & 0.0011 & t|207 & $7.22 \mathrm{E}+00$ & 0.0054 & bi206 & $2.81 \mathrm{E}+01$ & 0.0071 & po210 & $4.80 \mathrm{E}+01$ & 0.0061 \\
\hline t|207 & 9.77E-01 & 0.0009 & t|208 & $6.00 \mathrm{E}+00$ & 0.0045 & tl199 & $2.48 \mathrm{E}+01$ & 0.0062 & bi203 & $4.16 \mathrm{E}+01$ & 0.0053 \\
\hline pb209 & 9.33E-01 & 0.0008 & pb199 & $5.20 \mathrm{E}+00$ & 0.0039 & bi207m & $2.40 \mathrm{E}+01$ & 0.0061 & tl199 & $2.81 E+01$ & 0.0036 \\
\hline hg205 & 4.49E-01 & 0.0004 & bi202 & $4.78 \mathrm{E}+00$ & 0.0036 & pb201 & $2.34 \mathrm{E}+01$ & 0.0059 & pb201 & $2.80 \mathrm{E}+01$ & 0.0035 \\
\hline pb199 & $1.08 \mathrm{E}-01$ & 0.0001 & pb204m & $4.61 \mathrm{E}+00$ & 0.0034 & t1206 & $1.90 \mathrm{E}+01$ & 0.0048 & bi207m & $2.40 \mathrm{E}+01$ & 0.0030 \\
\hline pb204m & 1.03E-01 & 0.0001 & $\mathrm{t} \mid 207 \mathrm{~m}$ & $3.88 \mathrm{E}+00$ & 0.0029 & pb199 & $1.41 \mathrm{E}+01$ & 0.0035 & bi205 & $1.96 \mathrm{E}+01$ & 0.0025 \\
\hline bi202 & $9.70 \mathrm{E}-02$ & 0.0001 & hg205 & $3.60 \mathrm{E}+00$ & 0.0027 & bi202 & $1.41 \mathrm{E}+01$ & 0.0035 & tl206 & $1.90 \mathrm{E}+01$ & 0.0024 \\
\hline pb198 & $6.78 \mathrm{E}-02$ & 0.0001 & pb198 & $3.54 \mathrm{E}+00$ & 0.0026 & pb198 & $1.41 \mathrm{E}+01$ & 0.0035 & tl198 & $1.41 \mathrm{E}+01$ & 0.0018 \\
\hline bi203 & 4.14E-02 & 0.0000 & bi203 & $2.42 \mathrm{E}+00$ & 0.0018 & tl198 & $1.30 \mathrm{E}+01$ & 0.0033 & pb198 & $1.41 \mathrm{E}+01$ & 0.0018 \\
\hline pb201 & $3.48 \mathrm{E}-02$ & 0.0000 & pb203 & $2.07 E+00$ & 0.0015 & bi204 & $1.09 \mathrm{E}+01$ & 0.0027 & pb199 & $1.41 \mathrm{E}+01$ & 0.0018 \\
\hline pb203 & $3.45 \mathrm{E}-02$ & 0.0000 & pb201 & $2.01 \mathrm{E}+00$ & 0.0015 & pb204m & $9.96 \mathrm{E}+00$ & 0.0025 & bi202 & $1.41 \mathrm{E}+01$ & 0.0018 \\
\hline tl199 & $2.20 \mathrm{E}-02$ & 0.0000 & tl199 & $1.51 \mathrm{E}+00$ & 0.0011 & pb200 & $7.58 \mathrm{E}+00$ & 0.0019 & bi204 & $1.39 \mathrm{E}+01$ & 0.0018 \\
\hline bi206 & 2.06E-02 & 0.0000 & bi206 & $1.23 \mathrm{E}+00$ & 0.0009 & t|207 & $7.22 \mathrm{E}+00$ & 0.0018 & pb200 & $1.27 \mathrm{E}+01$ & 0.0016 \\
\hline bi204 & 1.45E-02 & 0.0000 & bi204 & 8.42E-01 & 0.0006 & bi205 & $6.85 \mathrm{E}+00$ & 0.0017 & $\mathrm{t} \mid 201$ & $1.19 \mathrm{E}+01$ & 0.0015 \\
\hline tl206m & 1.42E-02 & 0.0000 & pb200 & 4.46E-01 & 0.0003 & tl208 & $6.00 \mathrm{E}+00$ & 0.0015 & pb204m & $9.96 \mathrm{E}+00$ & 0.0013 \\
\hline
\end{tabular}

\begin{tabular}{|c|c|c|c|c|c|c|c|c|c|c|c|}
\hline \multicolumn{3}{|c|}{$7.0 \mathrm{~d}$} & \multicolumn{3}{|c|}{$14.0 \mathrm{~d}$} & \multicolumn{3}{|c|}{$30.0 \mathrm{~d}$} & \multicolumn{3}{|c|}{$60.0 d$} \\
\hline isotope & $\begin{array}{l}\text { Activity } \\
\text { (Ci) }\end{array}$ & \begin{tabular}{|c|}
$\begin{array}{c}\text { Fraction } \\
\text { of total }\end{array}$ \\
\end{tabular} & isotope & $\begin{array}{c}\text { Activity } \\
\text { (Ci) }\end{array}$ & $\begin{array}{c}\text { Fraction } \\
\text { of total }\end{array}$ & isotope & $\begin{array}{c}\text { Activity } \\
\text { (Ci) }\end{array}$ & \begin{tabular}{|c|}
$\begin{array}{c}\text { Fraction } \\
\text { of total }\end{array}$ \\
\end{tabular} & isotope & $\begin{array}{c}\text { Activity } \\
\text { (Ci) }\end{array}$ & $\begin{array}{c}\text { Fraction } \\
\text { of total }\end{array}$ \\
\hline all & $1.32 E+04$ & & all & $1.80 \mathrm{E}+04$ & & all & $2.16 \mathrm{E}+04$ & & all & $2.41 \mathrm{E}+04$ & \\
\hline bi210 & $1.10 \mathrm{E}+04$ & 0.8311 & bi210 & $1.51 \mathrm{E}+04$ & 0.8435 & bi210 & $1.74 \mathrm{E}+04$ & 0.8079 & bi210 & $1.77 \mathrm{E}+04$ & 0.7348 \\
\hline pb207m & $1.10 \mathrm{E}+03$ & 0.0830 & pb207m & $1.10 \mathrm{E}+03$ & 0.0611 & po210 & $1.91 \mathrm{E}+03$ & 0.0884 & po210 & $4.10 \mathrm{E}+03$ & 0.1704 \\
\hline pb209 & $2.63 E+02$ & 0.0199 & po210 & $6.74 \mathrm{E}+02$ & 0.0376 & pb207m & $1.10 \mathrm{E}+03$ & 0.0509 & pb207m & $1.10 \mathrm{E}+03$ & 0.0456 \\
\hline po210 & $2.20 \mathrm{E}+02$ & 0.0167 & pb209 & $2.63 E+02$ & 0.0147 & pb209 & $2.63 E+02$ & 0.0122 & bi206 & $2.67 E+02$ & 0.0111 \\
\hline pb203 & $1.75 \mathrm{E}+02$ & 0.0132 & bi206 & $2.11 \mathrm{E}+02$ & 0.0117 & bi206 & $2.58 \mathrm{E}+02$ & 0.0120 & pb209 & $2.63 \mathrm{E}+02$ & 0.0109 \\
\hline bi206 & $1.44 \mathrm{E}+02$ & 0.0109 & pb203 & $1.95 \mathrm{E}+02$ & 0.0108 & pb203 & $1.97 \mathrm{E}+02$ & 0.0091 & pb203 & $1.97 \mathrm{E}+02$ & 0.0082 \\
\hline bi203 & $4.22 \mathrm{E}+01$ & 0.0032 & bi205 & $7.26 \mathrm{E}+01$ & 0.0040 & bi205 & $1.15 \mathrm{E}+02$ & 0.0053 & bi205 & $1.45 \mathrm{E}+02$ & 0.0060 \\
\hline bi205 & $4.20 \mathrm{E}+01$ & 0.0032 & bi203 & $4.22 \mathrm{E}+01$ & 0.0024 & bi203 & $4.22 \mathrm{E}+01$ & 0.0020 & bi203 & $4.22 \mathrm{E}+01$ & 0.0018 \\
\hline tl199 & $2.81 \mathrm{E}+01$ & 0.0021 & tl199 & $2.81 \mathrm{E}+01$ & 0.0016 & $\mathrm{t} \mid 201$ & $2.82 \mathrm{E}+01$ & 0.0013 & tl199 & $2.81 \mathrm{E}+01$ & 0.0012 \\
\hline pb201 & $2.81 \mathrm{E}+01$ & 0.0021 & pb201 & $2.81 \mathrm{E}+01$ & 0.0016 & tl199 & $2.81 \mathrm{E}+01$ & 0.0013 & tl201 & $2.81 \mathrm{E}+01$ & 0.0012 \\
\hline bi207m & $2.40 \mathrm{E}+01$ & 0.0018 & $\mathrm{t} \mid 201$ & $2.68 \mathrm{E}+01$ & 0.0015 & pb201 & $2.81 \mathrm{E}+01$ & 0.0013 & pb201 & $2.81 \mathrm{E}+01$ & 0.0012 \\
\hline $\mathrm{t} \mid 201$ & $2.16 \mathrm{E}+01$ & 0.0016 & bi207m & $2.40 \mathrm{E}+01$ & 0.0013 & bi207m & $2.40 \mathrm{E}+01$ & 0.0011 & bi207m & $2.40 \mathrm{E}+01$ & 0.0010 \\
\hline tl206 & $1.90 \mathrm{E}+01$ & 0.0014 & tl206 & $1.90 \mathrm{E}+01$ & 0.0011 & tl206 & $1.90 \mathrm{E}+01$ & 0.0009 & tl206 & $1.90 \mathrm{E}+01$ & 0.0008 \\
\hline tl198 & $1.41 \mathrm{E}+01$ & 0.0011 & tl198 & $1.41 \mathrm{E}+01$ & 0.0008 & tl198 & $1.41 \mathrm{E}+01$ & 0.0007 & tl198 & $1.41 E+01$ & 0.0006 \\
\hline pb198 & $1.41 \mathrm{E}+01$ & 0.0011 & pb198 & $1.41 \mathrm{E}+01$ & 0.0008 & tl200 & $1.41 \mathrm{E}+01$ & 0.0007 & t1200 & $1.41 E+01$ & 0.0006 \\
\hline pb199 & $1.41 \mathrm{E}+01$ & 0.0011 & pb199 & $1.41 \mathrm{E}+01$ & 0.0008 & pb198 & $1.41 \mathrm{E}+01$ & 0.0007 & pb198 & $1.41 \mathrm{E}+01$ & 0.0006 \\
\hline bi202 & $1.41 \mathrm{E}+01$ & 0.0011 & pb200 & $1.41 \mathrm{E}+01$ & 0.0008 & pb199 & $1.41 \mathrm{E}+01$ & 0.0007 & pb199 & $1.41 \mathrm{E}+01$ & 0.0006 \\
\hline bi204 & $1.41 \mathrm{E}+01$ & 0.0011 & bi202 & $1.41 \mathrm{E}+01$ & 0.0008 & pb200 & $1.41 \mathrm{E}+01$ & 0.0007 & pb200 & $1.41 \mathrm{E}+01$ & 0.0006 \\
\hline pb200 & $1.40 \mathrm{E}+01$ & 0.0011 & bi204 & $1.41 \mathrm{E}+01$ & 0.0008 & bi202 & $1.41 \mathrm{E}+01$ & 0.0007 & bi202 & $1.41 \mathrm{E}+01$ & 0.0006 \\
\hline tl200 & $1.34 \mathrm{E}+01$ & 0.0010 & t1200 & $1.41 \mathrm{E}+01$ & 0.0008 & bi204 & $1.41 \mathrm{E}+01$ & 0.0007 & bi204 & $1.41 \mathrm{E}+01$ & 0.0006 \\
\hline
\end{tabular}


Table 14. Top 20 isotopes in cell 3 as a function of irradiation time (Continued)

\begin{tabular}{|c|c|c|c|c|c|c|c|c|}
\hline \multicolumn{3}{|c|}{$90.0 d$} & \multicolumn{3}{|c|}{$182.0 \mathrm{~d}$} & \multicolumn{3}{|c|}{$1.0 \mathrm{yr}$} \\
\hline isotope & $\begin{array}{l}\text { Activity } \\
\text { (Ci) }\end{array}$ & $\begin{array}{c}\text { Fraction } \\
\text { of total }\end{array}$ & isotope & $\begin{array}{l}\text { Activity } \\
\text { (Ci) }\end{array}$ & $\begin{array}{c}\text { Fraction } \\
\text { of total }\end{array}$ & isotope & $\begin{array}{c}\text { Activity } \\
\text { (Ci) }\end{array}$ & $\begin{array}{c}\text { Fraction } \\
\text { of total }\end{array}$ \\
\hline all & $2.60 \mathrm{E}+04$ & & all & $3.03 E+04$ & & all & $3.46 \mathrm{E}+04$ & \\
\hline bi210 & 1.77E+04 & 0.6812 & bi210 & $1.77 \mathrm{E}+04$ & 0.5838 & bi210 & $1.77 \mathrm{E}+04$ & 0.5114 \\
\hline po210 & $6.00 \mathrm{E}+03$ & 0.2309 & po210 & $1.03 E+04$ & 0.3403 & po210 & $1.46 \mathrm{E}+04$ & 0.4218 \\
\hline pb207m & $1.10 \mathrm{E}+03$ & 0.0422 & pb207m & $1.10 \mathrm{E}+03$ & 0.0362 & pb207m & $1.10 \mathrm{E}+03$ & 0.0317 \\
\hline bi206 & $2.67 \mathrm{E}+02$ & 0.0103 & bi206 & $2.67 \mathrm{E}+02$ & 0.0088 & bi206 & $2.67 \mathrm{E}+02$ & 0.0077 \\
\hline pb209 & $2.63 \mathrm{E}+02$ & 0.0101 & pb209 & $2.63 E+02$ & 0.0087 & pb209 & $2.63 E+02$ & 0.0076 \\
\hline pb203 & $1.97 \mathrm{E}+02$ & 0.0076 & pb203 & $1.97 \mathrm{E}+02$ & 0.0065 & pb203 & $1.97 \mathrm{E}+02$ & 0.0057 \\
\hline bi205 & $1.52 \mathrm{E}+02$ & 0.0059 & bi205 & $1.55 \mathrm{E}+02$ & 0.0051 & bi205 & $1.55 \mathrm{E}+02$ & 0.0045 \\
\hline bi203 & $4.22 E+01$ & 0.0016 & bi203 & $4.22 \mathrm{E}+01$ & 0.0014 & bi203 & $4.22 \mathrm{E}+01$ & 0.0012 \\
\hline tl199 & $2.81 E+01$ & 0.0011 & tl199 & $2.81 \mathrm{E}+01$ & 0.0009 & tl199 & $2.81 \mathrm{E}+01$ & 0.0008 \\
\hline tl201 & $2.81 \mathrm{E}+01$ & 0.0011 & $\mathrm{t} \mid 201$ & $2.81 \mathrm{E}+01$ & 0.0009 & $\mathrm{t} \mid 201$ & $2.81 \mathrm{E}+01$ & 0.0008 \\
\hline pb201 & $2.81 \mathrm{E}+01$ & 0.0011 & pb201 & $2.81 \mathrm{E}+01$ & 0.0009 & pb201 & $2.81 \mathrm{E}+01$ & 0.0008 \\
\hline bi207m & $2.40 \mathrm{E}+01$ & 0.0009 & bi207m & $2.40 \mathrm{E}+01$ & 0.0008 & bi207m & $2.40 \mathrm{E}+01$ & 0.0007 \\
\hline tl206 & $1.90 \mathrm{E}+01$ & 0.0007 & t1206 & $1.90 \mathrm{E}+01$ & 0.0006 & t1206 & $1.90 \mathrm{E}+01$ & 0.0005 \\
\hline tl198 & $1.41 \mathrm{E}+01$ & 0.0005 & hg203 & $1.41 \mathrm{E}+01$ & 0.0005 & hg203 & $1.50 \mathrm{E}+01$ & 0.0004 \\
\hline $\mathrm{t} \mid 200$ & $1.41 \mathrm{E}+01$ & 0.0005 & tl198 & $1.41 \mathrm{E}+01$ & 0.0005 & bi207 & $1.49 \mathrm{E}+01$ & 0.0004 \\
\hline pb198 & $1.41 \mathrm{E}+01$ & 0.0005 & $t \mid 200$ & $1.41 \mathrm{E}+01$ & 0.0005 & tl198 & $1.41 \mathrm{E}+01$ & 0.0004 \\
\hline pb199 & $1.41 \mathrm{E}+01$ & 0.0005 & pb198 & $1.41 \mathrm{E}+01$ & 0.0005 & t1200 & $1.41 \mathrm{E}+01$ & 0.0004 \\
\hline pb200 & $1.41 \mathrm{E}+01$ & 0.0005 & pb199 & $1.41 \mathrm{E}+01$ & 0.0005 & pb198 & $1.41 \mathrm{E}+01$ & 0.0004 \\
\hline bi202 & $1.41 \mathrm{E}+01$ & 0.0005 & pb200 & $1.41 \mathrm{E}+01$ & 0.0005 & pb199 & $1.41 \mathrm{E}+01$ & 0.0004 \\
\hline bi204 & $1.41 \mathrm{E}+01$ & 0.0005 & bi202 & $1.41 \mathrm{E}+01$ & 0.0005 & pb200 & $1.41 \mathrm{E}+01$ & 0.0004 \\
\hline
\end{tabular}

Table 15. Total activity and specific activity of all radioisotopes in the three cells at the shutdown inventory

\begin{tabular}{|c|c|c|c|}
\hline Cell & Mass $(\mathrm{g})$ & Total Activity $(\mathrm{Ci})$ & SA (Ci/g) \\
\hline 3 & $1.14 \mathrm{E}+06$ & $3.46 \mathrm{E}+04$ & $3.03 \mathrm{E}-02$ \\
\hline 8 & $2.10 \mathrm{E}+05$ & $3.22 \mathrm{E}+06$ & $1.53 \mathrm{E}+01$ \\
\hline 9 & $1.72 \mathrm{E}+05$ & $1.21 \mathrm{E}+05$ & $7.03 \mathrm{E}-01$ \\
\hline all & $1.52 \mathrm{E}+06$ & $3.38 \mathrm{E}+06$ & $2.22 \mathrm{E}+00$ \\
\hline
\end{tabular}


Table 16. Radioisotope inventory as a function of time after shutdown for cell 8

\begin{tabular}{|c|c|c|c|c|c|c|c|c|c|c|c|}
\hline \multicolumn{3}{|c|}{$1.0 \mathrm{hr}$} & \multicolumn{3}{|c|}{$8.0 \mathrm{hr}$} & \multicolumn{3}{|c|}{$1.0 \mathrm{~d}$} & \multicolumn{3}{|c|}{$7.0 \mathrm{~d}$} \\
\hline isotope & $\begin{array}{l}\text { Activity } \\
\text { (Ci) }\end{array}$ & $\begin{array}{l}\text { Fraction } \\
\text { of total }\end{array}$ & isotope & $\begin{array}{c}\text { Activity } \\
\text { (Ci) }\end{array}$ & $\begin{array}{c}\text { Fraction } \\
\text { of total }\end{array}$ & isotope & $\begin{array}{c}\text { Activity } \\
\text { (Ci) }\end{array}$ & \begin{tabular}{|c|} 
Fraction \\
of total
\end{tabular} & isotope & $\begin{array}{c}\text { Activity } \\
\text { (Ci) }\end{array}$ & $\begin{array}{c}\text { Fraction } \\
\text { of total }\end{array}$ \\
\hline total & $2.27 \mathrm{E}+06$ & & total & $1.60 \mathrm{E}+06$ & & total & $1.19 \mathrm{E}+06$ & & total & $5.32 \mathrm{E}+05$ & \\
\hline bi206 & $1.40 \mathrm{E}+05$ & 0.0618 & bi206 & $1.36 \mathrm{E}+05$ & 0.0849 & bi206 & $1.27 \mathrm{E}+05$ & 0.1072 & bi205 & $7.87 \mathrm{E}+04$ & 0.1479 \\
\hline pb203 & $1.39 \mathrm{E}+05$ & 0.0613 & pb203 & $1.30 \mathrm{E}+05$ & 0.0814 & pb203 & $1.10 \mathrm{E}+05$ & 0.0925 & bi206 & $7.04 \mathrm{E}+04$ & 0.1323 \\
\hline bi205 & $1.08 \mathrm{E}+05$ & 0.0476 & bi205 & $1.07 \mathrm{E}+05$ & 0.0665 & bi205 & $1.03 E+05$ & 0.0870 & po210 & $7.03 E+04$ & 0.1320 \\
\hline tl201 & $1.05 \mathrm{E}+05$ & 0.0464 & tl201 & $1.02 \mathrm{E}+05$ & 0.0640 & t|201 & $9.19 \mathrm{E}+04$ & 0.0774 & bi210 & $3.28 \mathrm{E}+04$ & 0.0616 \\
\hline tl200 & $8.86 E+04$ & 0.0391 & tl200 & $8.39 E+04$ & 0.0524 & bi210 & $7.52 \mathrm{E}+04$ & 0.0633 & au195 & $3.15 \mathrm{E}+04$ & 0.0593 \\
\hline bi210 & $8.58 E+04$ & 0.0379 & bi210 & $8.24 E+04$ & 0.0515 & po210 & $7.08 \mathrm{E}+04$ & 0.0597 & tl201 & $2.39 \mathrm{E}+04$ & 0.0450 \\
\hline pb201 & $7.73 E+04$ & 0.0341 & po210 & $7.08 \mathrm{E}+04$ & 0.0442 & $t \mid 200$ & $6.94 \mathrm{E}+04$ & 0.0585 & pb203 & $1.66 \mathrm{E}+04$ & 0.0313 \\
\hline po210 & $7.08 E+04$ & 0.0313 & hg197 & $5.76 \mathrm{E}+04$ & 0.0360 & hg197 & $4.88 \mathrm{E}+04$ & 0.0411 & ir188 & $1.63 \mathrm{E}+04$ & 0.0306 \\
\hline pb200 & $6.82 E+04$ & 0.0301 & pb200 & $5.46 \mathrm{E}+04$ & 0.0341 & pb200 & $3.26 \mathrm{E}+04$ & 0.0275 & ir189 & $1.62 \mathrm{E}+04$ & 0.0304 \\
\hline tl199 & $6.81 \mathrm{E}+04$ & 0.0300 & pb201 & $4.89 \mathrm{E}+04$ & 0.0305 & au195 & $3.22 E+04$ & 0.0272 & os185 & $1.59 \mathrm{E}+04$ & 0.0299 \\
\hline bi204 & $6.67 E+04$ & 0.0294 & bi204 & $4.51 \mathrm{E}+04$ & 0.0282 & ir188 & $2.27 \mathrm{E}+04$ & 0.0191 & $\mathrm{tl} 202$ & $1.48 \mathrm{E}+04$ & 0.0278 \\
\hline hg197 & $6.06 \mathrm{E}+04$ & 0.0267 & tl199 & $3.94 \mathrm{E}+04$ & 0.0246 & pt191 & $2.24 \mathrm{E}+04$ & 0.0189 & pt188 & $1.37 \mathrm{E}+04$ & 0.0257 \\
\hline tl198 & $5.87 E+04$ & 0.0259 & bi203 & $3.67 \mathrm{E}+04$ & 0.0229 & ir189 & $2.20 \mathrm{E}+04$ & 0.0185 & re183 & $1.33 E+04$ & 0.0251 \\
\hline bi203 & $5.52 E+04$ & 0.0244 & au195 & $3.23 E+04$ & 0.0202 & tl202 & $2.08 \mathrm{E}+04$ & 0.0175 & hg197 & $1.03 E+04$ & 0.0193 \\
\hline tl197 & $4.14 \mathrm{E}+04$ & 0.0183 & tl198 & $3.06 \mathrm{E}+04$ & 0.0191 & pt188 & $2.06 \mathrm{E}+04$ & 0.0173 & w181 & $9.64 \mathrm{E}+03$ & 0.0181 \\
\hline hg195 & $4.06 E+04$ & 0.0179 & au193 & $2.80 \mathrm{E}+04$ & 0.0175 & bi204 & $1.72 \mathrm{E}+04$ & 0.0145 & po206 & $8.78 \mathrm{E}+03$ & 0.0165 \\
\hline tl196 & $3.57 \mathrm{E}+04$ & 0.0157 & hg195 & $2.63 E+04$ & 0.0165 & os185 & $1.66 \mathrm{E}+04$ & 0.0140 & bi207 & $6.98 \mathrm{E}+03$ & 0.0131 \\
\hline au193 & $3.25 \mathrm{E}+04$ & 0.0143 & pt191 & $2.60 \mathrm{E}+04$ & 0.0162 & au193 & $1.59 \mathrm{E}+04$ & 0.0134 & ta178 & $5.54 \mathrm{E}+03$ & 0.0104 \\
\hline au195 & $3.23 E+04$ & 0.0142 & ir188 & $2.32 \mathrm{E}+04$ & 0.0145 & pb201 & $1.50 \mathrm{E}+04$ & 0.0126 & w178 & $5.54 \mathrm{E}+03$ & 0.0104 \\
\hline pb199 & $3.23 E+04$ & 0.0142 & ir189 & $2.25 \mathrm{E}+04$ & 0.0140 & bi203 & $1.43 E+04$ & 0.0120 & pt191 & $5.35 \mathrm{E}+03$ & 0.0100 \\
\hline
\end{tabular}

\begin{tabular}{|c|c|c|c|c|c|c|c|c|}
\hline \multicolumn{3}{|c|}{$14.0 \mathrm{~d}$} & \multicolumn{3}{|c|}{$30.0 \mathrm{~d}$} & \multicolumn{3}{|c|}{$182.0 \mathrm{~d}$} \\
\hline isotope & $\begin{array}{l}\text { Activity } \\
\text { (Ci) }\end{array}$ & $\begin{array}{c}\text { Fraction } \\
\text { of total }\end{array}$ & isotope & $\begin{array}{l}\text { Activity } \\
\text { (Ci) }\end{array}$ & $\begin{array}{c}\text { Fraction } \\
\text { of total }\end{array}$ & isotope & $\begin{array}{c}\text { Activity } \\
\text { (Ci) }\end{array}$ & \begin{tabular}{|c|}
$\begin{array}{c}\text { Fraction } \\
\text { of total }\end{array}$ \\
\end{tabular} \\
\hline total & $3.61 \mathrm{E}+05$ & & total & $2.32 \mathrm{E}+05$ & & total & $8.41 \mathrm{E}+04$ & \\
\hline po210 & $6.86 \mathrm{E}+04$ & 0.1900 & po210 & $6.37 \mathrm{E}+04$ & 0.2750 & po210 & $2.98 \mathrm{E}+04$ & 0.3539 \\
\hline bi205 & $5.74 \mathrm{E}+04$ & 0.1589 & au195 & $2.90 \mathrm{E}+04$ & 0.1251 & au195 & $1.64 \mathrm{E}+04$ & 0.1956 \\
\hline bi206 & $3.57 \mathrm{E}+04$ & 0.0989 & bi205 & $2.78 \mathrm{E}+04$ & 0.1200 & bi207 & $6.90 \mathrm{E}+03$ & 0.0821 \\
\hline au195 & $3.07 \mathrm{E}+04$ & 0.0851 & os185 & $1.34 \mathrm{E}+04$ & 0.0580 & os185 & $4.36 \mathrm{E}+03$ & 0.0518 \\
\hline os185 & $1.51 \mathrm{E}+04$ & 0.0419 & re183 & $1.06 \mathrm{E}+04$ & 0.0459 & h 3 & $4.26 \mathrm{E}+03$ & 0.0506 \\
\hline re183 & $1.25 \mathrm{E}+04$ & 0.0345 & w181 & $8.45 E+03$ & 0.0365 & tl204 & $3.64 \mathrm{E}+03$ & 0.0432 \\
\hline bi210 & $1.25 \mathrm{E}+04$ & 0.0345 & bi206 & $7.92 \mathrm{E}+03$ & 0.0342 & w181 & $3.54 \mathrm{E}+03$ & 0.0421 \\
\hline ir189 & $1.12 \mathrm{E}+04$ & 0.0311 & bi207 & $6.97 \mathrm{E}+03$ & 0.0301 & re183 & $2.36 \mathrm{E}+03$ & 0.0281 \\
\hline ir188 & $1.02 \mathrm{E}+04$ & 0.0283 & ir189 & $4.84 \mathrm{E}+03$ & 0.0209 & ta179 & $2.09 \mathrm{E}+03$ & 0.0248 \\
\hline t|202 & $9.95 \mathrm{E}+03$ & 0.0276 & h 3 & $4.36 \mathrm{E}+03$ & 0.0188 & po208 & $2.06 \mathrm{E}+03$ & 0.0245 \\
\hline w181 & $9.26 \mathrm{E}+03$ & 0.0257 & tl202 & $4.02 \mathrm{E}+03$ & 0.0174 & lu173 & $8.56 \mathrm{E}+02$ & 0.0102 \\
\hline pt188 & $8.49 E+03$ & 0.0235 & tl204 & $3.92 \mathrm{E}+03$ & 0.0170 & hf175 & $7.75 \mathrm{E}+02$ & 0.0092 \\
\hline bi207 & $6.97 \mathrm{E}+03$ & 0.0193 & hf175 & $3.49 \mathrm{E}+03$ & 0.0151 & Iu172 & $6.02 \mathrm{E}+02$ & 0.0072 \\
\hline po206 & $5.06 \mathrm{E}+03$ & 0.0140 & ir188 & $3.44 \mathrm{E}+03$ & 0.0149 & hf172 & $5.96 \mathrm{E}+02$ & 0.0071 \\
\hline tl201 & $4.85 \mathrm{E}+03$ & 0.0134 & pt188 & $2.86 \mathrm{E}+03$ & 0.0123 & pt193 & $4.60 \mathrm{E}+02$ & 0.0055 \\
\hline ta178 & $4.43 E+03$ & 0.0123 & ta178 & $2.65 \mathrm{E}+03$ & 0.0115 & nb 95 & $4.17 \mathrm{E}+02$ & 0.0050 \\
\hline w178 & $4.43 E+03$ & 0.0123 & w178 & $2.65 \mathrm{E}+03$ & 0.0115 & y 88 & $4.05 E+02$ & 0.0048 \\
\hline h 3 & $4.37 \mathrm{E}+03$ & 0.0121 & ta179 & $2.45 E+03$ & 0.0106 & ru106 & $3.16 \mathrm{E}+02$ & 0.0038 \\
\hline hf175 & $4.09 \mathrm{E}+03$ & 0.0113 & po208 & $2.28 \mathrm{E}+03$ & 0.0098 & rh106 & $3.16 \mathrm{E}+02$ & 0.0038 \\
\hline tl204 & $3.96 \mathrm{E}+03$ & 0.0110 & hg203 & $2.10 \mathrm{E}+03$ & 0.0090 & ir192 & $2.91 \mathrm{E}+02$ & 0.0035 \\
\hline
\end{tabular}


Table 17. Radioisotope inventory as a function of time after shutdown for cell 3

\begin{tabular}{|c|c|c|c|c|c|c|c|c|c|c|c|}
\hline \multicolumn{3}{|c|}{$1.0 \mathrm{hr}$} & \multicolumn{3}{|c|}{ 8.0hr } & \multicolumn{3}{|c|}{$1.0 \mathrm{~d}$} & \multicolumn{3}{|c|}{$7.0 \mathrm{~d}$} \\
\hline isotope & $\begin{array}{c}\text { Activity } \\
\text { (Ci) }\end{array}$ & $\begin{array}{c}\text { Fraction } \\
\text { of total }\end{array}$ & isotope & $\begin{array}{c}\text { Activity } \\
\text { (Ci) }\end{array}$ & $\begin{array}{c}\text { Fraction } \\
\text { of total }\end{array}$ & isotope & $\begin{array}{c}\text { Activity } \\
\text { (Ci) }\end{array}$ & $\begin{array}{c}\text { Fraction } \\
\text { of total }\end{array}$ & isotope & $\begin{array}{c}\text { Activity } \\
\text { (Ci) }\end{array}$ & $\begin{array}{c}\text { Fraction } \\
\text { of total }\end{array}$ \\
\hline total & $3.32 \mathrm{E}+04$ & & total & $3.22 \mathrm{E}+04$ & & total & $3.06 E+04$ & & total & $2.15 E+04$ & \\
\hline bi210 & $1.76 \mathrm{E}+04$ & 0.5295 & bi210 & $1.69 \mathrm{E}+04$ & 0.5239 & bi210 & $1.54 \mathrm{E}+04$ & 0.5033 & po210 & $1.44 \mathrm{E}+04$ & 0.6729 \\
\hline po210 & $1.46 \mathrm{E}+04$ & 0.4386 & po210 & $1.46 \mathrm{E}+04$ & 0.4516 & po210 & $1.46 \mathrm{E}+04$ & 0.4761 & bi210 & $6.72 \mathrm{E}+03$ & 0.3130 \\
\hline bi206 & $2.66 \mathrm{E}+02$ & 0.0080 & bi206 & $2.57 \mathrm{E}+02$ & 0.0080 & bi206 & $2.39 E+02$ & 0.0078 & bi206 & $1.23 E+02$ & 0.0057 \\
\hline pb209 & $2.11 \mathrm{E}+02$ & 0.0063 & pb203 & $1.80 \mathrm{E}+02$ & 0.0056 & pb203 & $1.49 \mathrm{E}+02$ & 0.0049 & bi205 & $1.13 \mathrm{E}+02$ & 0.0053 \\
\hline pb203 & $1.95 \mathrm{E}+02$ & 0.0059 & bi205 & $1.52 \mathrm{E}+02$ & 0.0047 & bi205 & $1.48 \mathrm{E}+02$ & 0.0048 & pb203 & $2.22 \mathrm{E}+01$ & 0.0010 \\
\hline bi205 & $1.54 \mathrm{E}+02$ & 0.0047 & pb209 & $4.74 \mathrm{E}+01$ & 0.0015 & tl201 & $2.50 \mathrm{E}+01$ & 8.2E-04 & bi207 & $1.49 \mathrm{E}+01$ & $6.9 \mathrm{E}-04$ \\
\hline bi203 & $3.97 \mathrm{E}+01$ & 0.0012 & $\mathrm{t} \mid 201$ & $2.76 \mathrm{E}+01$ & $8.6 E-04$ & bi207 & $1.49 \mathrm{E}+01$ & $4.9 \mathrm{E}-04$ & hg203 & $1.35 \mathrm{E}+01$ & 6.3E-04 \\
\hline $\mathrm{t} \mid 201$ & $2.81 \mathrm{E}+01$ & $8.5 \mathrm{E}-04$ & bi203 & $2.63 E+01$ & 8.1E-04 & hg203 & $1.48 \mathrm{E}+01$ & $4.8 \mathrm{E}-04$ & $\mathrm{t} \mid 201$ & $6.53 \mathrm{E}+00$ & $3.0 \mathrm{E}-04$ \\
\hline tl199 & $2.65 \mathrm{E}+01$ & $8.0 \mathrm{E}-04$ & pb201 & $1.55 \mathrm{E}+01$ & $4.8 \mathrm{E}-04$ & $\mathrm{t} \mid 200$ & $1.19 \mathrm{E}+01$ & $3.9 \mathrm{E}-04$ & $\mathrm{t} \mid 200$ & $6.29 \mathrm{E}-01$ & $2.9 \mathrm{E}-05$ \\
\hline pb201 & $2.60 \mathrm{E}+01$ & $7.8 \mathrm{E}-04$ & hg203 & $1.50 \mathrm{E}+01$ & $4.6 \mathrm{E}-04$ & bi203 & $1.02 \mathrm{E}+01$ & $3.3 \mathrm{E}-04$ & h 3 & $1.76 \mathrm{E}-01$ & 8.2E-06 \\
\hline hg203 & $1.50 \mathrm{E}+01$ & 4.5E-04 & bi207 & $1.49 \mathrm{E}+01$ & $4.6 \mathrm{E}-04$ & pb200 & $6.48 \mathrm{E}+00$ & 2.1E-04 & pb200 & 6.24E-02 & 2.9E-06 \\
\hline bi207 & $1.49 \mathrm{E}+01$ & $4.5 \mathrm{E}-04$ & tl199 & $1.49 \mathrm{E}+01$ & $4.6 \mathrm{E}-04$ & pb201 & $4.71 E+00$ & $1.5 \mathrm{E}-04$ & tl204 & $2.25 E-02$ & $1.0 \mathrm{E}-06$ \\
\hline tl200 & $1.41 \mathrm{E}+01$ & $4.2 \mathrm{E}-04$ & $\mathrm{t} \mid 200$ & $1.37 \mathrm{E}+01$ & $4.3 E-04$ & tl199 & $3.35 \mathrm{E}+00$ & 1.1E-04 & tl206 & $1.06 \mathrm{E}-02$ & 4.9E-07 \\
\hline tl198 & $1.38 \mathrm{E}+01$ & $4.2 \mathrm{E}-04$ & pb200 & $1.09 \mathrm{E}+01$ & 3.4E-04 & bi204 & $3.18 \mathrm{E}+00$ & $1.0 \mathrm{E}-04$ & bi208 & $3.16 \mathrm{E}-03$ & $1.5 \mathrm{E}-07$ \\
\hline pb200 & $1.36 \mathrm{E}+01$ & 4.1E-04 & bi204 & $8.55 \mathrm{E}+00$ & 2.7E-04 & pb209 & $1.57 \mathrm{E}+00$ & 5.1E-05 & bi203 & 2.11E-03 & $9.8 \mathrm{E}-08$ \\
\hline bi204 & $1.32 \mathrm{E}+01$ & 4.0E-04 & tl198 & $7.82 E+00$ & $2.4 \mathrm{E}-04$ & $\mathrm{tl} 198$ & $1.09 E+00$ & $3.6 \mathrm{E}-05$ & $\mathrm{t} \mid 202$ & $1.76 \mathrm{E}-03$ & 8.2E-08 \\
\hline pb198 & $1.04 \mathrm{E}+01$ & 3.1E-04 & pb198 & $1.36 \mathrm{E}+00$ & $4.2 \mathrm{E}-05$ & h 3 & 1.76E-01 & $5.8 \mathrm{E}-06$ & bi210m & 1.70E-03 & 7.9E-08 \\
\hline bi202 & $9.09 \mathrm{E}+00$ & 2.7E-04 & bi202 & 4.97E-01 & $1.5 \mathrm{E}-05$ & tl204 & 2.26E-02 & $7.4 \mathrm{E}-07$ & pb202 & 1.49E-03 & $6.9 \mathrm{E}-08$ \\
\hline pb199 & $8.66 \mathrm{E}+00$ & $2.6 \mathrm{E}-04$ & pb199 & 3.41E-01 & 1.1E-05 & tl206 & $2.20 \mathrm{E}-02$ & $7.2 \mathrm{E}-07$ & bi204 & 4.37E-04 & $2.0 \mathrm{E}-08$ \\
\hline pb204m & $5.18 \mathrm{E}+00$ & 1.6E-04 & h 3 & 1.76E-01 & 5.5E-06 & pb198 & 1.31E-02 & 4.3E-07 & po208 & 1.76E-04 & \\
\hline
\end{tabular}

\begin{tabular}{|c|c|c|c|c|c|c|c|c|}
\hline \multicolumn{3}{|c|}{$14.0 \mathrm{~d}$} & \multicolumn{3}{|c|}{$30.0 \mathrm{~d}$} & \multicolumn{3}{|c|}{$182.0 \mathrm{~d}$} \\
\hline isotope & $\begin{array}{l}\text { Activity } \\
\text { (Ci) }\end{array}$ & $\begin{array}{l}\text { Fraction } \\
\text { of total }\end{array}$ & isotope & $\begin{array}{c}\text { Activity } \\
\text { (Ci) }\end{array}$ & $\begin{array}{c}\text { Fraction } \\
\text { of total }\end{array}$ & isotope & $\begin{array}{c}\text { Activity } \\
\text { (Ci) }\end{array}$ & $\begin{array}{c}\text { Fraction } \\
\text { of total }\end{array}$ \\
\hline Ototal & $1.68 \mathrm{E}+04$ & & Ototal & $1.34 \mathrm{E}+04$ & & Ototal & $6.13 E+03$ & \\
\hline po210 & 1.41E+04 & 0.8377 & po210 & $1.31 \mathrm{E}+04$ & 0.9769 & po210 & $6.12 E+03$ & 0.9974 \\
\hline bi210 & $2.55 \mathrm{E}+03$ & 0.1517 & bi210 & $2.79 \mathrm{E}+02$ & 0.0208 & bi207 & $1.48 \mathrm{E}+01$ & 0.0024 \\
\hline bi205 & $8.21 E+01$ & 0.0049 & bi205 & $3.98 \mathrm{E}+01$ & 0.0030 & hg203 & $1.00 \mathrm{E}+00$ & $1.6 \mathrm{E}-04$ \\
\hline bi206 & $5.65 \mathrm{E}+01$ & 0.0034 & bi207 & $1.49 \mathrm{E}+01$ & 0.0011 & h 3 & 1.71E-01 & 2.8E-05 \\
\hline bi207 & $1.49 \mathrm{E}+01$ & 8.9E-04 & hg203 & $9.62 \mathrm{E}+00$ & $7.2 \mathrm{E}-04$ & bi205 & 4.09E-02 & 6.7E-06 \\
\hline hg203 & $1.22 \mathrm{E}+01$ & 7.3E-04 & bi206 & $9.55 \mathrm{E}+00$ & 7.1E-04 & t1204 & $2.06 \mathrm{E}-02$ & 3.4E-06 \\
\hline pb203 & $2.35 \mathrm{E}+00$ & 1.4E-04 & h 3 & $1.75 \mathrm{E}-01$ & 1.3E-05 & bi208 & $3.16 \mathrm{E}-03$ & $5.2 \mathrm{E}-07$ \\
\hline tl201 & $1.32 \mathrm{E}+00$ & 7.9E-05 & $\mathrm{t} \mid 201$ & 3.43E-02 & 2.6E-06 & t1206 & $1.70 \mathrm{E}-03$ & $2.8 \mathrm{E}-07$ \\
\hline h 3 & 1.76E-01 & 1.0E-05 & t1204 & 2.22E-02 & 1.7E-06 & bi210m & $1.70 \mathrm{E}-03$ & $2.8 \mathrm{E}-07$ \\
\hline t1204 & $2.24 \mathrm{E}-02$ & $1.3 E-06$ & pb203 & $1.39 \mathrm{E}-02$ & $1.0 \mathrm{E}-06$ & tl202 & $1.49 \mathrm{E}-03$ & $2.4 \mathrm{E}-07$ \\
\hline t1200 & $9.35 \mathrm{E}-03$ & $5.6 E-07$ & bi208 & $3.16 \mathrm{E}-03$ & $2.4 \mathrm{E}-07$ & pb202 & $1.49 \mathrm{E}-03$ & 2.4E-07 \\
\hline tl206 & $5.07 \mathrm{E}-03$ & 3.0E-07 & tl206 & 2.07E-03 & 1.5E-07 & po208 & $1.57 \mathrm{E}-04$ & $2.6 \mathrm{E}-08$ \\
\hline bi208 & $3.16 \mathrm{E}-03$ & 1.9E-07 & bi210m & $1.70 \mathrm{E}-03$ & 1.3E-07 & po209 & 3.25E-05 & 5.3E-09 \\
\hline bi210m & 1.70E-03 & $1.0 \mathrm{E}-07$ & $\mathrm{t} \mid 202$ & $1.56 \mathrm{E}-03$ & 1.2E-07 & pb205 & $2.68 \mathrm{E}-05$ & 4.4E-09 \\
\hline $\mathrm{t} \mid 202$ & $1.67 E-03$ & 9.9E-08 & pb202 & $1.49 \mathrm{E}-03$ & 1.1E-07 & bi210 & $6.36 \mathrm{E}-07$ & $1.0 \mathrm{E}-10$ \\
\hline pb202 & $1.49 \mathrm{E}-03$ & 8.8E-08 & po208 & 1.73E-04 & 1.3E-08 & bi206 & 4.48E-07 & $7.3 E-11$ \\
\hline pb200 & 2.77E-04 & 1.6E-08 & po209 & 3.26E-05 & 2.4E-09 & pb210 & 4.28E-07 & $7.0 \mathrm{E}-11$ \\
\hline po208 & $1.75 \mathrm{E}-04$ & $1.0 \mathrm{E}-08$ & pb205 & 2.67E-05 & 2.0E-09 & bi209 & $1.09 \mathrm{E}-10$ & $1.8 \mathrm{E}-14$ \\
\hline po209 & $3.26 \mathrm{E}-05$ & 1.9E-09 & pb210 & 4.33E-07 & $3.2 \mathrm{E}-11$ & au195 & $2.39 \mathrm{E}-12$ & $3.9 \mathrm{E}-16$ \\
\hline pb205 & $2.66 \mathrm{E}-05$ & 1.6E-09 & $\mathrm{t} 1200$ & 3.93E-07 & $2.9 \mathrm{E}-11$ & hg206 & 8.13E-15 & 1.3E-18 \\
\hline
\end{tabular}


Table 18. Radioisotope inventory as a function of time after shutdown for cell 9

\begin{tabular}{|c|c|c|c|c|c|c|c|c|c|c|c|}
\hline \multicolumn{3}{|c|}{$1.0 \mathrm{hr}$} & \multicolumn{3}{|c|}{ 8.0hr } & \multicolumn{3}{|c|}{$1.0 \mathrm{~d}$} & \multicolumn{3}{|c|}{$7.0 \mathrm{~d}$} \\
\hline isotope & $\begin{array}{l}\text { Activity } \\
\text { (Ci) }\end{array}$ & $\begin{array}{c}\text { Fraction } \\
\text { of total }\end{array}$ & isotope & $\begin{array}{c}\text { Activity } \\
\text { (Ci) }\end{array}$ & $\begin{array}{c}\text { Fraction } \\
\text { of total }\end{array}$ & isotope & $\begin{array}{c}\text { Activity } \\
\text { (Ci) }\end{array}$ & $\begin{array}{c}\text { Fraction } \\
\text { of total }\end{array}$ & isotope & $\begin{array}{l}\text { Activity } \\
\text { (Ci) }\end{array}$ & $\begin{array}{c}\text { Fraction } \\
\text { of total }\end{array}$ \\
\hline Ototal & $9.92 \mathrm{E}+04$ & & Ototal & $9.37 \mathrm{E}+04$ & & Ototal & $8.72 E+04$ & & Ototal & $5.91 \mathrm{E}+04$ & \\
\hline bi210 & $4.52 \mathrm{E}+04$ & 0.4556 & bi210 & $4.34 \mathrm{E}+04$ & 0.4636 & bi210 & $3.96 \mathrm{E}+04$ & 0.4539 & po210 & $3.71 E+04$ & 0.6287 \\
\hline po210 & $3.74 E+04$ & 0.3772 & po210 & $3.74 \mathrm{E}+04$ & 0.3997 & po210 & $3.75 E+04$ & 0.4294 & bi210 & $1.73 E+04$ & 0.2924 \\
\hline bi206 & $3.92 \mathrm{E}+03$ & 0.0395 & bi206 & $3.80 \mathrm{E}+03$ & 0.0405 & bi206 & $3.53 E+03$ & 0.0404 & bi206 & $1.82 \mathrm{E}+03$ & 0.0307 \\
\hline bi205 & $2.32 \mathrm{E}+03$ & 0.0233 & bi205 & $2.28 \mathrm{E}+03$ & 0.0244 & bi205 & $2.22 \mathrm{E}+03$ & 0.0254 & bi205 & $1.69 \mathrm{E}+03$ & 0.0286 \\
\hline pb203 & $2.27 E+03$ & 0.0229 & pb203 & $2.11 \mathrm{E}+03$ & 0.0225 & pb203 & $1.74 \mathrm{E}+03$ & 0.0200 & bi207 & $2.84 \mathrm{E}+02$ & 0.0048 \\
\hline pb209 & $2.17 E+03$ & 0.0219 & $\mathrm{t} \mid 201$ & $7.92 \mathrm{E}+02$ & 0.0085 & tl201 & $7.10 \mathrm{E}+02$ & 0.0081 & pb203 & $2.60 \mathrm{E}+02$ & 0.0044 \\
\hline bi204 & $1.03 E+03$ & 0.0104 & bi204 & $6.72 \mathrm{E}+02$ & 0.0072 & $\mathrm{t} \mid 200$ & $3.77 E+02$ & 0.0043 & tl201 & $1.85 \mathrm{E}+02$ & 0.0031 \\
\hline $\mathrm{t} \mid 201$ & $8.14 E+02$ & 0.0082 & pb209 & $4.88 \mathrm{E}+02$ & 0.0052 & bi207 & $2.84 \mathrm{E}+02$ & 0.0033 & $\mathrm{t} \mid 202$ & $1.42 \mathrm{E}+02$ & 0.0024 \\
\hline pb201 & $5.96 \mathrm{E}+02$ & 0.0060 & $\mathrm{t} \mid 200$ & $4.53 \mathrm{E}+02$ & 0.0048 & bi204 & $2.51 \mathrm{E}+02$ & 0.0029 & t1204 & $9.29 \mathrm{E}+01$ & 0.0016 \\
\hline bi203 & $5.29 \mathrm{E}+02$ & 0.0053 & pb201 & $3.68 \mathrm{E}+02$ & 0.0039 & $\mathrm{t} \mid 202$ & $2.00 \mathrm{E}+02$ & 0.0023 & hg203 & $8.08 \mathrm{E}+01$ & 0.0014 \\
\hline $\mathrm{t} \mid 200$ & $4.76 \mathrm{E}+02$ & 0.0048 & bi203 & $3.50 \mathrm{E}+02$ & 0.0037 & pb200 & $1.82 \mathrm{E}+02$ & 0.0021 & au195 & $2.05 \mathrm{E}+01$ & $3.5 \mathrm{E}-04$ \\
\hline pb200 & $3.82 \mathrm{E}+02$ & 0.0038 & pb200 & $3.05 \mathrm{E}+02$ & 0.0033 & bi203 & $1.36 \mathrm{E}+02$ & 0.0016 & hg197 & $1.99 \mathrm{E}+01$ & $3.4 \mathrm{E}-04$ \\
\hline bi207 & $2.84 \mathrm{E}+02$ & 0.0029 & bi207 & $2.84 \mathrm{E}+02$ & 0.0030 & pb201 & $1.13 E+02$ & 0.0013 & tl200 & $1.87 \mathrm{E}+01$ & 3.2E-04 \\
\hline tl199 & $2.16 \mathrm{E}+02$ & 0.0022 & $\mathrm{t} \mid 202$ & $2.07 \mathrm{E}+02$ & 0.0022 & hg197 & $9.42 \mathrm{E}+01$ & 0.0011 & nb 95 & $1.22 \mathrm{E}+01$ & 2.1E-04 \\
\hline tl202 & $2.11 E+02$ & 0.0021 & tl199 & $1.25 \mathrm{E}+02$ & 0.0013 & $\mathrm{t} \mid 204$ & $9.32 \mathrm{E}+01$ & 0.0011 & zr 95 & $1.17 \mathrm{E}+01$ & 2.0E-04 \\
\hline bi202 & $1.64 \mathrm{E}+02$ & 0.0016 & hg197 & $1.11 \mathrm{E}+02$ & 0.0012 & hg203 & $8.83 E+01$ & 0.0010 & po206 & $8.10 E+00$ & 1.4E-04 \\
\hline hg197 & $1.17 \mathrm{E}+02$ & 0.0012 & tl204 & $9.32 \mathrm{E}+01$ & 0.0010 & tl199 & $2.83 E+01$ & $3.2 \mathrm{E}-04$ & h 3 & $5.55 \mathrm{E}+00$ & 9.4E-05 \\
\hline bi201 & $1.13 \mathrm{E}+02$ & 0.0011 & hg203 & $8.92 \mathrm{E}+01$ & 0.0010 & au195 & $2.09 E+01$ & $2.4 \mathrm{E}-04$ & po208 & $3.03 \mathrm{E}+00$ & 5.1E-05 \\
\hline pb199 & $1.03 \mathrm{E}+02$ & 0.0010 & tl198 & $4.60 \mathrm{E}+01$ & $4.9 \mathrm{E}-04$ & pb209 & $1.62 \mathrm{E}+01$ & $1.9 \mathrm{E}-04$ & au198 & $2.52 \mathrm{E}+00$ & 4.3E-05 \\
\hline pb204m & $1.00 \mathrm{E}+02$ & 0.0010 & au193 & $2.24 \mathrm{E}+01$ & $2.4 \mathrm{E}-04$ & po206 & $1.30 \mathrm{E}+01$ & 1.5E-04 & pb200 & $1.76 \mathrm{E}+00$ & 3.0E-05 \\
\hline
\end{tabular}

\begin{tabular}{|c|c|c|c|c|c|c|c|c|}
\hline \multicolumn{3}{|c|}{$14.0 \mathrm{~d}$} & \multicolumn{3}{|c|}{$30.0 \mathrm{~d}$} & \multicolumn{3}{|c|}{$182.0 \mathrm{~d}$} \\
\hline isotope & $\begin{array}{l}\text { Activity } \\
\text { (Ci) }\end{array}$ & $\begin{array}{l}\text { Fraction } \\
\text { of total }\end{array}$ & isotope & $\begin{array}{c}\text { Activity } \\
\text { (Ci) }\end{array}$ & $\begin{array}{c}\text { Fraction } \\
\text { of total }\end{array}$ & isotope & $\begin{array}{l}\text { Activity } \\
\text { (Ci) }\end{array}$ & $\begin{array}{c}\text { Fraction } \\
\text { of total }\end{array}$ \\
\hline all & $4.55 \mathrm{E}+04$ & & all & $3.56 \mathrm{E}+04$ & & all & $1.61 \mathrm{E}+04$ & \\
\hline po210 & $3.62 \mathrm{E}+04$ & 0.7958 & po210 & $3.37 \mathrm{E}+04$ & 0.9444 & po210 & $1.57 \mathrm{E}+04$ & 0.9752 \\
\hline bi210 & $6.56 \mathrm{E}+03$ & 0.1441 & bi210 & $7.18 \mathrm{E}+02$ & 0.0202 & bi207 & $2.81 \mathrm{E}+02$ & 0.0174 \\
\hline bi205 & $1.23 \mathrm{E}+03$ & 0.0270 & bi205 & $5.96 \mathrm{E}+02$ & 0.0167 & t|204 & $8.51 \mathrm{E}+01$ & 0.0053 \\
\hline bi206 & $8.38 \mathrm{E}+02$ & 0.0184 & bi207 & $2.83 E+02$ & 0.0079 & au195 & 1.07E+01 & 6.6E-04 \\
\hline bi207 & $2.83 E+02$ & 0.0062 & bi206 & $1.44 \mathrm{E}+02$ & 0.0040 & hg203 & $5.99 \mathrm{E}+00$ & 3.7E-04 \\
\hline t1202 & $9.55 \mathrm{E}+01$ & 0.0021 & t1204 & $9.18 \mathrm{E}+01$ & 0.0026 & h 3 & $5.40 \mathrm{E}+00$ & $3.4 \mathrm{E}-04$ \\
\hline t1204 & $9.26 \mathrm{E}+01$ & 0.0020 & hg203 & $5.74 \mathrm{E}+01$ & 0.0016 & nb 95 & $3.45 \mathrm{E}+00$ & $2.1 \mathrm{E}-04$ \\
\hline hg203 & $7.28 \mathrm{E}+01$ & 0.0016 & tl202 & $3.86 E+01$ & 0.0011 & po208 & $2.71 \mathrm{E}+00$ & 1.7E-04 \\
\hline $\mathrm{t} \mid 201$ & $3.74 \mathrm{E}+01$ & $8.2 E-04$ & au195 & $1.88 \mathrm{E}+01$ & 5.3E-04 & zr 95 & $1.76 \mathrm{E}+00$ & 1.1E-04 \\
\hline pb203 & $2.76 \mathrm{E}+01$ & 6.1E-04 & nb 95 & $1.15 E+01$ & 3.2E-04 & bi205 & 6.13E-01 & 3.8E-05 \\
\hline au195 & $2.00 \mathrm{E}+01$ & 4.4E-04 & zr 95 & $9.11 \mathrm{E}+00$ & $2.6 \mathrm{E}-04$ & pt193 & 3.82E-01 & 2.4E-05 \\
\hline nb 95 & $1.21 \mathrm{E}+01$ & 2.7E-04 & h 3 & $5.53 E+00$ & $1.6 E-04$ & au194 & 1.12E-01 & $6.9 \mathrm{E}-06$ \\
\hline zr 95 & $1.08 \mathrm{E}+01$ & 2.4E-04 & po208 & $2.99 \mathrm{E}+00$ & 8.4E-05 & hg194 & 1.12E-01 & $6.9 \mathrm{E}-06$ \\
\hline h 3 & $5.55 \mathrm{E}+00$ & 1.2E-04 & po206 & $1.32 \mathrm{E}+00$ & 3.7E-05 & bi208 & 5.68E-02 & 3.5E-06 \\
\hline po206 & $4.67 \mathrm{E}+00$ & 1.0E-04 & t|201 & $9.72 \mathrm{E}-01$ & 2.7E-05 & ag110m & 2.73E-02 & 1.7E-06 \\
\hline hg197 & $3.23 \mathrm{E}+00$ & 7.1E-05 & pt193 & $3.84 \mathrm{E}-01$ & 1.1E-05 & t|202 & 2.41E-02 & $1.5 \mathrm{E}-06$ \\
\hline po208 & $3.02 E+00$ & 6.6E-05 & pb203 & $1.63 \mathrm{E}-01$ & $4.6 \mathrm{E}-06$ & nb 95m & 2.07E-02 & 1.3E-06 \\
\hline au198 & 4.19E-01 & $9.2 E-06$ & au194 & 1.12E-01 & 3.1E-06 & pb202 & 1.71E-02 & 1.1E-06 \\
\hline pt193 & 3.84E-01 & 8.4E-06 & hg194 & 1.12E-01 & $3.1 E-06$ & po209 & 1.01E-02 & $6.2 E-07$ \\
\hline tl200 & $2.74 \mathrm{E}-01$ & $6.0 \mathrm{E}-06$ & nb 95m & $1.07 \mathrm{E}-01$ & 3.0E-06 & tl206 & 4.37E-03 & 2.7E-07 \\
\hline
\end{tabular}


Table 19. Dose rate $(\mathrm{mR} / \mathrm{hr})$ calculations for the LBE cell 8 from the cylinder side at the midpoint

\begin{tabular}{|c|c|c|c|c|c|}
\hline \multirow{2}{*}{ Distance $(\mathrm{cm})$} & \multicolumn{5}{|c|}{ Time after shutdown (days) } \\
\cline { 2 - 6 } & 1 & 7 & 14 & 30 & 182 \\
\hline 1 & $4.1 \mathrm{E} 10$ & $1.7 \mathrm{E} 10$ & $1.0 \mathrm{E} 10$ & $4.9 \mathrm{E} 9$ & $1.1 \mathrm{E} 9$ \\
\hline 30 & $2.8 \mathrm{E} 9$ & $1.2 \mathrm{E} 9$ & $7.1 \mathrm{E} 8$ & $3.3 \mathrm{E} 8$ & $7.2 \mathrm{E} 7$ \\
\hline 60 & $8.5 \mathrm{E} 8$ & $3.6 \mathrm{E} 8$ & $2.2 \mathrm{E} 8$ & $1.0 \mathrm{E} 8$ & $2.2 \mathrm{E} 7$ \\
\hline 90 & $4.1 \mathrm{E} 8$ & $1.7 \mathrm{E} 8$ & $1.0 \mathrm{E} 8$ & $4.9 \mathrm{E} 7$ & $1.0 \mathrm{E} 7$ \\
\hline 120 & $2.4 \mathrm{E} 8$ & $1.0 \mathrm{E} 8$ & $6.2 \mathrm{E} 7$ & $2.9 \mathrm{E} 7$ & $5.9 \mathrm{E} 6$ \\
\hline 150 & $1.6 \mathrm{E} 8$ & $6.8 \mathrm{E} 7$ & $4.1 \mathrm{E} 7$ & $1.9 \mathrm{E} 7$ & $3.9 \mathrm{E} 6$ \\
\hline
\end{tabular}

Table 20. Dose rate $(\mathrm{mR} / \mathrm{hr})$ calculations for the LBE cell 8 from the cylinder face at the axis

\begin{tabular}{|c|c|c|c|c|c|}
\hline \multirow{2}{*}{ Distance $(\mathrm{cm})$} & \multicolumn{5}{|c|}{ Time after shutdown (days) } \\
\cline { 2 - 6 } & 1 & 7 & 14 & 30 & 182 \\
\hline 1 & $2.6 \mathrm{E} 9$ & $1.3 \mathrm{E} 9$ & $7.7 \mathrm{E} 8$ & $3.1 \mathrm{E} 8$ & $4.5 \mathrm{E} 7$ \\
\hline 30 & $2.6 \mathrm{E} 8$ & $1.2 \mathrm{E} 8$ & $7.6 \mathrm{E} 7$ & $3.0 \mathrm{E} 7$ & $4.5 \mathrm{E} 6$ \\
\hline 60 & $7.5 \mathrm{E} 7$ & $3.6 \mathrm{E} 7$ & $2.2 \mathrm{E} 7$ & $8.9 \mathrm{E} 7$ & $1.3 \mathrm{E} 6$ \\
\hline 90 & $3.5 \mathrm{E} 7$ & $1.7 \mathrm{E} 7$ & $1.0 \mathrm{E} 7$ & $4.1 \mathrm{E} 6$ & $6.0 \mathrm{E} 5$ \\
\hline 120 & $2.0 \mathrm{E} 7$ & $9.6 \mathrm{E} 6$ & $5.8 \mathrm{E} 6$ & $2.4 \mathrm{E} 6$ & $3.4 \mathrm{E} 5$ \\
\hline 150 & $1.3 \mathrm{E} 7$ & $6.2 \mathrm{E} 6$ & $3.8 \mathrm{E} 6$ & $1.5 \mathrm{E} 6$ & $2.2 \mathrm{E} 5$ \\
\hline
\end{tabular}




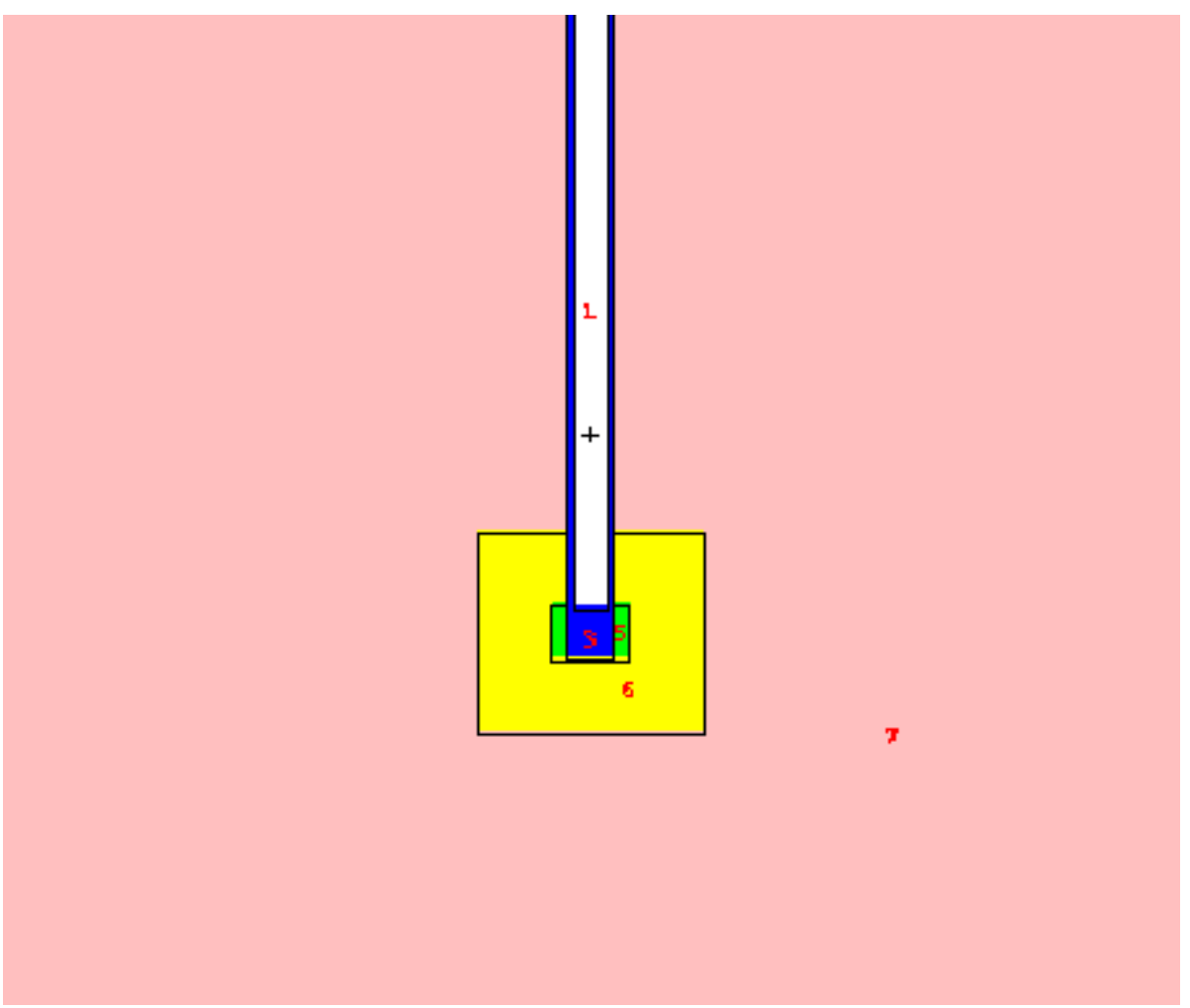

Figure 76. Schematic of the LBE system 


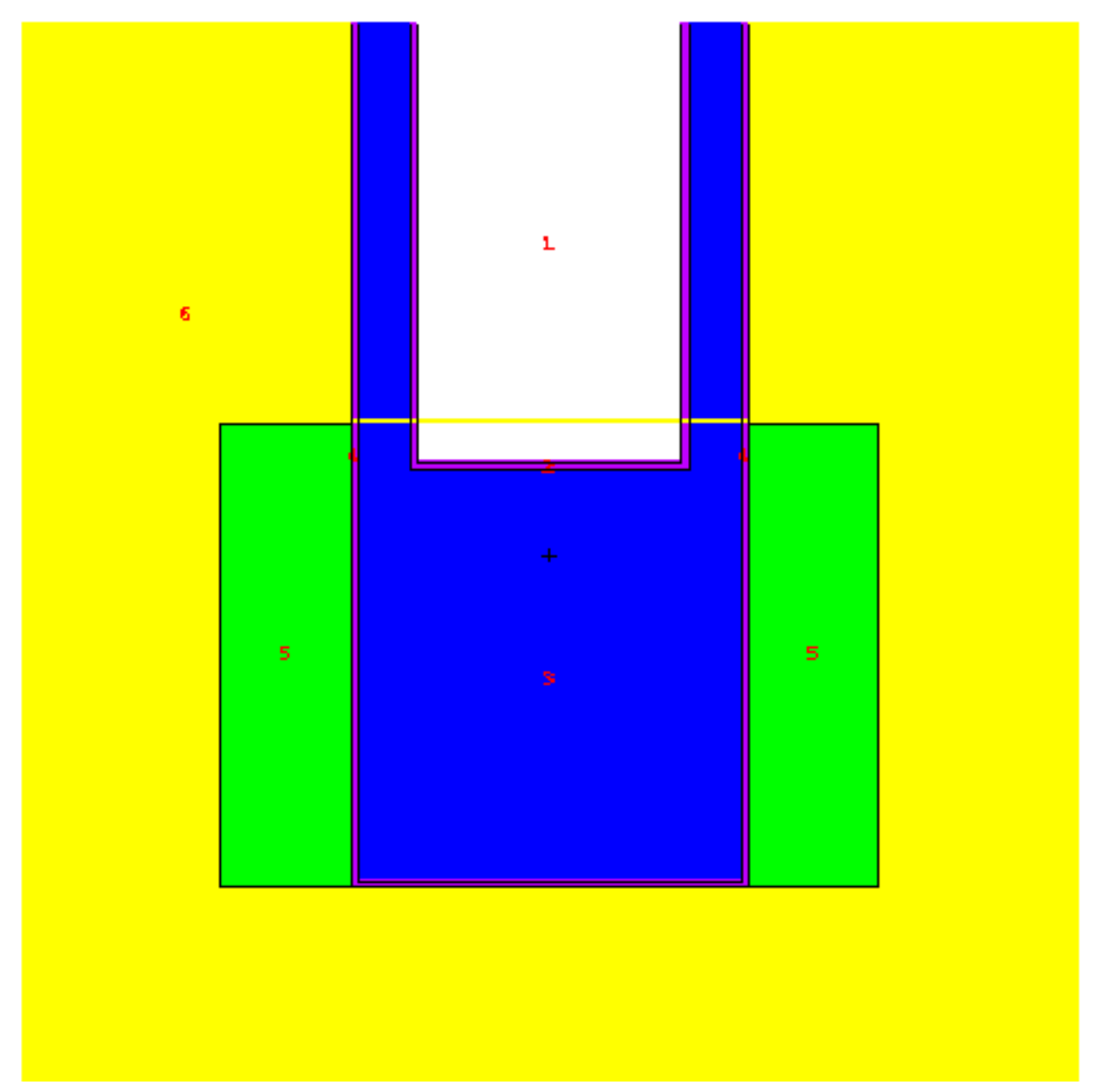

Figure 77. Expanded view of the LBE system 


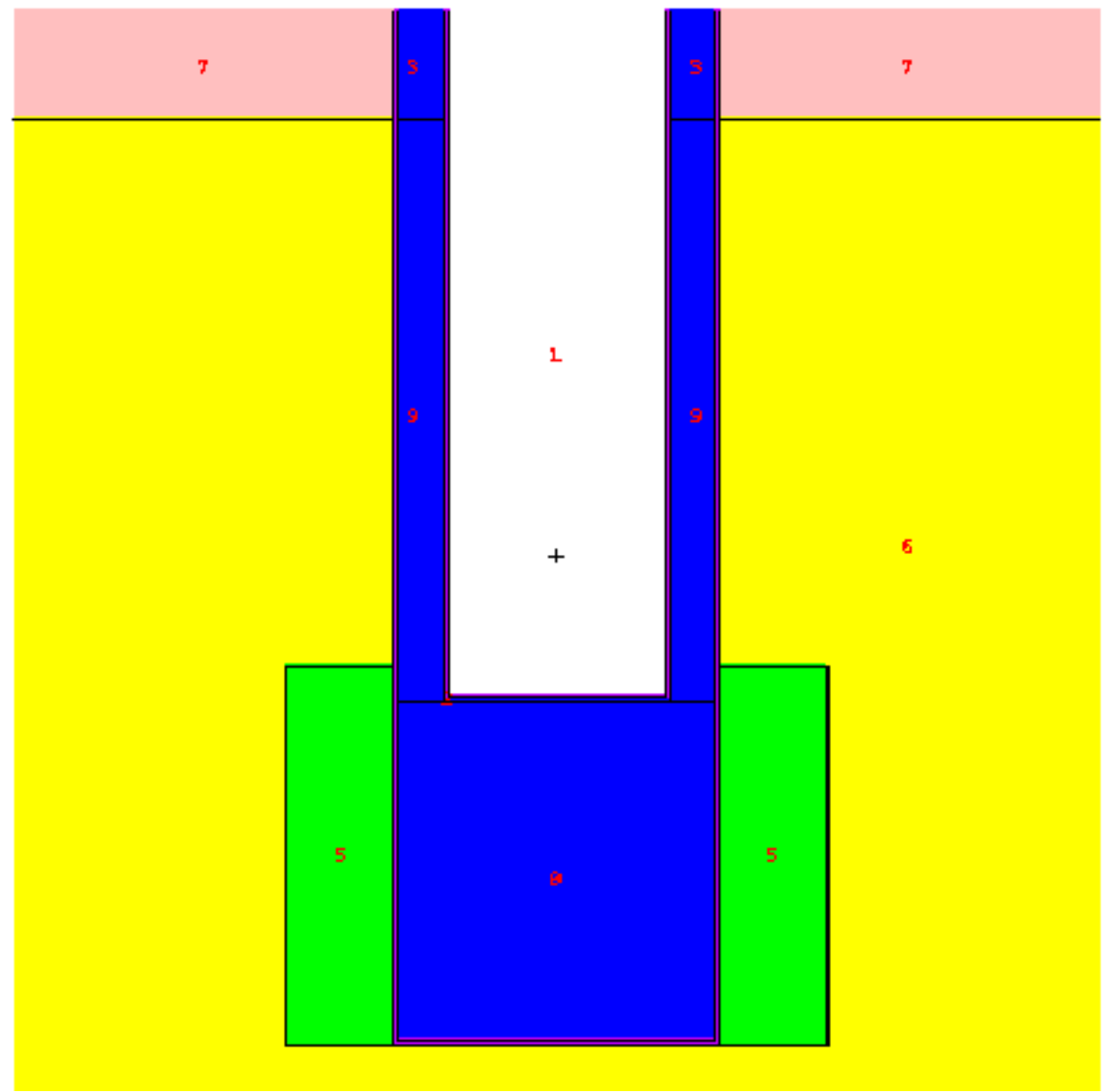

Figure 78. Breakup scheme of the LBE target 
Decay Power Buildup as a Function of Irradiation Time

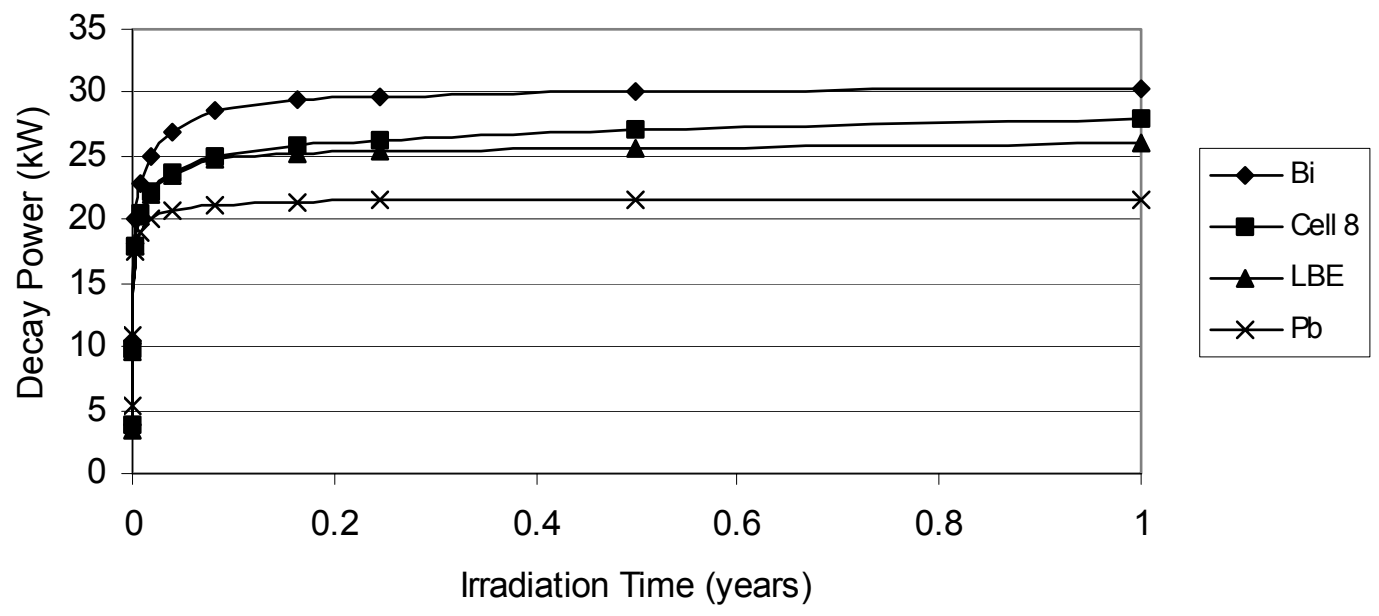

Figure 79. Buildup of decay power in a bismuth, lead, and LBE cylindrical target compared to cell 8

\section{Power After Shutdown in Cell 8}

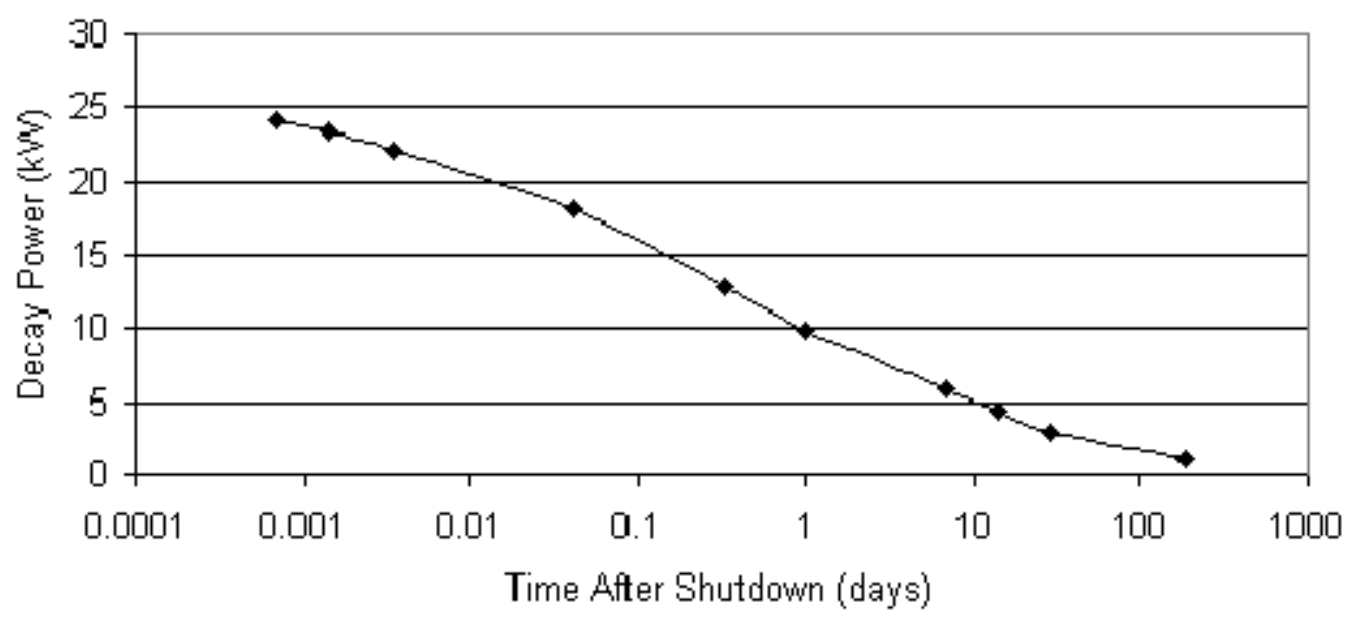

Figure 80. Decay of radioisotope power for cell 8 as a function of time after shutdown 


\section{Decay Power Buildup for Cell 9}

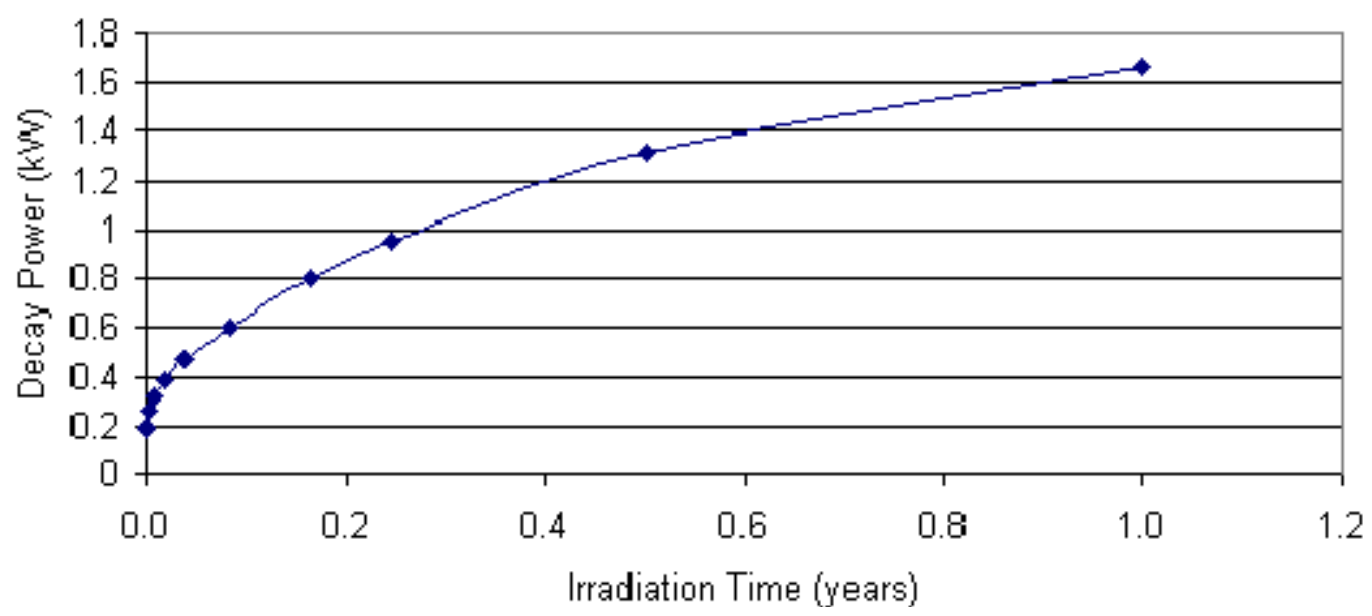

Figure 81. Buildup of decay power in cell 9 as a function of irradiation time

Decay Power Buildup for Cell 3

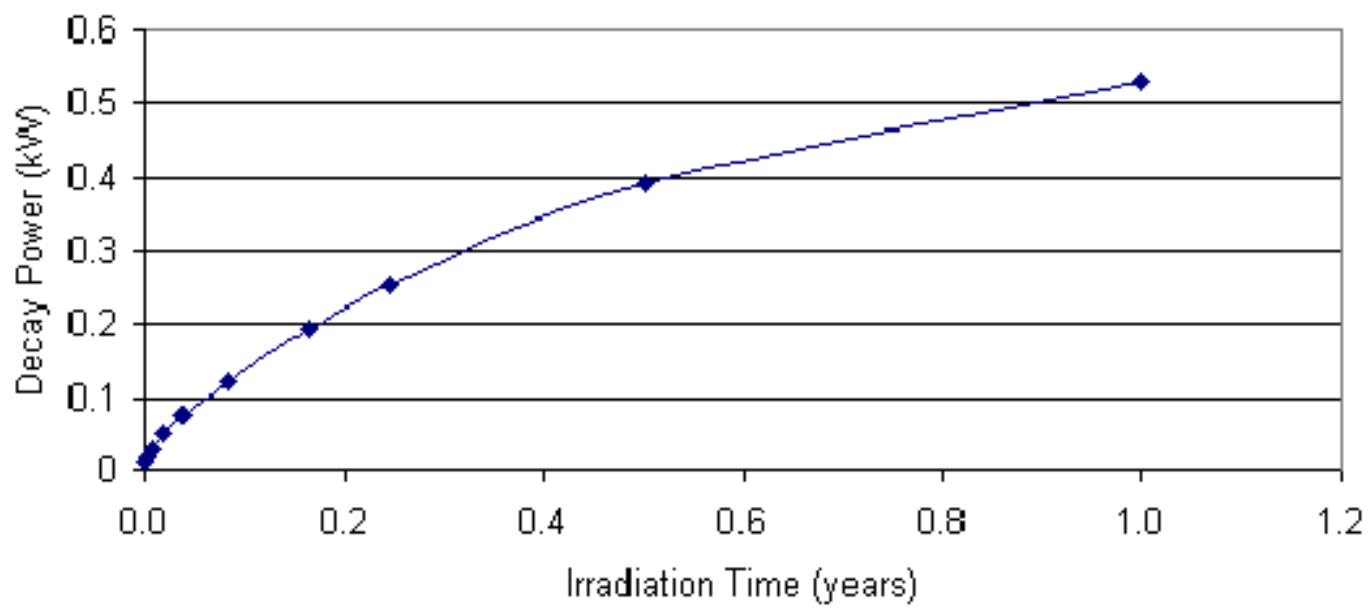

Figure 82. Buildup of decay power in cell 3 as a function of irradiation time 
Radioactive Inhalation Hazard for Cell 8

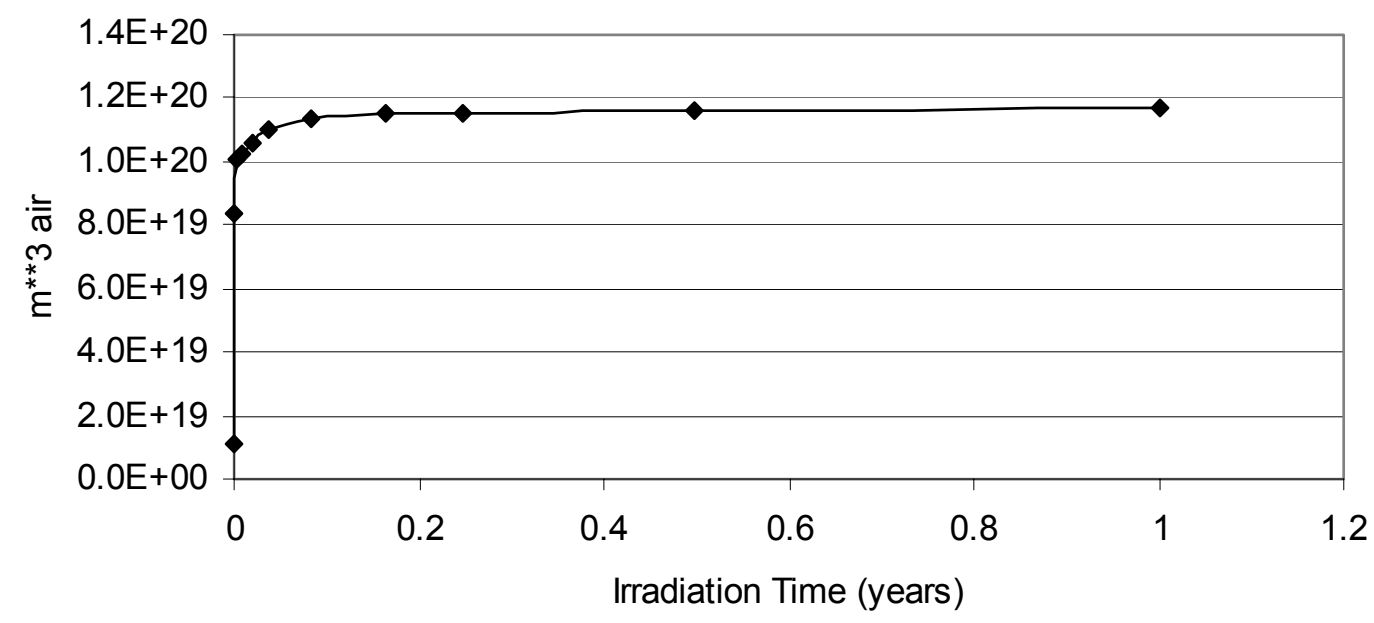

Figure 83. Radioactive inhalation hazard for cell 8 as a function of irradiation time

Radioactive Ingestion Hazard for Cell 8

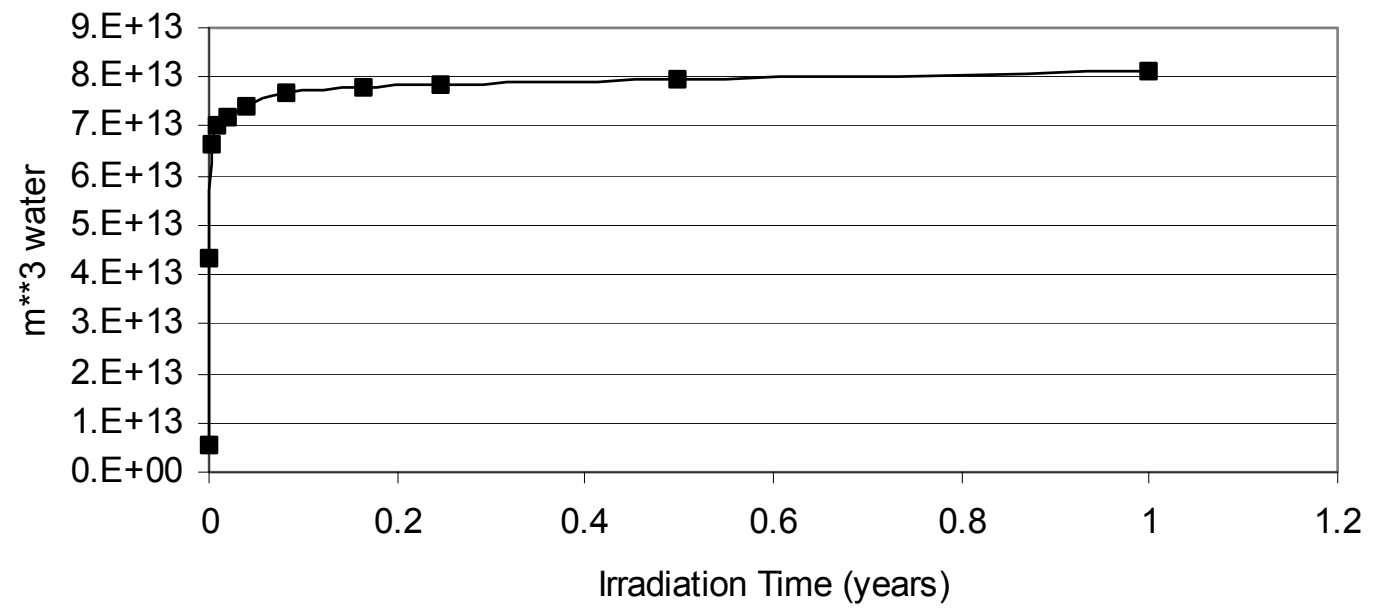

Figure 84. Radioactive ingestion hazard for cell 8 as a function of irradiation time 
Radioactive Inhalation Hazard for Cell 8

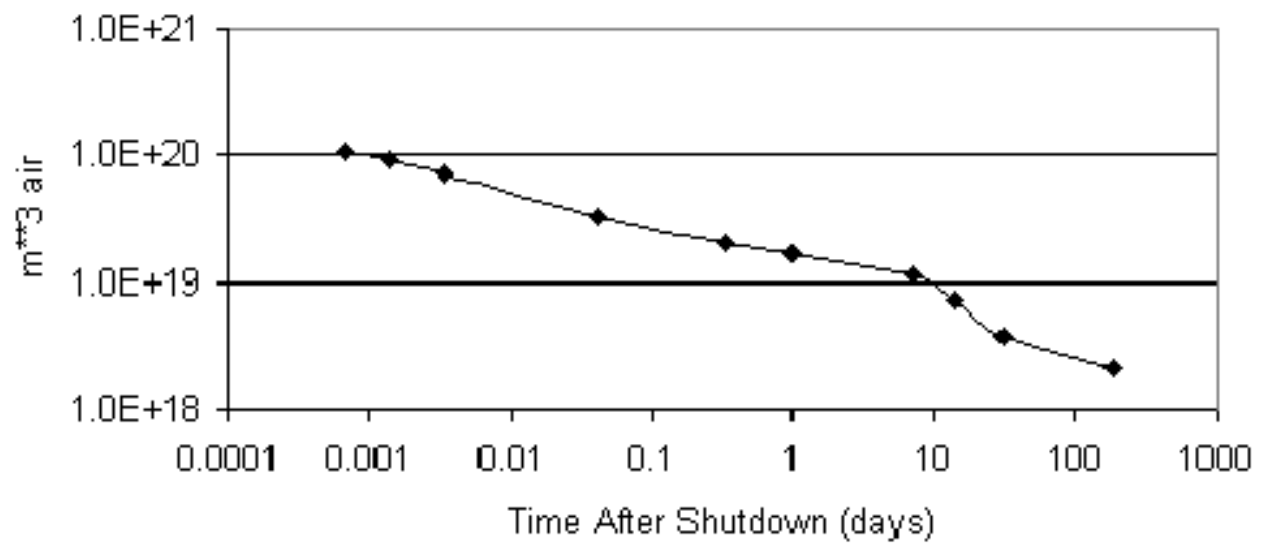

Figure 85. Radioactive inhalation hazard for cell 8 as a function of decay time

Radioactive Ingestion Hazard for Cell 8

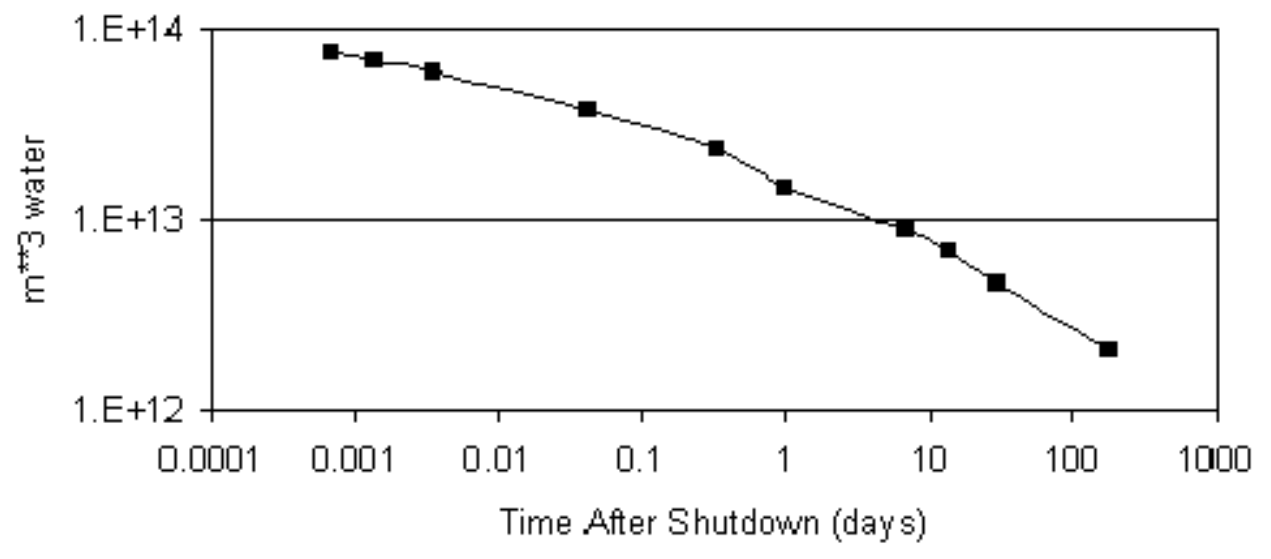

Figure 86. Radioactive ingestion hazard for cell 8 as a function of decay time 


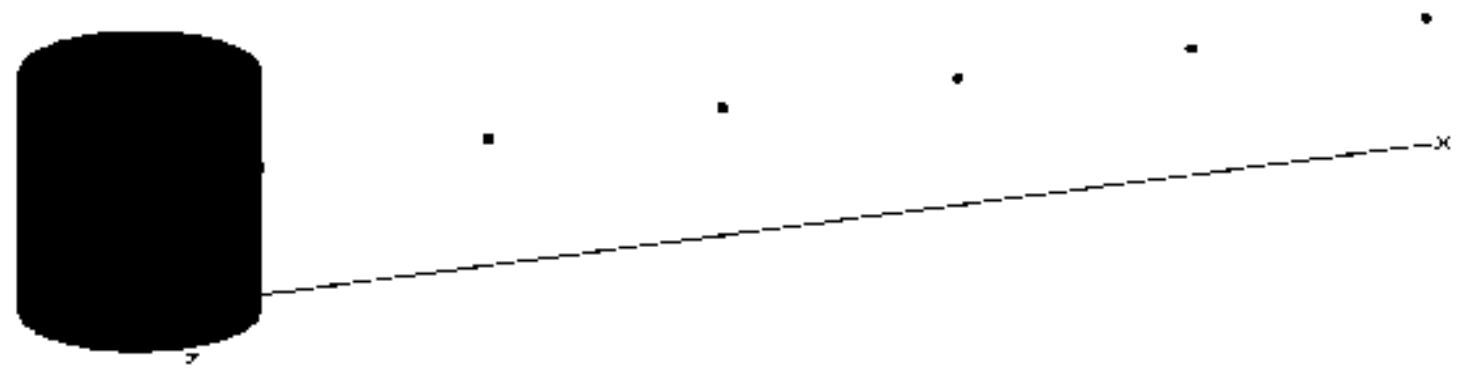

Figure 87. Geometry for the dose rate calculations from the cylinder side (for Table 19)

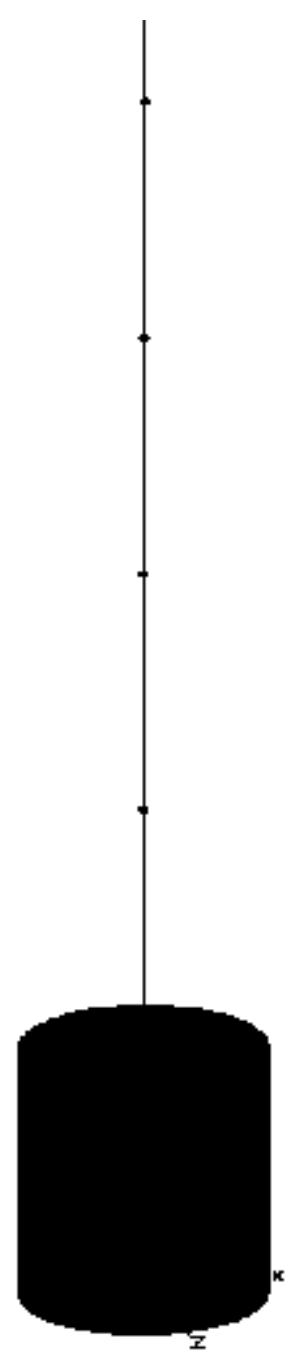

Figure 88. Geometry for the dose rate calculations from the cylinder face (for Table 20) 


\section{Structural material temperature during loss of flow event}

The decay heat within the liquid LBE inventory is much less than the decay heat within the driver fuel of the subcritical multiplier. However, it is substantial enough to warrant consideration to insure that the structural material temperature limits are not exceeded during loss of flow event. These limits depend on the selected structural material, the loading conditions, the normal operating temperature, and the nuclear response parameters (gas production and atomic displacement) accumulated at the time of the event. A detailed study will be required to define these limits and the allowable stay time at each temperature level. A very conservative assumption is to consider the maximum operating temperature during the normal operation as the limit during the loss of flow event. Other design study [12] defined $800^{\circ} \mathrm{C}$ as a limit for type 316SS during abnormal conditions for short period. This limit allows the system to reoperate without target replacement.

The radiological analysis calculated the LBE decay power as shown in Figure 89 as a function of the time after shutdown. These calculations include the decay heat generated due all types of nuclear interactions caused by the protons and the spallation products in the LBE target inventory. The primary heat sinks for decay heat removal from the liquid LBE are the back shine shield inside the beam tube shown in Figure 90, the structural and shield components connected to the target system, the LBE inventory, the LBE heat exchanger, and the gas surrounding the connective piping between the target and the heat exchanger within the containment vessel. Radiation heat transfer across the helium gap between the target inlet manifold and the guard tube is also contributing.

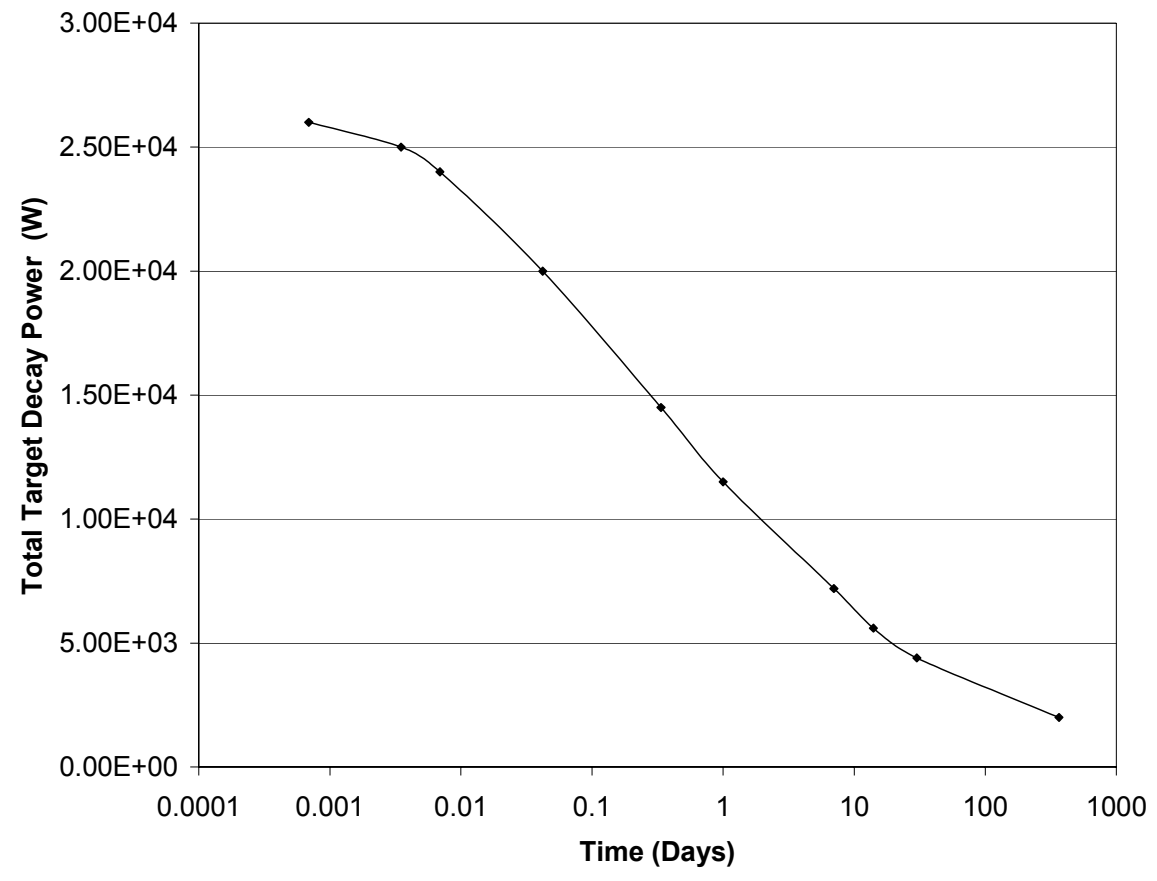

Figure 89. LBE decay power as a function of time after shutdown 


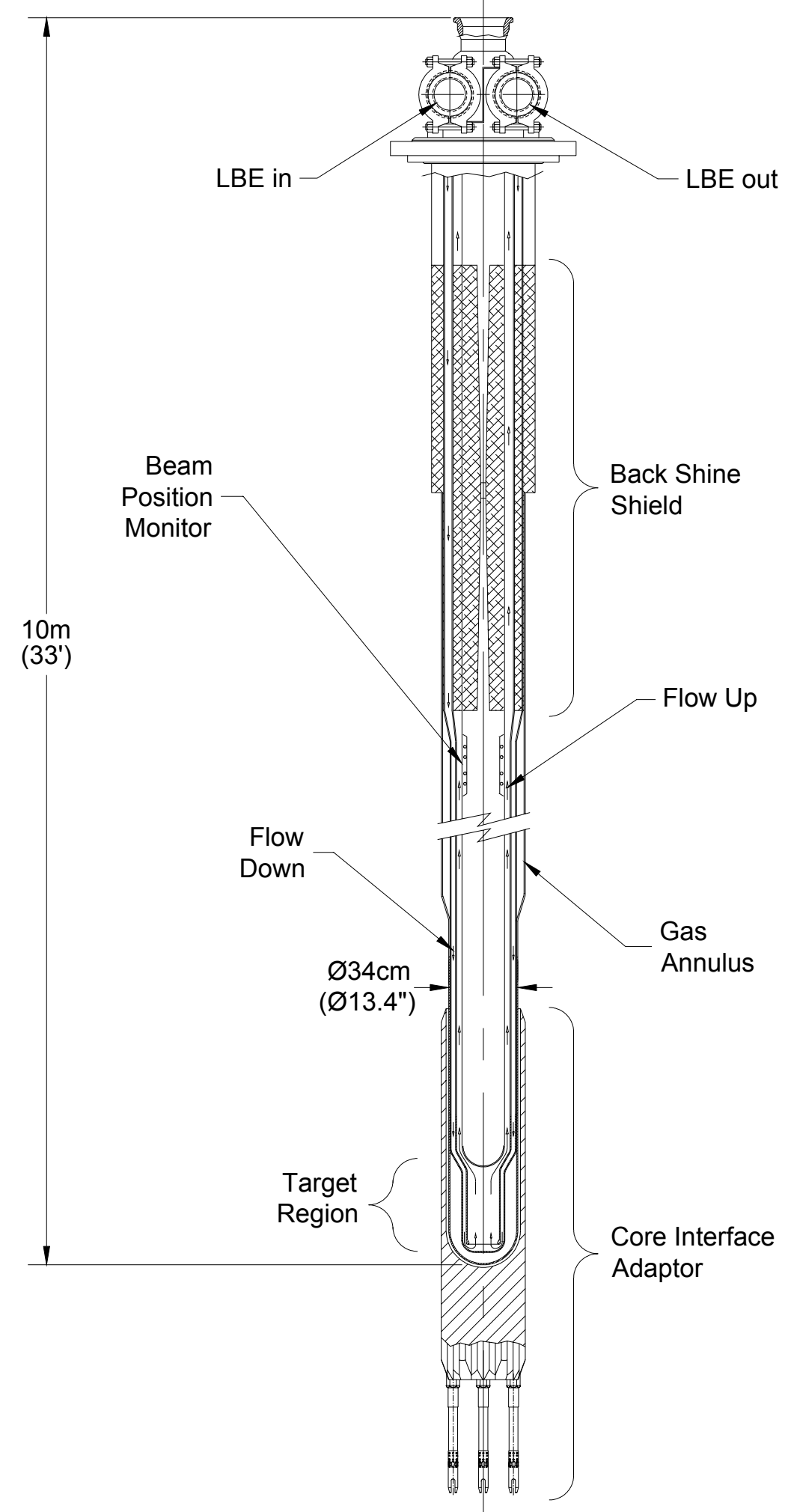

Figure 90. ADTF target design featuring the integration of the back shine shield and the other structural elements 


\section{VIII.1 Transient adiabatic heat-up for the LBE target}

In order to evaluate the target performance during loss of flow event under very conservative conditions without the use of an active engineering system, the adiabatic heat-up of the LBE inventory and the surrounding structural components is used to calculate the time for reaching the maximum normal operating temperature limit and the $800{ }^{\circ} \mathrm{C}$ limit. For this analysis, it is assumed that the proton beam is terminated at the onset of loss of flow conditions. Since the final details of all LBE system components have not been fully defined, the volume of the LBE and the volume of the surrounding steel structure are treated as parametric variables. The temperature of the LBE and the steel volumes are then evaluated as a function of time, LBE volume, and steel volume. The transient temperature is evaluated using the energy balance for the target system, shown in the following equation.

$$
\rho_{\text {LBE }} C_{\text {LBE }} V_{\text {LBE }} \frac{d \overline{T_{\text {LBE }}}}{d t}+\rho_{\text {steel }} c_{\text {steel }} V_{\text {steel }} \frac{d \overline{T_{\text {steel }}}}{d t}=q_{\text {decay }}(t)
$$

At the onset of the transient, the system is assumed to be in a fully isothermal state, with an initial temperature of $220^{\circ} \mathrm{C}$. Fully adiabatic boundary conditions are assumed. No credit is taken for radiation heat transfer to the guard vessel, convection to the gas within containment vessel or natural convection within the LBE target. As indicated by the notation in the above equation, the spatial dependence of the temperature within each region is neglected and the average value is evaluated in these calculations. Furthermore, in order to evaluate the transient heat-up of the system analytically, the temperature of the LBE and steel components are assumed to remain in an isothermal equilibrium throughout the transient (i.e., $\overline{\mathrm{T}_{\mathrm{LBE}}}(\mathrm{t})=\overline{\mathrm{T}_{\text {steel }}}(\mathrm{t})$ ). This is a conservative assumption since the heat capacity of the steel is much greater than the heat capacity of the LBE, and actual adiabatic heat up time will be longer in the actual system. Results of this analysis are shown for nine cases in Figure 91. These cases are defined in Table 21 with respect to the LBE and steel volume.

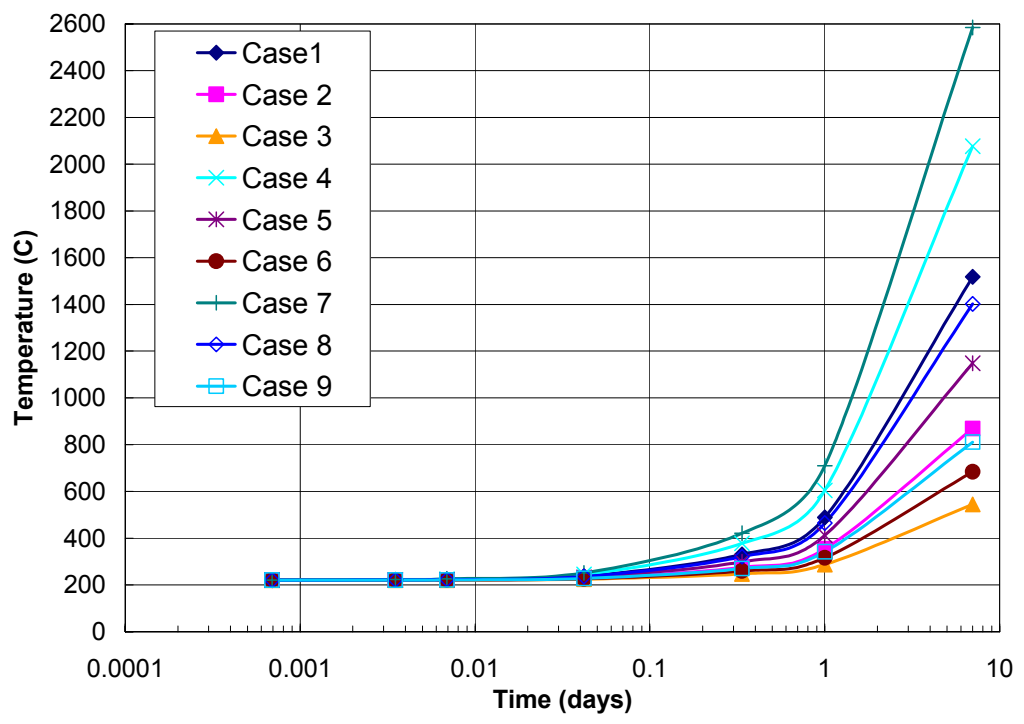

Figure 91. Adiabatic heat-up of the LBE target system 
Table 21. Definition of the different cases considered in the target temperature calculation

\begin{tabular}{|c|c|c|}
\hline Case & LBE Volume $\left(\mathrm{m}^{3}\right)$ & Steel Volume $\left(\mathrm{m}^{3}\right)$ \\
\hline 1 & 1.25 & .625 \\
\hline 2 & 2.5 & 1.25 \\
\hline 3 & 5.0 & 2.5 \\
\hline 4 & 1.25 & 0.3125 \\
\hline 5 & 2.5 & .625 \\
\hline 6 & 5.0 & 1.25 \\
\hline 7 & 1.25 & .15625 \\
\hline 8 & 2.5 & .3125 \\
\hline 9 & 5.0 & .625 \\
\hline
\end{tabular}

Case 5 is an approximation of the anticipated LBE target system configuration. For this case, the average system temperature remains under the system temperature limit of 550 and $800{ }^{\circ} \mathrm{C}$ for as long as 2 and 3 days following interruption of active heat removal. It should be noted that this time would increase if the other heat sinks were considered. Increasing the volume of LBE in the system reduces the volumetric heat generation rate and, consequently, increases the time before the temperature limit is reached. Increasing the volume of steel in the system increases the total heat capacity of the system and also increases the time before the temperature limit is reached.

\section{VIII.2 Transient heat-up with radiation heat exchange with the sodium pool for the LBE target}

Since most of the surface area of the target vessel is exposed to the guard vessel, substantial radiation heat transfer should be expected between the LBE inventory of the target and the sodium inventory of the surrounding SCM pool. Preliminary calculations have been completed to evaluate the steady state temperature in the LBE target system assuming that radiation heat transfer between the target vessel and guard vessel is the primary heat transfer mechanism. These calculations use the LBE and steel volumes used in case 5. The spatial dependence of the temperature within the LBE inventory and the sodium inventory is neglected. The conductive resistance of the target vessel walls and the guard vessel walls is neglected as well. However, radiation heat transfer properties of the steel vessel walls are used in the radiation calculation. The gap between the target vessel and guard vessel is treated as an idealized void with no conduction or radiative absorption considered in this region. The sodium pool is assumed to be at a uniform temperature of $370^{\circ} \mathrm{C}$ and is treated as an infinite medium 
surrounding the target module. No credit is taken for natural convection within the LBE inventory.

In order to solve the resulting transient energy balance equation, the decay heat load is approximated using the functional representation $q(t)=12484-2071.2 \ln (t)$, where $t$ is time in days. The actual decay power from the radiological analysis and functional representation of the decay heat are shown together in Figure 92 for comparison. Calculated system temperatures assuming adiabatic heat-up and using the functional representation of the decay power are shown in Table 22 as a function of time after shutdown. Calculated system temperatures taking credit for radiation heat transfer between the target and the sodium pool are shown in Table 22 and Figure 93 as a function of time after shutdown.

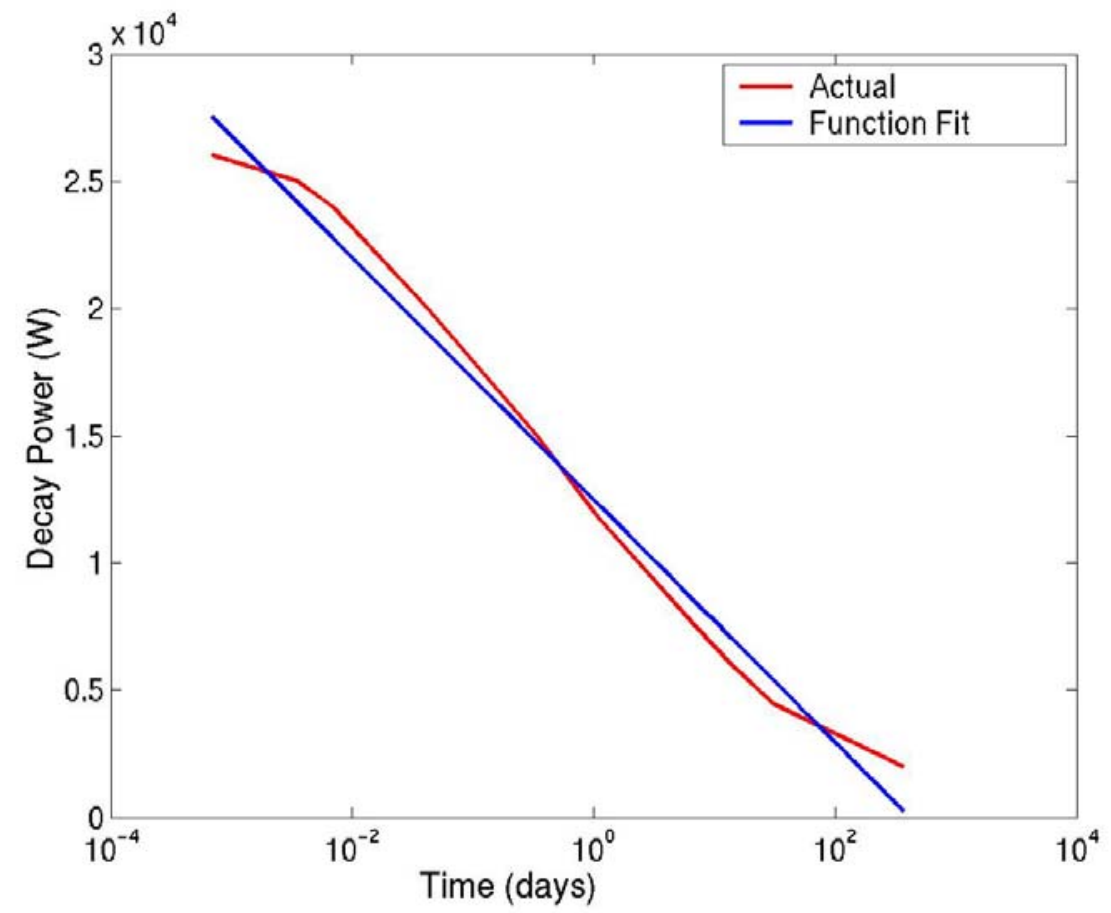

Figure 92. Comparison of the actual decay heat loads from the radiological calculation and decay heat loads predicted by the functional fit used in heat transfer evaluations

These calculations indicate that at significant lengths of time after shutdown of the system, the temperature of the LBE inventory approaches the temperature of the sodium pool as a result of radiation heat transfer from the guard vessel to the target vessel. Until the temperature of the LBE inventory approaches the temperature of the sodium inventory, radiation heat exchange between the target and the sodium pool increases the heat-up rate above that seen in the adiabatic case. When the temperature of the LBE inventory exceeds the temperature of the sodium pool, the heat- 
up rate is reduced by the radiation heat exchange. After approximately 8 days, the LBE inventory temperature reaches a peak value of approximately $752{ }^{\circ} \mathrm{C}(1025 \mathrm{~K})$ and begins to decrease.

Table 22. Comparison of predicted temperatures of the LBE inventory with and without consideration of radiation heat exchange between the LBE target and the sodium pool

\begin{tabular}{|c|c|c|}
\hline Time (Days) & $\begin{array}{c}\text { Temperature }(C)-\text { Without } \\
\text { Radiation Heat Exchange }\end{array}$ & $\begin{array}{c}\text { Temperature (C) - With } \\
\text { Radiation Heat Exchange }\end{array}$ \\
\hline 1 & 410 & 415 \\
\hline 2 & 564 & 549 \\
\hline 3 & 704 & 640 \\
\hline 4 & 834 & 695 \\
\hline 5 & 957 & 727 \\
\hline 6 & 1074 & 741 \\
\hline 7 & 1187 & 747 \\
\hline 8 & 1296 & 747 \\
\hline 9 & 1402 & 745 \\
\hline 10 & 1505 & 741 \\
\hline
\end{tabular}

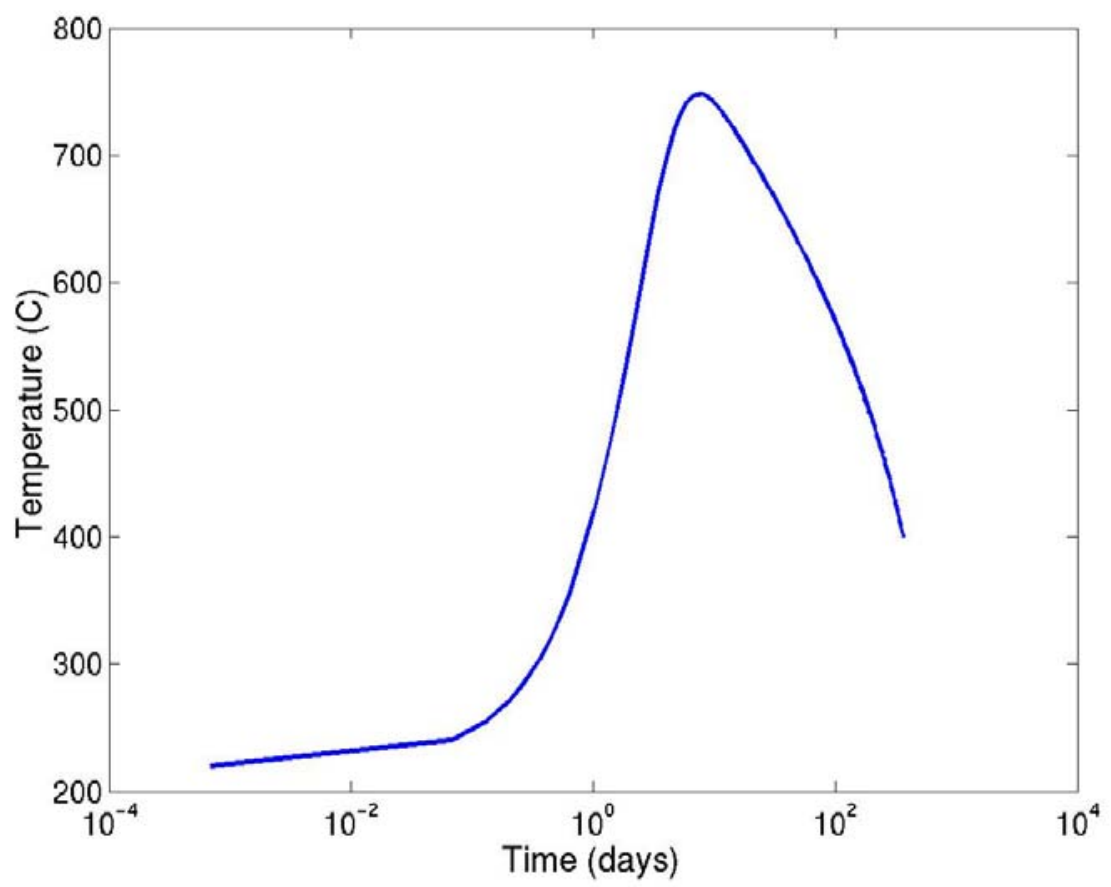

Figure 93. Temperature of the LBE inventory as a function of time after shutdown with consideration of radiation heat exchange with the sodium pool 
In conclusion, the management of decay heat in the ADTF LBE target concept may not require an active engineering system for the decay heat removal. Adiabatic heat up calculations provide a worst-case evaluation of the amount of time that the target can be maintained in operable condition with the loss of active cooling capacity in the LBE system. These evaluations indicate that at least two days without active heat removal are required for the LBE inventory and surrounding structural steel to reach the maximum allowable temperature during normal operation. After $\sim 8$ days, the maximum temperature reaches $752{ }^{\circ} \mathrm{C}$ and it starts going down when the heat transfer by radiation is considered. Upon finalization of the LBE loop layout, additional credit can be taken for the thermal inertia of the target system, which will provide further improvements for the adiabatic analysis.

\section{Subcritical multiplier performance parameters}

The MCNPX geometrical model of the lead-bismuth target design and the subcritical multiplier with the vertical proton beam mentioned in section III was also used to define the neutron flux, the energy deposition, and the radiation damage parameters in the lower grid. The model has EBR-II Mark-III driver fuel and $5 \mathrm{MW}$ beam power. The fuel loading is adjusted to provide a total power deposition of $100 \mathrm{MW}$ in the target and the subcritical multiplier. Figure 94 shows the spatial distribution of the fast neutron flux in the target and the fuel zone for neutrons in the energy range of 0.1 to $20 \mathrm{MeV}$. The proton beam radius is $\sim 8 \mathrm{~cm}$ and the buffer thickness is $7 \mathrm{~cm}$. The inner and outer fuel radii are 15 and $25 \mathrm{~cm}$, respectively. The peak fast flux is about $3 \times 10^{15} \mathrm{n} / \mathrm{cm}^{2} / \mathrm{s}$. The spatial distribution of high-energy neutrons above $20 \mathrm{MeV}$ is shown in Figure 95 with the fuel peak value of $2 \times 10^{13} \mathrm{n} / \mathrm{cm}^{2} / \mathrm{s}$. The high-energy neutron flux is less than $1 \%$ of the total flux. The energy spatial deposition distribution is shown in Figure 96. The power distribution shows clear distinction between the proton beam, the target buffer, and the fuel boundaries. The peak energy deposition in the fuel zone is 800 $\mathrm{W} / \mathrm{cm}^{3}$. Figure 97 shows the proton flux spatial distribution, which is diminishing very fast outside the beam boundary.

Another MCNPX geometrical model for the lead-bismuth target design and the subcritical multiplier with a vertical proton beam was developed to assess the nuclear responses in the grid plate. The target details are also included in the model. The structure material for the reflector and the target is type 316SS. However, the nuclear responses are calculated for iron. The beam power is 5-MW using $600 \mathrm{MeV}$ protons. The current density is $40 \mu \mathrm{A} / \mathrm{cm}^{2}$. The fuel volume was adjusted to yield $100 \mathrm{MW}$ from the whole system. In this analysis, the reflector composition is $85 \%$ type $316 \mathrm{SS}$ and $15 \%$ sodium. In the multiplier design, the bottom and top reflector may utilize more sodium fraction to minimize the pressure drop in the reflector zones. This will insure adequate mass flow rate to cool the fuel zone without increasing the system pressure. EBR-II reflector has a steel fraction in the range of 54 to $56 \%$. In this analysis, the results are given as a function of the reflector thickness as shown in Figures 98 and 99. The atomic displacement rate is shown in Figure 98, which is normalized to full power year. Also, the helium and hydrogen gas generation rates are similarly given in Figure 99. 
Based on the helium production, type 316SS can operate up to 20 appm of helium without concern about the irradiation damage. Operating at higher values is possible when the change in the mechanical properties is considered in the structural design process of the grid. The above range of helium production requires about $40 \mathrm{~cm}$ of the reflector material based on Figure 98 results, which is very close to the $50 \mathrm{~cm}$ reflector thickness of EBR-II design. If EBR-II reflector design is used, the required reflector thickness is $60 \mathrm{~cm}$. This thickness is needed in the area under the target zone. However, under the fuel zone, the helium production rate is less, which requires less thickness to protect the grid plate.

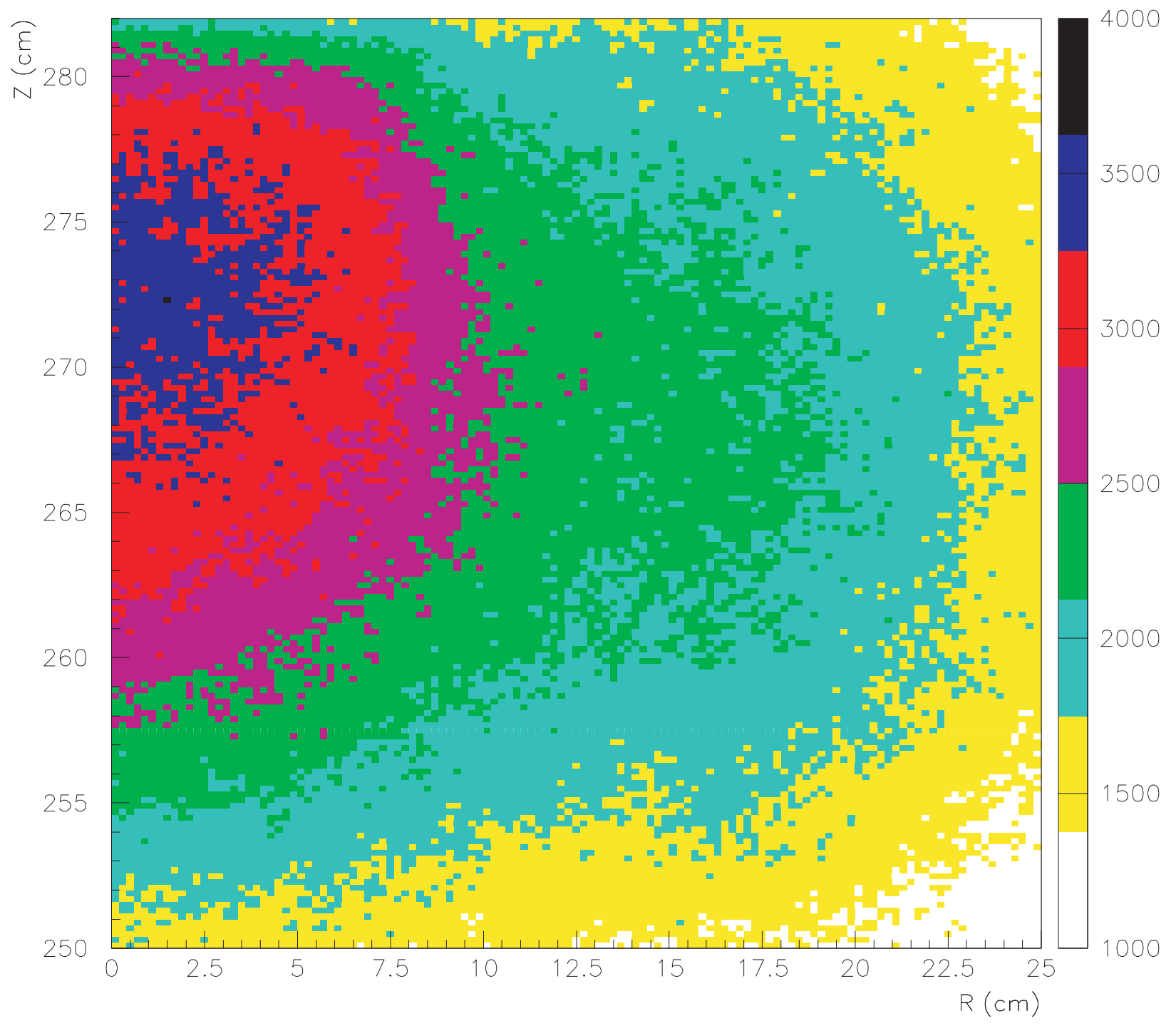

Figure 94 . SCM-100 fast neutron flux $(0.1$ to $20 \mathrm{MeV}) \mathrm{n} / \mathrm{cm}^{2} / \mathrm{s}$ with the lead-bismuth target 


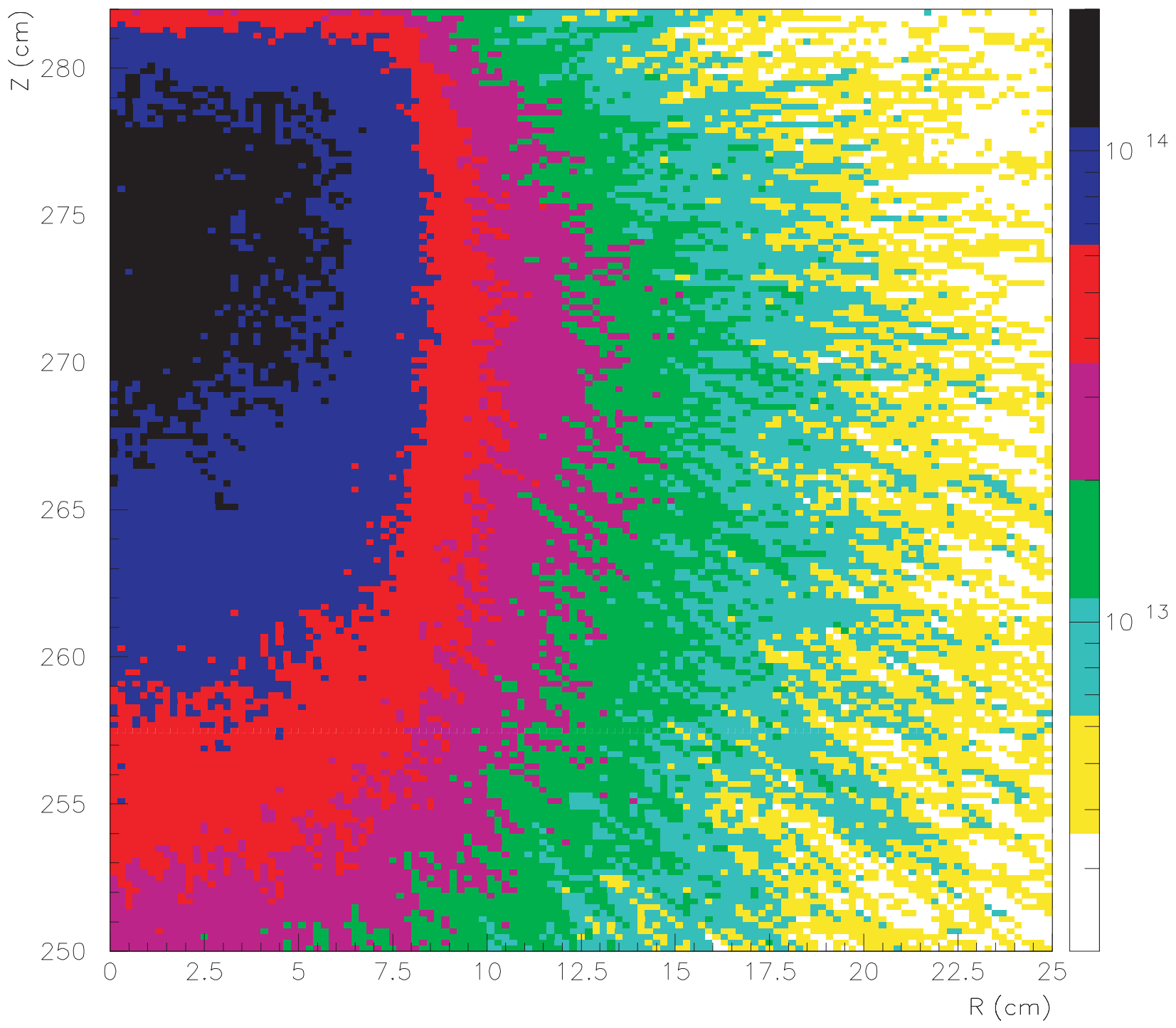

Figure 95. SCM-100 high-energy neutron flux (above $20 \mathrm{MeV}$ ) $\mathrm{n} / \mathrm{cm}^{2} / \mathrm{s}$ with the leadbismuth target 


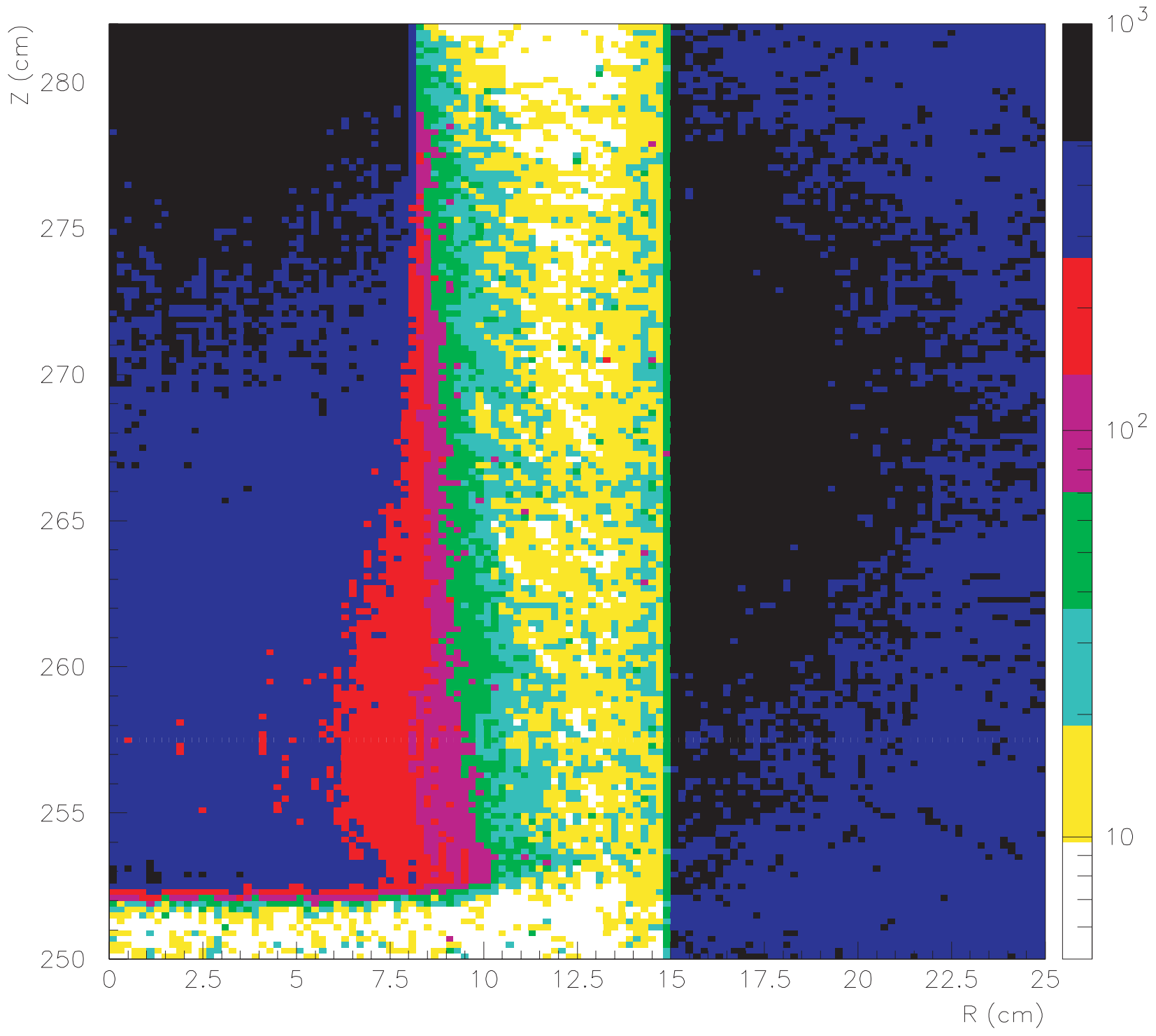

Figure 96. SCM-100 energy deposition with the lead-bismuth target, $\mathrm{W} / \mathrm{cm}^{3}$ 


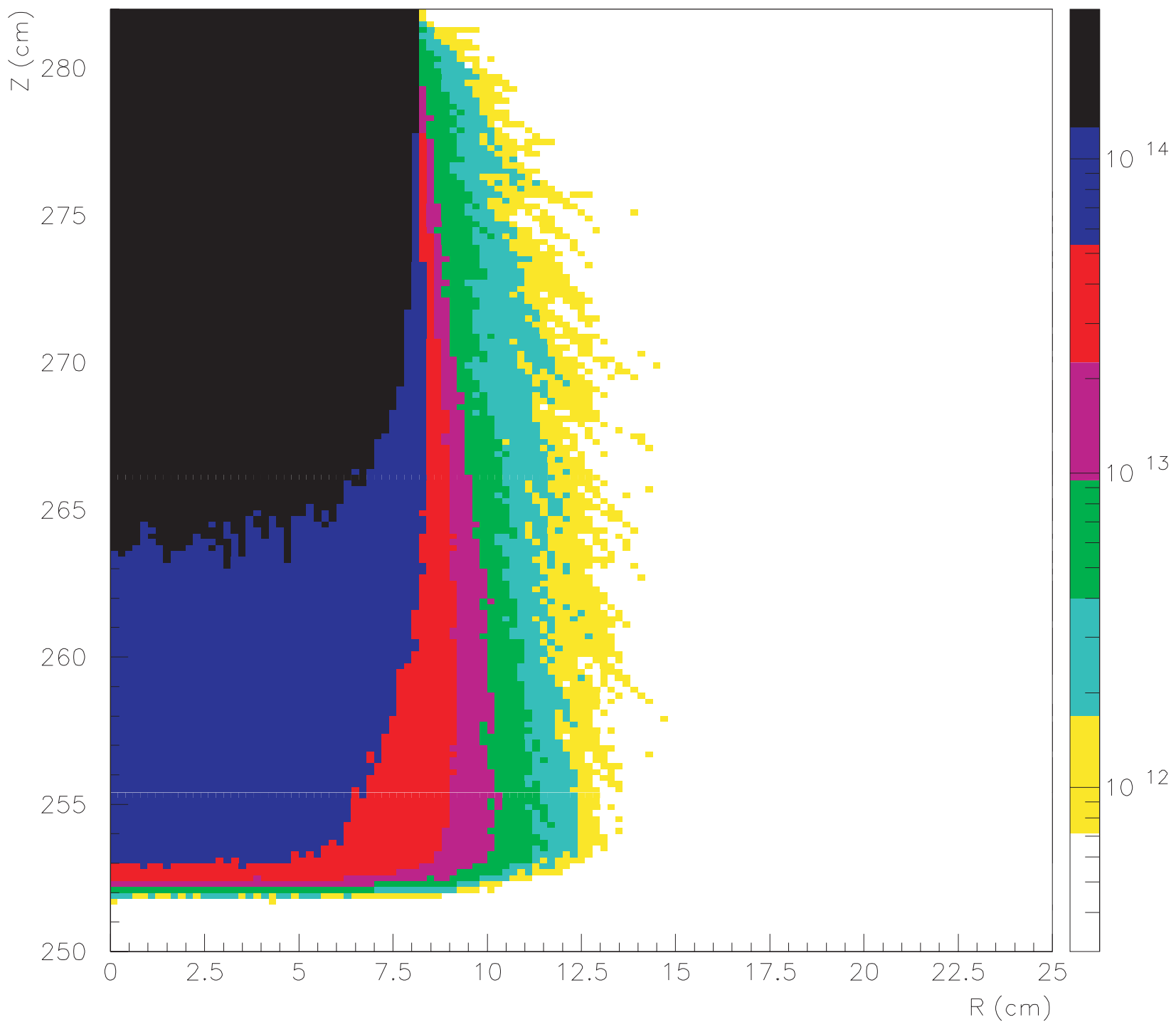

Figure 97 . SCM-100 proton flux distribution with the lead-bismuth target, $\mathrm{p} / \mathrm{cm}^{2} / \mathrm{s}$ 


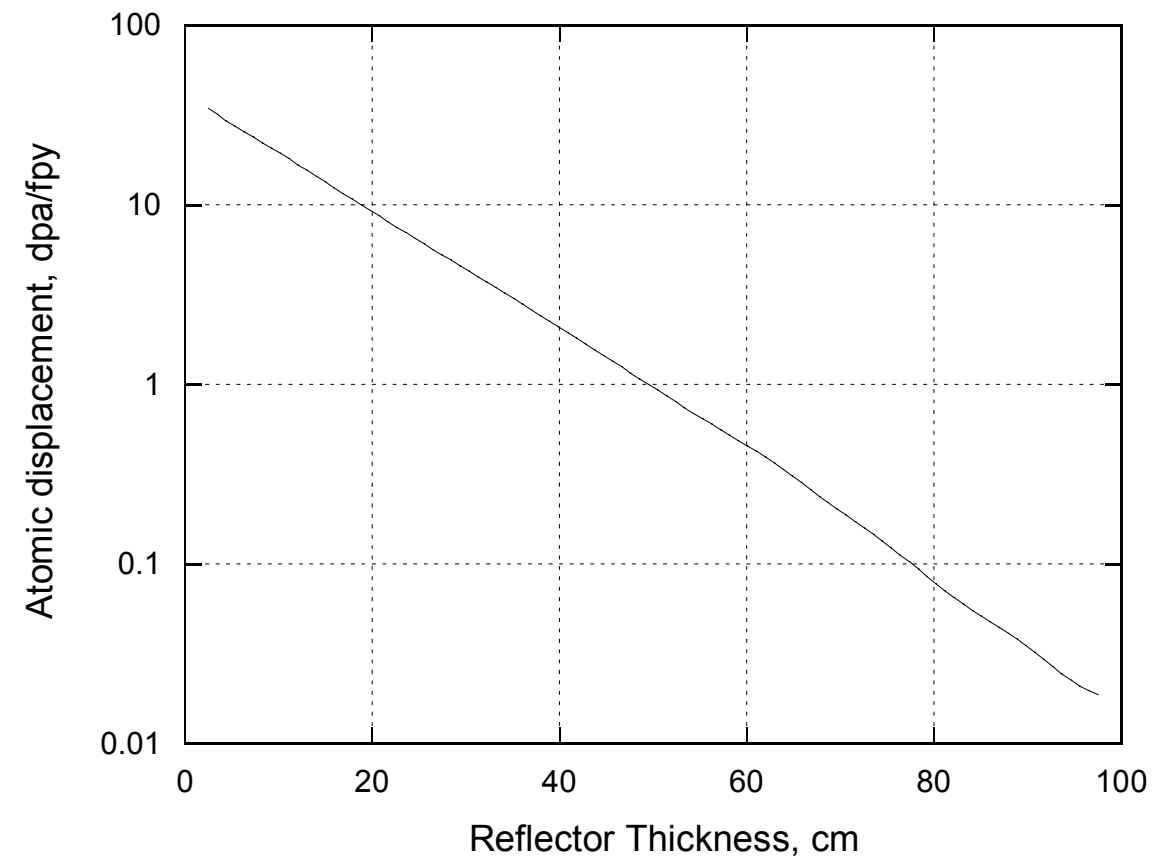

Figure 98. Atomic displacement rate in the grid plate per full power year as a function of the reflector zone thickness

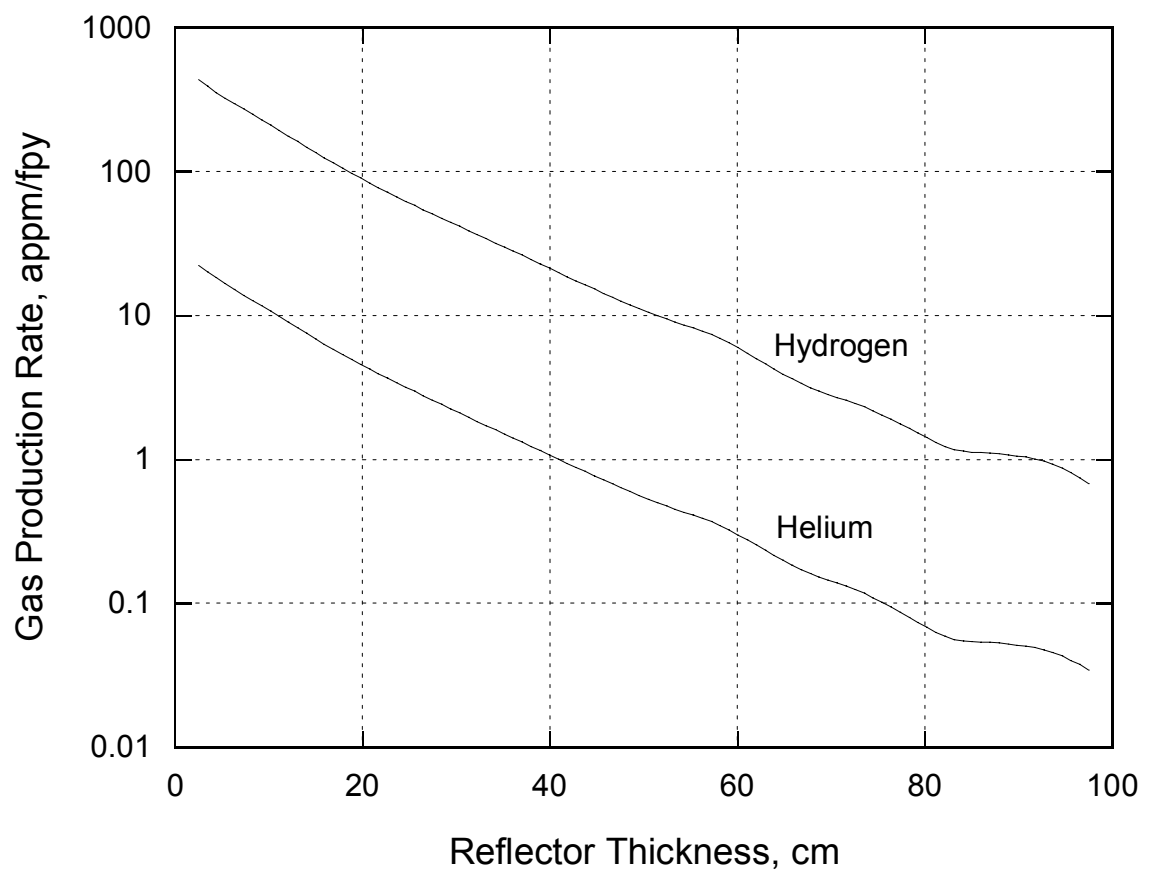

Figure 99. Gas production rate in the grid plate per full power year as a function of the reflector zone thickness 


\section{Conclusions}

An LBE target design has been developed successfully for the SCM station of the ADTF. Target design objectives and constraints were defined and utilized to satisfy different engineering requirements and to minimize the design development time and cost. The ADTF mission and goals did define some of the target objectives. Physics, heat-transfer, hydraulics, structural, radiological, and safety analyses were iterated to develop the current target design.

The design is based on a coaxial geometrical configuration to minimize the target footprint and to maximize the utilization of the spallation neutrons. The target is installed vertically along the SCM axis. LBE is the target material and the target coolant. Ferritic steel (HT-9) is the selected structural material for the target based on the current database and the design analyses. Austenitic steel (Type 316SS) is the backup choice. A uniform proton beam is employed to perform the spallation process. The proton beam has a total current of $8.33 \mathrm{~mA}$ with a radius of $8.14 \mathrm{~cm}$ resulting in a current density of $40 \mu \mathrm{A} / \mathrm{cm}^{2}$. The beam power is $5 \mathrm{MW}$ and the proton energy is $600 \mathrm{MeV}$. The beam tube has a $10-\mathrm{cm}$ radius to accommodate the halo current. A hemi-spherical geometry is used for the target window, which is connected to the beam tube. A conical target window with a rounded tip is also considered since it has a lower average temperature relative to the hemispherical geometry. The beam tube is enclosed inside two coaxial tubes to provide inlet and outlet manifolds for the LBE target coolant. The inlet and the outlet coolant manifolds and the proton beam are entered from the top above the SCM.

The target geometrical configuration has been carefully designed to insure adequate coolant velocity for cooling the target structural material and to enhance the LBE flow stability. Detailed MCNPX geometrical models for the target and the subcritical multiplier have been developed to calculate the nuclear responses in the structural material for the design process. Also, these models are used to generate the energy deposition and flux contour maps, to calculate the nuclear responses in the structural material, to optimize the target design parameters for satisfying the mission and the design goals of the ADTF.

The neutrons for the subcritical multiplier are generated from the spallation process driven by the $600-\mathrm{MeV}$ proton beam. A small LBE buffer between the target and the SCM is utilized based on design optimization to reduce the irradiation damage in the fuel elements from the scatter protons and the high-energy neutrons, to provide an adequate manifold for the LBE coolant, and to maximize the spallation neutron fraction of the subcritical multiplier. A special attention has been given to the target window design to enhance its lifetime. The window volumetric heating is about $766 \mathrm{~W} / \mathrm{cm}^{3}$ relative to 750 $\mathrm{W} / \mathrm{cm}^{3}$ in LBE for the $40-\mu \mathrm{A} / \mathrm{cm}^{2}$ current density. The results show that the nuclear heating from the proton beam diminishes at about $32 \mathrm{~cm}$ along the beam axis of the LBE target material. In the structure material outside the 7-cm LBE buffer, the neutron contribution to the atomic displacement is in the range of 98 to $\sim 100 \%$ and the proton beam contribution to the helium production is less than $3.5 \%$. In the window, the neutrons are responsible for $69 \%$ of the atomic displacement and the protons are 
generating more than $96 \%$ of the gas production rate. The proton contribution to the gas production vanishes outside the beam path.

Thermal hydraulic analyses were performed to define the velocity distribution and the flow stability of the lead-bismuth eutectic as well as the temperature distribution in the target structure and the target coolant. The hydraulic results were used to update the geometrical configuration and to improve the flow stability. Parametric analyses were performed and iterated with the other design analyses to define the reference geometrical configuration. The thermal hydraulics results show that the outlet temperature of LBE is $280^{\circ} \mathrm{C}$ for an inlet temperature of $200^{\circ} \mathrm{C}$. The LBE average velocity is $2 \mathrm{~m} / \mathrm{s}$ and the total pressure drop is $\sim 32 \mathrm{psi}$. The peak temperatures on the adiabatic and the wetted surfaces of the beam window are $502{ }^{\circ} \mathrm{C}$ and $341{ }^{\circ} \mathrm{C}$, respectively, for the 3.5-mm thick beam window.

Structural analyses were performed parametrically in conjunction with the thermal hydraulics to check the design compliance with the stress and the buckling design criteria developed for the Accelerator Production of Tritium project and the International Thermonuclear Experimental Reactor for irradiated structural materials. Also, the results are used to select the shape and the thickness of the beam window to maximize the engineering margins. The results show that the target structure including the beam window satisfies the structural design criteria for irradiated HT-9 with 72 dpa. This level of irradiation will allow the target to operate for more than full power year. However, most of the HT-9 database is obtained from fission irradiation, which needs to be confirmed for the target operating conditions including the influence of the high-energy neutron and the proton fluxes.

Radiological analyses were performed to define the spallation products. These products define the radiological toxicity and the decay heat source from LBE as a function of the time after shutdown. The design analyses utilize the decay heat source to check the design performance during abnormal conditions with respect to the maximum allowed temperature for the structural material. Also, the dose rate from the gamma rays of the LBE spallation products was calculated to define the required input for calculating the appropriate time and the shielding requirements for maintaining the target system. The loss of flow analysis show that the management of the decay heat in the ADTF LBE target design may not require an active engineering system for the decay heat removal. 


\section{REFERENCES}

1. L. S. Waters, Editor, MCNPX User's Manual - Version 2.1.5, TPO-E83-UG-X00001, Revision 0, Los Alamos Report, November 14, 1999.

2. Supplemental Structural Design Requirements, PPO-P00-G-PRD-X-00006, Rev. A

3. S. Majumdar and P. Smith, Treatment of irradiation effects in structural design criteria for fusion reactors, Fusion Engineering and Design 41, 1998.

4. Star-CD Version 3.1B, CD-Adapco Group.

5. F. P. Incorpera and D. P. Dewitt, Fundamentals of Heat and Mass Transfer, $3^{\text {rd }}$ ed., New York: Wiley \& Sons, 1990.

6. R. A. Seban, Transactions of the ASME, 72, 789, 1950.

7. I.E. Idelchik, Handbook of Hydraulic Resistance, $3^{\text {rd }}$ ed., Boca Raton, FL: CRC Press, 1994.

8. ANSYS Version 5.7, ANSYS, Inc.,2000.

9. E. Bloom, J. Weir Jr., Effect of Neutron Irradiation on The ductility of Austenitic Stainless Steel, Oak Ridge National Laboratory, Metals and Ceramics Division.

10. ASME Code Section VIII, Division 2, Article D-3; Shells of Revolution Under External Pressure.

11. APT Materials Handbook, Material Data for Particle Accelerator Applications, Los Alamos National Laboratory Report, LA-UR-99-2702, June 1999.

12. D. Smith, W. Dänner, Y. Gohar et al., "ITER Blanket, Shield and Material Data Base - Part A (ITER Blanket and Shield)," International Atomic Energy Agency, Vienna, ITER Documentation Series, No. 29, 1991. 


\section{Appendix A}

\section{Input file generation for ANSYS analysis}

\section{Program cone_gen}

C program generates a model of the adtf conical window parameter (NODES $=1800)$ ! must be greater than the max node number dimension X(NODES), Y(NODES), T(NODES) integer el character*10 title

c write out the ANSYS deck write $\left(6,{ }^{*}\right)$ '/batch' write $\left(6,{ }^{*}\right)$ '/filnam, atdf' write $\left(6,{ }^{*}\right)$ '/prep7' write $\left(6,{ }^{*}\right)$ '! axisymmetirc without extra displacement' write $\left(6,{ }^{*}\right)$ 'et, $1,42,, 1,1$ ' write $\left(6,{ }^{*}\right)$

C the constant material properties (Young's Modulus, Poisson's Ratio, Coeff. of Therm.

C Expansion) below are redefined as temperature-dependent (see Fig 9-13) write $\left(6,{ }^{*}\right)$ 'mp, ex ,1,1.951e+12'

write $\left(6,{ }^{*}\right)$ 'mp, nuxy ,1, .3'

write $\left(6,{ }^{*}\right)$ 'mp, alpx,1, 15.9e-6'

write $\left(6,{ }^{*}\right)$ 'mp, reft ,1, 294.0'

write $\left(6,{ }^{*}\right)$

write $\left(6,{ }^{*}\right)$ 'mat, 1 '

write $\left(6,{ }^{*}\right)$ 'type, 1 '

10 format ('n, 'i6,', ',f13.6,', ', f13.6,', ',f13.6)

20 format('e, ', 3(i6,', '),i6)

30 format('bf, ', i6, ', TEMP,',f13.6)

ny $=103$ ! number of elements along the $y$ axis (from the CFD)

$\mathrm{nx}=16 \quad$ ! number of elements through the thickness

numnp $=(n y+1)^{*}(n x+1)$ ! max node number

c read in the $(X, Y, T)$ data obtained from Argonne $\mathrm{Lab}$

$\operatorname{read}(5,(a 10) ')$ title

$\mathrm{z}=0.0$

write $\left(6,{ }^{*}\right)$ '! nodal points'

do $n=1$, numnp

$c$ note: switching the $X$ and $Y$ for the ANSYS model $\operatorname{read}\left(5,{ }^{*}\right) Y(n), X(n), T(n)$

write $(6,10) n, x(n), y(n), z$

enddo

write $\left(6,{ }^{*}\right)$ 'save'

c create axisymmetric model of the window/cylinder

$\mathrm{el}=1$

write $\left(6,{ }^{*}\right)$ '! elements ' 
write $\left(6,{ }^{*}\right)$ 'numstr,elem, ',el ! set the element starting number do $i=1$, ny

do $\mathrm{j}=1, \mathrm{nx}$

$\mathrm{n} 1=(\mathrm{i}-1)^{*}(\mathrm{nx}+1)+\mathrm{j}$

$\mathrm{n} 2=\mathrm{n} 1+1$

$\mathrm{n} 3=\mathrm{n} 2+(\mathrm{nx}+1)$

$\mathrm{n} 4=\mathrm{n} 3-1$

write $(6,20) n 1, n 2, n 3, n 4$

enddo

enddo

write $\left(6,{ }^{*}\right)$

write $\left(6,{ }^{*}\right)$ 'allsel'

write $\left(6,{ }^{*}\right)$ !! Nodal point temperatures from Argonne'

C write out the temperatures at each node point

do $\mathrm{n}=1$, numnp

write $(6,30) n, T(n)$

enddo

write $\left(6,{ }^{*}\right)$ '! boundary conditions'

C create the boundary conditions

C at free end fix y displacement (cylinder end)

write $\left(6,{ }^{*}\right)$ 'nsel,s, node, , ', 1, ',', nx+1

write $\left(6,{ }^{*}\right)$ 'd,all,uy'

c fix radial displacement at the center of cone

write $\left(6,{ }^{*}\right)$ 'nsel,s, node, , ',numnp-nx, ',',numnp

write $\left(6,{ }^{*}\right)$ 'd,all,ux'

write $\left(6,{ }^{*}\right)$ 'allsel'

write $\left(6,{ }^{*}\right)$ 'save'

write $\left(6,{ }^{*}\right)$ 'finish'

C start the solution module

write $\left(6,{ }^{*}\right)$ '/solu'

write $\left(6,{ }^{*}\right)$ 'antype, static'

write $\left(6,{ }^{*}\right)$ 'solve'

write $\left(6,{ }^{*}\right)$ 'save'

write $\left(6,{ }^{*}\right)$ 'finish'

write $\left(6,{ }^{*}\right)$ '/exit'

end

c to compile type "f77 model_gen.f" to generate output file

c place the new file "argonne.node" in the working directory 


\title{
Appendix B
}

\section{LBE pressure calculation at the beam window}

\section{Pressure State at the Conical/Spherical Window Level}

\author{
$\mathrm{h}_{\text {fluid }}:=8.07 \cdot \mathrm{m}$ \\ height of the fluid above the window \\ $\mathrm{T}_{\text {fluid }}:=550 \cdot \mathrm{K}$ \\ Bi-Pb Outlet Temperature \\ $\mathrm{g}=9.807 \frac{\mathrm{m}}{\mathrm{s}^{2}}$ \\ gravitational acceleration \\ $\gamma_{\text {fluid }}:=10738.09 \frac{\mathrm{kg}}{\mathrm{m}^{3}}-1.37562 \frac{\mathrm{kg}}{\mathrm{m}^{3} \cdot \mathrm{K}} \cdot \mathrm{T}_{\text {fluid }}$ \\ temperature-dependent coolant \\ mass density \\ $\gamma_{\text {fluid }}=9.981 \times 10^{3} \frac{\mathrm{kg}}{\mathrm{m}^{3}}$ \\ coolant density at operational temperature
}

$\mathrm{p}_{\text {head }}:=\gamma_{\text {fluid }} \cdot \mathrm{h}_{\text {fluid }} \mathrm{g}$

$\mathrm{p}_{\text {head }}=7.899 \times 10^{5} \mathrm{~Pa}$

gage pressure at the window level

$\mathrm{p}_{\text {head }}=0.79 \mathrm{MPa}$

$\mathrm{p}_{\text {head }}=114.57 \mathrm{psi}$ 


\title{
Appendix C
}

\section{Critical buckling load calculation for the type 316SS target structure}

\author{
SPHERICAL SHELL (5mm) UNDER EXTERNAL PRESSURE \\ $\mathrm{t}:=0.005 \mathrm{~m}$ \\ min. required thickness of formed \\ (hemispherical) head, in \\ $\mathrm{R}_{\mathrm{o}}:=0.105 \mathrm{~m}$ \\ the outside radius of hemispherical head, in \\ $\mathrm{T}_{\mathrm{K}}:=800 \mathrm{~K}$ \\ $\mathrm{T}_{\mathrm{K}}=1.44 \times 10^{3} \mathrm{R}$ \\ Maximum average temperature \\ $\mathrm{T}_{\mathrm{F}}:=\mathrm{T}_{\mathrm{K}}-460 \cdot \mathrm{R}$ \\ through the window wall \\ $\mathrm{T}_{\mathrm{F}}=980 \mathrm{R}$ \\ Temperature value on Fahrenheit scale
Step 1: $\quad A_{s}:=\frac{0.125}{\left(\frac{R_{0}}{t}\right)}$
$\mathrm{A}_{\mathrm{s}}=0.00595$

Step 2 and 3: $\quad B_{\mathrm{s} 316 \mathrm{~L}}:=4985.6$

$B$ value at $1000 \mathrm{~F}$ extrapolated from the $B$ value at $800 \mathrm{~F}$ using the same rate change of $B$ as for $600-800 F$

$$
\mathrm{B}_{\mathrm{s} 316}:=9500
$$

From Fig. HA-2 for SS316 at Tavg=1000 F

Step 4:

$$
\begin{aligned}
& \mathrm{P}_{\mathrm{as} 316 \mathrm{~L}}:=\frac{\mathrm{B}_{\mathrm{s} 316 \mathrm{~L}}}{\left(\frac{\mathrm{R}_{\mathrm{o}}}{\mathrm{t}}\right)} \\
& \mathrm{P}_{\mathrm{as} 316 \mathrm{~L}}=237.41
\end{aligned}
$$

$$
\begin{gathered}
\mathrm{P}_{\text {as } 316}:=\frac{\mathrm{B}_{\mathrm{s} 316}}{\left(\frac{\mathrm{R}_{\mathrm{o}}}{\mathrm{t}}\right)} \\
\mathrm{P}_{\text {as } 316}=452.381 \\
\mathrm{P}:=\mathrm{p}_{\text {head }} \\
\mathrm{P}=114.57 \mathrm{psi}
\end{gathered}
$$

Allowable external pressure for spherical $5 \mathrm{~mm}$-SS316L-wall window is higher than the working pressure of $114.57 \mathrm{psi}$. The window satisfies ASME buckling criteria.

Allowable external pressure for spherical $5 \mathrm{~mm}$-SS316-wall window is higher than the working pressure of $114.57 \mathrm{psi}$. The window satisfies ASME buckling criteria.

working pressure at the window level 


\section{CONICAL SHELL $(5 \mathrm{~mm})$ UNDER EXTERNAL PRESSURE}

$$
\alpha:=45 \cdot \operatorname{deg}
$$

$\mathrm{t}_{\mathrm{r}}:=0.005 \mathrm{~m}$

$\mathrm{D}_{\mathrm{L}}:=0.210 \mathrm{~m}$

$\mathrm{D}_{\mathrm{s}}:=0 \cdot \mathrm{m}$

$\mathrm{L}_{\mathrm{x}}:=0.100 \mathrm{~m}$

$\mathrm{L}_{\mathrm{e}}:=\left(\frac{\mathrm{L}_{\mathrm{x}}}{2}\right) \cdot\left(1+\frac{\mathrm{D}_{\mathrm{s}}}{\mathrm{D}_{\mathrm{L}}}\right)$

$\mathrm{L}_{\mathrm{e}}=0.05 \mathrm{~m}$

$\mathrm{t}_{\mathrm{e}}:=\mathrm{t}_{\mathrm{r}} \cdot \cos (\alpha)$

$\mathrm{t}_{\mathrm{e}}=3.536 \times 10^{-3} \mathrm{~m}$

Step 1: $\quad \mathrm{R}_{1}:=\frac{\mathrm{L}_{\mathrm{e}}}{\mathrm{D}_{\mathrm{L}}}$

$$
\mathrm{R}_{2}:=\frac{\mathrm{D}_{\mathrm{L}}}{\mathrm{t}_{\mathrm{e}}} \quad \mathrm{R}_{2}=59.397
$$

Step 2 and 3: $\mathrm{A}_{\text {cone }}:=0.015$

Step 4 and 5:

$$
\begin{aligned}
& \mathrm{B}_{\text {coneSS316L }}:=6950 \\
& \mathrm{~B}_{\text {cone } 1000}:=\mathrm{B}_{\text {coneSS } 316 \mathrm{~L}} \cdot \mathrm{T}_{2} \\
& \mathrm{~B}_{\text {cone } 1000}=5.699 \times 10^{3} \\
& \mathrm{~B}_{\text {coneSS316 }}:=10000
\end{aligned}
$$

Step 6:

$$
\begin{aligned}
& \mathrm{P}_{\mathrm{acSS} 316 \mathrm{~L}}:=4 \cdot \frac{\mathrm{B}_{\text {cone1000 }}}{3 \cdot\left(\frac{\mathrm{D}_{\mathrm{L}}}{\mathrm{t}_{\mathrm{e}}}\right)} \\
& \mathrm{P}_{\mathrm{acSS} 316 \mathrm{~L}}=127.93
\end{aligned}
$$$$
\mathrm{P}_{\mathrm{acSS} 316}:=4 \cdot \frac{\mathrm{B}_{\text {coneSS316 }}}{3 \cdot\left(\frac{\mathrm{D}_{\mathrm{L}}}{\mathrm{t}_{\mathrm{e}}}\right)}
$$

$\mathrm{P}_{\mathrm{acSS} 316}=224.478$ cone angle as defined per AD-300.1 of Ref.1

(Ref. 1: D-3 of Section VIII, Division 2)

minimum required thickness of cone at cone-to-cylinder junction, in

OD of large end of conical section, in

OD of small end of conical section, in axial length of cone, in (per Fig. AD-300.1 of Ref.1)

equivalent length of conical section, in

effective thickness of conical section, in

ratio $\mathrm{R} 2$ greater than 10

From Fig G of Ref.1 for R1 and R2

From Fig. HA-4 for SS316L at Tavg=800 F

$\mathrm{B}$ value at $1000 \mathrm{~F}$ extrapolated from $\mathrm{B}$ at $800 \mathrm{~F}$

From Fig. HA-2 for SS316 at $980 \mathrm{~F}$

Allowable external pressure for conical 5mm-SS316-wall window is higher than the working pressure of $114.57 \mathrm{psi}$. The window satisfies ASME buckling criteria.

Allowable external pressure for conical 5mm-SS316-wall window is higher than the working pressure of 114.57 psi. The window satisfies ASME buckling criteria. 
CYLINDRICAL SHELL $(5 \mathrm{~mm})$ UNDER EXTERNAL PRESSURE

$$
\begin{aligned}
& \mathrm{t}_{\text {cyl }}:=0.005 \mathrm{~m} \\
& \mathrm{~L}_{\text {cyl }}:=8.07 \cdot \mathrm{m} \\
& \mathrm{D}_{\text {ocyl }}:=0.21 \cdot \mathrm{m}
\end{aligned}
$$

Step 1:

$$
\begin{array}{ll}
\mathrm{R}_{1 \text { cyl }}:=\frac{\mathrm{L}_{\text {cyl }}}{\mathrm{D}_{\text {ocyl }}} & \mathrm{R}_{1 \text { cyl }}=38.429 \\
\mathrm{R}_{2 \text { cyl }}:=\frac{\mathrm{D}_{\text {ocyl }}}{\mathrm{t}_{\text {cyl }}} & \mathrm{R}_{2 \text { cyl }}=42
\end{array}
$$

Step 2 and 3: $\quad \mathrm{A}_{\text {cyl }}:=0.0006$

Step 4 and 5: $\quad \mathrm{B}_{\text {cylSS316L }}:=5250 \quad$ From Fig. HA-4 for SS316L at $530 \mathrm{~F}$

$$
\mathrm{B}_{\mathrm{cylSS} 316}:=7050 \quad \text { From Fig. HA-2 for SS316L at } 530 \mathrm{~F}
$$

Step 6:

$$
\begin{aligned}
& \mathrm{P}_{\text {acylSS316L }}:=4 \cdot \frac{\mathrm{B}_{\text {cylSS316L }}}{3 \cdot\left(\frac{\mathrm{D}_{\text {ocyl }}}{\mathrm{t}_{\text {cyl }}}\right)} \\
& \mathrm{P}_{\text {acylSS316L }}=166.667 \\
& \mathrm{P}_{\text {acylSS316 }}:=4 \cdot \frac{\mathrm{B}_{\text {cylSS316 }}}{3 \cdot\left(\frac{\left.\mathrm{D}_{\text {ocyl }}\right)}{\mathrm{t}_{\text {cyl }}}\right)} \\
& \mathrm{P}_{\text {acylSS316 }}=223.81 \\
& \sigma_{\text {cyl }}:=P_{\text {acylSS } 316 \mathrm{~L}} \cdot \frac{\mathrm{D}_{\text {ocyl }}}{2 \cdot \mathrm{t}_{\text {cyl }}} \\
& \sigma_{\text {cyl }}=3.5 \times 10^{3}
\end{aligned}
$$

Allowable external pressure for cylindrical $5 \mathrm{~mm}$-SS316L-wall target is higher than the working pressure of $114.57 \mathrm{psi}$. The window satisfies ASME buckling criteria.

Allowable external pressure for cylindrical $5 \mathrm{~mm}$-SS316-wall target is higher than the working pressure of $114.57 \mathrm{psi}$. The window satisfies ASME buckling criteria. 


$$
\begin{array}{ll}
\text { SPHERICAL SHELL (4 mm) UNDER EXTERNAL PRESSURE } \\
\mathrm{t}:=0.004 \mathrm{~m} & \begin{array}{l}
\text { min. required thickness of formed } \\
\text { (hemispherical) head, in }
\end{array} \\
\mathrm{R}_{\mathrm{o}}:=0.105 \mathrm{~m} & \text { the outside radius of hemispherical head, in } \\
\mathrm{T}_{\mathrm{K}}:=740 \mathrm{~K} & \begin{array}{l}
\text { Maximum average temperature } \\
\text { through the window wall }
\end{array} \\
\mathrm{T}_{\mathrm{K}}=1.332 \times 10^{3} \mathrm{R} & \text { Temperature value on Fahrenheit scale }
\end{array}
$$

Step 1: $\quad A_{s}:=\frac{0.125}{\left(\frac{R_{0}}{t}\right)}$

$$
\mathrm{A}_{\mathrm{s}}=0.00476
$$

$$
\begin{aligned}
& \text { Step 2 and 3: } \quad \begin{array}{l}
\mathrm{B}_{\mathrm{s} 316 \mathrm{~L}}:=5833 \\
\mathrm{~B}_{\mathrm{s} 900}:=\mathrm{B}_{\mathrm{s} 316 \mathrm{~L}} \cdot \mathrm{T}_{1} \\
\mathrm{~B}_{\mathrm{s} 900}=5.308 \times 10^{3} \\
\mathrm{~B}_{\mathrm{s} 316}:=9850
\end{array}
\end{aligned}
$$

From Fig. HA-4 for SS316L at Tavg=800 F

$B$ value at $900 \mathrm{~F}$ extrapolated from the $B$ value at $800 \mathrm{~F}$ using the same rate change of $B$ as for $600-800 F$

From Fig. HA-2 for SS316 at Tavg=880 F

Step 4:

$$
\begin{aligned}
& \mathrm{P}_{\mathrm{as} 316 \mathrm{~L}}:=\frac{\mathrm{B}_{\mathrm{s} 900}}{\left(\frac{\mathrm{R}_{\mathrm{o}}}{\mathrm{t}}\right)} \\
& \mathrm{P}_{\mathrm{as} 316 \mathrm{~L}}=202.211 \\
& \mathrm{P}_{\mathrm{as} 316}:=\frac{\mathrm{B}_{\mathrm{s} 316}}{\left(\frac{\mathrm{R}_{\mathrm{o}}}{\mathrm{t}_{\mathrm{t}}}\right)} \\
& \mathrm{P}_{\mathrm{as} 316}=375.238
\end{aligned}
$$

Allowable external pressure for spherical $4 \mathrm{~mm}$-SS316L-wall window is higher than the working pressure of $114.57 \mathrm{psi}$. The window satisfies ASME buckling criteria.

Allowable external pressure for spherical $4 \mathrm{~mm}$-SS316-wall window is higher than the working pressure of $114.57 \mathrm{psi}$. The window satisfies ASME buckling criteria. 


\section{CONICAL SHELL (4 mm) UNDER EXTERNAL PRESSURE}

$$
\alpha:=45 \cdot \operatorname{deg}
$$

$\mathrm{t}_{\mathrm{r}}:=0.004 \mathrm{~m}$

$\mathrm{D}_{\mathrm{L}}:=0.210 \mathrm{~m}$

$\mathrm{D}_{\mathrm{s}}:=0 \cdot \mathrm{m}$

$\mathrm{L}_{\mathrm{x}}:=0.100 \mathrm{~m}$

$\mathrm{L}_{\mathrm{e}}:=\left(\frac{\mathrm{L}_{\mathrm{x}}}{2}\right) \cdot\left(1+\frac{\mathrm{D}_{\mathrm{s}}}{\mathrm{D}_{\mathrm{L}}}\right)$

$\mathrm{L}_{\mathrm{e}}=0.05 \mathrm{~m}$

$\mathrm{t}_{\mathrm{e}}:=\mathrm{t}_{\mathrm{r}} \cdot \cos (\alpha)$

$\mathrm{t}_{\mathrm{e}}=2.828 \times 10^{-3} \mathrm{~m}$

Step 1: $\quad \mathrm{R}_{1}:=\frac{\mathrm{L}_{\mathrm{e}}}{\mathrm{D}_{\mathrm{L}}}$

$$
\mathrm{R}_{2}:=\frac{\mathrm{D}_{\mathrm{L}}}{\mathrm{t}_{\mathrm{e}}} \quad \mathrm{R}_{2}=74.246
$$

Step 2 and $3: \quad \mathrm{A}_{\text {cone }}:=0.01$

Step 4 and 5: $\quad B_{\text {coneSS316L }}:=6600$

$\mathrm{B}_{\text {cone900 }}:=\mathrm{B}_{\text {coneSS } 316 \mathrm{~L}} \cdot \mathrm{T}_{1}$

$\mathrm{B}_{\text {cone } 900}=6.006 \times 10^{3}$

$\mathrm{B}_{\text {coneSS } 316}:=10400$

Step 6:

$$
\begin{aligned}
& \mathrm{P}_{\text {acSS316L }}:=4 \cdot \frac{\mathrm{B}_{\text {cone900 }}}{3 \cdot\left(\frac{\mathrm{D}_{\mathrm{L}}}{\mathrm{t}_{\mathrm{e}}}\right)} \\
& \mathrm{P}_{\text {acSS316L }}=107.857 \\
& \mathrm{P}_{\mathrm{acSS} 316}:=4 \cdot \frac{\mathrm{B}_{\text {coneSS316 }}}{3 \cdot\left(\frac{\mathrm{D}_{\mathrm{L}}}{\mathrm{t}_{\mathrm{e}}}\right)} \\
& \mathrm{P}_{\mathrm{acSS} 316}=186.766
\end{aligned}
$$

cone angle as defined per AD-300.1 of Ref.1

(Ref. 1: D-3 of Section VIII, Division 2)

minimum required thickness of cone at cone-to-cylinder junction, in

$\mathrm{OD}$ of large end of conical section, in

OD of small end of conical section, in

axial length of cone, in (per Fig. AD-300.1of Ref.1)

equivalent length of conical section, in

effective thickness of conical section, in

ratio $\mathrm{R} 2$ greater than 10

From Fig G of Ref.1 for R1 and R2

From Fig. HA-4 for SS316L at Tavg $=800 \mathrm{~F}$

$B$ value at $900 \mathrm{~F}$ extrapolated from the $B$ value at $800 \mathrm{~F}$ using the same rate change of $B$ as for $600-800 F$

From Fig. HA-2 for SS316 at $880 \mathrm{~F}$

Allowable external pressure for conical $4 \mathrm{~mm}$-SS316L-wall window is lower than the working pressure of $114.57 \mathrm{psi}$. The window does not satisfy ASME buckling criteria. The wall needs to be thickened.

Allowable external pressure for conical $4 \mathrm{~mm}$-SS316-wall window is higher than the working pressure of 114.57psi. The window satisfies ASME buckling criteria. 


$$
\begin{aligned}
& \mathrm{t}_{\mathrm{cyl}}:=0.004 \mathrm{~m} \\
& \mathrm{~L}_{\mathrm{cyl}}:=8.07 \cdot \mathrm{m} \\
& \mathrm{D}_{\text {ocyl }}:=0.21 \cdot \mathrm{m}
\end{aligned}
$$

Step 1:

$$
\begin{array}{ll}
\mathrm{R}_{1 \text { cyl }}:=\frac{\mathrm{L}_{\text {cyl }}}{\mathrm{D}_{\text {ocyl }}} & \mathrm{R}_{1 \text { cyl }}=38.429 \\
\mathrm{R}_{2 \text { cyl }}:=\frac{\mathrm{D}_{\text {ocyl }}}{\mathrm{t}_{\text {cyl }}} & \mathrm{R}_{2 \text { cyl }}=52.5
\end{array}
$$

Step 2 and 3: $\quad \mathrm{A}_{\text {cyl }}:=0.00023$

Step 4 and 5: $\quad B_{\text {cylSS316L }}:=2833 \quad$ From Fig. HA-4 for SS316L at $530 \mathrm{~F}$

$$
\mathrm{B}_{\text {cylSS316 }}:=2840 \quad \text { From Fig. HA-2 for SS316L at } 530 \mathrm{~F}
$$

Step 6:

$$
\begin{aligned}
& \mathrm{P}_{\text {acylSS316L }}:=4 \cdot \frac{\mathrm{B}_{\text {cylSS316L }}}{3 \cdot\left(\frac{\mathrm{D}_{\text {ocyl }}}{\mathrm{t}_{\text {cyl }}}\right)} \\
& \mathrm{P}_{\text {acylSS316L }}=71.949
\end{aligned}
$$

Allowable external pressure for cylindrical $4 \mathrm{~mm}$-SS316L-wall target is lower than the working pressure of $114.57 \mathrm{psi}$. The cylinder does not satisfy ASME buckling criteria. The wall needs to be thickened.

$$
\mathrm{P}_{\text {acylSS316 }}:=4 \cdot \frac{\mathrm{B}_{\text {cylSS316 }}}{3 \cdot\left(\frac{\left.\mathrm{D}_{\text {ocyl }}\right)}{t_{\text {cyl }}}\right)}
$$

Allowable external pressure for cylindrical $4 \mathrm{~mm}$-SS316-wall target is lower than the working pressure of $114.57 \mathrm{psi}$. The $\mathrm{P}_{\mathrm{acylSS} 316}=72.127$ cylinder does not satisfy ASME buckling criteria. The wall needs to be thickened. 


$\begin{array}{ll}\text { SPHERICAL SHELL (3 mm) UNDER EXTERNAL PRESSURE } \\ \mathrm{t}:=0.003 \mathrm{~m} & \begin{array}{l}\text { min. required thickness of formed } \\ \text { (hemispherical) head, in }\end{array} \\ \mathrm{R}_{\mathrm{o}}:=0.105 \mathrm{~m} & \text { the outside radius of hemispherical head, in } \\ \mathrm{T}_{\mathrm{K}}:=700 \mathrm{~K} & \begin{array}{l}\text { Maximum average temperature } \\ \text { through the window wall }\end{array} \\ \mathrm{T}_{\mathrm{K}}=1.26 \times 10^{3} \mathrm{R} & \text { Temperature value on Fahrenheit scale }\end{array}$

Step 1: $\quad A_{s}:=\frac{0.125}{\left(\frac{\mathrm{R}_{\mathrm{o}}}{\mathrm{t}}\right)}$

$$
\mathrm{A}_{\mathrm{s}}=0.00357
$$

Step 2 and 3: $\quad B_{\mathrm{sSS} 316 \mathrm{~L}}:=5600$

From Fig. HA-4 for SS316L at Tavg=800 F

$$
\mathrm{B}_{\mathrm{SSS} 316}:=9750
$$

From Fig. HA-2 for SS316L at Tavg=800 F

Step 4:

$$
\begin{aligned}
& \mathrm{P}_{\text {asSS316L }}:=\frac{\mathrm{B}_{\mathrm{sSS} 316 \mathrm{~L}}}{\left(\frac{\mathrm{R}_{\mathrm{o}}}{\mathrm{t}}\right)} \\
& \mathrm{P}_{\text {asSS316L }}=160 \\
& \mathrm{P}_{\text {asSS316 }}:=\frac{\mathrm{B}_{\mathrm{sSS} 316}}{\left(\frac{\mathrm{R}_{\mathrm{o}}}{\mathrm{t}}\right)} \\
& \mathrm{P}_{\text {asSS316 }}=278.571 \\
& \mathrm{P}:=\mathrm{p}_{\text {head }} \\
& \mathrm{P}=114.57 \mathrm{psi}
\end{aligned}
$$

Allowable external pressure for spherical $3 \mathrm{~mm}$-SS316L-wall window is higher than the working pressure of $114.57 \mathrm{psi}$. The window satisfies ASME buckling criteria.

Allowable external pressure for spherical $3 \mathrm{~mm}$-SS316-wall window is higher than the working pressure of $114.57 \mathrm{psi}$. The window satisfies ASME buckling criteria.

working pressure at the window level 
CONICAL SHELL (3 mm)UNDER EXTERNAL PRESSURE

$\alpha:=45 \cdot \operatorname{deg}$

$\mathrm{t}_{\mathrm{r}}:=0.003 \mathrm{~m}$

$\mathrm{D}_{\mathrm{L}}:=0.210 \mathrm{~m}$

$\mathrm{D}_{\mathrm{s}}:=0 \cdot \mathrm{m}$

$\mathrm{L}_{\mathrm{x}}:=0.100 \mathrm{~m}$

$\mathrm{L}_{\mathrm{e}}:=\left(\frac{\mathrm{L}_{\mathrm{x}}}{2}\right) \cdot\left(1+\frac{\mathrm{D}_{\mathrm{s}}}{\mathrm{D}_{\mathrm{L}}}\right)$

$\mathrm{L}_{\mathrm{e}}=0.05 \mathrm{~m}$

$\mathrm{t}_{\mathrm{e}}:=\mathrm{t}_{\mathrm{r}} \cdot \cos (\alpha)$

$\mathrm{t}_{\mathrm{e}}=2.121 \times 10^{-3} \mathrm{~m}$

Step 1: $\quad \mathrm{R}_{1}:=\frac{\mathrm{L}_{\mathrm{e}}}{\mathrm{D}_{\mathrm{L}}}$

$$
\mathrm{R}_{1}=0.238
$$

$\mathrm{R}_{2}:=\frac{\mathrm{D}_{\mathrm{L}}}{\mathrm{t}_{\mathrm{e}}} \quad \mathrm{R}_{2}=98.995$

Step 2 and 3: $\mathrm{A}_{\text {cone }}:=0.007$

Step 4 and 5: $\quad B_{\text {coneSS } 316 \mathrm{~L}}:=6250$

$\mathrm{B}_{\text {coneSS316 }}:=10500$

Step 6: $\quad P_{\text {acSS316L }}:=4 \cdot \frac{B_{\text {coneSS316L }}}{3 \cdot\left(\frac{D_{\mathrm{L}}}{\mathrm{t}_{\mathrm{e}}}\right)}$

$\mathrm{P}_{\mathrm{acSS} 316 \mathrm{~L}}=84.179$

$\mathrm{P}_{\mathrm{acSS} 316}:=4 \cdot \frac{\mathrm{B}_{\text {coneSS} 316}}{3 \cdot\left(\frac{\mathrm{D}_{\mathrm{L}}}{\mathrm{t}_{\mathrm{e}}}\right)}$

$\mathrm{P}_{\mathrm{acSS} 316}=141.421$

$\mathrm{P}=114.57 \mathrm{psi}$ cone angle as defined per AD-300.1 of Ref.1

(Ref. 1: D-3 of Section VIII, Division 2)

minimum required thickness of cone at cone-to-cylinder junction, in

OD of large end of conical section, in

OD of small end of conical section, in

axial length of cone, in (per Fig. AD-300.1 of Ref.1)

equivalent length of conical section, in

effective thickness of conical section, in

ratio $\mathrm{R} 2$ greater than 10

From Fig 3 of Ref. 1 for R1 and R2

From Fig. HA-4 for SS316L at $800 \mathrm{~F}$

From Fig. HA-2 for SS316 at $800 \mathrm{~F}$

Allowable external pressure for conical 3mm-SS316L-wall window is lower than the working pressure of $114.57 \mathrm{psi}$. The window does not satisfy ASME buckling criteria. The wall needs to be thickened.

Allowable external pressure for conical 3mm-SS316-wall window is higher than the working pressure of $114.57 \mathrm{psi}$. The window satisfies ASME buckling criteria.

working pressure at the window level 
CYLINDRICAL SHELL (3 mm) UNDER EXTERNAL PRESSURE

$$
\begin{aligned}
& \mathrm{t}_{\text {cyl }}:=0.003 \mathrm{~m} \\
& \mathrm{~L}_{\text {cyl }}:=8.07 \cdot \mathrm{m} \\
& \mathrm{D}_{\text {ocyl }}:=0.21 \cdot \mathrm{m}
\end{aligned}
$$

Step 1:

$$
\begin{array}{ll}
\mathrm{R}_{1 \text { cyl }}:=\frac{\mathrm{L}_{\text {cyl }}}{\mathrm{D}_{\text {ocyl }}} & \mathrm{R}_{1 \text { cyl }}=38.429 \\
\mathrm{R}_{2 \text { cyl }}:=\frac{\mathrm{D}_{\text {ocyl }}}{\mathrm{t}_{\text {cyl }}} & \mathrm{R}_{2 \text { cyl }}=70
\end{array}
$$

Step 2 and 3: $\quad \mathrm{A}_{\text {cyl }}:=0.00023$

Step 4 and 5: $\quad B_{\text {cylSS316L }}:=2833 \quad$ From Fig. HA-4 for SS316L at $530 \mathrm{~F}$

$$
\mathrm{B}_{\text {cylSS316 }}:=2840 \quad \text { From Fig. HA-2 for SS316L at } 530 \mathrm{~F}
$$

Step 6:

$$
\begin{aligned}
& \mathrm{P}_{\text {acylSS316L }}:=4 \cdot \frac{\mathrm{B}_{\text {cylSS316L }}}{3 \cdot\left(\frac{\mathrm{D}_{\text {ocyl }}}{\mathrm{t}_{\text {cyl }}}\right)} \\
& \mathrm{P}_{\text {acylSS316L }}=53.962
\end{aligned}
$$

Allowable external pressure for cylindrical $3 \mathrm{~mm}$-SS316L-wall target is lower than the working pressure of $114.57 \mathrm{psi}$. The window does not satisfy ASME buckling criteria. The wall needs to be thickened.

$\mathrm{P}_{\text {acylSS316 }}:=4 \cdot \frac{\mathrm{B}_{\text {cylSS316 }}}{3 \cdot\left(\frac{\mathrm{D}_{\text {ocyl }}}{t_{\text {cyl }}}\right)}$

$\mathrm{P}_{\text {acylSS316 }}=54.095$
Allowable external pressure for cylindrical 3mm-SS316-wall target is lower than the working pressure of $114.57 \mathrm{psi}$. The window does not satisfy ASME buckling criteria. The wall needs to be thickened. 


\section{Appendix D}

ANSYS input file for the nonlinear buckling analysis of the hemi-spherical window

/batch

/filnam,nlbwt_si35

/prep7

/color,pbak,0 ! Change the background colour

! 4-node finite strain shell

et, 1,181

$\mathrm{R}, 1,0.35$, , , , , , ! sphere wall-thickness is $3.5 \mathrm{~mm}$

RMORE, , , , , , ,

$\mathrm{R}, 2,0.425,0.35,0.35,0.425,0,0, \quad$ ! transition from 3.5 to $4.25 \mathrm{~mm}$ (sphere)

RMORE, 0, 0, 0,0,0,0,

$\mathrm{R}, 3,0.5,0.425,0.425,0.5,0,0, \quad$ ! transition from 4.25 to $5.0 \mathrm{~mm}$ (cyl)

RMORE, $0,0,0,0,0,0$,

$\mathrm{R}, 4,0.5,,,,$, ! cylinder wall-thickness is $5 \mathrm{~mm}$

RMORE, , , , , , ,

! Temp-dependent (Celzius scale) MPs for HT9 steel

mptemp,1,149,204,260,316,371,427

! Alpha of HT9 (in/in/C)

mpdata,alpx,1,1,1.17e-5,1.20e-5,1.22e-5,1.24e-5,1.26e-5,1.28e-5

! E (MPa) vs T(C)

mpdata,ex,1,1,1.92e5,1.88e5,1.84e5,1.80e5,1.77e5,1.70e5

!Poisson (SS316L) vs T(C)

mpdata,nuxy, $1,1,0.302,0.307,0.311,0.316,0.320,0.324$

! Reference Temperature in "C" of $70 \mathrm{~F}$

$\mathrm{mp}$, reft ,1, 21.1

! Stress-Strain of HT-9 at 0 dpa (Bilinear Kinematic Hardening)

TB,BISO, 1,4,2,

TBTEMP, 400

TBDATA,,673,677,,,,

TBTEMP, 450

TBDATA, $, 516,630,,,$,

TBTEMP, 500

TBDATA, ,508,590,,,,

TBTEMP, 550

TBDATA, ,405,500,,,,

mat, 1 
type, 1

real, 1

csys, 1

cylend=-210 ! effective length of the 8 m-long cylinder (cm)

$\mathrm{K}, 1,10.325,0,0$,

$\mathrm{K}, 2,10.325,90,0$,

csys, 0

$\mathrm{K}, 3$, cylend, 10.325,0,

$\mathrm{K}, 4,0,0,0$,

$\mathrm{K}, 5$, cylend, 0,0 ,

larc, $1,2,4,10.25$,

Istr, 2,3

AROTAT,all, , , , , ,4,5,360, ,

kdele,4,5,1

esize, 1,0,

amesh,all

!redefining the sphere-cylinder transition

NSEL,S,LOC,X,0,1

ESLN,S,1

CM,sphere,ELEM

EMODIF,sphere,REAL,2, ! $3.5 \mathrm{~mm}$ to $4.25 \mathrm{~mm}$

NSEL,S,LOC,X,-1,0

ESLN,S,1

CM,cyl,ELEM

EMODIF,cyl,REAL,3,

! $4.25 \mathrm{~mm}$ to $5.0 \mathrm{~mm}$

NSEL,S,LOC,X,-1, cylend

ESLN,S,1

$\mathrm{cm}, \mathrm{cyl} 5$,elem

EMODIF,cyl5,REAL,4, ! 5.0 mm-wall cylinder

! Boundary Conditions

NSEL,S,LOC,X,cylend, cylend-1

$\mathrm{D}$,all,ux

$\mathrm{D}$,all,uy

$\mathrm{D}$, all,uz

allsel 
! Pressure and Thermal Load

sf,all,pres,-0.7899 ! External Pressure (MPa)

allsel

NSEL,S,LOC,X,cylend, 0.0

ESLN,S,1

$\mathrm{cm}$,lowt,elem

bfe,all,temp, 1,277

NSEL,S,LOC,X,-1.2,4.0

ESLN,S,1

$\mathrm{cm}$, midt,elem

bfe, all,temp, 1,300

NSEL,S,LOC,X,2.5,10.325

ESLN,S, 1

$\mathrm{cm}$, hight,elem

bfe,all,temp, 1,500,335

allsel

eplot

save

ISOLU

ANTYPE,STATIC ! STATIC ANALYSIS

PSTRES,ON

! CALCULATE PRESTRESS EFFECTS

OUTPR,all,all,

SOLVE

FINISH

ISOLU

ANTYPE,BUCKLE ! BUCKLING ANALYSIS

BUCOPT,SUBSP,3 ! mode extraction - subspace iteration method

SOLVE

finish

Isolu

EXPASS,ON

MXPAND

! EXPAND 3 MODE SHAPE

OUTRES,all,ALL

SOLVE

finish

! Nonlinear buckling analysis

/prep7

upgeom,0.005,1,1,nlbwt_si35,rst 


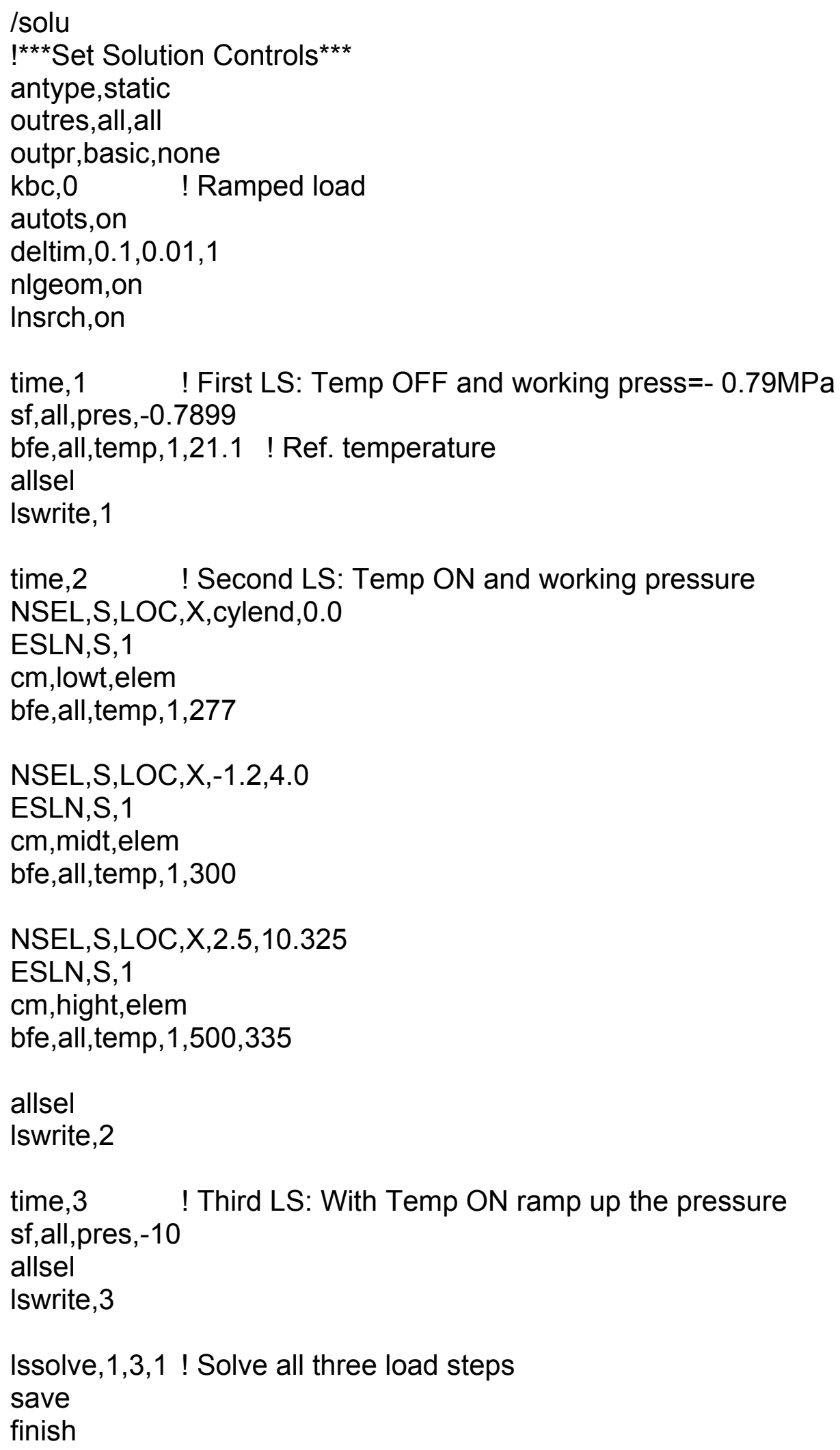




\section{Appendix E}

\section{Allowable HT-9 stresses}

The Supplemental Structural Design Requirements developed for the Accelerator Production of Tritium Program contain rules for developing allowable stresses for the structural design of the APT target-blanket components, APT SSDR [A]. These rules consider the degradation of the material properties due to irradiation effects from protons and spallation neutrons. These rules were developed since the standard design codes, i.e., ASME Boiler and Pressure Vessel Codes (e.g., Sections III or VIII), do not account for irradiation effects.

The irradiation spectrum of the ADTF target system is expected to be similar to that of the APT. However, the window temperatures will operate at much higher temperature, $\sim 500{ }^{\circ} \mathrm{C}$, than the operating temperature of the APT target, up to $\sim 200^{\circ} \mathrm{C}$. Irradiation data generated for APT structural materials from irradiation experiments conducted in the Los Alamos Neutron Science Center (LANSCE) proton facility were obtained up to a maximum temperature of $165^{\circ} \mathrm{C}[\mathrm{B}]$. Therefore, these data cannot be used directly in assessing higher temperature proton/neutron irradiation effects on structural materials for the ADTF Target Beam Window.

Except for the much faster decreases in tensile uniform elongation observed for materials irradiated in the LANSCE proton/spallation-neutron irradiation spectrum compared to those observed from irradiations conducted in a fission reactor neutron spectrum, effects on the tensile strength behavior of several APT structural materials at irradiation temperatures up to $\sim 165^{\circ} \mathrm{C}$ have been shown to be similar to effects produced in a fission neutron spectrum at such temperatures [B]. Therefore, fission reactor neutron irradiation data for tensile properties of several candidate ADTF target window materials irradiated (and tested) at temperatures in the range of $400{ }^{\circ} \mathrm{C}$ to $600^{\circ} \mathrm{C}$ have been utilized to make preliminary estimates of allowable stresses for sizing target components. These calculations have been made with proper regard to the faster decreases in tensile elongation values observed for materials irradiated in a proton/spallation-neutron spectrum. The candidate materials assessed include types 316SS and 304SS, the precipitation-hardened nickel-base alloy, Alloy 718, and the ferritic/martensitic steel, HT-9 (Fe-12Cr-1MoWV). It should be noted, however, that these calculations are solely based on changes in tensile properties, and have not included the effects of thermal creep, fatigue, etc.

The rules in the APT SSDR were utilized to calculate the limiting allowable stresses for primary membrane stresses $\left(S_{m}\right)$, primary plus secondary membrane stresses $\left(S_{e}\right)$, and primary plus secondary membrane and bending stresses $\left(S_{d 2}\right)$ based on tensile properties (yield strength, ultimate strength, uniform elongation, and reduction of area) obtained on materials irradiated in the range of $\sim 300^{\circ} \mathrm{C}$ to $600{ }^{\circ} \mathrm{C}$. Minimum irradiated yield strength or ultimate strength are used in the calculation of $S_{m}$, minimum irradiated ultimate strength and uniform elongation are used for calculating $S_{e}$, and minimum irradiated ultimate strength and reduction of area are used for calculation of 
$S_{\mathrm{d} 2}$. Below uniform elongation values of $2 \%, S_{e}$ and $S_{d 2}$ are solely a function of minimum irradiated ultimate strength.

HT-9 fission reactor neutron irradiation data indicate that for irradiation (and test) temperatures between $400^{\circ} \mathrm{C}$ and $450^{\circ} \mathrm{C}$ up to neutron doses of $\sim 72 \mathrm{dpa}$, the yield and ultimate strengths for this alloy increase slightly, while values for higher irradiation temperatures $\left(\sim 450^{\circ} \mathrm{C}\right.$ to $\left.600^{\circ} \mathrm{C}\right)$ remain about the same as for unirradiated material [D, $\mathrm{E}$, and F]. HT-9 uniform elongation values are only slightly above $\sim 2 \%$ for unirradiated material and these values are decreased by neutron irradiation. Based on the lower bounds for the yield strength and the ultimate strength data [C and D] and assuming uniform elongation values of less than $2 \%$ for unirradiated and irradiated material, values for $S_{m}, S_{e}$, and $S_{d 2}$ were calculated at $400{ }^{\circ} \mathrm{C}, 450{ }^{\circ} \mathrm{C}$, and $550{ }^{\circ} \mathrm{C}$ as shown in Table 7.

\section{Appendix E References}

A. Supplemental Structural Design Requirements, Accelerator Production of Tritium Program Document PPO-P00-G-PRD-X-00006, Rev. A, August 2000.

B. S. A. Maloy, M. R. James, W. R. Sommer, P. Ferguson, G. Willcutt, M. R. Louthan Jr., M. L. Hamilton, L. Sneak, and M. A. Sokolov, "The Change in the Mechanical Properties of Alloy 718, 304L and 316L Stainless Steel and Al6061 After Irradiation in a High Energy Proton Beam", Proceedings of the Third International Topical Meeting on Nuclear Applications of Accelerator Technology, Long Beach, CA, 14-18 November 1999, American Nuclear Society, pages 541 to 550.

C. A. L. Ward, J. M. Steichen, and R. L. Knecht, "Irradiation and Thermal Effects on the Tensile Properties of Inconel-718", Irradiation Effects on the Microstructure and Properties of Metals, ASTM Special Technical Publication STP No. 611, American Society for Testing and Materials, 1976, pages 156 to 170.

D. R. L. Klueh and P. J. Maziasz, "Effect of Irradiation in HFIR on Tensile Properties of Cr-Mo Steels", Journal of Nuclear Materials, Vol. 187 (1992), pages 43 to 54.

E. R. L. Klueh and J. M. Vitek, "Tensile Properties of $9 \mathrm{Cr}-1 \mathrm{MoVNb}$ and $12 \mathrm{Cr}-1 \mathrm{MoVW}$ Steels Irradiated to $23 \mathrm{dpa}$ at 390 to $550{ }^{\circ} \mathrm{C}$ ", Journal of Nuclear Materials, Vol. 182 (1991), pages 230 to 239 .

F. R. L. Klueh, P. J. Maziasz, and J. M. Vitek, "Postirradiation Tensile Behavior of Nickel-Doped Ferritic Steels", Journal of Nuclear Materials, Vol. 141-143 (1986), pages 960 to 965 . 


\title{
DISTRIBUTION LIST FOR ANL/TD/02-01
}

\section{$\underline{\text { Internal }}$}

R. K. Ahluwalia
S. K. Bhattacharyya
M. Billone
J. Brooks
J. Cahalan
Y. Chang
D. Crawford
D. Ehst
P. Finck
E. Fujita
Y. Gohar (5)
A. L. Hanson
J. Herczeg
D. Hill

R. K. Ahluwalia

R. Hill

H. Khalil

M. Koploy

J. Laidler

L. LeSage

R. Mattas

S. Majumdar

V. Maroni

R. McKnight

P. Mijatovic

B. Picologlou

W. David Pointer

C. Reed

J. Roglans
A. B. Smith
J. Saiveau
D. L. Smith
T. Sofu
T. Taiwo
R. Valentin
D. Wade
D. Weber
R. W. Weeks
M. Williamson
T. Yule
FPP Files
TIS

\section{External}

\author{
ANL-E Library \\ ANL-W Library \\ DOE/OSTI (2) \\ E. Adamov, Research and Development Institute of Power Engineering, Moscow, Russia \\ J. Anderson, Department of Energy, Germantown, MD \\ E. Arther, Los Alamos National Laboratory, Los Alamos, NM \\ R. Aymar, ITER Garching, Garching, Germany \\ C. Baker, University of California, San Diego, CA \\ D. Baldwin, General Atomic, San Diego, CA \\ C. G. Bathke, Los Alamos National Laboratory, Los Alamos, NM \\ A. Baxter, General Atomics, San Diego, CA \\ S. Berk, U.S. Department of Energy, Germantown, MD \\ E. E. Bloom, Oak Ridge National Laboratory, Oak Ridge, TN \\ C. Bolton, U.S. Department of Energy, Germantown, MD \\ M. Cappiello, Los Alamos National Laboratory, Los Alamos, NM \\ E. Cheng, TSI Research Inc., San Diego, CA \\ V. Chernov, Bochvar Research Institute of Inorganic Materials, Moscow, Russia \\ V. Chuyanov, ITER Garching, Garching, Germany \\ R. Conn, University of California, San Diego, CA \\ R. Dagazian, U.S. Department of Energy, Germantown, MD \\ J. Davis, The Boeing Company, St. Louis, MO \\ M. Eid, CEA, Gif-sur-Yvette, France \\ G. Emmert, University of Wisconsin, Madison, WI
}


V. Evtikhin, State Enterprise Red Star, Moscow, Russia

O. Filatov, Efremov Scientific Research Institute, St. Petersburg, Russia

U. Fischer, Forschungszentrum Karlsruhe, Germany

M. Fuetterer, CEA, Gif-sur-Yvette, France

W. Gauster, Sandia National Laboratories, Albuquerque, NM

M. Gasparotto, ENEA, Frascati, Italy

J. Gilleland, Archimedes Technology Group, Inc., San Diego, Ca

L. Giancarli, CEA, Gif-sur-Yvette, France

F. Goldner, Department of Energy, Germantown, MD

R. Goldston, Princeton Plasma Physics Laboratory, Princeton, NJ

J. Gulliford, AEA Technology, United Kingdom

W. G. Halsely, Los Alamos National Laboratory, Los Alamos, NM

G. Heusener, Forschungszentrum Karlsruhe, Karlsruhe, Germany

H. Kawamura, Japan Atomic Energy Research Institute, Oarai, Japan

V. Kirillov, Efremov Scientific Research Institute, St. Petersburg, Russia

J. U. Knebel, Forschungszentrum Karlsruhe, Karlsruhe, Germany

R. A. Krakowski, Los Alamos National Laboratory, Los Alamos, NM

G. Kulcinski, University of Wisconsin, Madison, WI

I. Lyublinski, State Enterprise Red Star, Moscow, Russia

H. Maekawa, Japan Atomic Energy Research Institute, Japan

S. Malang, Forschungszentrum Karlsruhe, Karlsruhe, Germany

D. Markovskij, Kurchatov Institute, Moscow Russia

W. Marton, U.S. Department of Energy, Germantown, MD

Y. Martynenko, Kurchatov Institute, Moscow, Russia

R. Matera, URC-IHCP, Ispra, Italy

S. Matsuda, Japan Atomic Energy Research Institute, Naka, Japan

B. Matthews, Los Alamos National Laboratory, Los Alamos, NM

K. McCarthy, Idaho National Engineering and Environmental Laboratory, Idaho Falls, ID

F. Najmabadi, University of California, San Diego, CA

R. Nygren, Sandia National Laboratories, Albuquerque, NM

A. Opdenaker, U.S. Department of Energy, Germantown, MD

R. Parker, Massachusetts Institute of Technology, Cambridge. MA

K. Pasamehmetoglu, Los Alamos National Laboratory, Los Alamos, NM

J. Perkins, Lawrence Livermore National Laboratory, Livermore, CA

D. Petti, Idaho National Engineering and Environmental Laboratory, Idaho Falls, ID

E. J. Pitcher, Los Alamos National Laboratory, Los Alamos, NM

S. Piet, Idaho National Engineering and Environmental Laboratory, Idaho Falls, ID

D. Post, Los Alamos National Laboratory, Los Alamos, NM

J. Raeder, ITER Garching, Garching, Germany

C. Rodriguez, General Atomics, San Diego, CA

M. Salvatores, CEA Cadarache, France

M. Sawan, University of Wisconsin, Madison, WI

F. Scaffidi-Argentina, EFDA Close Support Unit, Culham Science Cetre, United Kingdom

K. Schultz, General Atomic, San Diego, CA

T. Shannon, University of Tennessee, Knoxville, TN

G. Shatalov, Kurchatov Institute of Atomic Energy, Moscow, Russia

R. Sheffield, Los Alamos National Laboratory, Los Alamos, NM 
Yu. A. Sokolov, Minatom, Moscow, Russia

M. Solonin, Bochvar Research Institute of Inorganic Materials, Moscow, Russia

W. M. Stacey, Georgia Institute of Technology, Atlanta, GA

T. Schulenberg, Forschungszentrum Karlsruhe, Karlsruhe, Germany

Yu. A. Sokolov, Ministry of Atomic Power, Moscow, Russia

D. Steiner, Rensselaer Polytechnic Institute, Troy, NY

Y. Strebkov, Research and Development Institute of Power Engineering, Moscow, Russia

H. Takatsu, Japan Atomic Energy Research Institute, Tokyo, Japan

A Takahashi, Osaka University, Osaka, Japan

D. Thome, General Atomic, San Diego, CA

M. Todosow, Brookhaven National Laboratory, Upton, L.I., NY

$\mathrm{H}$. Trellue, Los Alamos National Laboratory, Los Alamos, NM

G. J. Van Tuyle, Los Alamos National Laboratory, Los Alamos, NM

J. Van der Laan, NRG Petten, Petten, The Netherlands

E. P. Velikov, Kurchatov Institute of Atomic Energy, Moscow, Russia

Laurie Waters, Los Alamos National Laboratory, Los Alamos, NM

C. Wong, General Atomics, San Diego, CA

H. Yoshida, ITER Naka, Naka, Japan

C.E.A. Library, Fontenay-aux-Roses, France

Librarian, Culham Laboratory, England

University of Illinois, Grainger Engineering Library Information Center 